\title{
WestVirginiaUniversity
}

THE RESEARCH REPOSITORY @ WVU

Graduate Theses, Dissertations, and Problem Reports

2009

\section{Steroid analysis by pH-mediated stacking MEKC}

Liliya Bykova

West Virginia University

Follow this and additional works at: https://researchrepository.wvu.edu/etd

\section{Recommended Citation}

Bykova, Liliya, "Steroid analysis by pH-mediated stacking MEKC" (2009). Graduate Theses, Dissertations, and Problem Reports. 4447.

https://researchrepository.wvu.edu/etd/4447

This Dissertation is protected by copyright and/or related rights. It has been brought to you by the The Research Repository @ WVU with permission from the rights-holder(s). You are free to use this Dissertation in any way that is permitted by the copyright and related rights legislation that applies to your use. For other uses you must obtain permission from the rights-holder(s) directly, unless additional rights are indicated by a Creative Commons license in the record and/ or on the work itself. This Dissertation has been accepted for inclusion in WVU Graduate Theses, Dissertations, and Problem Reports collection by an authorized administrator of The Research Repository @ WVU.

For more information, please contact researchrepository@mail.wvu.edu. 


\title{
STEROID ANALYSIS BY PH-MEDIATED STACKING MEKC
}

\author{
by \\ Liliya Bykova \\ Dissertation submitted to the Eberly College of Arts and Sciences \\ at West Virginia University \\ in partial fulfillment of the requirements \\ for the degree of \\ Doctor of Philosophy \\ in \\ Chemistry
}

Approved by

Lisa A. Holland, Ph.D., Committee Chairperson

Christy M. Foran, Ph.D.

Fred L. King, Ph.D.

Ronald B. Smart, Ph.D.

Björn C. Söderberg, Ph.D.

\section{Chemistry Department}

Morgantown, West Virginia

2009

Keywords: steroids, MEKC, pH-mediated stacking, cyclodextrin, endocrine disruption, fish Copyright $\odot 2009$ Liliya Bykova 


\section{Abstract \\ STEROID ANALYSIS BY PH-MEDIATED STACKING MEKC}

\section{by Liliya Bykova}

This dissertation is based on research that led to the development and application of capillary electrophoresis method for the analysis of sex steroid hormones in the blood or plasma of fish species. The analysis of steroid hormones is essential to reveal chemical compounds that are suspected in endocrine disruption, but it is challenging due to the similarity of the chemical structures of steroids, their low concentrations, and limited volumes of plasma or blood samples in fish available for analysis. There is therefore an acute need to develop reliable accurate and systematic analytical methods applicable for the analysis of structurally similar steroid hormones at very low concentrations. The method developed here is based on micellar electrokinetic chromatography, a type of capillary electrophoresis that incorporates secondary equilibria. The method utilizes $\mathrm{pH}$-stacking for steroid preconcentration to improve the detection limits. This method of pH-stacking is accomplished by using charged derivatives of cyclodextrin which become neutral (protonated) or anionic (deprotonated) based on the $\mathrm{pH}$ of the sample buffer. Preconcentration by means of $\mathrm{pH}$-stacking occurs upon introduction of the sample into the capillary at the $\mathrm{pH}$ junction, resulting in a fast and efficient separation analysis of steroids. Using the developed method the separation of eight targeted steroids, that include $\alpha, \beta$ dihydroxyprogesterone, ethynylestradiol, 17 $\beta$-estradiol, estrone, hydroxyprogesterone, 11ketotestosterone, progesterone, and testosterone is achieved in less than 4 min which is substantially faster than steroid analysis by immunoassay, GC-MS or LC-MS. For all targeted steroids, the within-day and day-to-day reproducibility in migration time is $<1$ and $<2 \%$ relative standard deviation (RSD), respectively. The reproducibility in peak area obtained in aqueous samples is below $6 \%$ and $22 \%$ (RSD) within-day and day-to-day respectively. The limits of detection range from 2 to $14 \mathrm{nM}$ using a $60 \mathrm{~s}$ electrokinetic injection. The method is validated by measuring the recovery of standard steroids added to the aqueous or fish plasma samples prior to sample preparation. The recovery of testosterone and $17 \beta$-estradiol added to the fish plasma prior to sample preparation range from $74 \%$ to $102 \%$. The method is successfully applied to the 
determination of sex steroid levels in blood plasma of yellow perch captured from natural aqueous habitats. The results are compared to radioimmunoassay. 


\section{DEDICATION}

To those who I love and those who love me.

To my dearly beloved husband Dr. Peter Maksymovych for his loving, caring and encouraging attitude, and more importantly for not letting me get away with loafing around while writing this dissertation. If it has not been for him being in my face now and then, reminding me that I needed to finish, I don't know if I would have ever done it at all.

I would like to express my sincere gratitude and love to my mom Alla Bykova for her long distance love and overwhelming support and patience during these past few years. She always believes that I can do anything even when I cannot fairly believe in myself. Thank you for being able to let me go from under your wing to the other side of the world and do what I do and be who I am although I know how hard that was for you to let me go. I miss you and I dedicate this dissertation to you.

In loving memory of my brother Viktor Bykov (1973-1995), an irresistible optimist and altruist, whose memory will never be erased as years may come and go. 


\section{ACKNOWLEDGMENTS}

There are so many people to acknowledge for supporting me during my graduate school years and helping me in creating this dissertation. First and foremost I would like to express my sincere gratefulness to my esteemed research advisor Dr. Lisa Holland who believed in me and accepted me as her Ph.D. student. This dissertation would not have been possible without her expert and patient guidance. She walked along with me in this journey as I struggled to create something new. I am grateful for all the words of encouragement, stimuli, for teaching me and helping me develop my research skills and critical thinking.

I would like to thank my doctoral committee - Dr. Christy Foran, Dr. Fred King, Dr. Ronald Smart, Dr. Björn Söderberg, and Dr. Ken Showalter for their time, supervision, advice and support over these few years.

My sincere recognition goes to Christy Foran, and Jennifer Stueckle from WVU Department of Biology; Kristine Willett of the University of Mississippi; Luke R. Iwanowicz and Vicki S. Blazer from U.S. Geological Survey Leetown Science Center, Kearneysville, WV for providing blood and plasma samples of the fish. Without their helpful collaboration and environmental concern I would not be able to get far with this project.

I would like to thank the faculty and staff at the Department of Chemistry in WVU for creating a positive work atmosphere. Thanks for the knowledge and experience I have acquired from all the coursework, departmental seminars and teaching.

I would like to thank Dr. Aaron Timperman and Dr. Björn Söderberg for letting me use some of the equipment in their laboratories. I would like to acknowledge students from both groups, Brent and Kathleen Reschke, Jeremiah Hubbard and Grissell Carrero Martinez for working late at nights and letting me in the labs when I needed.

I am delighted to thank my fellow group-mates Stephanie Archer-Hartmann, Ted Langan, Ruijuan Luo, Theron Pappas, Christian White, and Xingwei Wu for their teamwork, friendship and for sharing my laughs and sobs. I am tremendously thankful for them helping me edit the chapters of this dissertation and I am glad I will not have to edit theirs. 
In addition I would like to acknowledge two talented undergraduate students, Jesse Stokum and Cynthia Bollinger, for their endless enthusiasm and helping me with the sample preparation and data collection.

Finally, I would like to thank the Eberly College of Arts and Sciences at WVU for accepting me, a foreign student, as a prospective Ph.D. in chemistry a few years ago and providing the best opportunity for me to learn and work in my field. I would like to express my sincere gratitude to the ECAS who provided a generous financial support that was more than sufficient to conduct the research which led to my dissertation and enjoy life when away from school. In addition the ECAS financially supported all my trips to scientific conferences where I had a great chance to present my latest research findings and learn about the recent developments in chemistry and related disciplines. I would like to point out that I am particularly grateful for having Dean Fred King as a member of my graduate research committee and I appreciate the fact that despite his busy schedule he always finds time to teach, encourage and supervise graduate students. I also greatly appreciate the decision of the WVU Fellowship Committee to award me the dissertation fellowship 20082009 which helped me focus on writing and finishing my dissertation on time. 


\section{TABLE OF CONTENTS}

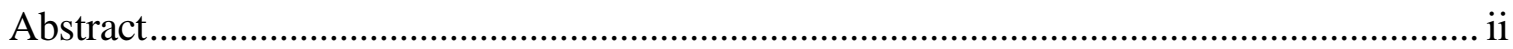

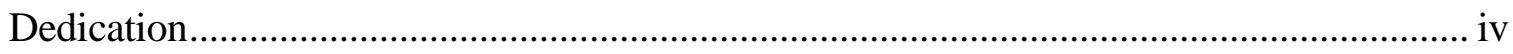

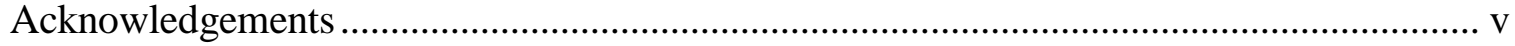

Table of Contents ................................................................................................. vii

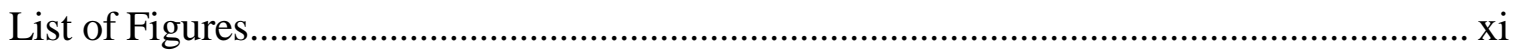

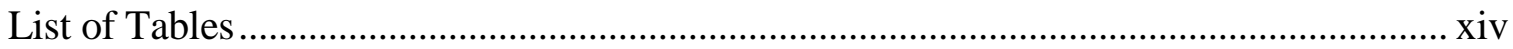

List of Symbols / Nomenclature ................................................................................. XV

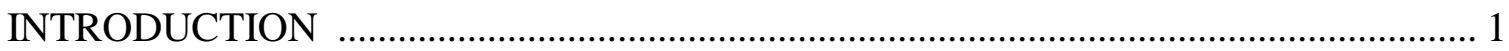

Chapter 1. BACKGROUND AND SIGNIFICANCE OF ENDOCRINE DISRUPTION . 3

1.1. PHENOMENON OF ENDOCRINE DISRUPTION .................................................... 4

1.1.1. Introduction .................................................................................. 4

1.1.2. Endocrine Disruption, Sources and Consequences ................................. 5

1.1.3. The Need for Biomonitors ...........................................................6

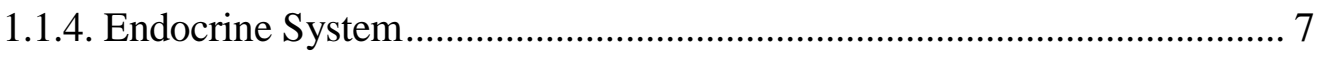

1.1.5. Steroid Hormones ......................................................................... 10

1.1.6. Disruption of Hormonal Regulation by Exogenous Compounds ............ 12

1.1.6.1. Hormone Receptor Agonists .................................................13

1.1.6.2. Hormone Receptor Antagonists ..............................................14

1.1.6.3. Mixed Agonists/Antagonists ....................................................14

1.1.6.4. Inhibitors of Hormone Synthesis ............................................15

1.2. LiTERATURE METHODS FOR STEROID ANALYSIS............................................. 16

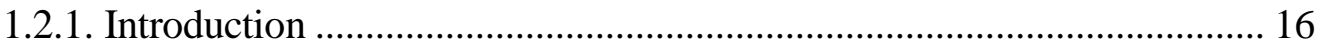

1.2.2. LC-MS and GC-MS of Steroids ........................................................... 17

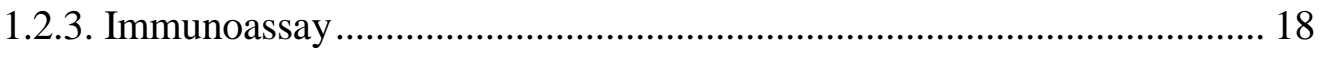

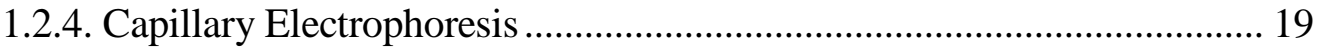

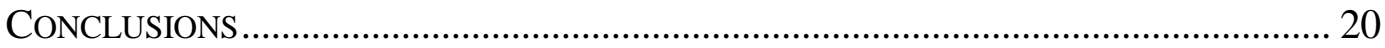

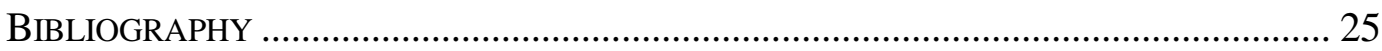

Chapter 2. DEVELOPMENT OF STEROID SEPARATION ....................................... 36 


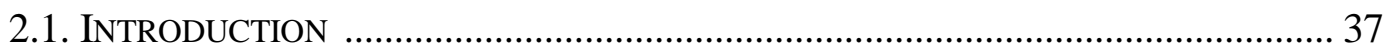

2.1.1. Theory of Capillary Electrophoresis......................................................... 37

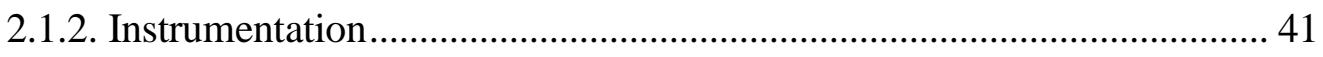

2.1.3. Micellar Electrokinetic Chromatography (MEKC) ................................. 42

2.1.4. Chemical and Physical Properties of Cyclodextrins ................................. 45

2.1.5. Cyclodextrin (CD) Modified-MEKC ...................................................... 47

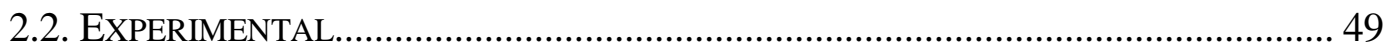

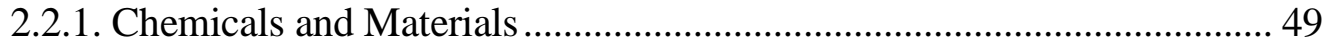

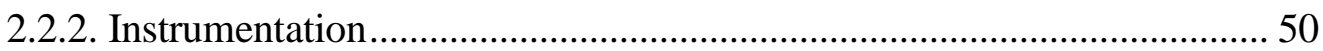

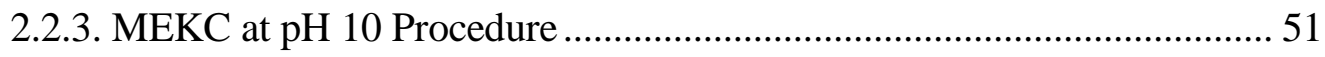

2.2.4. MEKC at $\mathrm{pH} 2$ Procedure ……………………….................................. 52

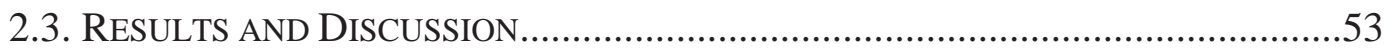

2.3.1. Steroids Targeted for Analysis.............................................................. 53

2.3.2. MEKC Separation of Steroids in Alkaline Medium ................................. 55

2.3.2.1. Separation Mechanism...................................................................... 55

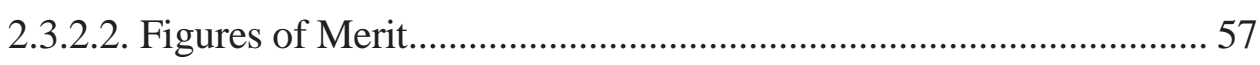

2.3.3. MEKC Separation of Steroids in Acidic Medium ................................... 57

2.3.4. Evaluation of MEKC of Steroids in Strongly Acidic Medium ( $\mathrm{pH}$ 2) .... 59

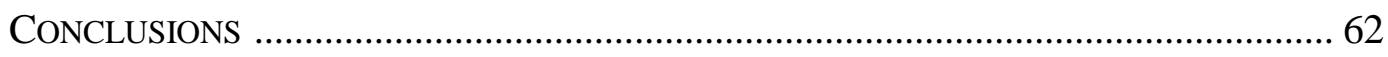

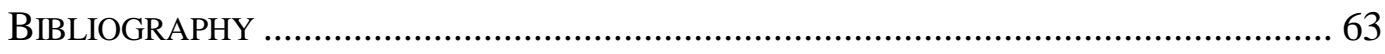

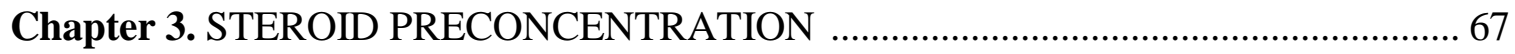

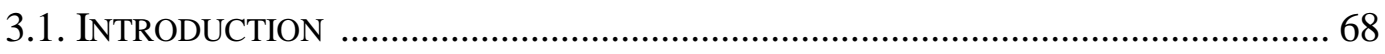

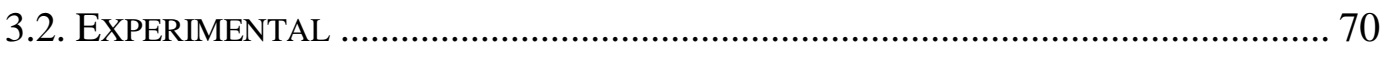

3.2.1. Chemicals and Materials .......................................................................... 70

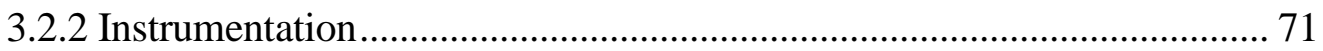

3.2.3. Capillary Packing Procedure ………………………………………....... 71

3.2.4. Chromatographic Preconcentration MEKC Procedure ............................. 73

3.2.5. pH-stacking MEKC Procedure ………………………………………....... 73

3.2.5.1. The Role of Cyclodextrins ........................................................73

3.2.5.2. Stacking Mechanism ..................................................................... 76

3.2.5.3. Capillary Flushes ……………………………………………..... 77 


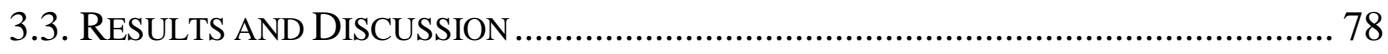

3.3.1. Chromatographic Preconcentration of Steroids ……………………….... 78

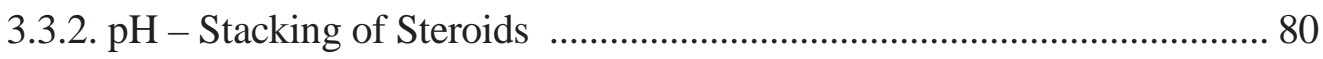

3.3.2.1. Stacking Effected by Conductivity of the Water Plug ..................... 84

3.3.2.2. Stacking Time Optimization.............................................................. 86

3.3.2.3. The Effect of CMCD Concentration on Stacking Efficiency......... 90

3.3.2.4. Stacking versus Phosphate Concentration .....................................92

3.3.2.5. Stacking versus Methanol Concentration in Sample Matrix ......... 94

3.3.2.6. Stacking versus $\mathrm{pH}$ of the Sample Buffer ....................................... 96

3.3.2.7. Stacking Enhancement...................................................................... 97

3.3.2.8. Stacking Figures of Merit ................................................................ 100

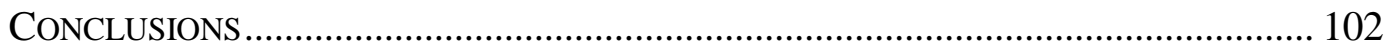

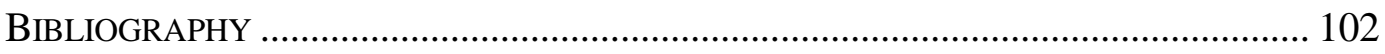

\section{Chapter 4. MODIFICATION OF THE METHOD FOR ANALYSIS OF FISH}

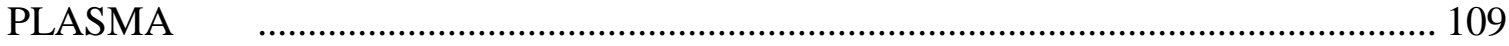

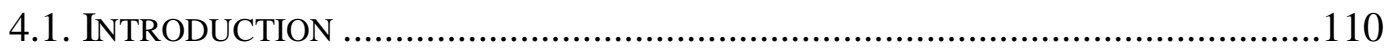

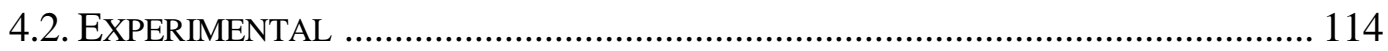

4.2.1. Chemicals and Materials ........................................................................ 114

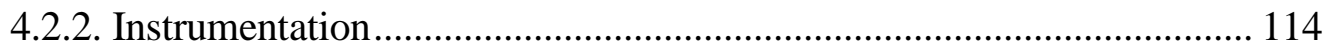

4.2.3. CE Separation .................................................................................... 115

4.2.4. Fish Blood/Plasma Samples................................................................ 115

4.2.5. Plasma Collection by USGS ................................................................ 116

4.2.6. Plasma Pretreatment Protocol \# 1 ............................................................ 117

4.2.7. Plasma Pretreatment Protocol \#2 ……………………………………...... 118

4.2.8. Plasma Pretreatment Protocol \#3 ........................................................... 119

4.2.9. Radioimmunoassay Procedure by USGS .............................................. 121

4.3. RESULTS AND DISCUSSION ………………………….................................... 123

4.3.1. Four Steroids Targeted for Analysis ....................................................... 123

4.3.2. Optimized Capillary Flushes ................................................................. 124

4.3.3. Method Selectivity ............................................................................... 125

4.3.4. Figures of Merit of Modified Method ................................................... 129 
4.3.5. Development of the Plasma Sample Purification Method 130

4.3.5.1. The Evaluation of the Steroid Elution from the SAX Cartridge .. 135

4.3.5.2. Recovery of Standard Steroids from C18 cartridge 136

4.3.5.3. Stability Studies 138

4.3.5.4. Effect of Temperature During Dry Down on the Recoveries....... 139

4.3.5.5. Recovery of Standard Steroids from Aqueous Solutions . 140

4.3.5.6. Steroid Recovery from Fish Plasma 142

4.3.5.7. Calibration Method and Effect of Plasma Volume on Stacking .. 147

4.3.6. Method Application to the Steroid Analysis in Yellow Perch 149

4.3.7. Method Comparison to Commercially Available Techniques 153

4.3.8. Fish Insight 155

CONCLUSIONS AND FUtURE DiRECTIONS 156

BIBLIOGRAPHY 158

Appendix 166

Curriculum Vitae 168 


\section{LIST OF FIGURES}

Figure 1.1. Endocrine signaling cascade of the reproductive system in the fish

Figure 1.2. Schematic demonstration of steroid biosynthesis in teleost fish 10

Figure 1.3. Basic structure of a steroid molecule

Figure 2.1. Schematic representation of separated peaks and EOF in CE 38

Figure 2.2. Schematic diagram of a CE instrument and an electropherogram. 41

Figure 2.3. Micelle formation and a sodium dodecyl sulfate (SDS) monomer 43

Figure 2.4. Different representations of a cyclodextrin molecule. 46

Figure 2.5. Photographs of the Beckman ${ }^{\circledR}$ automated capillary electrophoresis machine used in the work. 51

Figure 2.6. MEKC of steroids in alkaline medium. 56

Figure 2.7. Electrophoretic separation of steroids under acidic separation conditions....... 58

Figure 2.8. MEKC separation under acidic condition of steroids injected hydrodynamically at the short and long ends of the capillary. 60

Figure 2.9. Short end separation of steroids in acidic MEKC at different SDS/ HPCD ratios.

Figure 3.1. Dissociation of CMCD molecule versus $\mathrm{pH}$ 75

Figure 3.2. Schematic representation of $\mathrm{pH}$-stacking 77

Figure 3.3. Schematic representation of the stationary phase preconcentration cartridge used in the work 
Figure 3.4. Electropherograms of a blank sample and $60 \mu \mathrm{M} 17 \beta$-estradiol with and without chromatographic preconcentration

Figure 3.5. Schematic representation of the formation of $\mathrm{pH}$-junction 80

Figure 3.6. Superimposed electropherograms resulting from stacking and separating the blank and sample containing 6 steroids 82

Figure 3.7. Background subtracted electropherograms of 6 steroids following analyte stacking 83

Figure 3.8. The effect of a water plug on sample stacking. 86

Figure 3.9. Stacking enhancement versus injection time. 89

Figure 3.10. A plot of peak area versus CMCD concentration in the sample buffer. 91

Figure 3.11. Representative electropherograms of the stacking enhancement versus $\mathrm{CMCD}$ concentration in the sample buffer. 92

Figure 3.12. Stacking enhancement versus concentration of phosphate buffer and sample injection time.

Figure 3.13. Stacking enhancement versus methanol content in the sample buffer. 95

Figure 3.14. Stacking enhancement versus $\mathrm{pH}$ of the sample buffer. 97

Figure 3.15. Stacking enhancement of the sample containing $500 \mathrm{nM}$ estrone, ethynyl estradiol, and estradiol is injected at $10 \mathrm{kV}$ for $60 \mathrm{~s}$ versus $2 \mathrm{~s}$ 99

Figure 4.1. Flow chart of the plasma extraction protocol \#1 118

Figure 4.2. Flow chart of the plasma extraction protocol \#2 119

Figure 4.3. Flow chart of the plasma extraction protocol \#3 121

Figure 4.4. Illustrates the raw electropherograms obtained for 8 steroids simultaneously present in the analyzed sample. 126 
Figure 4.5. Background subtracted electropherograms obtained for 8 steroids simultaneously present in the analyzed sample.

Figure 4.6. Stacking electropherograms of progesterone; $\alpha, \alpha$-dihydroxyprogesterone; and $\alpha, \beta$-dihydroxyprogesterone. 128

Figure 4.7. The electropherograms obtained for the catfish blood extract. 132

Figure 4.8. Plot of the estradiol recovery (\%) versus the percent concentration of methanol in water used to elute steroids retained by $\mathrm{C} 18$ extraction cartridge during the plasma sample pretreatment.

Figure 4.9. Representative electropherograms for the steroid stability study. 138

Figure 4.10. Steroid recovery from fish plasma. Flow chart of the plasma sample preparation. 142

Figure 4.11. Steroid recovery data from a single catfish blood sample. 144

Figure 4.12. The electropherograms representing the analysis of a sample containing standard T, $11 \mathrm{KT}$, and E2, and yellow perch plasma extract. 146

Figure 4.13. Illustrative stacking electropherograms obtained by the method of standard addition for a blood plasma sample from a single yellow perch fish. 


\section{LIST OF TABLES}

Table 1.1. Figures of merit for steroid analysis by literature methods.

Table 2.1. Physical and chemical properties of CDs.

Table 2.2. Molecular properties of targeted steroids. .54

Table 2.3. Linear range of steroid detection via $\mathrm{pH} 10 \mathrm{MEKC}$ separation .57

Table 3.1. Cyclodextrins used in the research. .75

Table 3.2. Stacking enhancement factor in terms of peak area. .99

Table 3.3. Stacking - MEKC Figures of Merit (6 steroid set). .101

Table 4.1. Stacking - MEKC Figures of Merit(4 steroid set)

Table 4.2. Recovery of standard $17 \beta$-estradiol and testosterone from aqueous solution

Table 4.3. Recovery of standard steroids from fish

Table 4.4. Levels of plasma steroids in yellow perch fish measured by RIA reported in the literature. 150

Table 4.5. Analysis of endogenous steroids in blood plasma of yellow perch 152

Table A.1. Chemical structures of sex steroid hormones employed in research. 166 


\section{LIST OF SYMBOLS / NOMENCLATURE}

1. $\AA$ - angstrom $1 \times 10^{-10}$ meter;

2. A - area;

3. $\mathrm{AD}$ - androstenedione;

4. AVE - average;

5. BGE - background electrolyte;

6. ${ }^{\circ} \mathrm{C}$-degrees Celsius;

7. $\mathrm{cm}$ - centimeter;

8. CAPS - 3-[cyclohexylamino]-1-propanesulfonic acid;

9. $\mathrm{CD}-\mathrm{Cyclodextrin;}$

10. CE - capillary electrophoresis;

11. CHES - 2-[ cyclo-hexylamino]-ethanesulfonic acid;

12. CMC - critical micelle concentration;

13. CMCD - carboxymethyl- $\beta$-cyclodextrin;

14. CPM - counts per minute;

15. CZE - capillary zone electrophoresis;

16. E - applied electric field;

17. E1 - estrone;

18. E2 - $17 \beta$-estradiol;

19. E3 - estriol;

20. EDC - endocrine disrupting compound;

21. EE - ethynyl estradiol;

22. EOF - electroosmotic flow;

23. D - diffusion coefficient;

24. 17,20 $\alpha \mathrm{DHP}$ - dihydroxyprogesterone;

25. 17,20 $\beta$ DHP - dihydroxyprogesterone;

26. DNA - deoxyribonucleic acid;

27. g - gram;

28. GC-MS - gas chromatography - mass spectrometry;

29. GnRH - gonadotropin releasing hormone; 
30. GtH - gonadotropin;

31. $\mathrm{HCl}$-hydrochloric acid;

32. HP - hydroxyprogesterone;

33. HPCD - hydroxypropyl- $\beta$-cyclodextrin;

34. I - current;

35. IA - immunoassay;

36. id - inner diameter;

37. $\mathrm{kPa}$ - kilopascal;

38. 11KT - 11-ketotesteosterone;

39. kV - kilovolts;

40. L - liters;

41. LC-MS - liquid chromatography- mass spectrometry;

42. LOD - limit of detection;

43. $\log \mathrm{P}-\log$ partition coefficient;

44. LOQ - limit of quantitation;

45. $\mathrm{L}_{\mathrm{t}}$ - total length of the capillary;

46. $\mathrm{L}_{\mathrm{w}}-$ length to the capillary window;

47. $\Lambda$ - conductivity;

48. $\mathrm{M}-$ molar concentration, $\mathrm{mol} / \mathrm{L}$;

49. $\mathrm{mAu}$ - milliabsorbance units;

50. MEKC - micellar electrokinetic chromatography;

51. min - minutes;

52. $\mu_{\mathrm{eph}}$ - electrophoretic mobility;

53. $\mu \mathrm{L}-$ microliter;

54. $\mathrm{mL}$ - milliliter;

55. $\mu \mathrm{m}$ - micrometer;

56. $\mathrm{mm}$ - millimeter;

57. $\mu \mathrm{M}$ - micromolar;

58. $\mathrm{mM}$ - millimolar;

59. MOPS - 3-N-morpholino-propanesulfonic acid;

60. $\mathrm{n}$ - number of measurements; 
61. $\mathrm{NaOH}$ - sodium hydroxide;

62. ng - nanograms;

63. $\mathrm{nm}$ - nanometers;

64. $\eta$ - viscosity;

65. od - outer diameter;

66. $\mathrm{P}$ - partition coefficient;

67. $\mathrm{P}$ - progesterone;

68. $\mathrm{Pa}$ - pascal;

69. PDA - photodiode array;

70. PMT - photomultiplier tube;

71. psi - pounds per square inch;

72. $\rho$ - resistivity;

73. $\rho$-density of water;

74. $\mathrm{R}^{2}$ - correlation coefficient;

75. $\mathrm{R}$ - resistance;

76. q - ion charge;

77. $\mathrm{r}$ - ion radius;

78. $\mathrm{R}_{\mathrm{s}}$ - resolution;

79. RIA - radioimmunoassay;

80. mRNA - messenger ribonucleic acid;

81. RP C18 - reversed phase C18;

82. rpm - revolutions per minute;

83. RSD - relative standard deviation;

84. s - second;

85. SAX - strong anion exchange;

86. SD - standard deviation;

87. SDS - sodium dodecyl sulfate;

88. SEF - stacking enhancement factor;

89. SHBG - sex hormone-binding globulin;

90. SHR - steroid hormone receptor;

91. S/N - signal-to-noise ratio; 
92. $\mathrm{T}$ - testosterone;

93. $\mathrm{t}$ - migration time;

94. V - volts;

95. V - voltage;

96. $v_{e}$-electrophoretic velocity. 


\section{INTRODUCTION}

Rapid separation methods, such as capillary electrophoresis, are effective tools for screening the chemical composition of a wide variety of samples constituents. The following chapters describe the development of an effective analytical method for steroid analysis using capillary electrophoresis. Chapter 1 provides the literature background of endocrine disruption and discusses several known analytical methods used for steroid analyses. Chapter 2 proceeds with a detailed account of capillary electrophoresis, and describes the method developed in this work which is based on the micellar electrokinetic capillary chromatography (MEKC). Chapter 3 is devoted to in-capillary preconcentration methods, and much of the data in Chapter 3 is published in reference [1]. Chapter 3 includes a comparison of chromatographic preconcentration and $\mathrm{pH}-$ stacking preconcentration using charged cyclodextrin. The comparison indicates the latter technique is much more reproducible for the targeted analysis. The method is evaluated using six representative steroid hormones. The limits of detection were measured and stacking enhancement factor was calculated and compared to the steroid analysis at non-stacking conditions. Finally, Chapter 4 presents the application of the stacking-MEKC method to the analysis of steroids in fish blood or plasma samples. Data from this chapter comprises a manuscript in preparation. The flushing protocol used to regenerate the inner surface of the capillary in analysis of standard steroid samples needed to be modified in order to achieve reproducible results when used for plasma sample extracts. The analysis of the plasma samples required the development of an effective purification scheme to extract steroids while eliminating interfering compounds. The method was validated by recovering steroids spiked in the aqueous standard steroid solutions and in the fish plasma samples prior to extraction. To 
investigate the effect of the differences among the fish species on the stacking, four different fish species were used for analysis. The developed and optimized method was applied to the determination of steroids in plasma of yellow perch fish. The MEKC results were compared to the results independently measured by radioimmunoassay. The developed method allowed for determination of the steroids in plasma samples with the improved limits of detection obtained by the stacking preconcentration. 


\section{CHAP T E R 1}

\section{BACKGROUND AND SIGNIFICANCE OF EN D OCRINE D IS R UPT I O N}




\subsection{PHENOMENON OF ENDOCRINE DISRUPTION}

\subsubsection{INTRODUCTION}

The scientific interest in the occurrence of endocrine disruption dates back to the sixties and early seventies, when it was first reported that a synthetic estrogen, diethylstilbestrol, can have adverse effects on experimental animals and even humans (2). The pioneering work of John McLachlan, Howard Bern and other researchers has paved the way to the present field of endocrine disruption (3-6). However, the broad scientific and social recognition of the endocrine disruption problem was due to the work of Theo Colborn in the early nineties who found the evidence that certain non-hormone chemicals may also affect the sexual development of numerous wildlife species (7).

It is now known that a variety of environmental hormones and chemical pollutants in the environment disrupt human reproduction causing birth defects, sexual abnormalities, and reproductive failure. The threat of changes in the animal or human endocrine system by xenobiotic compounds (chemicals which are not normally produced or likely to be present in an organism but which are found in it) has become a major issue facing researchers today and continues to be a central topic at toxicological conferences, in the general press, as well as in the political arena (8). In particular, the problem of endocrine disruption has affected the state of West Virginia. In 2004, the researchers at the USGS (U.S. Geological Survey) reported $80 \%$ of the male bass fish collected from the South Branch of the Potomac River (Hardy County, WV) had female tissue developed inside their gonodal tissue (9-12). Smallmouth bass are valued game fish in much of the United States and a high occurrence of testicular oocytes (intersex) has gained great public 
attention $(13,14)$. Endocrine disrupting chemicals have been identified in some areas of the Potomac Watershed, and it is suspected that they are contributing to these occurrences $(15,16)$

\subsubsection{ENDOCRINE DISRUPTION, SOURCES AND CONSEQUENCES}

An endocrine disrupting compound (EDC) is a chemical compound that can potentially disturb the normal communication between the hormone and the cell receptor in the living organism, leading to the malfunctioning metabolism or catabolism of sex steroids, suppressed fertility and reproduction, and even complete sex-reversal in the organism itself or its next generation (17).

Among the significant sources of endocrine active chemicals affecting the environment are the agricultural waste products, atmospheric contamination, and sewage (18-20). The number of registered and potential endocrine disruptors is constantly growing. These include alkylphenols (21), heavy metals (22), pesticides $(23)$, phthalates $(24,25)$, polycyclic aromatic hydrocarbons (PAHs) and dioxin (26), polychlorinated biphenyls (PCBs) $(27,28)$, natural and synthetic steroid estrogens (29), and pharmaceutical drugs $(30-32)$.

All stages of the hormonal function of an organism can be affected including hormone synthesis, storage/release, transport/clearance, receptor recognition/binding, and post-receptor responses. The effects may be reversible or irreversible, immediate or latent. The intensity of the exposure depends on many factors including the dose of the pollutant, the interval of exposure, the body weight, stage of development etc. This 
complexity creates unique challenges in the detection and measurement of endocrine disruptors in the environment.

\subsubsection{THE NEED FOR BIOMONITORS}

The aquatic environment is exceptionally subject to xenobiotic damage. Water and sediment can act as a sink for many types of pollution from multiple sources. The pollutants can be retained in the sediments and subsequently absorbed into the aquatic organisms. To determine the safe maximum contaminant level in the environment one has to measure the rate of accumulation of pollutants by the aquatic organisms, explore the biochemical disruption mechanism and estimate the possibility of disruptions in the viability or fertility of the organisms and their offspring.

Biomonitoring is generally achieved by placing an animal into the test water containing a suspect chemical and observing its effects on the animal. A simple toxicity measure is the dose of a pollutant which kills $50 \%$ of the test animals $\left(\mathrm{LD}_{50}\right)(33)$. Laboratory toxicity tests commonly inspect the effects of a single pollutant for a relatively short period of time under controlled conditions. Exploring similar effects in the wildlife is equally important since the organisms are exposed to lower levels of complex mixtures, but over much longer time scales.

Fish accumulate pollutants in their fatty tissues such as liver and gonads, but the effects may become apparent only when concentrations in such tissues reach threshold level after several years. Thus the fish is a natural long-term biomonitor. 


\subsubsection{ENDOCRINE SYSTEM}

The endocrine system is the chemical communication system of the body comprising many glands such as ovaries, testes, pancreas, adrenal, thyroid, and parathyroid. The signals from the brain resulting from the external stimuli are modulated by the hypothalamic-pituitary system as changes in the hormone secretion. The hypothalamus produces gonadotropin releasing hormone which causes further release of gonadotropin from the pituitary gland. Gonadotropin is a peptide hormone that acts on the glands to stimulate secretion of sex steroid hormones and is the most concern in the context of reproduction. The secreted steroids in turn initiate changes in the secondary sexual characteristics, behavior, courtship, development and maturation of the gamets, and spawning (Fig. 1.1).

The endocrine signaling cascades similar to that in Figure 1.1 provide several sites where the endocrine signal can be regulated. For example, testosterone is secreted by the testis but regulates its own secretion by acting upstream at the pituitary gland and hypothalamic gland. Peptide hormones are commonly the intermediate messengers along a signaling cascade, while the terminal hormone is often of nonpeptide origin (i.e., steroids). Toxicologically the function of the terminal hormones appears to be most at risk of chemical disruption, where the foreign molecules bind to the nuclear receptors of these hormones in an agonistic or antagonistic manner (Section 1.1.6). The binding of a xenobiotic substance to the receptor results in abnormal receptor function with the associated toxicological outcome.

Steroid hormones are lipophilic in nature and can be transferred in the circulatory system from their point of origin to their target tissues only by specific carrier proteins 
such as sex hormone-binding globulin, corticosteroid-binding globulin, thyroxine-binding globulin (transthyretin), and albumin. Sex hormone-binding globulin (SHBG) binds testosterone, $17 \beta$-estradiol, and other sex steroids. Most steroid and thyroid hormones (> $95 \%$ ) are reversibly bound to proteins in the blood. Upon dissociation from the proteins, the steroid hormones can cross the cell membrane via diffusion due to their lipophilicity. Therefore, the vitally critical parameter is not the total hormone concentration in the plasma, but that of a free, unbound steroid.

The molecular mechanism of steroid receptor action described by Nelson and Cox (34) occurs as follows: after crossing the membrane of the target cell, the hormone binds to specific receptor proteins in the nucleus. The steroid hormone receptors (SHR) include the glucocorticoid, mineralcorticoid, progesterone, androgen, and estrogen receptors. The estrogen receptor is the major regulatory unit within the estrogen-signaling pathway. When functioning normally, the hormone binding changes the conformation of the receptor protein. It forms homo- or hetero-dimers with other hormone receptor complexes and binds to specific regulatory regions, called hormone response elements, in the DNA adjacent to specific genes. The binding regulates the transcription of the adjacent gene(s), increasing or decreasing the rate of the formation of mRNA. The hormone-regulated gene thus produces the specific cellular response to the hormone.

The bodily functions regulated by the endocrine system include reproduction, energy production, metabolism, fetal development, growth, and maturation. For example, ovaries release estrogen, which is necessary for growth, fetal development, and reproduction. The thyroid affects metabolism and brain development, and the pituitary controls other glands in the endocrine system. The endocrine system is very sensitive to 
very low levels of pollutants. Any anthropogenic substance, a substance caused by human activity, can potentially interfere with any of the steps described above to cause a disruption of the endocrine system.

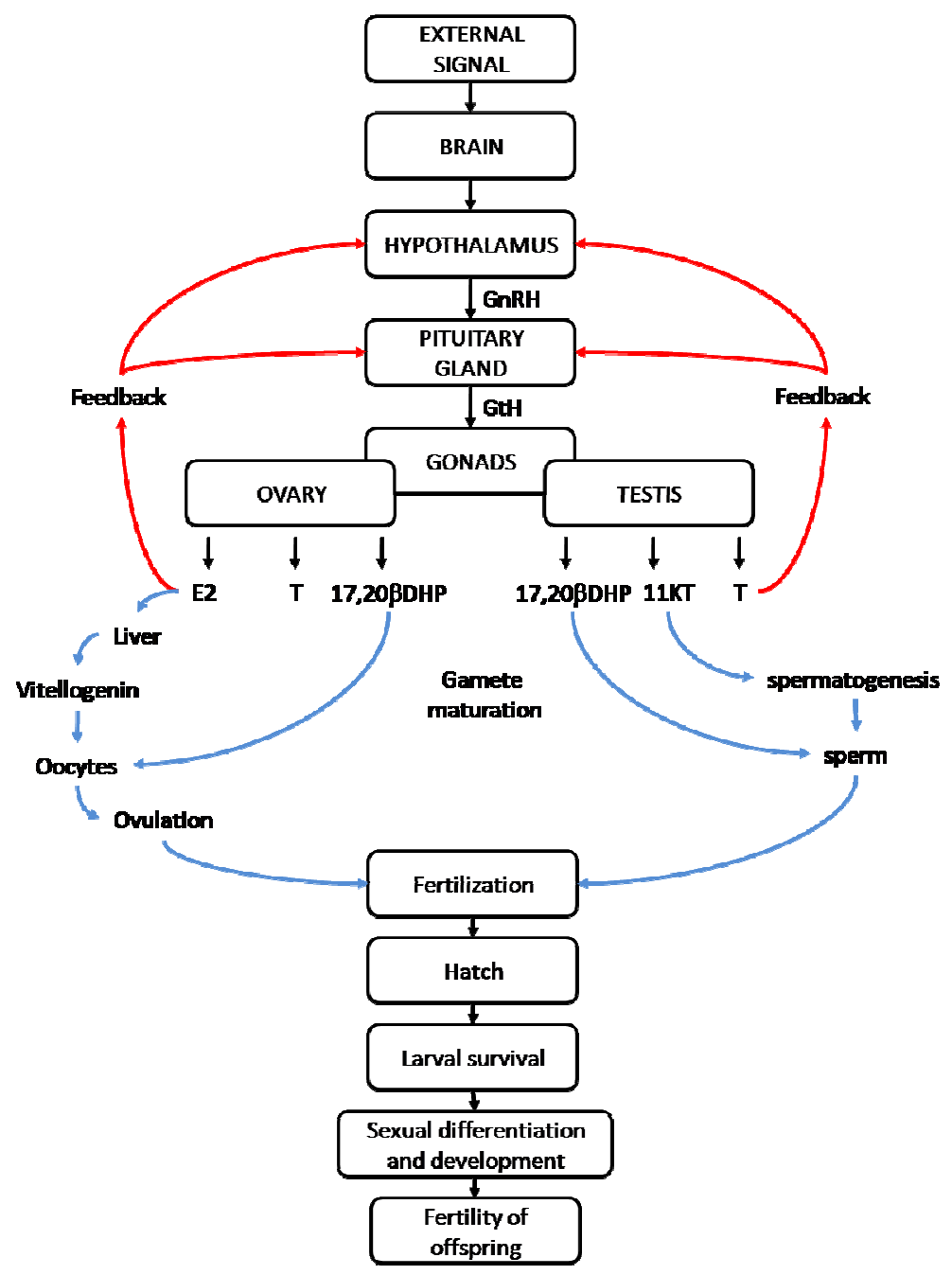

Figure 1.1. Endocrine signaling cascade of the reproductive system in the fish. (GnRH - gonadotropin releasing hormone, GtH - gonadotropin, E2 - 17 $\beta$-estradiol, T - testosterone, 11KT - 11-ketotesteosterone, 17,20ßDHP - dihydroxyprogesterone). Reproduced with kind permission of Springer Sciences from (35). 


\subsubsection{STEROID HORMONES}

The major difference between the endocrine system of the fish and the mammals are the steroid hormones. The main steroids in teleost fish, a large group of fishes with bony skeletons, their interrelationship via biosynthesis and the major enzymes are shown in Figure 1.2. The chemical structures of these steroids can be found in Table A1, Appendix 1.

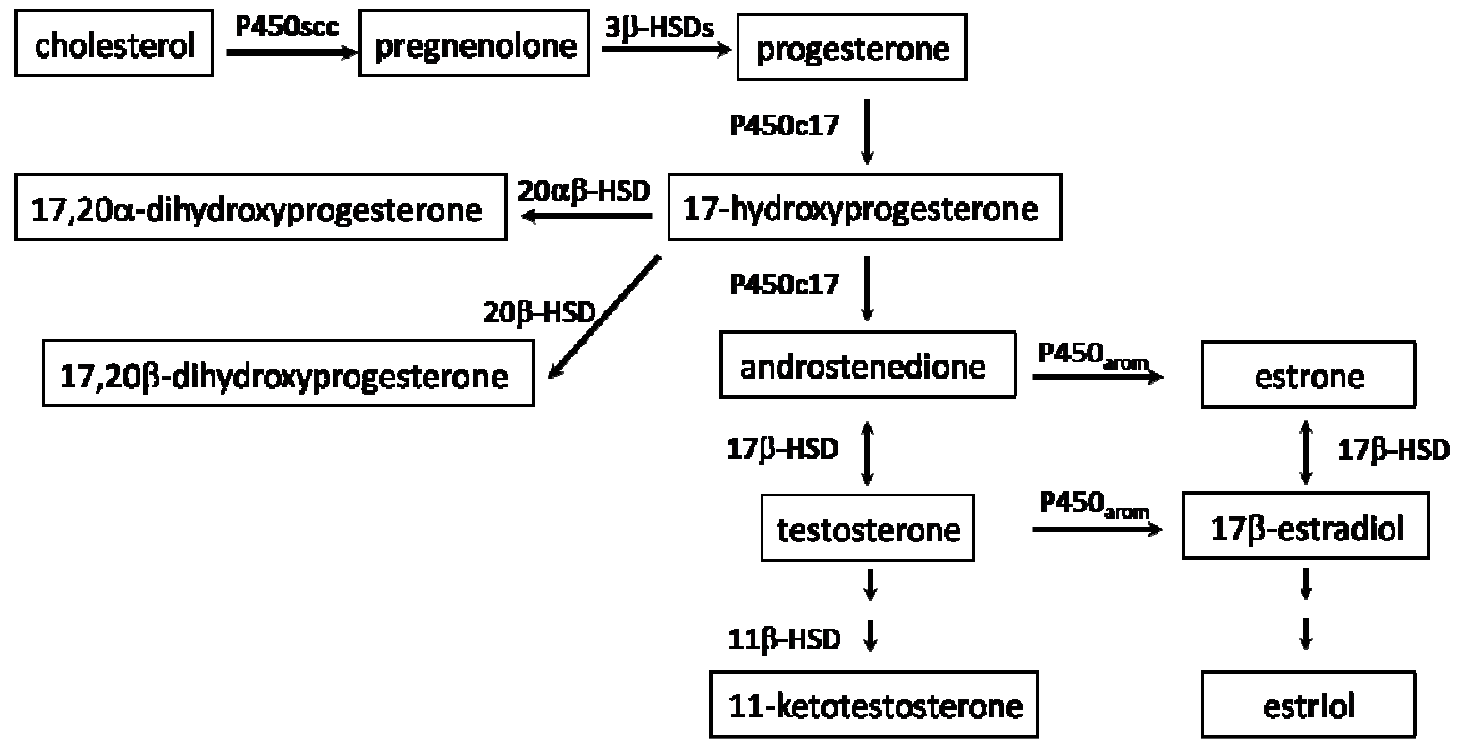

Figure 1.2. Schematic demonstration of steroid biosynthesis in teleost fish (for simplicity only major pathways are shown). Reproduced with kind permission of Springer Sciences from (35).

Steroids are oxidized derivatives of sterols. They have the sterol nucleus but lack of alkyl chain attached to ring D of cholesterol, and they are more polar than cholesterol, for which the logarithm of the partition coefficient $(\log \mathrm{P})$ is 9.9. A steroid hormone molecule consists of a tetracyclic ring structure with substituents at specific sites within the molecule (Fig. 1.3.). The substituents are usually hydroxyl, carbonyl and alkyl groups. 
Very often steroids and their metabolites differ only by the presence or absence of one functional group or a variation in the steric conformation of the ring.

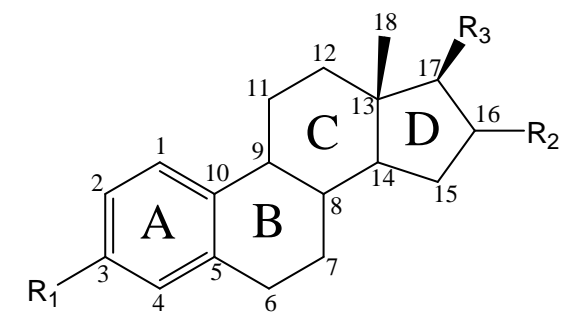

Figure 1.3. Basic structure of a steroid molecule.

The biosynthesis of steroid hormones starts from a common precursor, cholesterol, and proceeds via a complex sequence of biochemical reactions (Fig. 1.2). Kime (35) describes this process quite nicely, and briefly, cholesterol is converted to pregnenolone by the cholesterol side-chain cleavage enzyme (P450scc). Pregnenolone is then oxidized at position C-3 by $3 \beta$-hydroxysteroid dehydrogenases $/ \Delta^{5}-\Delta^{4}$ isomerases (3$\beta$-HSDs) producing progesterone. The $17 \alpha$-hydroxylation of progesterone by $17 \alpha$-hydroxylase $/ \mathrm{C}_{17-20}$ lyase (P450c17) results in the formation of 17-hydroxyprogesterone. 17-hydroxyprogesterone is further converted to androstenedione by the lyase activity of P450c17. The final steps of estrogen production are controlled by P450arom and 17HSDs. Aromatase catalyzes the aromatization of the androgens to estrogens, such as androstenedione to estrone or testosterone to estradiol (36), whereas $17 \beta$-HSDs are responsible for the interconversion between 17-ketosteroids, like androstenedione and estrone, and 17 $\beta$-hydroxysteroids, e.g. testosterone and estradiol (37). Finally testosterone is converted to 11-ketotestosterone. In teleost fish, 11-ketotestosterone is important for sexual differentiation and male sexual development (38). 
All steroid hormones act through nuclear receptors to change the level of expression of specific genes. Because hormones have very high affinity for their receptors, very low concentrations of hormones (nanomolar or less) are sufficient to produce responses in the target tissues of the fish. The exposure to hormonally active compounds does not necessarily lead to adverse effects. Sorting out adverse effects of endocrine disruptors is a scientific challenge but it is also practically important, since exposure to such compounds through food, air, water and many household products is everywhere and unavoidable. Therefore, in order to better identify the biological disruption, key steroids in the endocrine cycle must be profiled.

\subsubsection{DisRuption of HoRMonal REgULATION bY EXogENous CompoundS}

The structural requirements and mechanisms of action of endocrine disruptors are complicated by the fact that there exist multiple ways to interfere with the endocrine system. The predominant mechanisms of disruption of hormone activity by xenobiotics involve: (1) mimicking steroids by binding to the receptor and inducing (agonizing) or inhibiting (antagonizing) the steroid response; (2) modulating endogenous steroid hormone levels.

To bind to the receptor, xenobiotics first compete with hormones for the binding to the carrier protein, which, as mentioned earlier, act as a vessel that distributes steroid hormones throughout the body. For example, xenobiotics estrogens can be both endogenous (from within an organism) which regulate the growth and development of their target tissues, e.g. estradiol, and exogenous (from outside of an organism) with estrogenic 
and/or anti-estrogenic activities that induce or inhibit estrogenic response and may disrupt the regulatory pathways, e.g. ethynyl estradiol.

\subsubsection{Hormone Receptor Agonists}

A hormone receptor agonist is a compound that binds to and activates a hormone receptor. Endogenous hormones, for example $17 \beta$-estradiol and $5 \alpha$-androstan-3 $\alpha, 17 \beta$-diol (commonly known as dihydrotestosterone), function as agonists to their respective receptors. Xenobiotics can act as receptor agonists and stimulate receptor-dependent physiological processes in the absence of the endogenous receptor ligand (hormone).

The estrogen receptor is most susceptible to the agonistic action of xenobiotics due to their diverse molecular structures. Compounds which bind to the estrogen receptor and induce receptor-mediated response, are termed estrogens or estrogen receptor agonists. Whether a xenobiotic can fit into the binding-pocket of the receptor and function as a receptor agonist is determined by the structure of the xenobiotic and its electrical charge. Some drugs are rather potent estrogens (i.e. diethylstilbestrol); however, chemicals with estrogenic activity are typically weak agonists with activity several orders of magnitude less than that of $17 \beta$-estradiol. However, adult males, young individuals, and embryos all have been shown to exhibit endocrine toxicity resulting from xenoestrogen exposure due to the small amount of endogenous $17 \beta$-estradiol in these individuals (38). The physiological consequence of the xenoestrogenic activity is typically feminization, for example, breast development in males (gynecomastia) $(39,40)$. 


\subsubsection{Hormone Receptor Antagonists}

Receptor antagonists are chemicals that bind to a hormone receptor but do not activate it. These chemicals inhibit receptor activity by preventing the endogenous hormone from activating the receptor. Estrogen receptor antagonists include certain phytochemicals (i.e., flavonoids) and PCBs. Estrogen receptor antagonism typically leads to de-feminization. In laboratory animal studies, estrogen receptor antagonists have been shown to disrupt estrous cycles and damage fertility in females (41).

Chemicals that known to bind to the androgen receptor in an antagonistic way include, for example, the heart failure drugs, spironolactone and cimetidine, and antiandrogen prostate cancer drugs, cyproterone acetate and hydroxyflutamide (42). Environmental chemicals that have been shown to act as androgen receptor antagonists include the metabolites of the agricultural fungicide vinclozolin, the DDT metabolite $p$, p'-DDE, some hydroxylated PCBs, and the organophosphate insecticide fenitrothion (43). Androgen receptor antagonism, unlike that of the estrogen receptor, may result in demasculinization.

\subsubsection{Mixed Agonists/Antagonists}

Certain chemicals can function as either a receptor agonist or antagonist, and are referred to as mixed agonists/antagonists. The particular function depends on the level of endogenous hormone in the organism, the concentration of the xenoagonist, the binding affinity of the xenoagonist to the receptor, the concentration of the endogenous, and the binding affinity of the endogenous hormone to the receptor. For example, a weak agonist may bind to a receptor and stimulate some low-level receptor-mediated activity in the 
absence of the endogenous hormone. However, in the presence of the hormone, binding of the xenobiotic to the receptor may prevent the binding of the endogenous hormone and suppress the hormonal activity if the xenobiotic is a weaker activator.

The drug tamoxifen functions as an estrogen receptor antagonist in reproductive tissue but functions as an agonist with respect to the preservation of bone mineral density and reducing serum cholesterol concentrations (44). Accordingly tamoxifen can function as a prophylactic against the growth of estrogen-responsive breast cancers and osteoporosis via two different mechanisms, estrogen receptor antagonism and agonism, respectively.

\subsubsection{Inhibitors of Hormone Synthesis}

Endocrine toxicants can cause antihormone activity by lowering the levels of the endogenous hormones in the body. With steroid hormones, chemicals typically elicit this effect by inhibiting the enzymes necessary for the synthesis of the hormone. For example, cytochrome P450 enzyme (CYP19) is responsible for the aromatization of testosterone to form $17 \beta$-estradiol. CYP19 inhibitors such as breast cancer treatment drugs, fadrozol, anastrozole, letrozole, can lower the endogenous $17 \beta$-estradiol levels resulting in defeminization (45). Cytochrome P450s enzymes are also critical to various hydroxylation reactions that contribute to the synthesis of androgens and other steroid hormones. Inhibition of these enzymes can result in a variety of antisteroid hormone effects. For example, the agricultural and medicinal fungicides propiconazole, ketoconazole, and fenarimol are capable of inhibiting P450 enzymes and reducing synthesis and circulating levels of testosterone and other steroid hormones. Toxicological consequences of the 
lowering of the endogenous steroid hormone levels are typically comparable to the effects elicited by antagonists of the hormone's receptor.

\subsection{LITERATURE METHODS FOR STEROID ANALYSIS}

\subsubsection{INTRODUCTION}

Although the concentration of specific pollutants may be analyzed at very low levels, no single method can predict or detect all EDCs present in an environmental sample. Ultimately, this prevents the analysis of complex biological mechanisms of endocrine disruption in one simple test. To address this environmental problem, reliable analytical methods must combine several types of analysis including in vivo and in vitro bioassays, and analytical chemistry for the determination of structurally similar steroid hormones at very low concentrations. Monitoring the key steroid hormones in the endocrine cycle of fish is essential to provide insight into the complex metabolism involving steroid hormones and identify a biological disruption. Hormones can cause endocrine disruption at very low concentrations. For example, steroid estrogens can be harmful to the fish at a concentration as low as $2.0 \mathrm{ng} / \mathrm{L}$ (46). Profiling circulating steroids in biologically relevant concentrations to determine how EDCs affect the endocrine system thus requires highly sensitive analytical methods. The separation of steroid hormones is further complicated by the high hydrophobicity of steroid molecules and their similar chemical structures. Finally, the analysis of steroids in fish plasma is difficult due to the presence of interfering compounds and small amount of the fish blood plasma available.

Natural and synthetic sex steroid hormones can be analyzed by liquid or gas chromatography coupled to mass spectrometry, immunoassay, or capillary electrophoresis. 
A number of papers (47-60) reported the analysis of one or several steroids simultaneously present in water, urine, or sediments. There are fewer reports dealing with the blood or plasma (61-88). A brief introduction to the benefits and limitations of the available methods for steroid analysis is presented in the following sections.

\subsubsection{LC-MS AND GC-MS OF STEROIDS}

Natural and synthetic sex steroid hormones have been analyzed by liquid or gas chromatography coupled to mass spectrometry. Mass spectrometric detection allows for the structural elucidation of steroids and steroid metabolites, eliminating the need for predictive identification of steroids in the sample and enabling identification of steroid metabolites for which no immunoassay is available. Isotope-dilution GC-MS is a reference measurement procedure for plasma steroids listed in the database of the Joint Committee for Traceability in Laboratory Medicine (89). It has been widely used to validate immunoassays for steroid analysis as they require more thorough validation due to their cross reactivity (90). Despite isotope-dilution GC-MS being a de-facto gold reference method for steroid analysis, isotope-dilution LC-MS/MS has been proven to demonstrate the same accuracy for steroid analysis $(91,92)$ and is also used by clinical laboratories for the analysis of steroid hormones. Both LC-MS and GC-MS provide very low detection limits for LC-MS $\left(2.8-7.1 \cdot 10^{2} \mathrm{ng} / \mathrm{L}\right)(47-57,61-71,93)$ and GC-MS $(1-$ $\left.1.4 \cdot 10^{3} \mathrm{ng} / \mathrm{L}\right)(58,59,72-79)$. These methods cannot, however, be used for fast steroid profiling. It takes $20-45 \mathrm{~min}$ by LC-MS $(48,50,54,56,57,61-65,93)$, and $14.5-35 \mathrm{~min}$ by GC-MS $(58,72-74)$ to obtain a steroid profile, excluding sample preparation time. This is a considerably long time, especially when several hundred analyses or large-scale screening 
have to be performed. In addition, isotope-dilution methods require isotope labeled steroid standards which are expensive and not readily available for all the steroids of interest. Another shortcoming is the large sample injection volumes required by chromatography. For example, a typical sample injection volume in LC-MS is $2-100 \mu \mathrm{L}$, and $1-2.5 \mu \mathrm{L}$ in GC-MS. Additionally, liquid chromatography uses large volumes of flammable, expensive, and toxic mobile phases for analysis. While liquid chromatography does not require sample derivatization, gas chromatography method requires volatilization of the steroid analyte which can be obtained by derivatization of the analyte for $40-130 \min (72,73,75,76$, 78). Also, the use of gas chromatography for thermally degradable chemicals such as steroid hormones is questionable.

\subsubsection{IMMUNOASSAY}

Immunoassays are widely used in clinical laboratories for steroid analysis in the serum or plasma. Immunoassay measures the concentration of the analyte using the unique molecular recognition properties of an antibody (94). Immunoassays are widely applicable, specific, and sensitive (LOD < $0.3-64 \mathrm{ng} / \mathrm{L})(80-88,96,97)$. The instrumental equipment is relatively cheap and accessible. However, the analysis can be affected by the crossreactivity of antibodies with steroid metabolites from the sample matrix as many of the immunoassays are preformed directly on a non-purified plasma or serum samples to decrease the analysis time or on a sample pretreated with the extraction or chromatographic purification prior to incubation with an antibody (95). Immunoassay cannot be used for steroid profiling, since the method is typically used for analysis of one steroid at a time. To analyze several steroids in a single sample one would need to partition the sample and 
incubate each portion of the sample with a specific steroid antibody. Typically immunoassay requires $10-200 \mu \mathrm{L}$ of a reconstituted plasma sample to be introduced in each well of a 96-well mirotiter plate for incubation $(81,85-87,95,97)$. Since the volume of plasma sample available from a single fish is typically from $10 \mu \mathrm{l}$ to $<1000 \mu \mathrm{l}$, the entire sample of fish plasma is often used to determine one steroid only. Given the likelihood of variations of steroid concentrations between fish plasma samples, profiling using multiple fish plasma samples is error prone, not to mention the increased analysis time since the incubation time in immunoassay ranges from 45 - 90 min up to several hours $(80-82,84-$ 88, 96). Finally, the immunoassay analysis should be confirmed using GC-MS or LC-MS. For example, isotope dilution GC-MS does not suffer from cross-reactivity and does not depend on the presence of interferences in plasma samples as a result it has been used as a "gold" reference standard method for validating immunoassays (89). Figures of merit for steroid analysis reported in the literature are summarized in Table 1.1.

\subsubsection{CAPILLARY ELECTROPHORESIS}

Capillary electrophoresis (CE) provides rapid and unsophisticated method development, versatility, high efficiency and resolution, various modes to vary selectivity, simple separation mechanism and extremely small sample volumes required (98-101). CE separations are faster comparing to other methods discussed above. For example, previous works reported steroid analysis separation times less than 14 min using conventional capillaries (102-112) and less than 7 min with microfluidic devices (102). In addition, in CE the same instrument can be used for the separation and analysis of a wide range of analytes such as large biomolecules (proteins and nucleic acids), metal and organic ions, 
enantiomers and neutral molecules. These advantages of CE can help overcome the shortcomings of LC-MS, GC-MS, and immunoassay for steroid analysis discussed earlier.

\section{CONCLUSIONS}

The goal of the research presented within the framework of this dissertation is the development of an analytical technique which would allow for the high-throughput determination of the low concentrations of endogenous steroids in fish blood or plasma in order to be able to control the cause and effects of the endocrine disruption in aquatic fauna. As discussed above, many analytical methods have been developed for the analysis of steroids in environmental and biological samples. Despite the advantages of the low detection limits these methods are time consuming and are difficult to apply to volumelimited plasma samples. These technical difficulties suggested a need for a new approach to hormone analysis compatible with stringent demands of high throughput screening in real life applications dealing with small sample volumes and complicated matrix composition.

Chapter 2 discusses the fundamentals of capillary electrophoresis, which was chosen as the baseline approach for analysis of steroid hormones. Development of the separation protocol using micellar electrokinetic chromatography under acidic conditions to rapidly separate steroids is outlined in this chapter as well. The developed method is evaluated with respect to the selectivity and migration times for analyzed steroids. 
Table 1.1. Figures of merit for steroid analysis by literature methods. Literature search was limited to the publications published by 2008 and reported analysis of at least two (or one for immunoassay) of the following steroids: progesterone (P), testosterone (T), estrone (E1), estradiol (E2), and estriol (E3). Sample was either blood serum or blood plasma.

\begin{tabular}{|c|c|c|c|c|c|c|c|c|c|c|c|c|c|c|}
\hline \# & Steroid & Method & $\begin{array}{c}\text { Sample } \\
\text { matrix }\end{array}$ & $\begin{array}{l}\text { Sample } \\
\text { prep. }\end{array}$ & $\begin{array}{c}\text { Derivati } \\
\text { zation }\end{array}$ & $\begin{array}{c}\text { Sample } \\
\text { volume } \\
(\mathrm{mL})\end{array}$ & $\begin{array}{c}\text { Sample } \\
\text { injection } \\
\text { volume, } \\
(\mu \mathrm{L})\end{array}$ & $\begin{array}{c}\text { Analysis } \\
\text { time } \\
(\text { min) }\end{array}$ & $\begin{array}{c}\text { LOD } \\
\text { (ng/L) }\end{array}$ & $\begin{array}{c}\text { LOQ } \\
\text { (ng/L) }\end{array}$ & $\begin{array}{l}\text { RSD } \\
(\%)\end{array}$ & $\begin{array}{c}\text { Linear } \\
\text { range } \\
(\mathrm{ng} / \mathrm{L})\end{array}$ & $\begin{array}{c}\text { Recovery } \\
(\%)\end{array}$ & Ref. \\
\hline 1 & $\begin{array}{c}\text { Various } \\
\text { steroids } \\
\text { including E3, } \\
\text { E2, E1, P }\end{array}$ & $\begin{array}{l}\text { HPLC- } \\
\text { UV-VIS } \\
\text { diode } \\
\text { array } \\
\end{array}$ & $\begin{array}{l}\text { Human } \\
\text { plasma }\end{array}$ & SPE & NO & 2 & 20 & $\begin{array}{c}10 \text { (most } \\
\text { steroids); } \\
43(\mathrm{P})\end{array}$ & $\begin{array}{c}4.0 \cdot 10^{3}- \\
1.6 \cdot 10^{5}\end{array}$ & NR & NR & $\begin{array}{c}1.0 \cdot 10^{5}- \\
3.0 \cdot 10^{6} \\
\left(\mathrm{R}^{2} \geq\right. \\
0.995) \\
\end{array}$ & $\begin{array}{l}85.2- \\
99.9\end{array}$ & 61 \\
\hline 2 & $\begin{array}{c}\text { T, P, E1, E2, } \\
\text { E3 }\end{array}$ & LC-UV & $\begin{array}{c}\text { Human } \\
\text { serum }\end{array}$ & SPE & NO & 0.08 & NR & 45 & NR & NR & 4 & $10^{4}-10^{5}$ & NR & 62 \\
\hline 3 & $\begin{array}{c}\text { Various } \\
\text { steroids } \\
\text { including E3, } \\
\text { E2, E1, T, AD }\end{array}$ & $\begin{array}{l}\text { HPLC - } \\
\text { DAD }\end{array}$ & Serum & SPE & NO & 1 & 20 & $\begin{array}{c}30 \\
\text { (multistep } \\
\text { gradient); } \\
40 \text { (linear } \\
\text { gradient) }\end{array}$ & NR & NR & NR & $\begin{array}{c}1.5-30 \\
10^{4}\end{array}$ & NR & 63 \\
\hline 4 & $\begin{array}{c}\text { Various } \\
\text { steroids } \\
\text { including E2, } \\
\mathrm{E} 1, \mathrm{~T}, \mathrm{AD}, \mathrm{P} \\
\end{array}$ & $\begin{array}{l}\text { HPLC - } \\
\text { PDA }\end{array}$ & $\begin{array}{l}\text { Serum; } \\
\text { gonodal } \\
\text { tissues }\end{array}$ & SPE & NO & 10 & 25 & 30 & NR & NR & NR & NR & NR & 65 \\
\hline 5 & $\mathrm{E} 2, \mathrm{E} 1$ & $\begin{array}{c}\text { LC- } \\
\text { (APCI)- } \\
\text { MS/MS }\end{array}$ & $\begin{array}{l}\text { Human } \\
\text { plasma }\end{array}$ & $\begin{array}{l}\text { Solvent } \\
\text { extraction }\end{array}$ & YES & 0.5 & 15 & 5 & $\begin{array}{l}3.5(\mathrm{E} 1) \\
2.8(\mathrm{E} 2)\end{array}$ & $\begin{array}{c}11.9 \\
(\mathrm{E} 1) ; \\
6.3(\mathrm{E} 2)\end{array}$ & $\begin{array}{c}\text { Inter- } \\
\text { assay: } \\
4-20 \\
(\mathrm{n}=20)\end{array}$ & $\begin{array}{c}10-600 \\
\left(\mathrm{R}^{2} \geq\right. \\
0.995)\end{array}$ & $\begin{array}{c}93-108 \\
(\mathrm{E} 1) ; \\
100-110 \\
(\mathrm{E} 2)\end{array}$ & 66 \\
\hline 6 & $\begin{array}{c}\text { Deuterated E2 } \\
\text { and E1 }\end{array}$ & $\begin{array}{c}\text { LC- } \\
\text { MS/MS }\end{array}$ & $\begin{array}{l}\text { Mouse } \\
\text { plasma }\end{array}$ & $\begin{array}{l}\text { Solvent } \\
\text { extraction }\end{array}$ & YES & 0.05 & NR & NR & NR & 50 & $\begin{array}{c}\text { Intra-, } \\
\text { inter-day } \\
\text { precision } \\
12.9\end{array}$ & $\begin{array}{c}50-2 \cdot 10^{4} \\
\left(\mathrm{R}^{2}=\right. \\
0.995)\end{array}$ & 83 & 69 \\
\hline 7 & E1, E2 & $\begin{array}{c}\text { LC- } \\
\text { (APCI)- } \\
\text { MS/MS }\end{array}$ & $\begin{array}{l}\text { Serum; } \\
\text { urine }\end{array}$ & $\begin{array}{l}\text { Solvent } \\
\text { extraction }\end{array}$ & YES & 0.01 & 10 & 5 & $300-710$ & NR & NR & NR & $\begin{array}{c}93.8- \\
100.9 \\
\text { (serum); } \\
93.5- \\
107.9 \\
\text { (urine) } \\
(\mathrm{n}=2)\end{array}$ & 70 \\
\hline
\end{tabular}




\begin{tabular}{|c|c|c|c|c|c|c|c|c|c|c|c|c|c|c|}
\hline$\#$ & Steroid & Method & $\begin{array}{l}\text { Sample } \\
\text { matrix }\end{array}$ & $\begin{array}{l}\text { Sample } \\
\text { prep. }\end{array}$ & $\begin{array}{l}\text { Derivati } \\
\text { zation }\end{array}$ & $\begin{array}{c}\text { Sample } \\
\text { volume } \\
(\mathbf{m L})\end{array}$ & $\begin{array}{c}\text { Sample } \\
\text { injection } \\
\text { volume, } \\
(\mu \mathrm{L})\end{array}$ & $\begin{array}{c}\text { Analysis } \\
\text { time }\end{array}$ & $\begin{array}{c}\text { LOD } \\
(\mathbf{n g} / \mathbf{L})\end{array}$ & $\begin{array}{c}\text { LOQ } \\
(\mathbf{n g} / \mathrm{L})\end{array}$ & $\begin{array}{c}\text { RSD } \\
(\%)\end{array}$ & $\begin{array}{l}\text { Linear } \\
\text { range } \\
(\text { ng/L) }\end{array}$ & $\begin{array}{c}\text { Recovery } \\
(\%)\end{array}$ & Ref. \\
\hline 8 & $\begin{array}{c}\text { E2, E3, E1, } \\
\text { EE, } \\
\text { diethylstilbest } \\
\text { rol }\end{array}$ & $\begin{array}{c}\text { LC- } \\
\text { MS/MS, } \\
\text { GC- } \\
\text { MS/MS }\end{array}$ & $\begin{array}{l}\text { Water, } \\
\text { serum }\end{array}$ & $\begin{array}{c}\text { SPE } \\
\text { (C18 col.) }\end{array}$ & $\begin{array}{c}\text { (GC-MS/MS): } \\
\text { YES }\end{array}$ & $\begin{array}{c}1000 \\
\text { (water); } \\
2 \text { (serum) }\end{array}$ & $\begin{array}{c}\text { NR (LC- } \\
\text { MS/MS); } \\
1 \text { (GC- } \\
\text { MS/MS) }\end{array}$ & $\begin{array}{c}20(\mathrm{LC}- \\
\mathrm{MS} / \mathrm{MS}) \\
65(\mathrm{GC}- \\
\mathrm{MS} / \mathrm{MS})\end{array}$ & NR & $\begin{array}{c}5 \cdot 10^{3} \\
(\mathrm{LC}- \\
\mathrm{MS} / \mathrm{MS}) \\
(2-15) \\
\cdot 10^{3} \\
(\mathrm{GC}- \\
\mathrm{MS} / \mathrm{MS})\end{array}$ & NR & NR & 90 & 71 \\
\hline 9 & $\begin{array}{l}14 \text { adrenal- } \\
\text { cortical } \\
\text { steroids incl. } \\
\text { E1, AD, E2, } \\
\text { T, P, E3 }\end{array}$ & GC-MS & $\begin{array}{l}\text { Blood } \\
\text { serum }\end{array}$ & $\begin{array}{l}\text { Solvent } \\
\text { extraction }\end{array}$ & YES & 1 & 2 & $\begin{array}{c}\text { 14.5- } \\
\text { separation } \\
(240 \\
\text { total time })\end{array}$ & $100-1000$ & NR & $\begin{array}{c}\text { Intra- } \\
\text { assay: } \\
5.0-18.0 \\
\text { inter- } \\
\text { assay: } \\
6.0-19.0\end{array}$ & NR & $\begin{array}{l}71.4- \\
100.0\end{array}$ & 72 \\
\hline 10 & $\begin{array}{c}\text { Various } \\
\text { steroids incl. } \\
\text { E1, E2, T, } \\
\text { AD, P }\end{array}$ & GC-MS & $\begin{array}{l}\text { Fish } \\
\text { plasma }\end{array}$ & SPE & YES & $1 \mathrm{~g}$ & 2.5 & 33 & $100 \mathrm{ng} / \mathrm{kg}$ & NR & NR & NR & $85-118$ & 73 \\
\hline 11 & $\begin{array}{c}\text { EDCs, E1, } \\
\text { E2, E3, EE, P, } \\
\text { T }\end{array}$ & GC-MS & Serum & $\begin{array}{l}\text { SPE- } \\
\text { HPLC }\end{array}$ & NO & 3.6 & 2 & 20 & NR & NR & NR & NR & NR & 74 \\
\hline 12 & E1, E2 & $\begin{array}{c}\text { GC- } \\
\text { MS/MS }\end{array}$ & Serum & $\begin{array}{c}\text { SPE; } \\
\text { solvent } \\
\text { extraction; } \\
\text { semi-prep. } \\
\text { HPLC; }\end{array}$ & YES & 2 & 2 & 6 & 1 & 2 & 10 & NR & 24 & 75 \\
\hline 13 & $\begin{array}{c}\text { Estramustine } \\
\text { phosphate + } \\
\text { metabolites: } \\
\text { E1, E2 }\end{array}$ & $\begin{array}{l}\text { GC- } \\
\text { (SIM)- } \\
\text { MS }\end{array}$ & $\begin{array}{l}\text { Human } \\
\text { plasma }\end{array}$ & $\begin{array}{c}\text { SPE } \\
+ \\
\text { solvent } \\
\text { extraction }\end{array}$ & YES & 1 & 2 & 15 & $\begin{array}{l}1.4 \cdot 10^{3} \\
(\mathrm{E} 1) \\
0.54 \cdot 10^{3} \\
(\mathrm{E} 2)\end{array}$ & $\begin{array}{l}3.2 \cdot 10^{3} \\
(\mathrm{E} 1) ; \\
2.2 \cdot 10^{3} \\
(\mathrm{E} 2)\end{array}$ & $\begin{array}{l}1.3-14 \\
(\mathrm{E} 1) \\
2.1-11 \\
(\mathrm{E} 2)\end{array}$ & $\begin{array}{c}1.4 \cdot 10^{3}- \\
1.5 \cdot 10^{5} \\
(\mathrm{E} 1) ; \\
0.54 \cdot 10^{3} \\
-0.30 \cdot 10^{5} \\
(\mathrm{E} 2)\end{array}$ & $70-90$ & 76 \\
\hline 14 & $\mathrm{E} 1, \mathrm{E} 2, \mathrm{E} 3$ & GC-MS & Serum & $\begin{array}{c}\text { Solvent } \\
\text { extraction }\end{array}$ & YES & 0.5 & NR & $\begin{array}{c}.5(30 \\
\text { samples/ } \\
\text { day) }\end{array}$ & NR & NR & $\begin{array}{c}\text { Inter- } \\
\text { assay: } \\
3.42-3.73\end{array}$ & $\begin{array}{c}100-500 \\
\text { pg }\end{array}$ & $\begin{array}{c}96.47- \\
97.88\end{array}$ & 77 \\
\hline
\end{tabular}




\begin{tabular}{|c|c|c|c|c|c|c|c|c|c|c|c|c|c|c|}
\hline$\#$ & Steroid & Method & $\begin{array}{c}\text { Sample } \\
\text { matrix }\end{array}$ & $\begin{array}{l}\text { Sample } \\
\text { prep. }\end{array}$ & $\begin{array}{l}\text { Derivati } \\
\text { zation }\end{array}$ & $\begin{array}{c}\text { Sample } \\
\text { volume } \\
(\mathrm{mL})\end{array}$ & $\begin{array}{c}\text { Sample } \\
\text { injection } \\
\text { volume, } \\
(\mu \mathrm{L})\end{array}$ & $\begin{array}{c}\text { Analysis } \\
\text { time }\end{array}$ & $\begin{array}{c}\text { LOD } \\
\text { (ng/L) }\end{array}$ & $\begin{array}{c}\text { LOQ } \\
\text { (ng/L) }\end{array}$ & $\begin{array}{c}\text { RSD } \\
(\%)\end{array}$ & $\begin{array}{l}\text { Linear } \\
\text { range } \\
(\text { ng/L) }\end{array}$ & $\begin{array}{c}\text { Recovery } \\
(\%)\end{array}$ & Ref. \\
\hline 15 & E1, E2, E3 & $\begin{array}{c}\text { GC- } \\
(\mathrm{EI})-\mathrm{MS}\end{array}$ & Serum & $\begin{array}{c}\text { Solvent } \\
\text { extraction }\end{array}$ & NO & 0.2 & NR & 13 & $\begin{array}{c}50 \\
(\mathrm{E} 1, \mathrm{E} 2) ; \\
1000(\mathrm{E} 3)\end{array}$ & NR & NR & $\begin{array}{c}50- \\
5 \cdot 10^{4}\end{array}$ & NR & 78 \\
\hline 16 & E2, P, T & RIA & $\begin{array}{c}\text { Blood } \\
\text { plasma }\end{array}$ & NR & NO & 10 total & NR & $\begin{array}{c}3-4 \mathrm{hr} \text { at } \\
\text { room T }\end{array}$ & $\begin{array}{l}8(\mathrm{E} 2) \\
20(\mathrm{P}) \\
64(\mathrm{~T})\end{array}$ & NR & NR & NR & NR & 80 \\
\hline 17 & $\begin{array}{l}\text { E1, E1- } \\
\text { sulfate }\end{array}$ & RIA & $\begin{array}{c}\text { Human } \\
\text { serum }\end{array}$ & Extraction & NO & 1 & 200 & $\begin{array}{c}16-20 \mathrm{hr} \\
\text { at } 0^{\circ} \mathrm{C}\end{array}$ & 4.7 (E1) & NR & NR & NR & NR & 81 \\
\hline 18 & $\begin{array}{c}\mathrm{E} 1, \mathrm{E} 2, \mathrm{E} 3, \mathrm{~T}, \\
\mathrm{AD}, 5 \alpha- \\
\text { dihydrotestost } \\
\text { erone }\end{array}$ & RIA & $\begin{array}{l}\text { Human } \\
\text { plasma }\end{array}$ & $\begin{array}{c}\text { Solvent } \\
\text { extraction } \\
+ \text { column } \\
\text { chromatog } \\
\text { raphy + } \\
\text { TLC }\end{array}$ & NO & 1 & NR & $\begin{array}{c}12 \mathrm{hr} \text { at } \\
\pm 4^{\circ} \mathrm{C}\end{array}$ & $\begin{array}{l}2.6-15 \\
\mathrm{pg} / \text { tube }\end{array}$ & NR & $\begin{array}{c}\text { Intra- } \\
\text { assay: } \\
2.8-8.3 ; \\
\text { Inter- } \\
\text { assay: } \\
1.3-10.5\end{array}$ & NR & $\begin{array}{c}61.2-73.7 \\
(\mathrm{n}=90)\end{array}$ & 82 \\
\hline 19 & $\begin{array}{l}\text { E1, E2 E1- } \\
\text { sulfate }\end{array}$ & RIA & $\begin{array}{l}\text { Blood } \\
\text { plasma }\end{array}$ & $\begin{array}{l}\text { SPE, } \\
\text { HPLC }\end{array}$ & NO & 2 & 200 & NR & $0.7-6$ & NR & $\begin{array}{c}\text { Intra- } \\
\text { assay: } \\
<10\end{array}$ & NR & $55-70$ & 83 \\
\hline 20 & E1, E2 & EIA & $\begin{array}{l}\text { Bovine } \\
\text { plasma }\end{array}$ & $\begin{array}{c}\text { Sephadex } \\
\text { LH-20 }\end{array}$ & NO & 0.1 & 100 & $\begin{array}{l}\text { overnight } \\
\text { at } 4^{\circ} \mathrm{C}\end{array}$ & $\begin{array}{l}<0.3 \\
(\mathrm{E} 1) ; \\
<1.2 \\
(\mathrm{E} 2)\end{array}$ & NR & $\begin{array}{c}\text { Intra- } \\
\text { assay: } \\
4.8-5.6 \\
\text { Inter- } \\
\text { assay: } \\
1.9-8.8 \\
\end{array}$ & $\begin{array}{l}0.25-1000 \\
\text { (E1); } \\
1-5000 \\
\text { (E2) }\end{array}$ & $\begin{array}{l}94.5 \text { (E1); } \\
93.9 \text { (E2) }\end{array}$ & 85 \\
\hline 21 & E2 & EIA & $\begin{array}{l}\text { Human } \\
\text { serum } \\
\text { or } \\
\text { plasma }\end{array}$ & NR & NO & NR & 25 & $110 \mathrm{~min}$ & 10 & NR & $\begin{array}{c}\text { Intra- } \\
\text { assay: } \\
4.1-24.1 ; \\
\text { Inter- } \\
\text { assay: } \\
6.4-26.7\end{array}$ & $\begin{array}{c}0-1000 ; \\
\text { cross- } \\
\text { reactivity: } \\
2.10 \% \\
\text { (E1), } \\
1.50 \% \\
\text { (E3) }\end{array}$ & $\begin{array}{l}89.2- \\
112.6\end{array}$ & 86 \\
\hline 22 & $\mathrm{~T}$ & EIA & $\begin{array}{c}\text { Human } \\
\text { serum }\end{array}$ & NR & NO & NR & 10 & $110 \mathrm{~min}$ & 50 & NR & $\begin{array}{c}\text { Intra- } \\
\text { assay: } \\
\text { 5.0-10.0; } \\
\text { Inter- } \\
\text { assay: } \\
4.4-8.4\end{array}$ & $\begin{array}{c}0-18000 ; \\
\text { cross- } \\
\text { reactivity: } \\
0.86 \% \\
(\mathrm{DHT}) \\
0.89 \% \\
(\mathrm{AD})\end{array}$ & $\begin{array}{l}70.4- \\
127.5\end{array}$ & 87 \\
\hline
\end{tabular}




\begin{tabular}{|c|c|c|c|c|c|c|c|c|c|c|c|c|c|c|}
\hline$\#$ & Steroid & Method & $\begin{array}{c}\text { Sample } \\
\text { matrix }\end{array}$ & $\begin{array}{c}\text { Sample } \\
\text { prep. }\end{array}$ & $\begin{array}{c}\text { Derivati } \\
\text { zation }\end{array}$ & $\begin{array}{c}\text { Sample } \\
\text { volume } \\
(\mathrm{mL})\end{array}$ & $\begin{array}{c}\text { Sample } \\
\text { injection } \\
\text { volume, } \\
(\mu \mathrm{L})\end{array}$ & $\begin{array}{c}\text { Analysis } \\
\text { time }\end{array}$ & $\begin{array}{c}\text { LOD } \\
(\mathbf{n g} / \mathrm{L})\end{array}$ & $\begin{array}{c}\text { LOQ } \\
\text { (ng/L) }\end{array}$ & $\begin{array}{c}\text { RSD } \\
(\%)\end{array}$ & $\begin{array}{c}\text { Linear } \\
\text { range } \\
(\text { ng/L) }\end{array}$ & $\begin{array}{c}\text { Recovery } \\
(\%)\end{array}$ & Ref. \\
\hline 23 & $\mathrm{P}$ & EIA & $\begin{array}{l}\text { Human } \\
\text { serum } \\
\text { or } \\
\text { plasma }\end{array}$ & NR & NO & NR & 25 & $110 \mathrm{~min}$ & 300 & NR & $\begin{array}{c}\text { Intra- } \\
\text { assay: } \\
2.4-7.1 \text {; } \\
\text { Inter- } \\
\text { assay: } \\
2.6-12.6\end{array}$ & $0-50000$ & $\begin{array}{l}80.4- \\
118.6\end{array}$ & 88 \\
\hline
\end{tabular}

NR-not reported 


\section{BIBLIOGRAPHY}

1. Bykova, L.; Holland, L. A. Stacking Enhanced Determination of Steroids by CE. Electrophoresis 2008, $29(18), 3794-3800$.

2. McLachlan, J. A.; Dixon, R. L. Toxicological Comparisons of Experimental and Clinical Exposure to Diethylstilbestrol During Gestation. Adv. Sex Horm. Res. 1977, 3, 309-336.

3. Allen, B. M.; Bern, H. Influence of Diethylstilbestrol upon the Adrenal Cortex of the Guinea Pig. Endocrinology 1942, 31, 586-591.

4. Bern, H. A. Some Effect of Long-Continued Estrogen Treatment on Male Dutch Rabbits. Cancer Res. 1949, 9, 65-73.

5. Shah, H. C.; McLachlan, J. A. The Fate of Diethylstilbestrol in the Pregnant Mouse. J. Pharmacol. Exp. Ther. 1976, 197 (3), 687-696.

6. McLachlan, J. A. Prenatal Exposure to Diethylstilbestrol in Mice. Toxicological studies. J. Toxicol. Environ. Health 1977, 2 (3), 527-537.

7. Colborn, T.; Clement, C., Eds.; Chemically-Induced Alterations in Sexual and Functional Development: The Wildlife/Human Connection; Advances in Modern Environmental Toxicology; Princeton Scientific Publishing Co., Inc.: Princeton, NJ, 1992; Vol. 21.

8. Keith, L. H.; Jones-Lepp, T. L.; Needham, L. L., Eds. Analysis of Environmental Endocrine Disruptors, ACS Symposium Series 747; American Chemical Society: Washington, DC, 2000; pp 1-10.

9. Fahrenthold, D. A. Abnormal Fish Found Closer to Washington: Waste Suspected in Egg-Bearing Males. The Washington Post, Dec 19, 2004, p C 01.

10. Chambers, D. B.; Leiker, T. J. A Reconnaissance for Emerging Contaminants in the South Branch Potomac River, Cacapon River, and Williams River Basins, West Virginia; Open-File Report 2006-1393 U. S. Geological Survey: Reston, VA, April-October 2004.

11. Fahrenthold, D. A. Update: Pollution Confusing Fish Hormone Systems, Scientists Say. The Washington Post, Aug 7, 2005, p C 02.

12. Fogg, J. Potomac's Intersex Fish a Puzzle for Scientists. The Washington Post, July 27, 2005, p. B 01. 
13. Blazer, V. S.; Iwanowicz, L. R.; Iwanowicz, D. D.; Smith, D. R.; Young, J. A.; Hedrick, J. D.; Foster, S. W.; Reeser, S. J. Intersex (Testicular Oocytes) in Smallmouth Bass Micropterus Dolomieu From the Potomac River and Selected Nearby Drainages. J. Aquat. Anim. Health 2007, 19, $242-253$.

14. Ripley, J. L; Iwanowicz, L. R.; Blazer, V. S.; Foran, C. M. Utilization of Protein Profiles as Indicators of Environmental Impairment of Smallmouth Bass (Micropterus Dolomieu) from the Shenandoah River, VA, USA. Environ. Toxicol. Chem. 2008, 27, 1756-1767.

15. Iwanowicz, L. R.; Blazer, V. S.; Guy, C. P.; Pinkney, A. E; Mullican, J. E.; Alvarez. D. A. Reproductive Health of Bass in the Potomac, USA, Drainage: Part 1. Exploring the Effects of Proximity to Wastewater Treatment Plant Effluent Discharge. Environ. Toxicol. Chem. 2008, 28 (5), 1072-1083.

16. Alvarez, D. A.; Cranor, W. L.; Perkins, S. D.; Schroeder, V. L.; Iwanowicz, L. R.; Clark, R. C.; Guy, C. P.; Pinkney, A. E.; Blazer, V. S.; Mullican, J. E. Reproductive Health of Bass in the Potomac, USA, Drainage: Part 2: Seasonal Occurrence of Persistent and Emerging Organic Contaminants. Environ. Toxicol. Chem. 2008, 28 (5), 1084-1095.

17. Metzler, M., Ed. Endocrine disruptors, Part I, 1st ed.; Springer, NY, 2001; Chapters 3, 5.

18. Desbrow, C.; Routledge, E. J.; Brighty, G. C.; Sumpter, J. P.; Waldock, M. Identification of Estrogenic Chemicals in STW Effluent. 1. Chemical Fractionation in vitro Biological Screening. Environ. Sci. Technol. 1998, 32, 1549-1558.

19. Ternes, T. A.; Stumpf, M.; Mueller, J.; Haberer, K.; Wilken, R.-D.; Servos, M. Behavior and Occurrence of Estrogens in Municipal Sewage Treatment Plants. I. Investigations in Germany, Canada and Brazil. Sci. Total Environ. 1999, 225, 81-90.

20. Brooks, B. W.; Riley, T. M.; Taylor, R. D. Water Quality of Effluent-Dominated Ecosystems: Ecotoxicological, Hydrological, and Management Considerations. Hydrobiologia 2006, 556, 365-379.

21. Jobling, S.; Sheahan, D.; Osborne, J. A.; Matthiessen, P.; Sumpter, J. P. Inhibition of Testicular Growth in Rainbow Trout (Oncorhynchus Mykiss) Exposed to Estrogenic Alkylphenolic Chemicals. Environ. Toxicol. Chem. 1996, 15, 194-202.

22. Henson, M. C.; Chedrese, P. J. Endocrine Disruption by Cadmium, a Common Environmental Toxicant with Paradoxical Effects on Reproduction. Exp. Biol. Med. 2004, 229, 383-392.

23. Baatrup, E.; Junge, M. Antiandrogenic Pesticides Disrupt Sexual Characteristics in the Adult Male Guppy (Poecilia Reticulata). Environ. Health Perspect. 2001, 109, 1063-1070. 
24. Oehlmann, J.; Oetken, M.; Schulte-Oehlmann, U. A Critical Evaluation of the Environmental Risk Assessment for Plasticizers in the Freshwater Environment in Europe, with Special Emphasis on Bisphenol A and Endocrine Disruption. Environ. Res. 2008, 108 (2), 140-149.

25. Bradlee, C. A.; Thomas, P. Aquatic Toxicity of Phthalate Esters. In the Handbook of Environmental Chemistry; Springer Berlin/Heidelberg, 2002; Vol. 3Q, pp 263-298.

26. Louiz, I.; Kinani, S.; Gouze, M.-E.; Ben-Attia, M.; Menif, D.; Bouchonnet, S.; Porcher, J. M.; BenHassine, O. K.; Ait-Aissa, S. Monitoring of Dioxin-Like, Estrogenic and Anti-Androgenic Activities in Sediments of the Bizerta Lagoon (Tunisia) by Means of in vitro Cell-Based Bioassays: Contribution of Low Concentrations of Polynuclear Aromatic Hydrocarbons (PAHs). Sci. Total Environ. 2008, 402 (2-3), 318-329.

27. Kawano, M.; Hasegawa, J.; Enomoto, T.; Onishi, H.; Nishio, Y.; Matsuda, M.; Wakimoto, T. Hydroxylated Polychlorinated Biphenyls (OH-PCBs): Recent Advances in Wildlife Contamination Study. Environ. Sci. 2005, 12 (6), 315-324.

28. Ross, G. The Public Health Implications of Polychlorinated Biphenyls (PCBs) in the Environment. Ecotoxicol. Environ. Saf. 2004, 59 (3), 275-291.

29. Rempel, M. A.; Schlenk, D. Effects of Environmental Estrogens and Antiandrogens on Endocrine Function, Gene Regulation, and Health in Fish. Int. Rev. Cell Mol. Biol. 2008, 267, 207-252.

30. Daughton, C. G.; Ternes, T. A. Pharmaceuticals and Personal Care Products in the Environment: Agents of Subtle Change? Environ. Health Perspect. 1999, 107 (Suppl. 6), 907-938.

31. Richards, S. M.; Wilson, C. J.; Johnson, D. J.; Castle, D. M.; Lam, M.; Mabury, S. A.; Sibley, P. K.; Solomon, K. R. Effects of Pharmaceutical Mixtures in Aquatic Microcosms. Environ. Toxicol. Chem. 2004, 23, 1035-1042.

32. Webb, S.; Ternes, T.; Gilbert, M.; Olejniczak, K. Indirect Human Exposure to Pharmaceuticals via Drinking Water. Toxicol. Lett. 2003, 142, 157-167.

33. Hodgson, E. A Textbook of Modern Toxicology, 3rd ed.; Wiley \& Sons: New York, 2004; Chapter 1, pp 3-12.

34. Nelson, D. L.; Cox, M. M., Eds.; Lehninger Principles of Biochemistry, 4th ed.; W. H. Freeman: New York, NY, 2004; Chapter 12, pp 412-479. 
35. Kime, D.E. Endocrine disruption in fish, 1st ed.; Springer Kluwer: Boston, MA, 1998; Figure 4.3, Figure 4.7.

36. Simpson, E. R.; Mahendroo, M. S.; Means, G. D.; Kilgore, M. W.; Hinshelwood, M. M.; GrahamLorence, S.; Amarneh, B.; Ito, Y.; Fisher, C. R.; et al. Aromatase Cytochrome P450, the Enzyme Responsible for Estrogen Biosynthesis. Endocr. Rev. 1994, 15 (3), 342-355.

37. Peltoketo, H.; Luu-The, V.; Simard, J.; Adamski, J. 17 beta-Hydroxysteroid Dehydrogenase (HSD)/17Ketosteroid Reductase (KSR) Family; Nomenclature and Main Characteristics of the 17HSD/KSR Enzymes. J. Mol. Endocrinol. 1999, 23 (1), 1-11.

38. Borg, B. Androgens in Teleost Fishes. Comp. Biochem. Physiol., C: Pharmacol. Toxicol. Endocrinol. 1994, 109 C, 219-245.

39. Sikka, S. C.; Wang, R. Endocrine Disruptors and Estrogenic Effects on Male Reproductive Axis. Asian J. Androl. 2008, 10 (1), $134-145$.

40. Basrur, P. K. Disrupted Sex Differentiation and Feminization of Man and Domestic Animals. Environ. Res. 2006, 100 (1), 18-38.

41. Murr, A. S.; Goldman, J. M. Twenty-Week Exposures to the Drinking Water Disinfection By-Product Dibromoacetic Acid: Reproductive Cyclicity and Steroid Concentrations in the Female SpragueDawley Rat. Reprod. Toxicol. 2005, 20 (1), 73-80.

42. Vinggaard, A. M.; Bonefeld Joergensen, E. C.; Larsen, J. C. Rapid and Sensitive Reporter Gene Assays for Detection of Antiandrogenic and Estrogenic Effects of Environmental Chemicals. Toxicol. Appl. Pharmacol. 1999, 155 (2), 150-160.

43. Sanseverino, J.; Eldridge, M. L.; Layton, A. C.; Easter, J. P.; Yarbrough, J.; Schultz, T. W.; Sayler, G. S. Screening of Potentially Hormonally Active Chemicals Using Bioluminescent Yeast Bioreporters. Toxicol. Sci. 2009, 107 (1), 122-134.

44. Czerny, B.; Pawlik, A.; Juzyszyn, Z.; Mysliwiec, Z. Effect of Tamoxifen on Bone Mineral Density and Blood Lipids in Ovariectomized Rats. Pol. J. Pharmacol. 2003, 55 (6), 1137-1142.

45. Odum, J.; Ashby, J. Detection of Aromatase Inhibitors in vitro Using Rat Ovary Microsomes. Toxicol. Lett. 2002, $129(1-2), 119-122$. 
46. Jobling, S.; Sheahan, D.; Osborne, J. A.; Matthiessen, P.; Sumpter, J. P. Inhibition of Testicular Growth in Rainbow Trout (Oncorhynchus Mykiss) Exposed to Estrogenic Alkylphenolic Chemicals. Environ. Toxicol. Chem. 1996, 15 (2), 194-202.

47. Lopez de Alda, M. J.; Barcelo, D. Use of Solid-Phase Extraction in Various of its Modalities for Sample Preparation in the Determination of Estrogens and Progestogens in Sediment and Water. J. Chromatogr., A 2001, 938 (1-2), 145-153.

48. Vulliet, E.; Baugros, J.-B.; Flament-Waton, M.-M.; Grenier-Loustalot, M.-F. Analytical Methods for the Determination of Selected Steroid Sex Hormones and Corticosteriods in Wastewater. Anal. Bioanal. Chem. 2007, 387 (6), 2143-2151.

49. Petrovic, M.; Tavazzi, S.; Barcelo, D. Column - Switching System with Restricted Access Pre - Column Packing for an Integrated Sample Cleanup and Liquid Chromatographic-Mass Spectrometric Analysis of Alkylphenolic Compounds and Steroid Sex Hormones in Sediment. J. Chromatogr., A 2002, 971 (1-2), $37-45$.

50. Seifert, M.; Brenner-Weiss, G.; Haindl, S.; Nusser, M.; Obst, U.; Hock, B. A New Concept for the Bioeffects-Related Analysis of Xenoestrogens. Hyphenation of Receptor Assays with LC-MS. Fresenius. J. Anal. Chem. 1999, 363 (8), 767-770.

51. Ferguson, P. L.; Iden, C. R.; McElroy, A. E.; Brownawell, B. J. Determination of Steroid Estrogens in Wastewater by Immunoaffinity Extraction Coupled with HPLC-Electrospray-MS. Anal. Chem. 2001, 73 (16), 3890-3895.

52. Benijts, T.; Dams, R.; Gunther, W.; Lambert, W.; De Leenheer, A. Analysis of Estrogenic Contaminants in River Water Using Liquid Chromatography Coupled to Ion Trap Based Mass Spectrometry. Rapid Commun. Mass Spectrom. 2002, 16 (14), 1358-1364.

53. Loos, R.; Wollgast, J.; Huber, T.; Hanke, G. Polar Herbicides, Pharmaceutical Products, Perfluorooctanesulfonate (PFOS), Perfluorooctanoate (PFOA), and Nonylphenol and its Carboxylates and Ethoxylates in Surface and Tap Waters around Lake Maggiore in Northern Italy. Anal. Bioanal. Chem. 2007, 387 (4), 1469-1478.

54. Borges, C. R.; Miller, N.; Shelby, M.; Hansen, M.; White, C.; Slawson, M. H.; Monti, K.; Crouch, D. J. Analysis of a Challenging Subset of World Anti-Doping Agency-Banned Steroids and Antiestrogens by LC-MS-MS. J. Anal. Toxicol. 2007, 31 (3), 125-131. 
55. Cui, C. W.; Ji, S. L.; Ren, H. Y. Determination of Steroid Estrogens in Wastewater Treatment Plant of a Controceptives Producing Factory. Environ. Monit. Assess. 2006, 121 (1-3), 409-419.

56. Baronti, C.; Curini, R.; D'Ascenzo, G.; Di Corcia, A.; Gentili, A.; Samperi, R. Monitoring Natural and Synthetic Estrogens at Activated Sludge Sewage Treatment Plants and in Receiving River Water. Environ. Sci. Technol. 2000, 34 (24), 5059-5066.

57. Gentili, A.; Perret, D.; Marchese, S.; Mastropasqua, R.; Curini, R.; Di Corcia, A. Analysis of Free Estrogens and Their Conjugates in Sewage and River Waters by Solid-Phase Extraction then Liquid Chromatography-Electrospray-Tandem Mass Spectrometry. Chromatographia 2002, 56 (1/2), 25-32.

58. Noppe, H.; Verheyden, K.; Gillis, W.; Courtheyn, D.; Vanthemsche, P.; De Brabander, H. F. Multi Analyte Approach for the Determination of ng L (-1) Levels of Steroid Hormones in Unidentified Aqueous Samples. Anal. Chim. Acta 2007, 586 (1-2), 22-29.

59. Hajkova, K.; Pulkrabova, J.; Schurek, J.; Hajslova, J.; Poustka, J.; Napravnikova, M.; Kocourek, V. Novel Approaches to the Analysis of Steroid Estrogens in River Sediments. Anal. Bioanal. Chem. 2007, 387 (4), 1351-1363.

60. Shore, L. S.; Gurevitz, M.; Shemesh, M. Estrogen as an Environmental Pollutant. Bull. Environ. Contam. Toxicol. 1993, 51 (3), 361-366.

61. Zarzycki, P. K.; Kulhanek, K. M.; Smith, R.; Clifton, V. L. Determination of Steroids in Human Plasma Using Temperature - Dependent Inclusion Chromatography for Metabolomic Investigations. J. Chromatogr., A 2006, 1104 (1-2), 203-208.

62. Oka, K.; Ijitsu, T.; Minagawa, K.; Hara, S.; Noguchi, M. Efficient Chromatographic Fractionation of Steroids in Human Serum Through Regulation of Liquid-Liquid Distribution Ratios. J. Chromatogr. 1985, 339 (2), 253-261.

63. Kuronen, P.; Volin, P.; Laitalainen, T. Reversed-Phase High-Performance Liquid Chromatographic Screening Method for Serum Steroids Using Retention Index and Diode-Array Detection. J. Chromatogr., B: Biomed. Sci. Appl. 1998, 718 (2), 211-224.

64. Katayama, M.; Taniguchi, H. Determination of Estrogens in Plasma by High-Performance Liquid Chromatography after Pre-Column Derivatization with 2-(4-carboxyphenyl)-5, 6-Dimethylbenzimidazole. J. Chromator., B: Biomed. Appl. 1993, 616 (2), 317-322. 
65. Lowartz, S.; Petkam, R.; Renaud, R.; Beamish, F. W. H.; Kime, D. E.; Raeside, J.; Leatherland, J. F. Blood Steroid Profile and in vitro Steroidogenesis by Ovarian Follicles and Testis Fragments of Adult Sea Lamprey, Petromyzon Marinus. Comp. Biochem. Physiol., A: Mol. Integr. Physiol. 2003, 134A (2), 365-376.

66. Nelson, R. E.; Grebe, S. K.; O'Kane, D. J.; Singh, R. J. Liquid Chromatography-Tandem Mass Spectrometry Assay for Simultaneous Measurement of Estradiol and Estrone in Human Plasma. Clin. Chem. 2004, 50 (2), 373-384.

67. Shou, W. Z.; Jiang, X.; Naidong, W. Development and Validation of a High - Sensitivity Liquid Chromatography/Tandem Mass Spectrometry (LC/MS/MS) Method with Chemical Derivatization for the Determination of Ethinyl Estradiol in Human Plasma. Biomed. Chromatogr. 2004, 18 (7), 414-421.

68. Li, W.; Li, Y.-H.; Li, A. C.; Zhou, S.; Naidong, W. Simultaneous Determination of Norethindrone and Ethinyl Estradiol in Human Plasma by High Performance Liquid Chromatography with Tandem Mass Spectrometry-Experiences on Developing a Highly Selective Method Using Derivatization Reagent for Enhancing Sensitivity. J. Chromatogr. B, Anal. Technol. Biomed. Life Sci. 2005, 825 (2), 223-232.

69. Xia, Y.-Q.; Chang, S. W.; Patel, S.; Bakhtiar, R.; Karanam, B.; Evans, D. C. Trace Level Quantification of Deuterated 17 beta-Estradiol and Estrone in Ovariectomized Mouse Plasma and Brain Using Liquid Chromatography/Tandem Mass Spectrometry Following Dansylation Reaction. Rapid Commun. Mass Spectrom. 2004, 18 (14), 1621-1628.

70. Higashi, T.; Takayama, N.; Nishio, T.; Taniguchi, E.; Shimada, K. Procedure for Increasing the Detection Responses of Estrogens in LC-MS Based on Introduction of a Nitrobenzene Moiety Followed by Electron Capture Atmospheric Pressure Chemical Ionization. Anal. Bioanal. Chem. 2006, 386 (3), 658665.

71. Croley, T. R.; Hughes, R. J.; Koenig, B. G.; Metcalfe, C. D.; March, R. E. Mass Spectrometry Applied to the Analysis of Estrogens in the Environment. Rapid Commun. Mass Spectrom. 2000, 14 (13), 10871093.

72. Ichimura, K.; Yamanaka, H.; Chiba, K.; Shinozuka, T.; Shiki, Y.; Saito, K.; Kusano, S.; Ameniya, S.; Oyama, K.; et al. Simultaneous Quantitative Measurement of Fourteen Adrenal Steroids by Capillary Column Gas Chromatography-Mass Spectrometry, and its Clinical Application. J. Chromatogr. 1986, $374(1), 5-16$. 
73. Labadie, P.; Budzinski, H. Alteration of Steroid Hormone Profile in Juvenile Turbot (Psetta Maxima) as a Consequence of Short-Term Exposure to $17 \alpha$-Ethynylestradiol. Chemosphere 2006, 64 (8), 1274-1286.

74. Hjelmborg, P. S.; Ghisari, M.; Bonefeld-Jorgensen, E. C. SPE-HPLC Purification of EndocrineDisrupting Compounds from Human Serum for Assessment of Xenoestrogenic Activity. Anal. Bioanal. Chem. 2006, 385 (5), 875-887.

75. Courant, F.; Antignac, J.-P.; Maume, D.; Monteau, F.; Andersson, A.-M.; Skakkebaek, N.; Andre, F.; Le Bizec, B. Exposure Assessment of Prepubertal Children to Steroid Endocrine Disrupters 1. Analytical Strategy for Estrogens Measurement in Plasma at Ultra-Trace Level. Anal. Chim. Acta 2007, 586 (1-2), 105-114.

76. Edman, K.; Svensson, L.; Eriksson, B.; Gunnarsson, P. O. Determination of Estramustine Phosphate and its Metabolites Estromustine, Estramustine, Estrone and Estradiol in Human Plasma by Liquid Chromatography with Fluorescence Detection and Gas Chromatography with Nitrogen-Phosphorus and Mass Spectrometric Detection. J. Chromatogr., B: Biomed. Sci. Appl. 2000, 738 (2), 267-279.

77. Iwai, M.; Kanno, H.; Hashino, M.; Suzuki, J.; Yanaihara, T.; Nakayama, T.; Mori, H. Determination of Serum Unconjugated Estrone, $17 \beta$-Estradiol and Estriol during Pregnancy by Selected Ion Monitoring. J. Chromatogr. 1981, 225 (2), 275-282.

78. Tserng, K. Y.; Danish, R. K.; Bendt, J. S. Rapid Simultaneous Assay of Serum Estrone, Estradiol, and Estriol in Pregnant Women Using Methyl Ether Acetate Derivatives by Capillary Gas Chromatography and Electron-Impact Mass Spectrometry. J. Chromatogr. 1983, 272 (2), 233-241.

79. Biddle, S.; Teale, P.; Robinson, A.; Bowman, J.; Houghton, E. Gas Chromatography-Mass Spectrometry/Mass Spectrometry Analysis to Determine Natural and Post - Administration Levels of Oestrogens in Bovine Serum and Urine. Anal. Chim. Acta 2007, 586 (1-2), 115-121.

80. Al-Habsi, A. A.; Alkindi, A. Y. A.; Mahmoud, I. Y.; Owens, D. W.; Khan, T.; al-Abri, A. Plasma Hormone Levels in the Green Turtles Chelonia Mydas During Peak Period of Nesting at Ras Al-HaddOman. J. Endocrinol. 2006, 191 (1), 9-14.

81. Dibbelt, L.; Von Postel, G.; Beyer, A.; Haupt, O.; Knuppen, R.; Rohlfs, G.; Kuhnz, W. Determination of Natural and Synthetic Estrogens by Radioimmunoassay. Part 2. Development of a Sensitive and Highly Specific Method for the Determination of Estrone and Adaptation of this Assay to the Quantitation of Estrone Sulfate. Clin. Lab. 1998, 44 (4), 251-262. 
82. Paradisi, R.; Lodi, S.; Bolelli, G.; Venturoli, S. Radioimmunoassay of Three Estrogens and Three Androgens in the Same Plasma Sample After Extraction and Chromatographic Separation. Acta Endocrinol. 1980, 94 (2), 229-234.

83. Johannessen, D. C.; Engan, T.; Salle, E. D.; Zurlo, M. G.; Paolini, J.; Ornati, G.; Piscitelli, G.; Kvinnsland, S.; Loenning, P. E. Endocrine and Clinical Effects of Exemestane (PNU 155971), a Novel Steroidal Aromatase Inhibitor, in Postmenopausal Breast Cancer Patients: a Phase I Study. Clin. Cancer Res. 1997, 3 (7), 1101-1108.

84. Brown, B. L. The Determination of the Sex of an Individual from a Dried Bloodstain Using Radioimmunoassay of Testosterone, Progesterone, and $17 \beta$-Estradiol. J. Forensic Sci. 1981, 26 (4), 766781.

85. Takenouchi, N.; Oshima, K.; Shimada, K.; Takahashi, M. The Development of a Sensitive Enzyme Immunoassay for the Determination of Estrone and Estradiol-17 $\beta$ in Bovine Blood Plasma Based on the Same Homologous Combination with Antiserum and Steroid-Enzyme Conjugate. J. Vet. Med. Sci. 2004, 66 (11), 1315-1321.

86. OXIS International, Inc. Home Page. http://www.oxisresearch.com/pub/PDF/inserts/11110insert.pdf (accessed April 2, 2007)

87. OXIS International, Inc. Home Page. http://www.oxisresearch.com/pub/PDF/inserts/11150.pdf (accessed April 2, 2007)

88. OXIS International, Inc. Home Page. http://www.oxisresearch.com/pub/PDF/inserts/11130insert.pdf (accessed April 2, 2007)

89. JCTLM: Joint Committee for Traceability in Laboratory Medicine Home Page. http://www.bipm.org/jctlm (accessed March 17, 2009)

90. Taieb, J.; Mathian, B.; Millot, F.; Patricot, M.-C.; Mathieu, E.; Queyrel, N.; Lacroix, I.; Somma-Delpero, C.; Boudou, P. Testosterone Measured by 10 Immunoassays and by Isotope-Dilution Gas Chromatography-Mass Spectrometry in Sera from 116 Men, Women, and Children. Clinical Chem. 2003, 49 (8), 1381-1395.

91. Wang. C; Catlin, D. H.; Demers, L. M.; Starcevic, B.; Swerdloff, R. S. Measurement of Total Serum Testosterone in Adult Men: Comparison of Current Laboratory Methods versus Liquid ChromatographyTandem Mass Spectrometry. J. Clin. Endocrinol. Metab. 2004, 89 (2), 534-543. 
92. Thienpont, L. M.; Van Uytfanghe, K.; Blincko, S.; Ramsay, C. S.; Xie, H.; Doss, R. C.; Keevil, B. G.; Owen, L. J.; Rockwood, A. L.; Kushnir, M. M.; Chun, K. Y.; Chandler, D. W.; Field, H. P.; Sluss, P. M. State-of-the-Art of Serum Testosterone Measurement by Isotope Dilution Liquid Chromatography/Tandem Mass Spectrometry. Clinical Chem. 2008, 54 (8), 1290-1297.

93. Joos, P. E.; Van Ryckeghem, M. Liquid Chromatography - Tandem Mass Spectrometry of Some Anabolic Steroids. Anal. Chem. 1999, 71 (20), 4701-4710.

94. Wisdom, G. B. Enzyme Immunoassay. Clinical Chem. 1976, 22 (8), 1243-1255.

95. Aga, D. S.; Thurman, E. M., Eds., Immunochemical Technology for Environmental Applications, ACS Symposium Series 657; American Chemical Society, Washington, DC, 1996; pp 22-37.

96. Li, X.; Huo, T.; Chu, X.; Xu, C. Time - Resolved Fluoroimmunoassay for 19 - Nortestosterone Residues in Aquaculture Tissues. Anal. Sci. 2007, 23 (3), 321-325.

97. Shore, L. S.; Gurevitz, M.; Shemesh, M. Estrogen as an Environmental Pollutant. Bull. Environ. Contam. Toxicol. 1993, 51 (3), 361-366.

98. Landers, J. P., Ed., Handbook of Capillary and Microchip Electrophoresis and Associated Microtechniques, 3rd ed.; CRC Press: NW, 2007; pp 7-21.

99. Terabe, S.; Otsuka, K.; Nishi, H. Separation of Enantiomers by Capillary Electrophoretic Techniques. J. Chromatogr., A 1994, 666 (1-2), 295-319.

100. Marina, M. L.; Rios, A; Valcárcel, M., Eds., Analysis and Detection by Capillary Elestrophoresis. In: Comprehensive Analytical Chemistry; Elsevier B.V.: Amsterdam, The Netherlands, 2005; Vol. XLV, pp $1-30$.

101.Khaledi, M. G., Ed., High performance capillary electrophoresis. In: Chemical Analysis; WileyInterscience: New York, 1998; Vol. 146, pp 3-24.

102.Collier, A.; Wang, J.; Diamond, D.; Dempsey, E. Microchip Micellar Electrokinetic Chromatography Coupled with Electrochemical Detection for Analysis of Synthetic Oestrogen Mimicking Compounds. Anal. Chim. Acta 2005, 550 (1-2), 107-115.

103.Ji, A. J.; Nunez, M. F.; Machacek, D.; Ferguson, J. E.; Iossi, M. F.; Kao, P. C.; Landers, J. P. Separation of Urinary Estrogens by Micellar Electrokinetic Chromatography. J. Chromatography, B: Biomed. Appl. 1995, 669 (1), 15-26. 
104.Chan, K. C.; Muschik, G. M.; Issaq, H. J.; Siiteri, P. K. Separation of Estrogens by Micellar Electrokinetic Chromatography. J. Chromatogr., A 1995, 690 (1), 149-154.

105.Deng, Y.; Zhou, J.; Perkins, M. D.; Lunte, S. M. Capillary Electrophoretic Separation of Estrogens Using Anionic Sulfobutyl Ether $\beta$-Cyclodextrin. Anal. Comm. 1997, 34 (5), 129-131.

106. Mohammad, A. A.; Petersen, J. R.; Bissell, M. G. Steroid Analysis by Micellar Electrokinetic Capillary Chromatography. Methods Mol. Med. 1999, 27, 177-187.

107.Amundsen, L. K.; Siren, H. Partial Filling Micellar Electrokinetic Chromatography Analysis of Androgens and Testosterone Derivatives Using Two Sequential Pseudostationary Phases. $J$. Chromatogr., A 2006, 1131 (1-2), 267-274.

108.Siren, H.; Seppaenen-Laakso, T.; Oresic, M. Capillary Electrophoresis with UV Detection and Mass Spectrometry in Method Development for Profiling Metabolites of Steroid Hormone Metabolism. J. Chromatogr., B: Analyt. Technol. Biomed. Life Sci. 2008, 871 (2), 375-382.

109. Katayama, M.; Matsuda, Y.; Shimokawa, K.; Kaneko, S. Simultaneous Determination of 16 Estrogens, Dehydroepiandrosterone and Their Glucuronide and Sulfate Conjugates in Serum Using Sodium Cholate Micelle Capillary Electrophoresis. Biomed. Chromatogr. 2003, 17 (4), 263-267.

110.Cho, S.-H.; Jung, B. H.; Lee, W.-Y.; Chung, B. C. Direct Determination of Estriol Conjugates in Amniotic Fluid by Capillary Electrophoresis with Electrospray Tandem Mass Spectrometry. Rapid Commun. Mass Spectrom. 2006, 20 (19), 2995-2998.

111.Goeroeg, S.; Gazdag, M.; Kemenes-Bakos, P. Analysis of Steroids. Part 50. Derivatization of Ketosteroids for Their Separation and Determination by Capillary Electrophoresis. J. Pharm. Biomed. Anal. 1996, 14 (8-10), 1115-1124.

112.Regan, F.; Moran, A.; Fogarty, B.; Dempsey, E. Novel Modes of Capillary Electrophoresis for the Determination of Endocrine Disrupting Chemicals. J. Chromatogr., A 2003, 1014 (1-2), 141-152. 


\section{CHAP T E R 2}

\section{DEVELOPMENT OF STEROID SEPARATION}




\subsection{INTRODUCTION}

The long term goal of the research presented in this chapter was to develop a CE method for profiling steroids in blood plasma of fish which can assist in monitoring endocrine disruption. In order to fully understand the principle of the analytical approach used in this study a brief review of the capillary electrophoresis, micellar electrokinetic chromatography (MEKC) and cyclodextrin-modified MEKC based on introduction to the high performance capillary electrophoresis by Heiger ( 1 ) is presented below.

\subsubsection{THEORY OF CAPILLARY ELECTROPHORESIS}

Capillary zone electrophoresis (CZE) of ionic species using narrow inner diameter fused silica capillaries $(<100 \mu \mathrm{m})$, high voltage up to $30 \mathrm{kV}$ and on-line UV-visible absorbance detection was first demonstrated by Jorgenson and Lukacs in 1981 (2), who also investigated the relationships between the operational parameters and separation quality of $\mathrm{CE}(3,4)$. The separation of analytes in $\mathrm{CE}$ is affected by two transport processes: electrophoresis and electroosmosis. The net result of both is the separation of charged and neutral analytes. Separation of charged analytes is based on their respective charge-to-size ratios. Electrophoresis is the movement of a charged solute through a conductive solution toward or away from an electrode (anode or cathode) by the electric field. The movement of the solute depends on the mobility of the solute and the magnitude of the applied electric field and is called the electrophoretic velocity $\left(v_{e}\right)$ :

$$
v_{e}=\mu_{e} E
$$


where values $v_{e}, \mu_{e}$, and $E$ are ion velocity, electrophoretic mobility, and applied electric field, respectively. The electric field is a function of applied voltage and capillary length (in volts $/ \mathrm{cm})$. Electrophoretic mobility is dependent on the solute and the buffer properties:

$$
\mu_{e}=\frac{q}{6 \pi \eta r}
$$

where $q, r$, and $\eta$ are ion charge and radius, and viscosity of the solution, respectively. Cationic solutes with the largest charge-to-size ratio have therefore the highest net mobility and elute faster toward the cathode. For anions the trend is opposite while for neutral (uncharged) solutes electrophoretic mobility is zero. Figure 2.1 shows CE separation at normal polarity where the cathode and the anode are at the outlet and at the inlet of the capillary respectively. The opposite arrangement of the cathode and the anode will be referred to as reversed polarity in this dissertation.

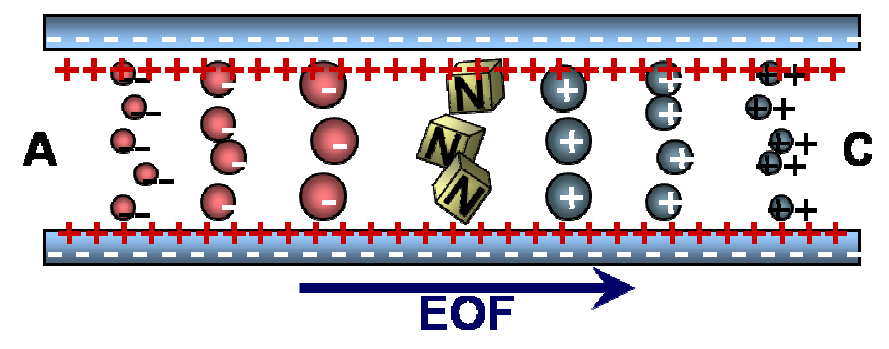

Figure 2.1. Schematic representation of separated analyte bands in CE and EOF.

Electroosmotic flow (EOF) is a distinctive element of CE. EOF is the bulk movement of the solvent being dragged by the positively-charged ions migrating toward the cathode. As mentioned above, $\mathrm{CE}$ is usually performed in capillaries made from fused silica. Surface charges on the interior of the capillary induce the formation of a double layer 
upon application of the electric field. In a fused silica capillary, the surface silanol ( $\mathrm{Si}-\mathrm{OH})$ groups are ionized to negatively charged silanoate $\left(\mathrm{Si}^{-} \mathrm{O}^{-}\right)$groups at $\mathrm{pH}$ above three. These negatively charged silanoate groups attract positively charged cations from the buffer solution, which form an inner layer of cations (Stern layer) at the capillary wall. The density of these cations is not sufficient to neutralize all the negative charges, so a second, outer layer of cations (Gouy-Chapman layer) forms. The electric potential at the sheer plane of the double layer is called the zeta $(\zeta)$ potential. While the inner layer is tightly held by the $\mathrm{Si}^{-} \mathrm{O}^{-}$groups, the outer layer of cations is not tightly held because of its larger distance from the silanoate groups. Under the influence of an electric field, the outer layer of cations is pulled toward the negatively charged cathode. Since these cations are solvated, they drag the bulk buffer solution with them, thus causing EOF, as represented in Figure 2.1. The existence of the EOF means that under normal polarity neutral and charged molecules, even negatively charged ones, will be swept along towards the cathode.

The magnitude of EOF is highly dependent on the $\mathrm{pH}$ of the running buffer because the $\zeta$-potential is largely controlled by the ionization of the acidic silanols on the capillary wall. At $\mathrm{pH} \leq 3$, the ionization is small and the EOF flow rate is therefore not significant. At $\mathrm{pH} \geq 9$ the silanols are fully ionized and EOF flow rate is high. For example, in $20 \mathrm{mM}$ borate buffer at $\mathrm{pH} 9.0$ in a $50 \mu \mathrm{m}$ inner diameter capillary the velocity of EOF is approximately $4 \mathrm{~nL} / \mathrm{s}$. The magnitude of EOF also decreases with increased concentration of the running buffer. Increasing ionic strength causes double-layer compression, which results in reduction of the level of EOF. Additionally higher ionic strength will increase the current across the capillary and increase the likelihood of Joule heating and band 
broadening $(5,6)$. EOF can be suppressed by chemically coating the inner surface of capillaries (7-9) or by using acidic running buffer (10).

EOF is generated throughout the entire length of the capillary and is characterized by a flow profile that is plug-like in nature. Consequently, solutes are swept along at the same rate regardless of their radial position in the capillary minimizing sample dispersion. This is an advantage compared to the laminar flow encountered in pumped systems such as in HPLC. In laminar flow, the solution is pushed from one end of the column. The solution at the column walls moves slower than the solution in the middle of the column due to the shear effect resulting in different solute speeds across the cross-section of the column. Therefore, the laminar flow tends to broaden the peaks as they travel along the column.

The apparent mobility $\mu_{a}$ of a solute is the sum of its electrophoretic mobility and the electroosmotic mobility:

$$
\mu_{a}=\mu_{e}+\mu_{E O F}
$$

Under normal polarity the apparent mobility of cationic species is therefore generally greater than EOF (Fig. 2.1). Neutral species do not have charges and therefore migrate as a single peak at the same velocity as EOF. Apparent mobility of anionic species is smaller than EOF since the anions have electrophoretic attraction toward the anode while EOF is driven by the cathode attraction. If EOF is strong enough, all species will migrate towards the cathode allowing single run detection of all analytes (Fig.2.1). 


\subsubsection{INSTRUMENTATION}

CE offers high efficiency, selectivity, and low cost operation. CE instrumentation is schematically shown in Figure 2.2-A. The key component is the separation capillary filled with running buffer. The length and inner diameter of a separation capillary typically range from 30 to $100 \mathrm{~cm}$ and 10 to $100 \mu \mathrm{m}$ respectively. Both ends of the capillary are submerged into buffer vials also containing platinum electrodes. The sample is introduced at the inlet site by applying a high voltage potential (electrokinetic injection) or by pressure (hydrodynamic injection). Migration through the capillary is driven by the applied field, and analytes are detected on-capillary as they pass a detection window at the capillary outlet. The high voltage power supply is capable of supplying up to $30 \mathrm{kV}$ voltage across the capillary to assist sample injection and separation. Most commercial instruments use UV-visible absorbance detection. This is accomplished in-capillary by burning off a portion of the polyimide coating from the fused silica to form a detection window. The output of the detector is a plot of detector response versus time and is called an electropherogram (Fig. 2.2-B).

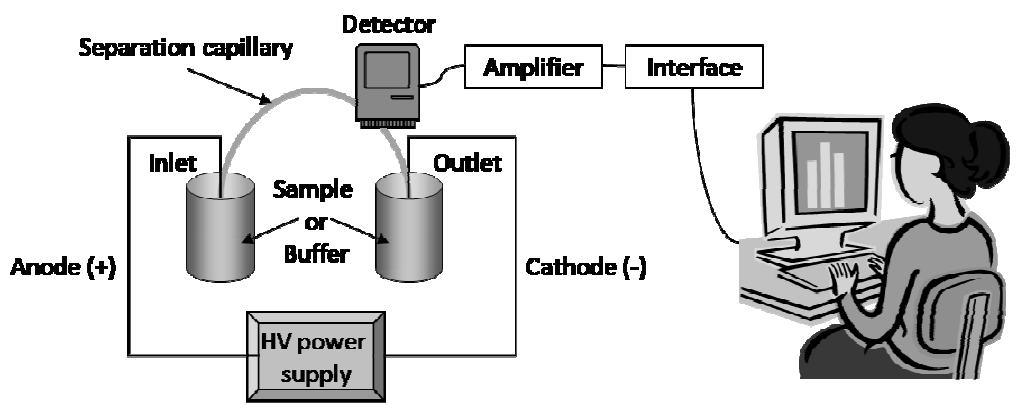

A

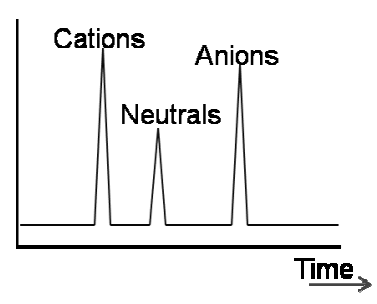

B

Figure 2.2. Schematic diagram of a CE instrument (A), and a representative CE electropherogram (B). 
In $\mathrm{CE}$ the range of separated molecules is limited to those carrying a charge. The co-elution of neutral analytes in the CZE is one of the major limitations of electrophoresis. Steroid molecules are neutral and therefore require a pseudo-stationary phase to assist separation by means of secondary equilibria. Micellar electrokinetic chromatography is an extension of capillary electrophoresis which is used to separate neutral molecules (11-17).

\subsubsection{MicelLAR ELECTROKINETIC CHROMATOGRAPHY (MEKC)}

Micellar electrokinetic chromatography (MEKC) for the separation of neutral compounds by adding surfactants such as sodium dodecyl sulfate (SDS) to the running buffer was first introduced in 1984 by Terabe and co-workers (11). Micellar electrokinetic chromatography combines the phenomenon of EOF with a form of partition chromatography to expand the range of separated molecules including neutral molecules. EOF drags all the neutral molecules through the capillary with essentially the same rate. Partition chromatography in its simplest form consists of a stationary phase and a mobile phase where the separation of molecules is based on different affinities of the analytes for the two phases. The separation of neutral analytes can be achieved by introducing charged additives, such as surfactants, soluble polymers, crown ethers, cyclodextrins, antibodies, and proteins into the running buffer solution. The most popular additive is a surfactant.

The surfactant molecules are amphiphilic with both hydrophobic (e.g., alkyl moiety) and hydrophilic (polar or charged) groups, and they behave as solvated monomers at very low concentrations. When the concentration is increased beyond a minimum level, termed the critical micelle concentration $(C M C)$, these monomers spontaneously start to form micelles. A micelle is an ordered aggregate of surfactant monomers enclosing their 
hydrophobic tails and exposing polar head groups toward the water or other polar solvents (Fig. 2.3) (18).

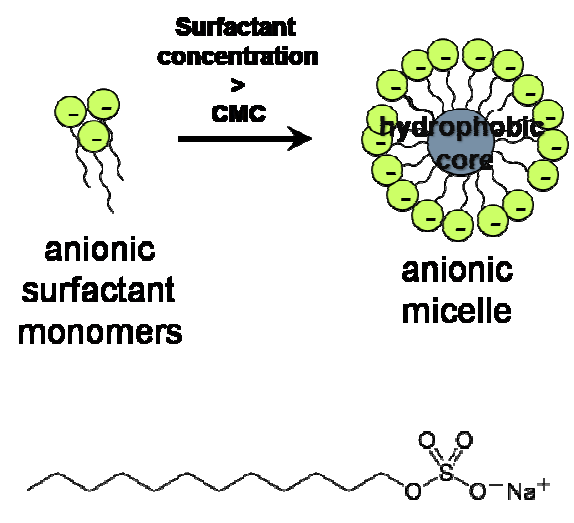

Figure 2.3. Micelle formation (top). Sodium dodecyl sulfate (SDS) monomer (bottom).

The micelles in MEKC are the equivalent of the stationary phase in HPLC and often called pseudostationary phase. Because micelles are not stationary, they are subject to both EOF and electrophoresis. Separation in MEKC is thus based on the different ability of the analyte molecules to partition between the solution and the inside of the micelles. In the presence of EOF, all the analyte molecules and the micelles will pass through the detector window because the negatively charged micelles are attracted to the anode, but the greater magnitude of the EOF sweeps them toward the detector at the cathode end of the capillary. In reality, solutes are distributed in MEKC between the pseudostationary and aqueous phase and a partition coefficient $(\mathrm{P})$ is defined as:

$$
P=\frac{C_{P S}}{C_{s}}
$$


where, $C_{P S}$ and $C_{s}$ are the molar concentrations of a solute in the pseudostationary and aqueous phase respectively. Both, $\mathrm{CMC}$ and partition coefficient are temperature dependent. An increase in temperature causes an increase in CMC, hence a decrease in micellar concentration which consequently reduces the retention factor. On the other hand, higher temperatures lower the partition coefficient and also reduce the retention factor (19). It is well known that temperature increase reduces the viscosity of the running buffer which ultimately increases electrophoretic and EOF velocities and reduces the migration time. Therefore in order to maintain a reproducible MEKC separation temperature control is critical (20).

In all separation techniques, the primary goal is to achieve good resolution, $R_{s}$. In $\mathrm{CE}$, the resolution can be calculated from an electropherogram using the following equation,

$$
R_{s}=\frac{2 \Delta t}{\omega_{1}+\omega_{2}}
$$

where $\Delta t$ is the difference in migration time of two analytes, and $\omega$ is the peak baseline width in time units. The resolution in MEKC can be improved by optimizing efficiency, selectivity, and retention factor. The latter is the easiest to control since in general, there is a linear correlation between an increasing concentration of the surfactant. However, a potential problem when using too concentrated surfactants is an increase of Joule heating due to an increase in the effective resistance, thus the dissipated power $\left(V \cdot I=I^{2} \cdot R\right)$ of the running buffer (21). Even with the narrowest capillaries, an efficient cooling is necessary to eliminate the excess heat generated by extremely high electric field. 
Another way of improving the resolution is to extend the elution window. In the separation of neutral analytes, all analytes elute between $t_{E O F}$ and $t_{\text {micelle. }}$. Hydrophobic

analytes totally retained in micelles elute with them at $t_{\text {micelle }}$. On the other hand, very hydrophilic analytes do not interact at all with micelles and elute with EOF. Even though the elution window is often fairly small, the peak capacity can be very high because of the high efficiency. It is also easy to manipulate the selectivity by changing the physical nature of the micelle such as size, charge, and geometry and by using different surfactants. The use of surfactants may have dramatic affect on the EOF by interacting with the capillary wall. When EOF is suppressed only charged pseudostationary phase migrates through the aqueous phase.

Unfortunately, CE separations of native steroids cannot be accomplished with the use of only micellar hydrophobic pseudostationary phase because lipophilic steroidal compounds readily partition inside of SDS micelles in aqueous solutions and often comigrate. The separation of steroids by MEKC requires the secondary equilibrium by means of the introduction of another additive to the running buffer. One such additive is cyclodextrin which is used to control the high affinity of steroids to the micelles and thus the separation resolution and efficiency (22-24). The background on cyclodextrin chemistry is briefly discussed below.

\subsubsection{Chemical and PhysiCal Properties of CyClodeXtrins}

Cyclodextrins are well-known in host-guest chemistry. Cyclodextrin (CD) was first mentioned in 1891 by Villiers; however, Schardinger gave the first detailed description of the preparation and isolation of this group of macrocyclic molecules and helped develop 
the fundamentals of CD chemistry. Later in the 1930s, Pringsheim significantly advanced the progress of $\mathrm{CD}$ research when he discovered that organic compounds have a tendency to form complexes with crystalline CDs (25). The compounds are industrially synthesized from the degradation of starch mediated by the simple enzymatic conversion. CDs are nontoxic and can be widely used in food, medication, and cosmetics (26).

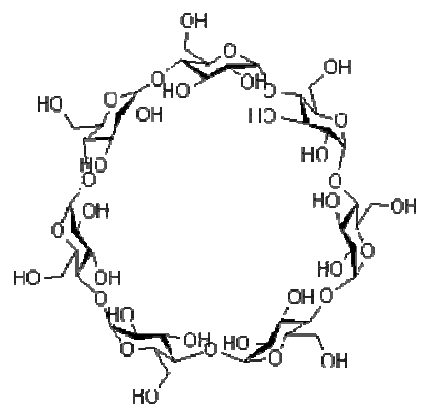

Figure 2.4. Chemical structure of a $\beta$-cyclodextrin molecule.

$\mathrm{CD}$ is a cyclic oligomer of $\alpha$-D-glucose. $\mathrm{CD}$ normally used in the analytical separations are $\alpha$-cyclodextrin (six glucose units); $\beta$-cyclodextrin (seven units), and $\gamma$ cyclodextrin (seven units). The CD molecule resembles a doughnut and is typically represented as a shallow truncated cone (Fig. 2.4). For a molecule with $\mathrm{m}$ glucose units, one cavity opening is contoured with m primary hydroxyl groups and has a reduced diameter compared to the other cavity opening contoured with $2 \mathrm{~m}$ secondary hydroxyl groups. The interior of the cavity is decorated with a row of $\mathrm{CH}$ groups ( $\mathrm{C}-3$ carbons) then a row of glycosidic oxygens, and then a row of $\mathrm{CH}$ groups ( $\mathrm{C}-5$ carbons).

The hollow structure makes the cyclodextrin attractive subjects for chemical studies and applications. Whereas the interior of the cavity is non-polar, the exterior of the cyclodextrin is covered with hydroxyl groups making it soluble in water (27). At $25^{\circ} \mathrm{C}$, the 
least soluble is $\beta$-CD $(1.85 \mathrm{~g} / 100 \mathrm{~mL})$, and most soluble is $\gamma$-CD $(23.2 \mathrm{~g} / 100 \mathrm{~mL})$. These compounds are therefore studied as "hosts" for "guest" molecules capable of entering the cavity partially or completely and forming non-covalent host-guest inclusion complexes. Since cyclodextrins are neutral molecules, they move along with the EOF. In addition, they are inert and stable at a wide range of $\mathrm{pH}$ values, and have low $\mathrm{UV}$ absorptivity at short wavelengths. These properties make them very useful additives in chromatographic applications. Table 2.1 summarizes dimensions and physical properties of cyclodextrin molecules (28).

Table 2.1. Physical and chemical properties of CDs.

\begin{tabular}{ccccccc}
\hline $\mathbf{C D}$ & $\begin{array}{c}\text { \# glucose units, } \\
\mathbf{m}\end{array}$ & $\begin{array}{c}\mathbf{M W}, \\
\mathbf{g} / \mathbf{m o l}\end{array}$ & $\begin{array}{c}\text { Solubility in water, } \\
\mathbf{g} / \mathbf{1 0 0} \mathbf{~ m L}\end{array}$ & $\mathbf{A}, \AA$ & $\mathbf{B}, \AA$ & $\mathbf{C}, \AA$ \\
\hline$\alpha$ & 6 & 972 & 14.5 & 14.6 & $4.7-5.3$ & 7.9 \\
$\beta$ & 7 & 1135 & 1.85 & 15.4 & $6.0-6.5$ & 7.9 \\
$\gamma$ & 8 & 1297 & 23.2 & 17.5 & $7.5-8.3$ & 7.9 \\
\hline
\end{tabular}

To overcome the limited selectivity of MEKC the addition of cyclodextrins into the micellar phase is used to prevent the elution of highly hydrophobic analytes with micelles. This technique is referred to as CD modified MEKC.

\subsubsection{CYCLODEXTRIN (CD) MODIFIED-MEKC}

Due to the presence of a relatively hydrophobic cavity in CDs, they act as another pseudostationary phase and significantly contribute to the selectivity of the separation system. When a CD is added into the micellar system, the CDs and micelles compete to form inclusion complexes with the analyte. Because native CDs are neutral, the analytes 
having greater affinity to neutral CD migrate at the velocity of the EOF. The success of desired selectivity depends on the binding constant of the analyte with $\mathrm{CD}$ and the concentration of the $\mathrm{CD}$, as the change in the concentration will shift the equilibrium toward to or away from the formation of the analyte-CD inclusion complex. Addition of a very high concentration of $\mathrm{CD}$ might, however, disturb the micelle formation (29).

The literature publications reported the MEKC analysis of sex steroid hormones are summarized in Chapter 1. Most works so far have, however, focused mainly on the optimization of the separation parameters and do not report required figures of merit, such as LODs, the reproducibility of the method nor its validation using biological samples. The analysis of steroids by cyclodextrin modified MEKC is the focus of this dissertation and will be discussed in details below in this chapter. The method is optimized to enable selective and rapid analysis of steroids. Two particular aspects are addressed: 1) how the affinity of targeted steroids either to the micelles or to CDs affects the migration order of the steroids in basic and acidic separation media, and 2) possible ways of manipulation and optimization of the steroid separation speed and resolution. 


\subsection{EXPERIMENTAL}

\subsubsection{CHEMICALS AND MATERIALS}

Sodium dodecyl sulfate (SDS), 3-[cyclohexylamino]-1-propanesulfonic acid (CAPS), 2-[cyclo-hexylamino]-ethanesulfonic acid (CHES), n-decanophenone, 11ketotestosterone, and testosterone were purchased from Sigma-Aldrich (St. Louis, MO, USA). Hydroxypropyl- $\beta$-cyclodextrin (HPCD) was purchased from VWR (West Chester, PA, USA). Steroids, androstenedione, 17 $\beta$-estradiol, estrone, 17-hydroxyprogesterone, and progesterone were purchased from Steraloids, Inc (Newport, RI, USA). 17 $\alpha$-ethynyl estradiol was purchased from Cayman Chemical (Ann Arbor, MI, USA). Sodium phosphate monobasic salt was purchased from Fisher Scientific (Fair Lawn, NJ, USA). Methanol was purchased from EMD Chemicals (San Diego, CA, USA). Deionized water was purified using ELGA Purelab Ultra (Lowell, MA, USA).

Buffered solutions were prepared by weighing solid reagents, dissolving them in deionized water, and adjusting $\mathrm{pH}$ of the solution with aqueous solutions of $1 \mathrm{~N}$ hydrochloric acid or $1 \mathrm{~N}$ sodium hydroxide, as appropriate. Standard stock solutions of each sex steroid hormone were prepared by weighing out the solid steroid reagent and dissolving it in methanol. Before use, all the prepared steroid stock solutions were stored in a freezer at $-20{ }^{\circ} \mathrm{C}$ and in the dark to avoid possible degradation. Stock samples were diluted to a desired concentration each day prior to use with the proper buffer. The CE background electrolyte and the samples to be analyzed were prepared fresh every day prior to use. 
The presence of air bubbles should be eliminated as they can be injected into a capillary where they can cause large resistance during the electrophoresis leading to disruption or large fluctuations of the separation current during electrophoresis (from Ohm's law: $\mathrm{V}=\mathrm{I} \cdot \mathrm{R}$, where $\mathrm{V}$ is the potential applied across the separation capillary in volts, $\mathrm{R}$ is the resistance in ohms, and I is the current in amperes). Micro-sized air bubbles can also be generated by Joule heating during electrophoresis, blocking the flow pathway and causing the current fail. In order to remove the dissolved air bubbles trapped in the solution the vials containing freshly made running buffers and samples were degassed using vacuum for $1 \mathrm{~min}$ for $2 \mathrm{~mL}$ vial or $15 \mathrm{sec}$ for $250 \mu \mathrm{L}$ vial. Ultrasonication was also used for this purpose when necessary. All buffer solutions were filtered using $0.45 \mu \mathrm{m}$ porous filters before use to remove foreign particles which can clog the capillary or be injected and interfere with the separation analysis producing extra peaks in the electropherogram.

\subsubsection{INSTRUMENTATION}

CE measurements were carried out using a Beckman Coulter P/ACE MDQ capillary electrophoresis instrument (Beckman coulter, Fullerton, CA, USA) (Fig. 2.5). The instrument was equipped with a photodiode array UV-visible absorbance detection system (PDA) which provided simultaneous determination of steroids at multiple wavelengths in a single analysis or with photomultiplier tube (PMT) which allowed the detection of steroids at a specific wavelength. 


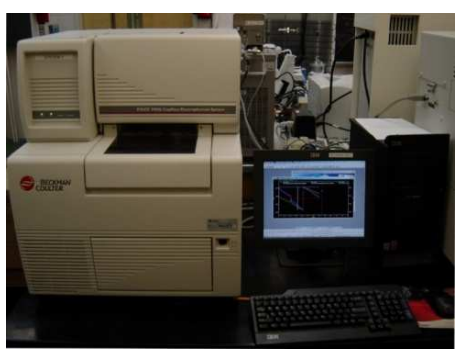

Instrument

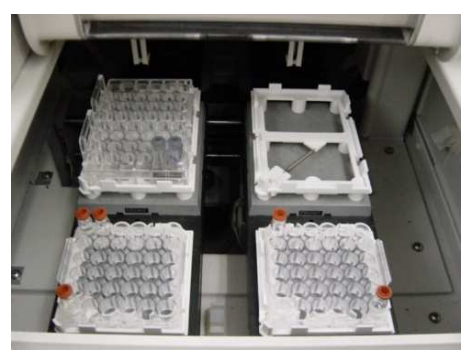

Inside

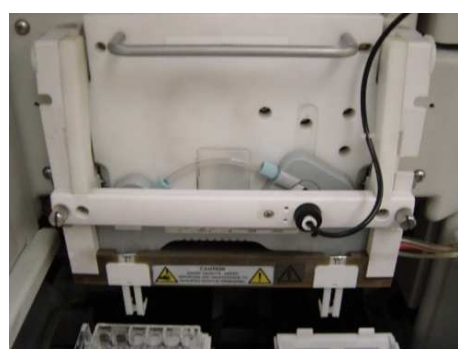

Capillary cartridge

Figure 2.5. Photographs of the Beckman ${ }^{\circledR}$ automated capillary electrophoresis machine used in the work. The light source is a UV-visible absorbance, with a PMT or PDA detector.

The electropherograms were collected at the wavelengths of UV-light where the analytes showed strong light absorption (200 nm for estrogens, $254 \mathrm{~nm}$ for androgens and progesterone, or $225 \mathrm{~nm}$ for all targeted steroids). All separations were performed using 26 $\mu \mathrm{m}$ inner diameter (id), $360 \mu \mathrm{m}$ outer diameter (od), $30 \mathrm{~cm}$ long fused silica separation capillary (Polymicro Technologies, LLC, Phoenix, AZ, USA) with the detection window positioned 10.2 (short end separation) or $19.8 \mathrm{~cm}$ (long end separation) from the cathodic or anodic reservoir located at the sample inlet. The temperature of the capillary cartridge and sample storage trays inside the instrument was maintained at $25 \pm 1{ }^{\circ} \mathrm{C}$ because the distribution coefficients are temperature sensitive.

\subsubsection{MEKC AT PH 1O PROCEDURE}

For this experiment, the running buffer containing $30 \mathrm{mM}$ HPCD and $50 \mathrm{mM}$ SDS dissolved in $50 \mathrm{mM}$ CHES buffered at $\mathrm{pH} 10$ was used. The steroid sample was prepared by adding aliquots of standard methanol stock solutions of six sex steroid hormones, estrone, $17 \beta$-estradiol, estriol, testosterone, $\alpha, \beta$-dihydroxyprogesterone and progesterone, 
to the running buffer. The concentration of each steroid in the final dilution was $200 \mu \mathrm{M}$. In order to avoid steroid precipitation the organic content was maintained at $20 \%$ of methanol in the sample. However, the addition of small amounts of methanol increases the CMC of SDS. In fact, when the methanol content of the solution is $40 \% \mathrm{v} / \mathrm{v}$ or more the inverted micelles begin to form. In an inverted micelle, the polar head-groups of the surfactant monomers are centered in the interior while the lipophilic tails stand out into the nonpolar solvent (30). n-Decanophenone was used as the hydrophobic micelle marker. The sample was hydrodynamically injected into a silica capillary (effective length to the detection window $\left.\mathrm{L}_{\mathrm{w}}=19.8 \mathrm{~cm}\right)$ at $3.4 \mathrm{kPa}(0.5 \mathrm{psi})$ for $4.0 \mathrm{sec}$. Separation was performed with a 16 $\mathrm{kV}$ potential drop across the capillary and normal polarity (cathode at the outlet), while being monitored at a detection wavelength of $225 \mathrm{~nm}$ where all steroids absorb light equally well and can be detected in a single run.

\subsubsection{MEKC AT PH 2 PROCEDURE}

The running buffer is comprised of $18 \mathrm{mM}$ HPCD and $30 \mathrm{mM}$ SDS dissolved in 10 $\mathrm{mM}$ phosphate buffered at $\mathrm{pH}$ 2.0. Standard solutions of steroids progesterone, $17 \alpha, 20 \beta$ dihydroxyprogesterone, testosterone, androstenedione, estrone, $17 \beta$-estradiol, and estriol were prepared in the running buffer at the concentrations of $100 \mu \mathrm{M}$ progesterone and 17 $\alpha, 20 \beta$-dihydroxyprogesterone, $150 \mu \mathrm{M}$ testosterone and $17 \beta$-estradiol, $200 \mu \mathrm{M}$ androstenedione, and $250 \mu \mathrm{M}$ estrone with the addition of $20 \%$ methanol. Steroid sample was injected into a bare fused silica capillary (effective $\left.\mathrm{L}_{\mathrm{w}}=10.2 \mathrm{~cm}\right)$ at $3.4 \mathrm{kPa}(0.5 \mathrm{psi})$ 
for $3.0 \mathrm{sec}$. CE was performed at $16 \mathrm{kV}$ and reversed polarity (anode at the outlet), and the detection wavelength of $225 \mathrm{~nm}$.

\subsection{RESULTS AND DISCUSSION}

\subsubsection{STEROIDS TARGETED FOR ANALYSIS}

The goal of the research presented in this dissertation chapter was to develop a rapid method to profile relative change in the steroid composition to better define physiological dysfunction following exposure to endocrine-disrupting chemicals. A simplified steroid metabolism pathway was used as a basis for the steroids targeted for analysis. The initial separation targets were progesterone, hydroxyprogesterone, 11ketotestosterone, estrone, estradiol, and ethynyl estradiol. These analytes were selected because of their role in enabling or disrupting the chemical messaging in blood plasma samples. The presence of these steroidal compounds would therefore offer insight into the pathways involved in environmentally triggered endocrine disruption in fish. The molecular properties of the targeted steroids are summarized in Table 2.2. 
Table 2.2. Molecular properties of targeted steroids ${ }^{\text {a }}$

\begin{tabular}{|c|c|c|c|c|c|c|}
\hline Steroid & CAS \# & CAS name & $\log P$ & HA & HD & MW \\
\hline $\begin{array}{l}\text { 17- } \alpha \text {-ethynyl } \\
\text { estradiol }\end{array}$ & $57-63-6$ & $\begin{array}{l}\text { (17 } \alpha) \text {-19-norpregna-1,3,5(10)-trien-20-yne- } \\
\text { 3,17-diol }\end{array}$ & 4.5 & 2 & 2 & 296.40 \\
\hline $17 \beta$-estradiol & $50-28-2$ & (17ß)-estra-1,3,5(10)-triene-3,17-diol & 4.1 & 2 & 2 & 272.38 \\
\hline progesterone & $57-83-0$ & pregn-4-ene-3,20-dione & 4.0 & 2 & 0 & 314.46 \\
\hline Estrone & $53-16-7$ & 3-hydroxy-estra-1,3,5(10)-trien-17-one & 3.7 & 2 & 1 & 270.37 \\
\hline Testosterone & $58-22-0$ & (17ß)-17-hydroxy-androst-4-en-3-one & 3.5 & 2 & 1 & 288.42 \\
\hline Estriol & $50-27-1$ & $(16 \alpha, 17 \beta)$ - estra-1,3,5(10)-triene-3,16,17-triol & 2.9 & 3 & 3 & 288.38 \\
\hline $\begin{array}{l}\alpha \alpha \text {-dihydroxy } \\
\text { Progesterone }\end{array}$ & $652-69-7$ & (20S)-17,20-dihydroxy-pregn-4-en-3-one & 2.9 & 3 & 2 & 332.48 \\
\hline $\begin{array}{l}\alpha \beta \text {-dihydroxy } \\
\text { Progesterone }\end{array}$ & $1662-06-2$ & (20R)-17,20-dihydroxy-pregn-4-en-3-one & 2.9 & 3 & 2 & 332.48 \\
\hline $\begin{array}{l}\text { 17-hydroxy- } \\
\text { progesterone }\end{array}$ & $68-96-2$ & 17-hydroxy-pregn-4-ene-3,20-dione & 2.9 & 3 & 1 & 330.46 \\
\hline Androstenedione & $63-05-8$ & androst-4-ene-3,17-dione & 2.9 & 2 & 0 & 286.41 \\
\hline $\begin{array}{l}\text { 11-keto } \\
\text { Testosterone }\end{array}$ & $564-35-2$ & (17ß)-17-hydroxy-androst-4-ene-3,11-dione & 1.7 & 3 & 1 & 302.41 \\
\hline \multicolumn{7}{|c|}{$\begin{array}{l}\text { Log P - logarithm of partition coefficient; HA - number of proton acceptors; HD - number of proton donors. } \\
\text { avalues reported by Scifinder, version 2006; Chemical Abstract Services: Columbus, OH, 2006; CAS \#, MW, log D, } \\
\text { HA and HD calculated using Advanced Chemistry Development (ACD/Labs) Software V8.14 for Solaris (C 1994- } \\
2008 \text { ACD/Labs) (accessed on March 18, 2009). }\end{array}$} \\
\hline
\end{tabular}




\subsubsection{MEKC SEPARATION OF STEROIDS IN AN ALKALINE MEDIUM}

In the early phase of the method development, the separation of sex steroid hormones was performed in the basic medium by MEKC. The alkaline buffer consisted of CHES buffered at $\mathrm{pH} 10$. SDS was used as the micelle forming agent due to SDS possesses high aqueous solubility, low critical micelle concentration $(8 \mathrm{mM})$, low UV molar absorptivity, availability and small cost. HPCD was used as a cyclodextrin additive. Theoretically these separations are possible using any neutral $\beta-\mathrm{CD}$; however, HPCD has higher aqueous solubility in contrast to an unsubstituted CD (31), and it was therefore used in this work. The molecular substitution of the HPCD was not controlled.

\subsubsection{Separation Mechanism}

EOF has a high velocity at $\mathrm{pH} 10$. Neutral cyclodextrins migrate along with the EOF while SDS micelles migrate slower due to their anodic electrophoretic mobility. Neutral steroids are separated based on the difference in the distribution coefficients between a polar aqueous buffer and the non-polar micelle or unoccupied cyclodextrin cavities (32). Figure 2.6 illustrates a schematic diagram of the separation process as well as the acquired electropherogram for steroids separated via $\mathrm{pH} 10$ method. All targeted steroids were separated in less than 3.5 minutes, substantially faster than standard immunoassay analysis. The elution order of the steroids in the basic medium corresponds to increasing affinity of the analytes to SDS (Fig. 2.6, right). Estriol, 17ß-estradiol, and estrone migrate first due to their preferential interaction with HPCDs while testosterone, 
$\alpha, \beta$-dihydroxyprogesterone, and progesterone migrate last due to their stronger partitioning into SDS micelles.

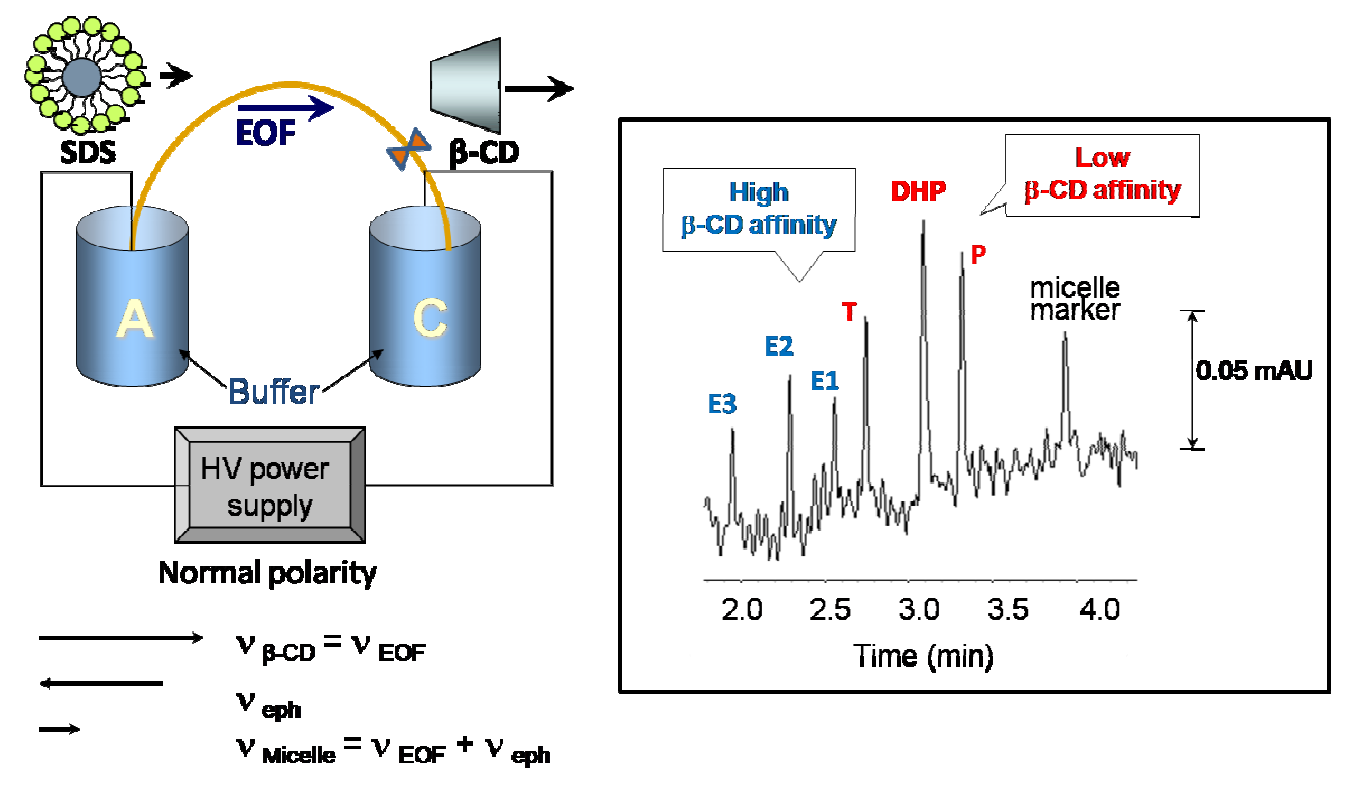

Figure 2.6. MEKC of steroids in alkaline medium. Schematic diagram of the separation process is on the right and the resulted electropherogram is on the left. E3 - estriol, E2 - 17ß-estradiol, E1 - estrone, T testosterone, DHP - 17 $\alpha, 20 \beta$-dihydroxyprogesterone, and P - progesterone, at $200 \mu \mathrm{M}$ each. Injection conditions: $0.5 \mathrm{psi}, 4.0 \mathrm{sec}, \mathrm{L}_{\mathrm{w}}=19.8 \mathrm{~cm}$. Separation at $16 \mathrm{kV}$, normal polarity. Detection at $\lambda=225 \mathrm{~nm}$.

Separation of estriol, $17 \beta$-estradiol, and estrone is due to the difference in their chemical structures, namely the presence of the hydrophilic hydroxyl and ketone groups attached to the ring D. According to the literature, hydrophilic hydroxyl groups remain exposed to the solvent even after forming a complex with cyclodextrin $(28,33)$. The aromatic hydroxyl group is an exception to the rule because it can penetrate deeply into the cyclodextrin cavity where it forms hydrogen-bonds to one of hydroxyl groups in cyclodextrin molecule (34). The host-guest stoichiometry is reported to be 1:1 $(35,36)$. The $\mathrm{pH} 10$ separation data shows that estriol has the highest association with cyclodextrin 
followed by $17 \beta$-estraiol and estrone at the experimental conditions.

\subsubsection{Figures of Merit}

Calibration curves for the separation of sex steroid hormones using MEKC were determined from nine calibration curves measured 3 per day for 3 days. The linear range and correlation coefficients obtained for the $\mathrm{pH} 10$ separation system are summarized in Table 2.3 below. The curves were measured separately for each analyte. Detection was performed by UV-visible absorbance at detection wavelength of $200 \mathrm{~nm}$ for estrone, 17ßesradiol, and estriol, or $254 \mathrm{~nm}$ for androstenedione, dihydroxyprogesterone, and progesterone.

Table 2.3. Linear range of steroid detection via $\mathrm{pH} 10 \mathrm{MEKC}$ separation.

\begin{tabular}{ccccccc}
\hline & $\mathbf{E} 1$ & $\mathbf{E 2}$ & $\mathbf{E 3}$ & $\mathbf{A D}$ & $\boldsymbol{\alpha}, \boldsymbol{\beta}-\mathbf{D H P}$ & $\mathbf{P}$ \\
\hline $\begin{array}{c}\text { Linear range, } \\
\left(\times 10^{2}\right)\end{array}$ & $0.50-4.0$ & $0.50-16$ & $0.50-16$ & $0.50-16$ & $0.30-1.0$ & $0.50-16$ \\
$\mathrm{R}^{2}$ & 0.993 & 0.999 & 0.999 & 0.991 & 1.00 & 1.00 \\
\hline
\end{tabular}

\subsubsection{MEKC SEPARATION OF STEROIDS IN AN ACIDIC MEDIUM}

If the $\mathrm{pH}$ of the running buffer is less than three, the velocity of the EOF approaches zero and thus does not assist the separation of the analytes. In this experiment, the separation of steroids under acidic conditions was performed at reversed polarity (anode at the outlet) because under suppressed EOF neither neutral cyclodextrins, which have the velocity of EOF, nor SDS micelles attracted to the anode would reach the detection 
window if the normal polarity (cathode is at the outlet) was used. Phosphate buffered at $\mathrm{pH}$ 2.0 containing SDS and CD was used as a background electrolyte. At the reversed polarity experimental conditions the SDS micelles carrying steroid molecules migrate faster than the EOF (Fig. 2.7, left). As a result, the steroids with higher affinity to the micelles will migrate earlier followed by the steroids with higher affinity to the cyclodextrins.

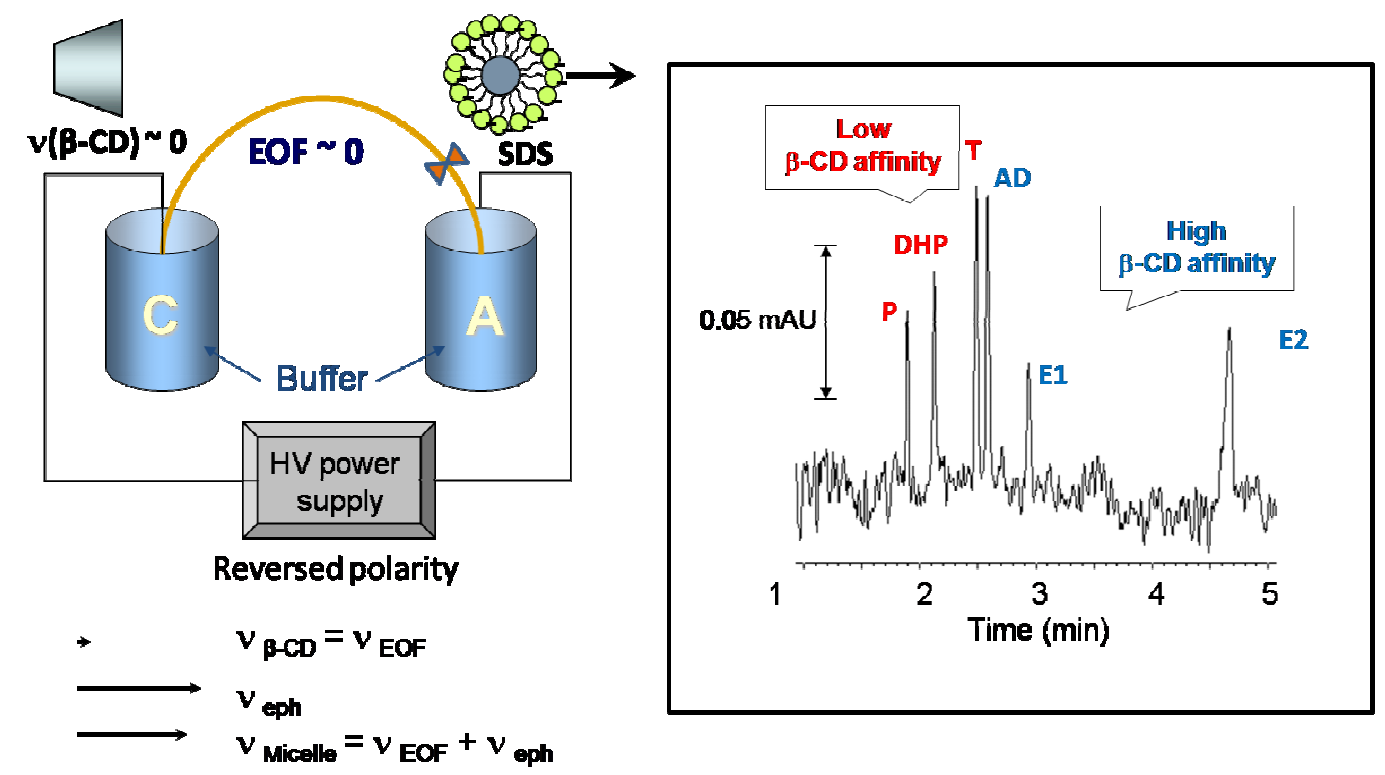

Figure 2.7. Electropherograms measured for steroids under acidic separation conditions. $\mathrm{P}$ - progesterone $(100 \mu \mathrm{M}), \mathrm{DHP}-17 \alpha, 20 \beta$-dihydroxyprogesterone $(100 \mu \mathrm{M}), \mathrm{T}-$ testosterone $(150 \mu \mathrm{M}), \mathrm{AD}-$ androstenedione $(200 \mu \mathrm{M}), \mathrm{E} 1$ - estrone $(250 \mu \mathrm{M}), \mathrm{E} 2$ - 17ß-estradiol $(150 \mu \mathrm{M})$. Injection conditions: $0.5 \mathrm{psi}$, $3.0 \mathrm{sec} . \mathrm{L}_{\mathrm{w}}=10.2 \mathrm{~cm}$. Separation at $16 \mathrm{kV}$, reversed polarity. Detection at: $\lambda=225 \mathrm{~nm}$.

The resulting electropherogram is shown in Figure 2.7 (right). All the steroids, except for estriol, were separated in less than 5 minutes. At $\mathrm{pH}$ 2.0, estriol (not shown) migrates very slowly because of its strong affinity to the cyclodextrin. As a result, estriol peak is very broad, yielding small signal-to-noise ratio and unsuitable for chromatographic 
quantitation. However, by manipulating the SDS to HPCD ratio or the separation voltage it is possible to force estriol to migrate faster as a sharp peak at the expense of lowering the resolution for early migrating steroids. The effect of the capillary length to the detection window and SDS to HPCD ratio on the separation time, resolution and selectivity is discussed below.

\subsubsection{EVALUATION OF MEKC of STERoIds in STRONGLy ACIDIC MEDIUM (PH 2)}

Separation in highly acidic media can be complicated since the analytes move through the capillary much slower under suppressed EOF. However, the separation time can be decreased by increasing the separation voltage. It can also be decreased by decreasing the length of the capillary, albeit at the expense of the resolution. Additionally, an increased capillary length leads to a decrease of the electric field strength at constant voltage $(\mathrm{E}=\mathrm{V} / \mathrm{L}, \mathrm{V}-$ applied voltage, $\mathrm{L}-$ capillary length $)$ and higher voltages have to be used for the separation. In CE, it is common to start a method development using a shorter capillary (typically $20-50 \mathrm{~cm}$ to the detection window) and then change the length of the capillary until the best resolution for all the analytes is achieved. The length of the separation capillary used for both types of CE analysis was $30 \mathrm{~cm}$. In $\mathrm{pH} 10$ method the detection window was positioned $19.8 \mathrm{~cm}$ from the injection point while the other end of the capillary was positioned $10.2 \mathrm{~cm}$ from the detection window. This method is referred to as the long end separation. In $\mathrm{pH} 2$ method the effective length of the capillary was $10.2 \mathrm{~cm}$ with the detection window positioned closer to the inlet. This is the case of the short end separation. 
Figure 2.8 shows the separation of steroids injected at short and long ends of the separation capillary. Even though the resolution improves, the detection signal decreases for slower migrating analytes such as ethynyl estradiol due to band broadening effects caused by longitudinal diffusion. Longitudinal diffusion is the diffusion of the solute molecules from the center of the analyte zone to the more dilute regions in front of and behind the zone. On the other hand it is evident that a short end separation under acidic conditions results in at least $60 \%$ faster separation comparing to the long end separation and the separation efficiency (the narrow shape of the peak) for ethynyl estradiol improved dramatically which was predicted by the theory; however, the resolution suffered in the short end separation leading to the overlapping peaks for testosterone and androstenedione (Fig. 2.8-A).

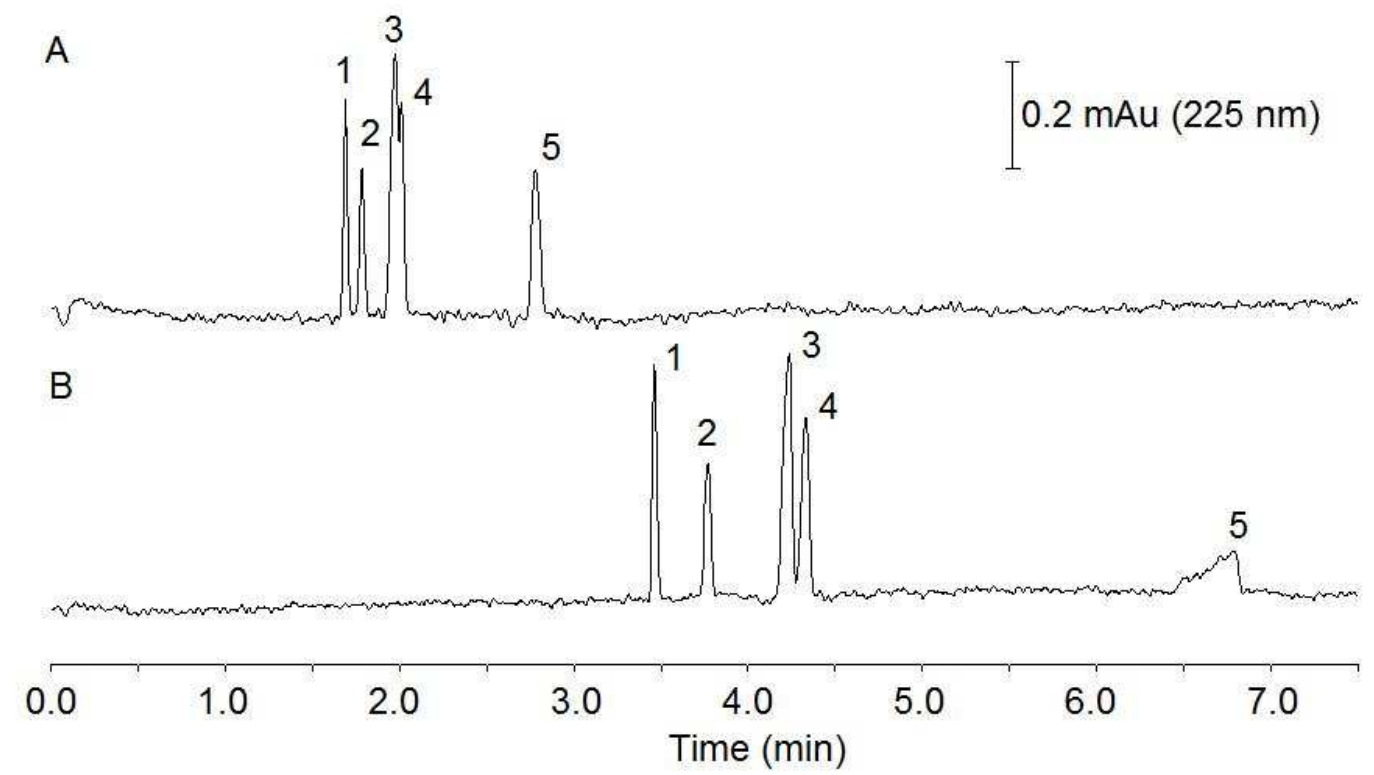

Figure 2.8. Acidic MEKC of steroids injected hydrodynamically ( $0.5 \mathrm{psi}, 4 \mathrm{sec})$ at short end (A) and long end (B). $350 \mu \mathrm{M}$ progesterone (1); $250 \mu \mathrm{M}$ hydroxyprogesterone (2); $500 \mu \mathrm{M}$ testosterone (3); $400 \mu \mathrm{M}$ androstenedione (4); $300 \mu \mathrm{M}$ ethynyl estradiol (5). BGE: $40 \mathrm{mM}$ SDS, $20 \mathrm{mM}$ HPCD, $20 \%$ methanol in 10 $\mathrm{mM}$ phosphate buffered at $\mathrm{pH}$ 3.1. Separation: $16 \mathrm{kV}$ and normal polarity. 
The poorer resolution of testosterone and androstenedione peaks in the short-end analysis can be improved by changing the SDS/HPCD ratio of the running buffer as illustrated in Figure 2.9. As discussed earlier, the steroids with a higher affinity to SDS micelles migrate first under acidic conditions and reversed polarity. The migration order of steroids under acidic conditions (Fig.2.8-B) demonstrates that testosterone has higher affinity to SDS comparing to androstenedione which preferentially forms inclusion complexes with $\mathrm{CD}$. If the ratio of SDS to HPCD is high the equilibrium will be shifted toward the inclusion of the steroids inside of SDS micelle cores and therefore steroids will spend more time travelling with the micelles thus migrating faster and producing worse resolution (Fig. 2.9-A). By increasing the amount of HPCD in the separation buffer the equilibrium is shifted toward the formation of the inclusion complexes of steroids with cyclodextrin cavities. Therefore, if the amount of HPCD in running buffer is increased androstenedione can be separated from testosterone. The representative electropherograms shown in Figure 2.9 were obtained using three running buffers of different ratios of SDS/HPCD: 2.2 (40 mM/18 mM), 2.0 (40 mM/20 mM), and $1.7(30 \mathrm{mM} / 18 \mathrm{mM})$. 


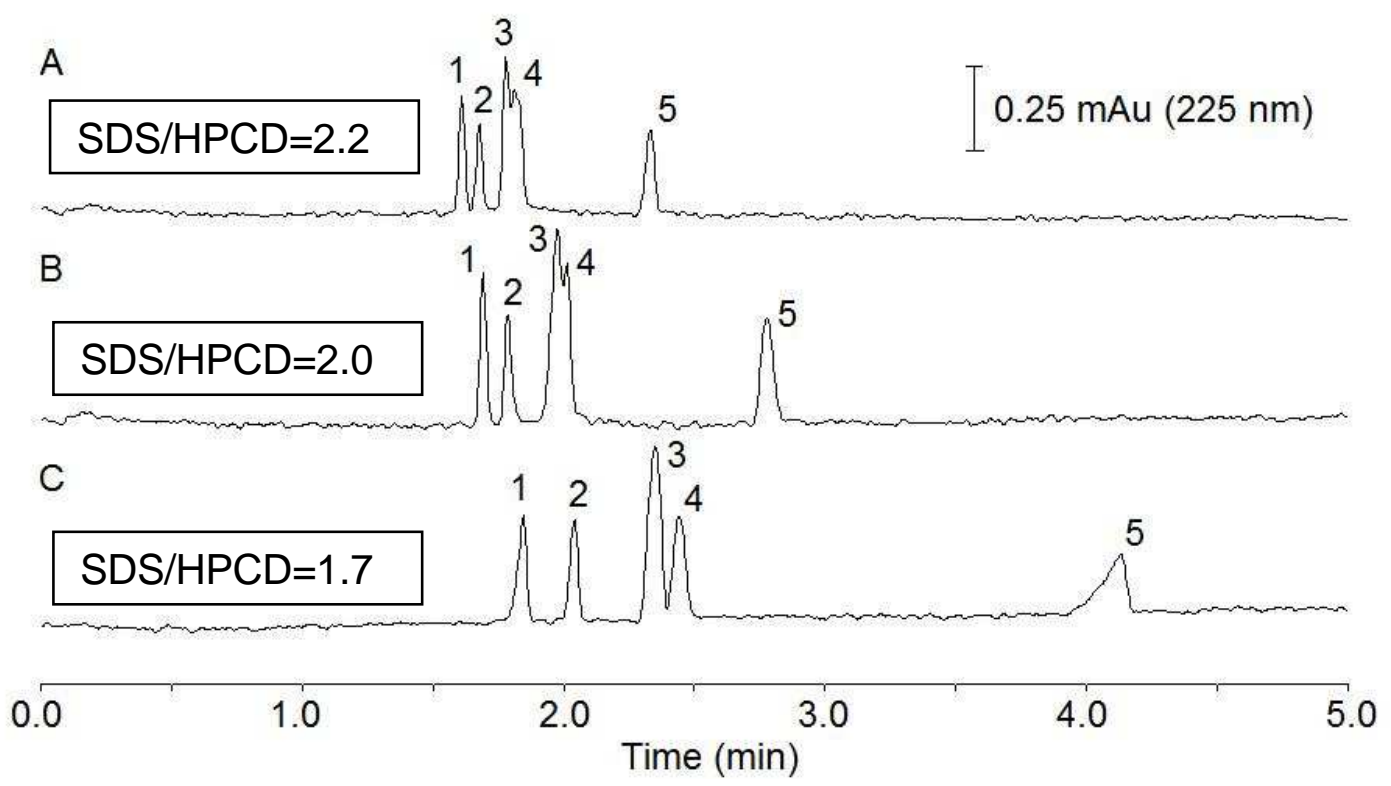

Figure 2.9. Short end separation of steroids in acidic MEKC. SDS/ HPCD is 2.2 (A), 2.0 (B), 1.7 (C). Sample injected hydrodynamically at $0.5 \mathrm{psi}, 4 \mathrm{sec} .350 \mu \mathrm{M}$ progesterone (1); $250 \mu \mathrm{M}$ hydroxyprogesterone (2); 500 $\mu \mathrm{M}$ testosterone (3); $400 \mu \mathrm{M}$ androstenedione (4); $300 \mu \mathrm{M}$ ethynyl estradiol (5). BGE is SDS/HPCD, 20\% methanol in $10 \mathrm{mM}$ phosphate buffered at $\mathrm{pH} 3.1$. Separation at $16 \mathrm{kV}$ and normal polarity.

The electropherogram in Figure 2.9-C demonstrates baseline resolution for all peaks obtained using SDS/HPCD $=1.7$ although ethynyl estradiol peak is too broad if $\mathrm{SDS} / \mathrm{HPCD} \leq 1.7$. The analysis time however is $40 \%$ faster for the short end comparing to the long end separation and is beneficial for the fast screening of multiple steroid samples.

\section{CONCLUSIONS}

The separation of selected steroid hormones by conventional MEKC has been conducted under both basic and acidic conditions. The study has shown that the migration order of steroids depends on their affinity to the hydrophobic cavities of SDS micelle or cyclodextrin molecule and can be manipulated by changing the $\mathrm{pH}$ of the running buffer and the polarity of the potential applied across the separation capillary. The resolution of 
the steroid peaks in the electropherogram depends on the ratio of SDS to cyclodextrin in the running buffer and therefore can be controlled. The electropherograms measured at basic conditions demonstrated the baseline separation of steroids in less than $3.5 \mathrm{~min}$. The separation in acidic medium under suppressed EOF was achieved in less that 5 min. The latter was obtained using reversed polarity and a short end separation with the effective length of the capillary being $10.2 \mathrm{~cm}$ from the injection point to the detection window. Although the acidic method yields baseline resolved peaks and fast separation of steroids, the limits of detection for steroid analysis must still be compatible with the low levels of endogenous steroids in plasma. The development of a preconcentration technique for improving the steroid detection limits by MEKC-UV-visible absorbance detection is the subject of the next chapter.

\section{BIBLIOGRAPHY}

1. Heiger, D. N., Ed. High Performance Capillary Electrophoresis - An Introduction, 2nd ed.; HewlettPackard Company: France, 1992.

2. Jorgenson, J. W.; Lukacs, K. D. Zone Electrophoresis in Open Tubular Glass Capillaries. Anal. Chem. 1981, 53, 1298-1302.

3. Jorgenson, J. W.; Lukacs, K. D. Capillary Zone Electrophoresis. Science 1983, 222 (4621), 266-272.

4. Lukacs, K. D.; Jorgenson, J. W. Capillary Zone Electrophoresis: Effect of Physical Parameters on Separation Efficiency and quantitation. HRC CC J. High Resolut. Chromatogr. Chromatogr. Commun. 1985, $8(8), 407-411$.

5. Evenhuis, C. J.; Hruska, V.; Guijt, R. M.; Macka, M.; Gas, B.; Marriott, P. J.; Haddad, P. R. Reliable Electrophoretic Mobilities Free From Joule Heating Effects Using CE. Electrophoresis 2007, 28 (20), 3759-3766. 
6. Ding, W.; Thornton, M. J.; Fritz, J. S. Capillary Electrophoresis of Anions at High Salt Concentrations. Electrophoresis 1998, 19 (12), 2133-2139.

7. Gilges, M; Kleemiss, M. H.; Schomburg, G. Capillary Zone Electrophoresis Separations of Basic and Acidic Proteins Using Poly (vinyl alcohol) Coatings in Fused Silica Capillaries. Anal. Chem. 1994, 66 (13), 2038-2046.

8. Janini, G. M.; Muschik, G. M.; Issaq, H. J. Micellar Electrokinetic Chromatography in ZeroElectroosmotic Flow Environment. J. Chromatogr., B: Biomed. Appl. 1996, 683 (1), 29-35.

9. Janini, G. M.; Issaq, H. J.; Muschik, G. M. Electrokinetic Chromatography without Electroosmotic Flow. J. Chromatogr., A 1997, $792(1+2), 125-141$.

10. Quirino, J. P.; Terabe, S. Sample Stacking of Fast-Moving Anions in Capillary Zone Electrophoresis with pH - Suppressed Electroosmotic Flow. J. Chromatogr., A 1999, $850(1+2), 339-344$.

11. Terabe, S.; Otsuka, K.; Ichikawa, K.; Tsuchiya, A.; Ando, T. Electrokinetic Separations with Micellar Solutions and Open-Tubular Capillaries. Anal. Chem. 1984, 56, 111-113.

12. Khaledi, M. G., Ed. Micellar electrokinetic chromatography. In High Performance Capillary Electrophoresis; Wiley-Interscience: New York, 1998; Chapter 3.

13. Yang, S.; Khaledi, M. G. Chemical Selectivity in Micellar Electrokinetic Chromatography: Characterization of Solute-Micelle Interactions for Classification of Surfactants. Anal. Chem. 1995, 67, 499-510.

14. Khaledi, M. G.; Smith, S. C.; Strasters, J. K. Micellar Electrokinetic Capillary Chromatography of Acidic Solutes: Migration Behavior and Optimization Strategies. Anal. Chem. 1991, 63, 1820-1830.

15. Strasters, J. K.; Khaledi, M. G. Migration Behavior of Cationic Solutes in Micellar Electrokinetic Capillary Chromatography. Anal. Chem. 1991, 63, 2503-2508.

16. Quang, C.; Strasters, J. K., and Khaledi, M.G. Computer-Assisted Modeling, Prediction, and Multifactor Optimization in Micellar Electrokinetic Chromatography of Ionizable Compounds. Anal. Chem. 1994, $66,1646-1653$.

17. Foley, J. P. Optimization of Micellar Electrokinetic Chromatography. Anal. Chem. 1990, 62, 1302-1308. 
18. Fuguet, E.; Rafols, C.; Roses, M.; Bosch, E. Critical Micelle Concentration of Surfactants in Aqueous Buffered and Unbuffered Systems. Anal. Chim. Acta 2005, 548 (1-2), 95-100.

19. Terabe, S.; Katsura, T.; Okada, Y.; Ishihama, Y.; Otsuka, K. Measurement of Thermodynamic Quantities of Micellar Solubilization by Micellar Electrokinetic Chromatography with Sodium Dodecyl Sulfate. J. Microcolumn Sep. 1993, 5 (1), 23-33.

20. Pyell, U.; Buetehorn, U. Optimization Strategies in Micellar Electrokinetic Capillary Chromatography. Optimization of the Temperature of the Separation Capillary. Chromatographia 1995, 40 (1/2), 69-77.

21. Yu, L.; Seals, T.; Davis, J. M. Reexamination of Dependence of Plate Number on SDS Concentration in Micellar Electrokinetic Chromatography. Anal. Chem. 1996, 68 (23), 4270-4280.

22. Ji, A. J.; Nunez, M. F.; Machacek, D.; Ferguson, J. E.; Iossi, M. F.; Kao, P. C.; Landers, J. P. Separation of Urinary Estrogens by Micellar Electrokinetic Chromatography. J. Chromatogr., B: Biomed. Appl. 1995, 669 (1), 15-26.

23. Chan, K. C.; Muschik, G. M.; Issaq, H. J.; Siiteri, P. K. Separation of Estrogens by Micellar Electrokinetic Chromatography. J. Chromatogr., A 1995, 690 (1), 149-154.

24. Deng, Y.; Zhou, J.; Perkins, M. D.; Lunte, S. M. Capillary Electrophoretic Separation of Estrogens Using Anionic Sulfobutyl Ether $\beta$-Cyclodextrin. Anal. Commun. 1997, 34 (5), 129-131.

25. Szejtli, J. Introduction and General Overview of Cyclodextrin Chemistry. Chem. Rev. 1998, 98 (5), $1743-1753$

26. Steed, J. W.; Atwood, J. L. Supramolecular Chemistry, 2nd ed.; John Wiley \& Sons, U. K., 2009; pp 327-335.

27. Coleman, A. W.; Nicolis, I.; Keller, N.; Dalbiez, J. P. Aggregation of Cyclodextrins: an Explanation of the Abnormal Solubility of $\beta$ - Cyclodextrin. J. Inclus. Phenom. Mol. 1992, 13 (2), 139-143.

28. Connors, K. A. The Stability of Cyclodextrin Complexes in Solution. Chem. Rev. 1997, 97 (5), $1325-$ 1357.

29. Lin, C.-E.; Huang, H.-C.; Chen, H.-W. A Capillary Electrophoresis Study on the Influence of $\beta$ Cyclodextrin on the Critical Micelle Concentration of Sodium Dodecyl Sulfate. J. Chromatogr., A 2001, 917 (1-2), 297-310. 
30. Lopez-Grio, S.; Baeza-Baeza, J. J.; Garcia-Alvarez-Coque, M. C. Influence of the Addition of Modifiers on Solute-Micelle Interaction in Hybrid Micellar Liquid Chromatography. Chromatographia 1998, 48 (9/10), 655-663.

31. Yoshida, A.; Yamamoto, M.; Irie, T.; Hirayama, F.; Uekama, K. Some Pharmaceutical Properties of 3Hydroxypropyl- and 2,3-Dihydroxypropyl- $\beta$-Cyclodextrins and Their Solubilizing and Stabilizing Abilities. Chem. Pharm. Bull. 1989, 37 (4), 1059-1063.

32. Shakalisava, Y.; Regan, F. Determination of Association Constants of Inclusion Complexes of Steroid Hormones and Cyclodextrins from their Electrophoretic Mobility. Electrophoresis 2006, 27 (15), 30483056.

33. Rekharsky, M.V.; Inoue, Y. Complexation Thermodynamics of Cyclodextrins. Chem. Rev. 1998, 98 (5), 1875-1917

34. Ross, P. D.; Rekharsky, M. V. Thermodynamics of Hydrogen Bond and Hydrophobic Interactions in Cyclodextrin Complexes. Biophys. J. 1996, 71 (4), 2144-2154.

35. Sadlej-Sosnowska, N. Thermodynamic Parameters of the Formation of a Complex Between Cyclodextrins and Steroid Hormones. J. Chromatogr., A 1996, $728(1+2), 89-95$.

36. Sadlej-Sosnowska, N. Influence of the Structure of Steroid Hormones on Their Association with Cyclodextrins: a High-Performance Liquid Chromatography Study. J. Inclus. Phenom. Mol. 1997, 27 (1), $31-40$. 


\section{CHAP T ER 3}

STEROID PRECONCENTRATION 


\subsection{INTRODUCTION}

While the MEKC separation described earlier is fast and consumes low sample and reagent volumes, it has poor concentration limits of detection if measured by UVvisible absorption due to limited sample loading capacity and small path length for light absorbance. In CE, the inner diameter of the separation capillary has to be smaller than 100 $\mu \mathrm{m}$ to minimize the solute dispersion caused by Joule heating and to obtain the high separation efficiency (1). A detection window in a silica capillary is prepared by burning off polyimide coating from a segment of the capillary. Due to a small diameter of the capillary, the path length for light absorbance is small (from Beer's law: $A=\varepsilon b C$, where $\varepsilon$ is the molar extinction coefficient of the sample, $\mathrm{C}$ is the sample molar concentration, and $\mathrm{b}$ is light path that equals to the capillary diameter) and therefore the detection limits are frequently poor and in the range of $10^{-5}-10^{-7} \mathrm{M}(2)$.

The capillary dimensions lead to injection volumes of a few nanoliters. If the injection volume is much larger than $1 \%$ of the total length of the capillary, sample overloading occurs and the peaks broaden (3). Without improved detection limits CE cannot be used in bioanalytical studies such as analysis of very low levels of steroids in biological fluids. The approaches for the enhancement of the detection limits in CE include the use of laser-induced fluorescence $(4,5)$, electrochemical detection $(6,7)$, and mass spectrometry (8) as they allow the low detection limits comparing to UV-visible absorbance; chemical derivatization (9); extended length cells in UV-visible absorbance detectors (z-cells, bubble cells) $(10,11)$ and sample enrichment by means of the liquidliquid extraction (12), selective membrane extraction (13), and solid phase extraction (14), 
which are carried out before or after the capillary electrophoresis analysis. However, these methods are not directly applicable to the goal of this dissertation. For example, steroid molecules are neutral and require the use of MEKC separation which is not directly compatible with a mass spectrometer detector due to the non-volatile surfactant molecules that contaminate the ionization chamber, reducing the ionization efficiency and deteriorating the limits of detection (15). Steroids also lack of chromophores, required for LIF analysis, and would therefore need to be chemically modified.

An in-capillary sample preconcentration method can be a good alternative for steroid preconcentration without the use of expensive detectors and other modification of the instrument or time-consuming derivatization sample pretreatment. The current incapillary sample preconcentration techniques are based on electrokinetic injection of large sample volumes. These techniques combine the sample injection and separation in a single capillary and are based on the changes in the electrophoretic velocity of the analytes at the boundary between the sample and the running buffer zones. This allows narrowing the analyte bandwidth and increasing the amount of the sample that can be loaded into capillary leading to a better detection.

A series of preconcentration techniques used in combination with $\mathrm{CE}$ have been developed and include: field amplified sample stacking, sweeping, isotachophoresis, $\mathrm{pH}$ stacking, or chromatographic preconcentration $(16,17)$. Field amplified sample stacking involves ions electrophoretically migrating through a low-conductivity buffer solution into a high conductivity buffer solution. The migrating ions slow down dramatically at the boundary of the two buffers and preconcentrate $(18,19)$. Isotachophoresis is performed with a discontinuous buffer in which the sample zone is between the background 
electrolyte of higher (leading electrolyte) and lower (terminal electrolyte) electrophoretic mobilities (20). The ionic species are preconcentrated according to the difference in mobility by applying an electric field. The preconcentration by $\mathrm{pH}$-stacking occurs at the boundary of two buffer solutions of high and low $\mathrm{pH}$ (21). Sweeping is based on the ability of non-polar analyte molecules to partition into a pseudo-stationary phase (22). Finally, chromatographic preconcentration uses silica beads modified by immobilized ligand which captures and preconcentrates a target analyte in-capillary (23).

The present chapter discusses the design and performance of two preconcentration techniques that were developed for steroid analysis: (1) a chromatographic preconcentration by means of a modified silica cartridge integrated in-capillary, and (2) a pH-stacking using functionalized cyclodextrins. Both methods can improve the selectivity and concentration limits of detection for steroid analysis and enable efficient steroid separation analysis in complex mixtures such as blood plasma. Investigation of the influence of several parameters that are used to obtain more efficient and more reproducible chromatographic separations is also discussed.

\subsection{EXPERIMENTAL}

\subsubsection{CHEMICALS AND Materials}

Carboxymethyl- $\beta$-CD, SDS, 3-[cyclohexylamino]-1-propanesulfonic acid (CAPS), 11-ketotestosterone, and testosterone were purchased from Sigma-Aldrich (St. Louis, MO, USA). HPCD was purchased from VWR (West Chester, PA, USA). Steroids, 17 $\beta$ estradiol, estrone, 17-hydroxyprogesterone, and progesterone were purchased from 
Steraloids, Inc (Newport, RI, USA). 17 $\alpha$-ethynyl estradiol was purchased from Cayman Chemical (Ann Arbor, MI, USA). Sodium phosphate monobasic salt was purchased from Fisher Scientific (Fair Lawn, NJ, USA). Methanol was purchased from EMD Chemicals (San Diego, CA, USA). Deionized water was purified using ELGA Purelab Ultra (Lowell, MA, USA). Buffered solutions and standard stock solution of each sex steroid hormone were prepared as described in Section 2.2.1. The running buffer and the samples to be analyzed were prepared fresh every day prior to use.

\subsubsection{INSTRUMENTATION}

All CE measurements were carried out as described in Section 2.2.2. Briefly, the electropherograms were collected at the wavelengths of UV-light where the analytes showed strong absorption (200 $\mathrm{nm}$ for estrogens and $254 \mathrm{~nm}$ for androgens and progesterone). All the separations were performed using $25 \mu \mathrm{m}$ id, $360 \mu \mathrm{m}$ od, $30 \mathrm{~cm}$ long fused silica separation capillary (Polymicro Technologies, LLC, Phoenix, AZ, USA) with the detection window positioned $10.2 \mathrm{~cm}$ from the cathodic reservoir located at the sample inlet. The capillary cartridge and sample trays inside the instrument were maintained at 25 $\pm 1^{\circ} \mathrm{C}$ while the trays holding the vials filled with the separation buffer were maintained at the room temperature which varied from 20 to $24{ }^{\circ} \mathrm{C}$. All vials containing running buffers and samples were treated before analysis as described in Section 2.2.2.

\subsubsection{Capillary Packing Procedure}

This type of preconcentration design uses silica beads with an immobilized ligand as a preconcentration plug held inside of the separation capillary by a porous frit. The 
stationary phase captures and preconcentrates the targeted analytes. Silica beads modified with hydrophobic alkyl groups are widely used in reversed phase liquid chromatography as a packing material for chromatography columns. This material is ideal for strong retention of hydrophobic compounds, including steroids, and therefore was utilized in this project.

A pressure packing technique called slurry packing was used in-house to fabricate a capillary with the built-in stationary phase preconcentration cartridge similar to a previous work by Hoyt and colleagues (24). The polyimide coating was first removed from one end of a bare fused silica capillary ( $26 \mu \mathrm{m}$ id) using a heating element. To make a temporary frit a small amount of silica was then introduced into this end of the capillary by gently tapping the end of the capillary into a vial containing the silica beads. The temporary frit was formed with a heating element. Slurry comprised of stable bond chromatography packing material Zorbax SB-C8 with the particle size of 5 micron (Agilent Technologies Inc., Santa Clara, CA, USA) and isopropyl alcohol was placed into a closed pressurized stainless steel container with two connectors. One of the connectors was attached to a high pressure LC system pump while the other one was connected to the fritless end of the capillary. After a high pressure had been applied to the capillary, the slurry was introduced into the capillary where it was held by the temporary frit while only the liquid component passed through. The packed capillary was then successively flushed with methanol and water at $14 \times 10^{3} \mathrm{kPa}\left(2 \times 10^{3} \mathrm{psi}\right)$. While the capillary was flushed with water the stationary phase was gently sintered using commercially available Innova capillary fitting device. This procedure resulted in the formation of another frit, which held the stationary phase in 
place. The temporary frit with the excess of the silica phase was then removed by trimming the cartridge to $\sim 1 \mathrm{~mm}$ length and was used for the further CE experiment.

\subsubsection{CHROMATOGRAPHIC PRECONCENTRATION MEKC PROCEDURE}

Prior to each analysis, the capillary with the chromatographic cartridge was sequentially flushed with acetonitrile: water (50: 50, v/v), water, $0.1 \mathrm{~N}$ hydrochloric acid, and the separation buffer which was $10 \mathrm{mM}$ SDS in $10 \mathrm{mM}$ phosphate buffered at $\mathrm{pH} 2.0$. Acidic conditions were preferred due to the stability of the stationary phase at $\mathrm{pH}<6(25)$. Standard solution of estradiol in methanol was diluted in the mixture of methanol: separation buffer (20: 80, v/v) to $60 \mu \mathrm{M}$ concentration and injected at $69 \mathrm{kPa}(10 \mathrm{psi})$ for $15 \mathrm{sec}$ onto the activated preconcentrator. The retained steroid molecules were eluted from the stationary phase by flushing it with acetonitrile: $10 \mathrm{mM}$ phosphate buffered at $\mathrm{pH} 2.0$ $(70: 30, \mathrm{v} / \mathrm{v})$ at $17 \mathrm{kPa}(2.5 \mathrm{psi})$ for $1 \mathrm{~min}$ and then with the separation buffer only at $6.9 \mathrm{kPa}$ (1.0 psi) for $1 \mathrm{~min}$. After elution the sample was analyzed in-capillary by MEKC at $16 \mathrm{kV}$, reversed polarity, and the detection wavelength of $200 \mathrm{~nm}$.

\subsubsection{PH-STACKING MEKC PROCEDURE}

\subsubsection{The Role of Cyclodextrins}

Several books $(26,27)$ and a number of articles $(28-31)$ are dedicated to CD hostguest chemistry. An important characteristic of CDs making them useful is their unique ability to solubilize lipophilic molecules in their molecular cavities forming inclusion complexes. This is accomplished without formation of chemical bonds and changing the 
guest molecules structure. The selectivity of this interaction is governed by the size, geometry, and physicochemical properties of both analyte and CD. Intramolecular interactions occur as the secondary hydroxyl groups at C2 and C3 (see Figure 2.4) can form hydrogen bonds. This restricts the free movement of their relative positions, maintaining the freedom of motion of the hydroxyl groups $(27,32)$. The cavity of the cyclodextrin is moderately hydrophobic, making it amenable to a wide variety of organic guests. Van der Waals and hydrophobic interactions are believed to be the main factors involved in complexation (33-36). However, steric effects and hydrogen bonding play a role as well $(37,38)$. The size of the cavity and the CD ring structure is very important. A tight spatial fit of the guest is necessary to maximize the interaction energy due to noncovalent bonding or allow complexation. Selectivity is determined by the size, structure, and physiochemical properties of both the guest and CD. In chromatographic applications, the formation of an inclusion complex is beneficial for nonpolar analytes increasing their solubility in water. Many groups can be introduced into the $\mathrm{CD}$ structure to increase the solubility of CDs (39). In this dissertation neutral and charged CD derivatives are used for the preconcentration and separation of steroid hormones.

Carboxymethyl- $\beta-C D$ was chosen as a preconcentration agent. This compound is commercially available and readily soluble in common $\mathrm{CE}$ running buffers. Sulfobutylether-CD is a popular anionic $\mathrm{CD}$ and has high aqueous solubility. However, it is relatively unaffected by $\mathrm{pH}$ due to its $\mathrm{pK}_{\mathrm{a}}$ being too low for stacking at $\mathrm{pH} 2.5$ (40). Additionally, this material is more expensive and multiple labeled sulfobutylether- $\beta-C D$ can lead to peak broadening since the electrophoretic mobility changes with the degree of 
substitution. CMCD molecules form inclusion complexes with steroids in aqueous solutions $(41,42)$. Kano and co-workers (43) reported an apparent $\mathrm{pK}_{\mathrm{a}}$ of $\sim 5$ for 2,3-di$O$-carboxymethyl- $\beta-\mathrm{CD}\left(25^{\circ} \mathrm{C}, 0.1 \mathrm{M} \mathrm{NaCl}\right)$. The $\mathrm{pK}_{\mathrm{a}}$ of $\mathrm{CMCD}$ is suitable for stacking a sample prepared in a basic medium and injected in a capillary filled with acidic running electrolyte. In the basic solution carboxylic groups surrounding CMCD molecule will become deprotonated thus making the entire molecule be negatively charged which allows electrokinetic injection into the separation capillary. Alternatively, while in the solution with low $\mathrm{pH}$ the carboxylic groups will be protonated back producing neutral CMCD molecule (Figure 3.1). Some physical and chemical properties of CDs used in the research are summarized in Table 3.1.

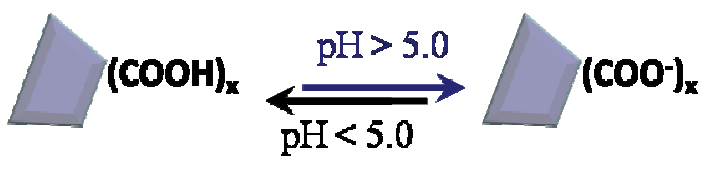

Figure 3.1. Dissociation of CMCD molecule depends on $\mathrm{pH}$ of the solution.

Table 3.1. Cyclodextrins used in the research.

\begin{tabular}{|c|c|c|c|}
\hline CD & $\begin{array}{c}\text { Solubility in water, } \mathrm{g} / 100 \\
\mathrm{~mL}\end{array}$ & $\mathbf{M W}_{\mathrm{AVE}}$ & $-\mathbf{R}$ \\
\hline$\beta-C D$ & 1.8 & 1135 & $-\mathrm{H}$ \\
\hline Carboxymethyl- $\beta-C D$ & 5.0 & 1541 & $-\mathrm{CH}_{2} \mathrm{COOH}$ \\
\hline Hydroxypropyl- $\beta-C D$ & 33 & 1483 & $-\mathrm{CH}_{2} \mathrm{CH}\left(\mathrm{CH}_{3}\right) \mathrm{OH}$ \\
\hline
\end{tabular}




\subsubsection{Stacking Mechanism}

Steroid standards prepared in methanol were diluted to desired concentrations with an aqueous solution comprised of $1 \mathrm{mM}$ CMCD in $50 \mathrm{mM}$ CAPS buffered at $\mathrm{pH} 10$. The concentration of methanol in the final sample was $5 \%$ to aid the dissolution of a hydrophobic steroid. The running buffer comprised of $30 \mathrm{mM}$ SDS, $13 \mathrm{mM}$ HPCD in 200 $\mathrm{mM}$ phosphate buffered to $\mathrm{pH}$ 2.5. No methanol was added to the running buffer.

The capillary was first filled with the running buffer followed by the injection of a deionized water plug at $13.8 \mathrm{kPa}(2 \mathrm{psi})$ for $6 \mathrm{sec}$. The steroid sample was then injected electrokinetically upon application of $10 \mathrm{kV}$ high voltage at reversed polarity for $60 \mathrm{sec}$. The neutral steroid molecules carried by the CMCDs which are fully deprotonated (negatively charged) at high $\mathrm{pH}$ were driven into the separation capillary. Once in contact with the acidic running buffer, the neutral steroid-CD complex concentrated in a narrow zone at the $\mathrm{pH}$ junction. The negatively charged SDS micelles migrated as a function of electrophoretic mobility towards the anode, which was located past the detection window. The velocity of the neutral HPCD was insignificant as the EOF was suppressed (see Fig. 3.2-A). Following stacking, the reverse polarity run at $16 \mathrm{kV}$ was started and the separation was initiated by replacing the sample vial with a cathodic reservoir containing $30 \mathrm{mM}$ SDS, $13 \mathrm{mM}$ HPCD in $200 \mathrm{mM}$ phosphate buffered at $\mathrm{pH} \mathrm{2.5.} \mathrm{(Figure} \mathrm{3.2).} \mathrm{The} \mathrm{steroids}$ partitioned or associated competitively with the SDS and CDs and were separated as illustrated in Figure 3.2-B,C,D. 


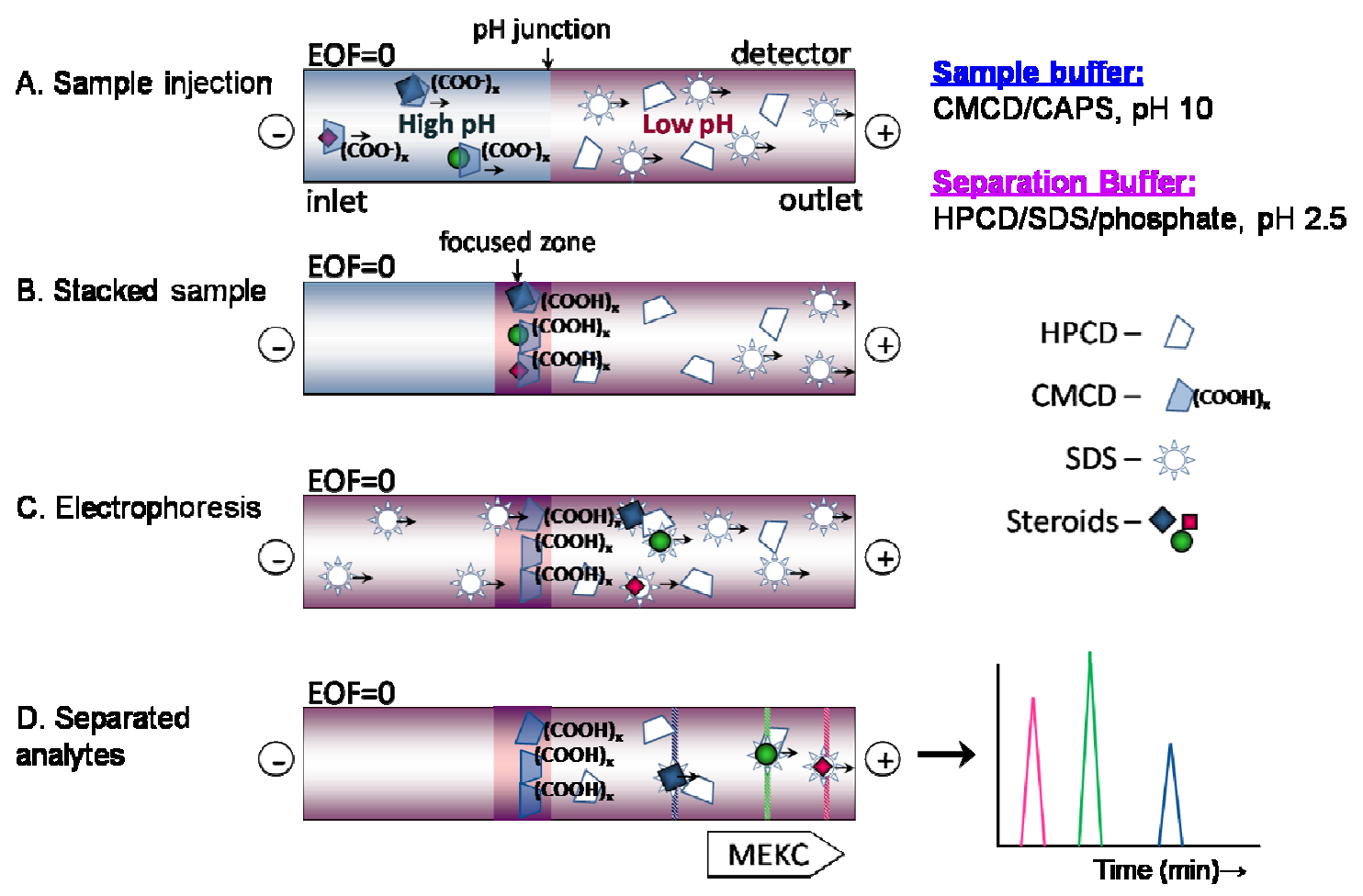

Figure 3.2. Schematic representation of $\mathrm{pH}$-stacking using functionalized cyclodextrin.

\subsubsection{Capillary Flushes}

A special preconditioning and washing sequence was performed on each capillary to ensure more reproducible separation conditions. At the beginning of each day the capillary was conditioned with several timed flushes at $172 \mathrm{kPa}(25 \mathrm{psi})$. The sequence of these flushes was $5 \mathrm{~min}$ methanol, $5 \mathrm{~min}$ water, $25 \min 0.1 \mathrm{~N}$ hydrochloric acid, $5 \mathrm{~min}$ water, 25 min running electrolyte comprised of $30 \mathrm{mM}$ SDS $13 \mathrm{mM}$ HPCD, $200 \mathrm{mM}$ phosphate buffered at $\mathrm{pH} 2.5$. In between runs the capillary was flushed at $172 \mathrm{kPa}$ (25 psi) for 2 min with the running electrolyte. The methanol was used to rinse the capillary interior after steroid stacking analysis. To suppress the ionization of the silica surface silanol groups and as a result the EOF $0.1 \mathrm{~N}$ hydrochloric acid was used. The water was 
used to remove any excess of the $\mathrm{Cl}^{-}$ions and finally the capillary was filled with the running electrolyte used for the separation.

\subsection{RESULTS AND DISCUSSION}

\subsubsection{Chromatographic Preconcentration of Steroids}

The chromatographic preconcentration by means of reversed-phase silica gel beads forming an in-capillary preconcentration plug was investigated and demonstrated good concentration enhancement despite several procedural limitations. In the following experiment the acidic separation buffer was used and the steroid separation was optimized at acidic conditions under suppressed EOF due to the preferential use of silica packing material stable at low $\mathrm{pH}$ for the fabrication of the preconcentration cartridge. The preconcentrator used in this study is schematically illustrated in Figure 3.3.

Figure 3.4 shows electropherograms obtained for the MEKC separation of the 60 $\mu \mathrm{M} 17 \beta$-estradiol with and without the in-capillary chromatographic preconcentration step. The represented data confirms that the use of the solid phase preconcentrator produces higher estradiol peak while keeping its width small. The injection of the same sample at the same conditions without the preconcentrator results in a broad and short sample peak, significantly degrading the separation efficiency. The injected sample volume using the plug was approximately 75 times larger comparing to the volume of the sample injected using conventional MEKC under acidic conditions. This number was estimated by comparing the injection time and pressure used for acidic MEKC and chromatographic preconcentration MEKC in this work. However, while conducting this study it was noticed 
that after just a few days of use the preconcentrator plug could be easily pushed out of its place and out of the separation capillary with the applied pressure. The biggest technical issue of this technique was the sensitivity of the preconcentrator to the storage conditions and incompatibility with the solvents used. Because of these technical difficulties, $\mathrm{pH}-$ stacking was tested as an alternative preconcentration method which could be integrated into a CE instrument without interfering with the automation (44-46).

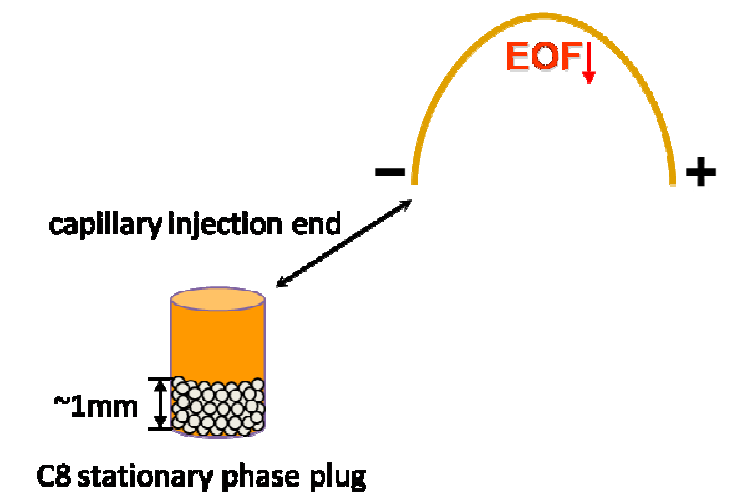

Figure 3.3. Schematic representation of the stationary phase preconcentration cartridge

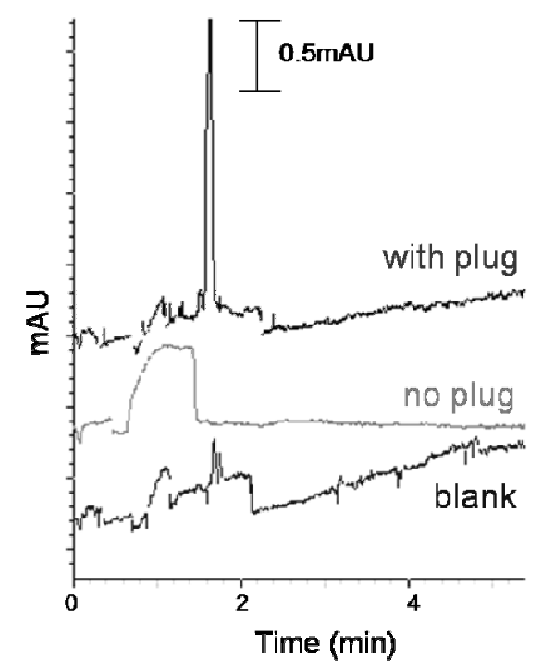

Figure 3.4. Electropherograms of a blank sample and $60 \mu \mathrm{M} 17 \beta$-estradiol with and without chromatographic preconcentration. 


\subsubsection{PH - STACKING OF STEROIDS}

Stacking can be used for charged and neutral compounds, such as steroid hormones. The effective mobility of weak acids and bases in the capillary is a function of $\mathrm{pH}$. This mode of stacking utilizes a $\mathrm{pH}$ junction formed at the boundary of two buffer zones, when the buffer solutions of low and high $\mathrm{pH}$ values are introduced into a separation capillary. The analyte preconcentration at the $\mathrm{pH}$ junction is referred to as $\mathrm{pH}$-stacking (Fig. 3.5). The efficiency of $\mathrm{pH}$-stacking depends on the $\mathrm{pH}$ of the solutions, the concentration of the sample matrix, as well as the $\mathrm{pK}_{\mathrm{a}}$ of the stacked molecule.

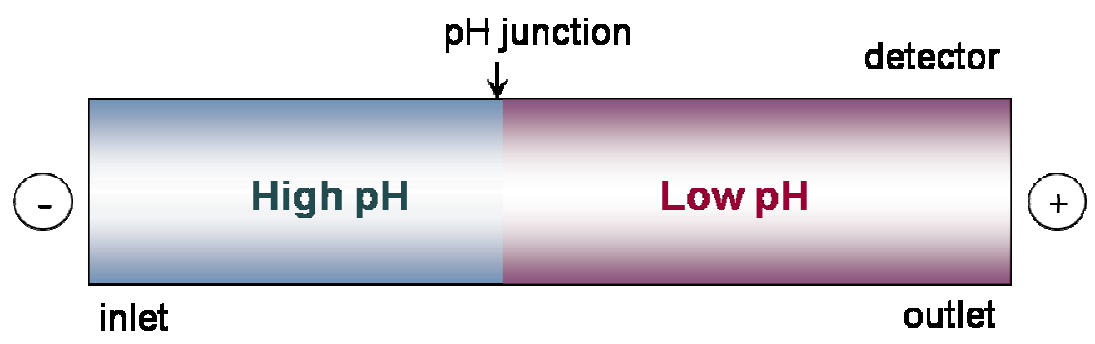

Figure 3.5. Formation of pH-junction at the interface of two, basic and acidic, buffer solutions.

Preconcentration by $\mathrm{pH}$-stacking can be carried out using modified cyclodextrins. Only a few papers reported stacking preconcentration prior to MEKC separation of neutral steroids. Quirino and colleagues (47) demonstrated up to a 280-fold stacking enhancement for steroid determination using on-line sample preconcentration that was accomplished by using stacking and sweeping under $\mathrm{pH}$-suppressed $\mathrm{EOF}$ in the presence of sulfated $\beta$ cyclodextrin. Urban and co-workers (48) studied the separation of three anabolic steroids (methyltestosterone, methandrostenolone and testosterone) using charged CD derivatives and online reverse migrating sample stacking with large-volume injection followed by 
MEKC with UV-visible absorption. The detection limits obtained for these compounds were approximately $2.8 \times 10^{-7}-5 \times 10^{-5} \mathrm{M}$ while the sensitivity enhancement factors were in the range from 100 - 190. In another report by Munro and co-workers (40) sweeping afforded detection of approximately $430 \mathrm{nM}$ estrone and estradiol (S/N 55) using a $99 \mathrm{~s}$ hydrodynamic injection of steroids in sulfated $\beta-C D$ followed by separation using an aqueous separation buffer comprising borate, phosphate, cholate, and acetonitrile. BritzMcKibbin and colleagues (49) demonstrated over a 100-fold enhancement using a dynamic $\mathrm{pH}$ junction-sweeping preconcentration with borate and $\gamma$-CD. In the present work, pH-mediated stacking of anionic steroid-CD complexes followed by MEKC provides at least a 500-fold enhancement in detection limit over hydrodynamic introduction of native steroids. The separation targets were progesterone, hydroxyprogesterone, 11-ketotestosterone, estrone, estradiol, and ethynyl estradiol. These analytes vary in CD affinity and therefore served as a model sample set to demonstrate the possibility of quantitative analysis following sample stacking by means of CD inclusion for molecules with different molecular characteristics.

The selectivity toward the targeted steroids requires a proper balance between the SDS and CD. Under reversed polarity, the androgens and progesterone used in this study migrate faster than estrogens as they have higher affinity to SDS micelles. Changes in the $\mathrm{CD}$ concentration affected the separation time and resolution. For example, using $30 \mathrm{mM}$ SDS and $18 \mathrm{mM} \mathrm{HPCD,} \mathrm{progesterone,} \mathrm{hydroxyprogesterone,} \mathrm{and} \mathrm{11-ketotestosterone} \mathrm{were}$ baseline resolved in less than 5 minutes, but the migration times of the remaining estrogens increased and the peaks broadened substantially. Running electrolyte comprised of $30 \mathrm{mM}$ 
SDS and $10 \mathrm{mM}$ HPCD degraded the resolution of progesterone, hydroxyprogesterone, and 11-ketotestosterone, but resulted in the baseline resolution of estrone, estradiol, ethynyl estradiol in under 5 minutes. The electropherogram shown in Figure 3.6 was obtained using running buffer comprised of $30 \mathrm{mM}$ SDS and $13 \mathrm{mM}$ HPCD. The run was finished in less than 5 minutes. Sample stacking with the procedure described in Section 3.2.5 was not affected by varying degree of carboxymethyl substitution, as there was no change in the overall charge for $\mathrm{CD}$ under the loading at $\mathrm{pH} 10$ no during stacking at $\mathrm{pH} 2.5$.

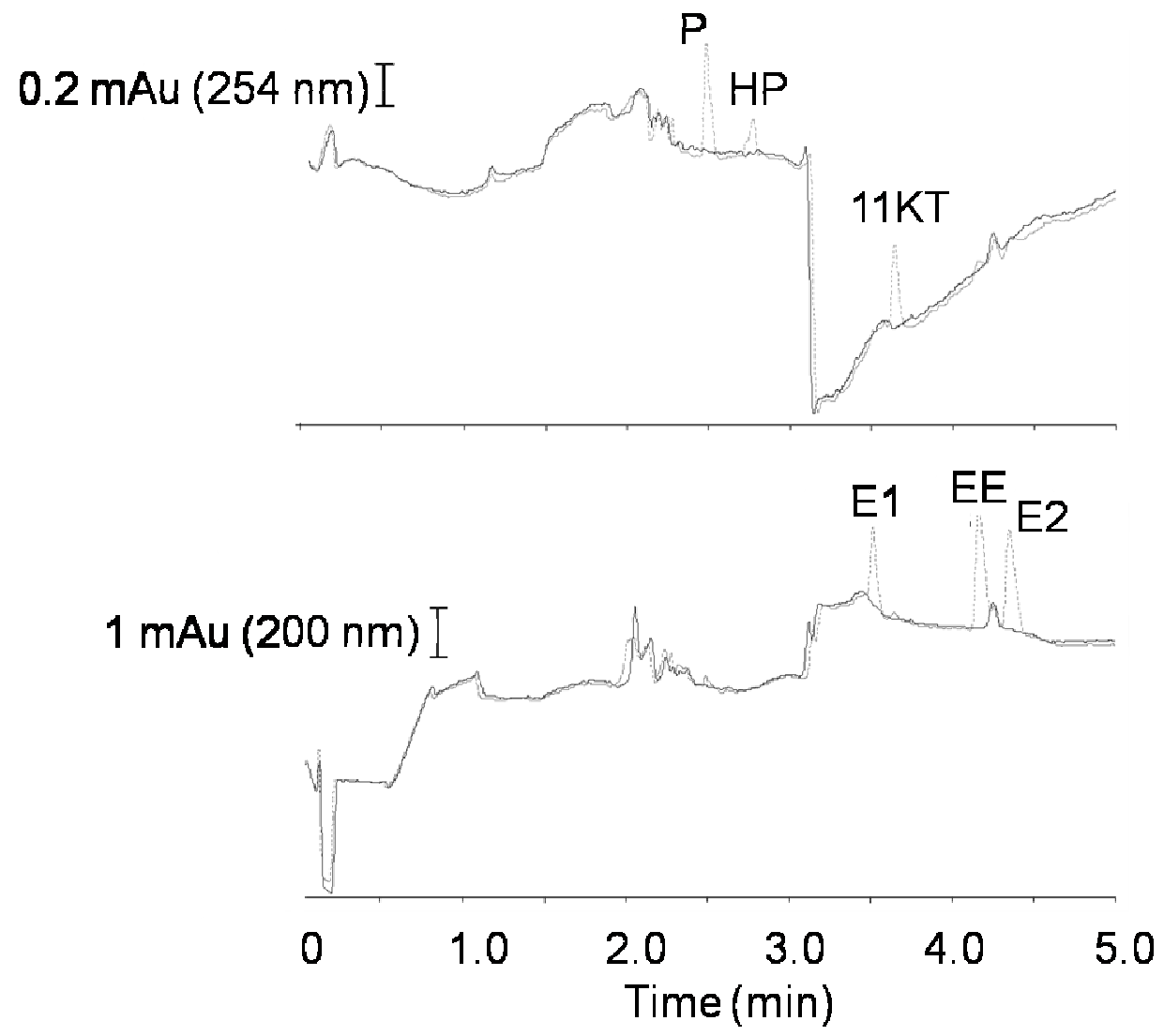

Figure 3.6 displays superimposed electropherograms resulting from stacking and separating the blank (solid) and sample containing 6 steroids (dot). Data was collected at $254 \mathrm{~nm}$ and $200 \mathrm{~nm}$. The analytes are labeled as follows: P - progesterone, HP - 17-hydroxyprogesterone, E1 - estrone, 11KT - 11-ketotestosterone, EE $17 \alpha$-ethynyl estradiol, E2 - 17 $\beta$-estradiol. Separation conditions are summarized in text. Reproduced with permission from (58). 

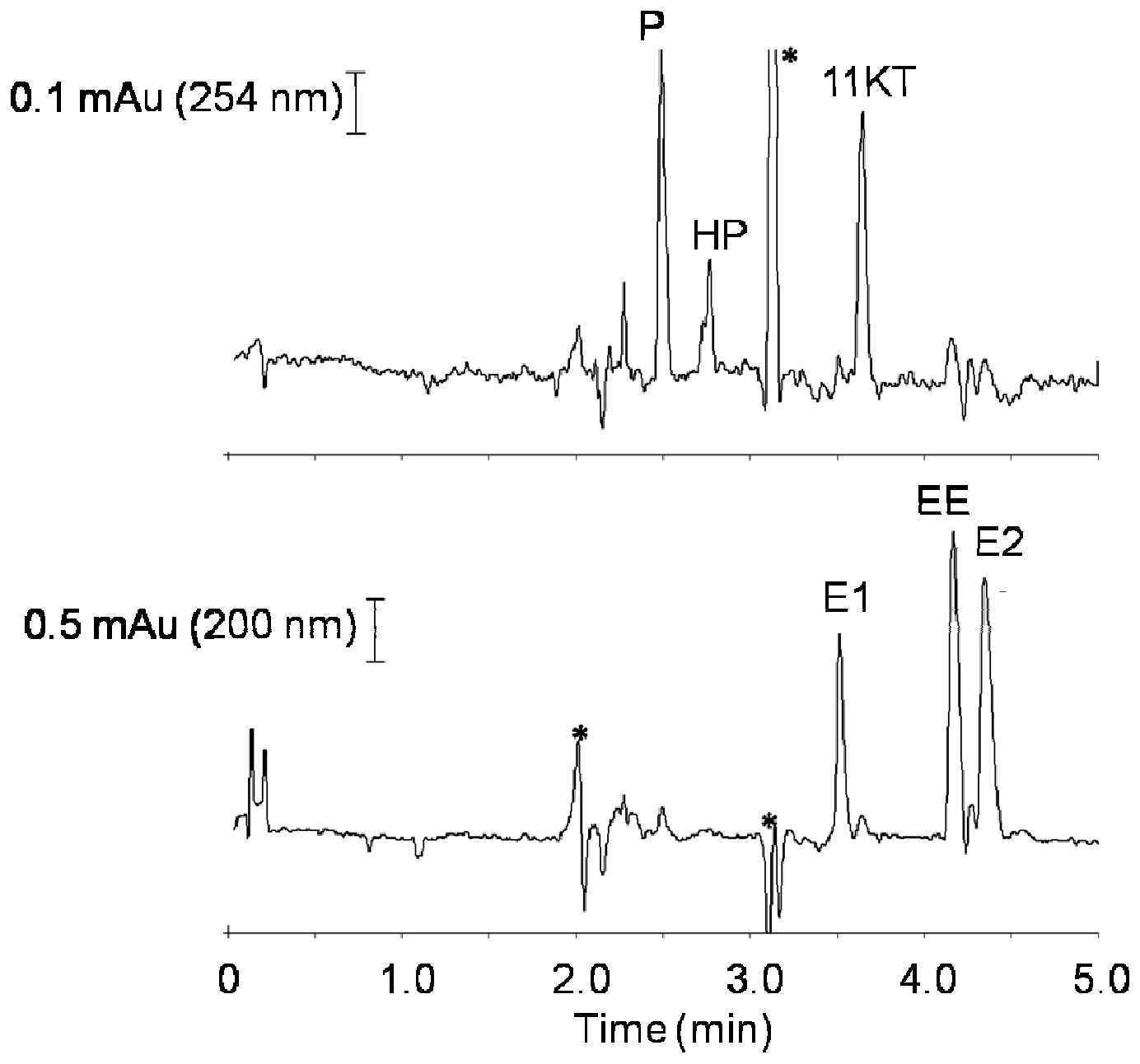

Figure 3.7 displays the background subtracted electropherograms of 6 steroids following analyte stacking. The electropherograms were collected simultaneously using PDA detection. The analytes are labeled as follows: P - progesterone, HP - 17-hydroxyprogesterone, E1 - estrone, 11KT - 11-ketotestosterone, HP 17 $\alpha$-ethynyl estradiol, E2 - 17 $\beta$-estradiol. Peaks labeled $*$ are an artifact resulting from the background subtraction. Separation conditions are outlined in text. Reproduced with permission from (58). 


\subsubsection{StaCking EFFECTED BY Conductivity of the WATER Plug}

A CE or MEKC analysis comprises three steps: (1) flushing the capillary with the separation buffer of a certain $\mathrm{pH}$; (2) the sample injection, and (3) the electrophoresis of the analytes. In $\mathrm{CE}$ the electric potential applied across the separation capillary causes the ions in the solution to migrate generating the electric current flow. The ability of an aqueous solution to conduct the electric current depends on the concentration of the salts dissolved in water and is called a conductivity. Highly concentrated solutions are more conductive than those with the lower contents of free ions and therefore less resistant. Conductivity of very dilute solutions can be described by Kohlraush law (50) which sums the conductivity contributions of all ions in the solution:

$$
\Lambda=\rho \cdot \Sigma\left(\lambda_{i} \cdot C_{i}\right)
$$

where $\Lambda$ is conductivity, $\rho$ is density of water, $\lambda_{i}$ and $c_{i}$ are equivalent ionic conductance and concentration of an ion ' $i$ ' respectively. On the other hand, the conductivity of a solution is inversely proportional to the electric filed (Equation 3.2) and to resistivity (Equation 3.3):

$$
J=\sigma \cdot E
$$

where $J$ is the current density and $E$ is the electric field strength.

$$
\sigma=\frac{1}{\rho}
$$


In order to accomplish better stacking in the present method, a water plug was introduced into the separation capillary immediately after filling it with the phosphate buffer and right before the sample injection. As a result, the low conductivity should provide an ion-vacant region to concentrate negative ions deeper into the capillary away from the injection point as well as ensure proper enhancement of the electric field at the injection point. The higher electric field, in turn, increases the electrophoretic velocity of the anionic CMCD molecules (Equation 2.1) which carry the neutral steroid analytes injected electrokinetically into the capillary water zone toward the pH-junction preconcentration boundary.

In this experiment, in the beginning of each CE run the capillary was rinsed at 172 $\mathrm{kPa}(25 \mathrm{psi})$ for 2 min with the running buffer. Then a water plug was hydrodynamically injected by $14 \mathrm{kPa}(2 \mathrm{psi})$ pressure for $13.5 \mathrm{sec}, 6 \mathrm{sec}$, and $0 \mathrm{sec}$ right before the sample injection performed for durations of time: 5, 10, 20, 40, 60, and 80 sec.

According to Fig. 3.8, stacking was not affected by the conductivity of the water plug in contrast to previous works $(51,52)$. In fact, the effectiveness of the sample stacking did not depend on the presence or the absence of the water plug in the capillary. However, to provide a small ion-free region for the stacked sample a water plug injected for $6 \mathrm{sec}$ was used in the further studies. The length of the water plug injected for $6 \mathrm{sec}$ was measured to be $5.5 \mathrm{~mm}$ or $5.4 \%$ of the effective capillary length. This measurement was conducted by injecting the water at 2 psi into the capillary containing the running buffer and measuring the migration time of the water plug to the detection window. 


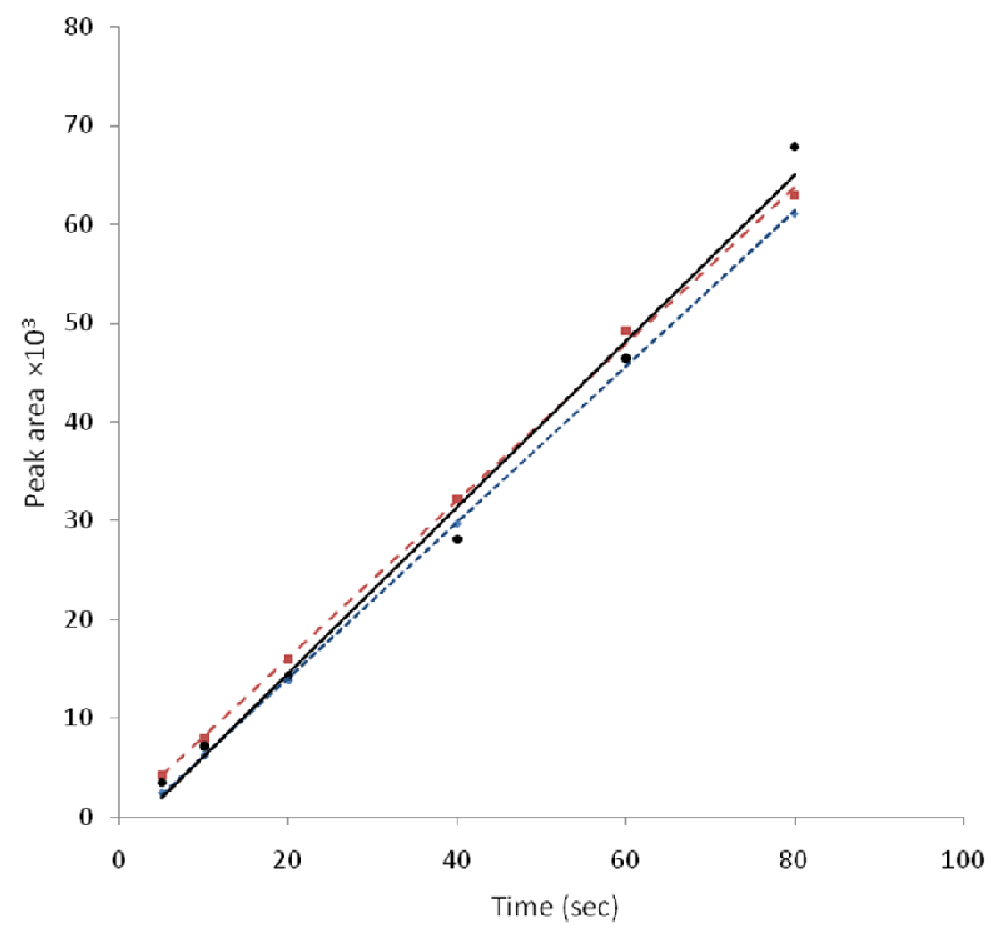

Figure 3.8. The effect of water plug on sample stacking. Plot of the peak area versus sample injection time. Sample was injected electrokinetically at $8 \mathrm{kV}$ and was $400 \mu \mathrm{M}$ ethynyl estradiol in $10 \mathrm{mM} \mathrm{CMCD}, 5 \%$ methanol, $50 \mathrm{mM}$ CAPS buffered at $\mathrm{pH} 10$. BGE was $30 \mathrm{mM}$ SDS, $10 \mathrm{mM}$ HPCD in 50mM phosphate buffered at $\mathrm{pH}$ 2.5. Separation: at $16 \mathrm{kV}$ and normal polarity. Water plug injection: $2 \mathrm{psi} 13.5 \mathrm{sec}(\ldots . . .),. 2 \mathrm{psi} 6$ $\sec (-\rightarrow)$ no plug $(\rightarrow$

\subsubsection{STACKING TIME OPTIMIZATION}

CE separation is affected by the length of the injection plug. This is because the longer the sample plug the broader the peak in the resulted electropherogram. Sample preconcentration by $\mathrm{pH}$-mediated stacking provides a way to concentrate sample molecules in a narrow zone at the boundary of two buffer solutions of different $\mathrm{pH}$ values allowing the increase of the injection time without sacrificing the efficiency. Using electrokinetic injection, charged ions can be easily introduced into the capillary as a result of their electrophoretic migration $(53,54)$. 
As mentioned earlier all CE measurements were conducted using a Beckman Coulter P/ACE MDQ capillary electrophoresis instrument (Beckman coulter, Fullerton, CA, USA). This instrument is fully automated and managed using $32 \operatorname{Karat}^{\mathrm{TM}}$ v7.0 Software. The software provides numerous control and analysis functions allowing programming various capillary electrophoresis runs. The programming option of the instrumental software allows injecting sample with the voltage of up to $10 \mathrm{kV}$ for no longer than 99.9 sec. Both options allow controlling the duration to reach the injection voltage, so called "ramp time". However, while in the separation option a desirable ramp time has to be set, the injection option compensates the ramp time automatically, therefore the precise injection time is known. In this work the injection voltage was selected to be $10 \mathrm{kV}$ as it's the highest possible voltage that can be applied by the instrument for the electrokinetic injection. However, in order to determine the optimal injection duration that would provide the best sample signal, the limited timing conditions needed to be exceeded. To increase the injection time limits the separation option available in method programming was used. With this option a sample can be injected for the infinite duration of time.

The following set of experiments uses only one steroid, ethynyl estradiol, a potential endocrine disruption compound and a component of birth control pills. The concentration of ethynyl estradiol in $1 \mathrm{mM}$ CMCD sample was $10 \mu \mathrm{M}$. The data obtained with the use of the injection option correlates with the data measured using the separation option for sample injection which is demonstrated in Figure 3.9. A 60 sec injection was chosen to be the optimal duration despite the maximum sample stacking being obtained with the injection at $10 \mathrm{kV}$ for $70 \mathrm{sec}$. The further increase in the duration time of the 
sample injection resulted in lower sample stacking. This can be due to the fact that longer injection durations can lead to the EOF formation in the water region of the capillary which will slowly drag the CMCD anions toward the cathode located at the inlet and therefore away from the $\mathrm{pH}$-junction and even out of the capillary back to the sample vial. The 70 sec injection however, resulted in the splitting of ethynyl estradiol peak due to the sample overloading. Injection plug lengths longer than the diffusion controlled zone width will proportionally broaden peak width and in extreme cases distorted peak shapes, peak broadening and peak splitting is observed (55). The appearance of the peak splitting can be due to sample overloading, or electromigration dispersion, that can occur due to the differences in the electric field between the sample and the separation buffer if the plug is too wide (56). In this study a water plug was introduced in the capillary before the sample was injected. This created a capillary region with high electric field comparing to the region of the capillary filed with the separation buffer containing SDS and HPCD. As mentioned earlier upon application of the injection voltage both anionic CMCD carrying steroids and SDS micelles present in the capillary would start moving toward the anode. However, because of the high electric filed in the water filled region, CMCD anions will migrate much faster toward the $\mathrm{pH}$-junction were they will be slowed down and preconcentrated. At the same time some steroids can exchange into micellar phase located on the other side of the $\mathrm{pH}$-junction and start moving toward the outlet. If the injection duration is short, the SDS micelles entering the capillary upon application of the separation voltage will move faster toward the stacking zone where they will catch up the micelles which have already moved toward the outlet with steroids reached the junction during the first seconds of the stacking injection. If the injection time is too long, the 
micelles entering the capillary will be separated by a longer distance from the first micellar band carrying the steroids. Therefore a split peak will appear in the resulting electropherogram.

The peak areas were used for signal quantitation as they provided longer dynamic ranges comparing to the peak heights. The increases in peak heights were not linear as the sample concentration increased due to the band broadening effects.

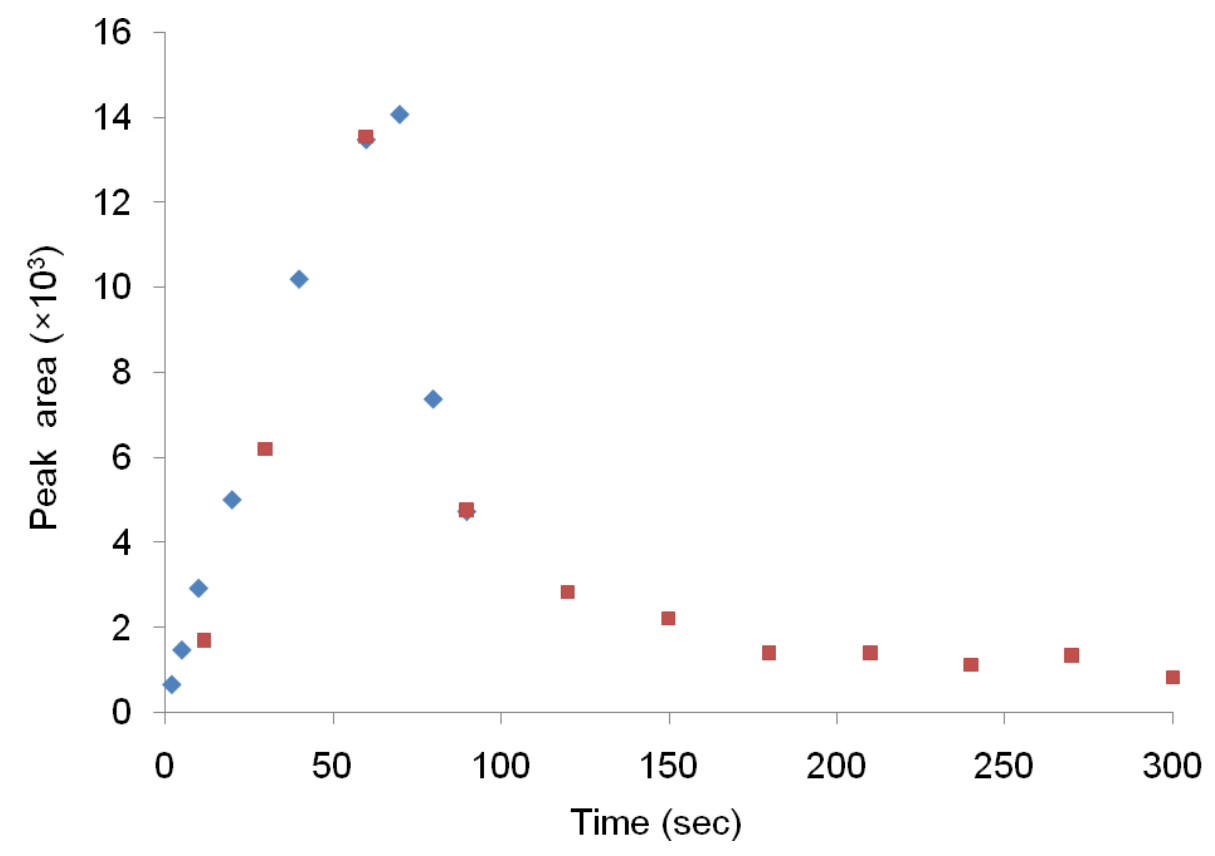

Figure 3.9. Stacking enhancement versus injection time. Sample injected electrokinetically at $10 \mathrm{kV}$ by injection (blue) and separation (red) options in the instrument method programming. Sample is $10 \mu \mathrm{M}$ ethynyl estradiol in $1 \mathrm{mM} \mathrm{CMCD}$, 5\% methanol, $50 \mathrm{mM}$ CAPS buffered at $\mathrm{pH} 10$. BGE is $30 \mathrm{mM}$ SDS, $13 \mathrm{mM}$ HPCD in 50mM phosphate buffered at $\mathrm{pH} 2.5$. Separation: at $16 \mathrm{kV}$ and normal polarity. 


\subsubsection{The Effect of CMCD Concentration on Stacking Efficiency}

The use of charged CMCD for steroid stacking is attractive as it requires no chemical derivatization of steroids. The effect of the addition of CMCD to the sample solution and its effect on the stacking enhancement are demonstrated in Figure 3.10, that plots the estradiol peak area versus CMCD concentration in the sample buffer. The studies confirmed that the maximum stacking was obtained with the use of $1 \mathrm{mM}$ carboxymethyl- $\beta-C D$. The further increase of $C M C D$ concentration decreased the signal area as seen in the Figure 3.11.

There are a few reasons for lower stacking at the higher $\mathrm{CMCD}$ concentration. 1) As the concentration of CMCD increases, there is higher chance of injecting empty CMCDs into the capillary due to their higher electrophoretic mobility comparing to those CDs carrying steroids. Therefore fewer steroids will be preconcentrated at the $\mathrm{pH}$ junction. 2) It is known from the literature that CD-steroid complex is mostly 1:1 ratio, although 2:1 complex formation can take place as well (57). If this were the case, one steroid molecule would be "locked up" by two CD molecules and this would affect the interaction with SDS micelles which serve to remove steroids from the stacking zone and carry them toward the detection window. 3) Finally, as the concentration of CD increases compared to the concentration of SDS in the running buffer, the equilibrium will be shifted toward the formation of the steroid-CD complex as discussed in Section 2.3.4 and away from incorporation into micellar phase, therefore decreasing the steroid detection response. The steroid concentration in the sample does not determine the optimal 
concentration of CMCD if increased from $500 \mathrm{nM}$ to $10 \mu \mathrm{M}$ that still provides the best stacking efficiency using $1 \mathrm{mM} \mathrm{CMCD}$. Based on these observations $1 \mathrm{mM}$ CMCD was chosen as the optimal concentration for better stacking efficiency.

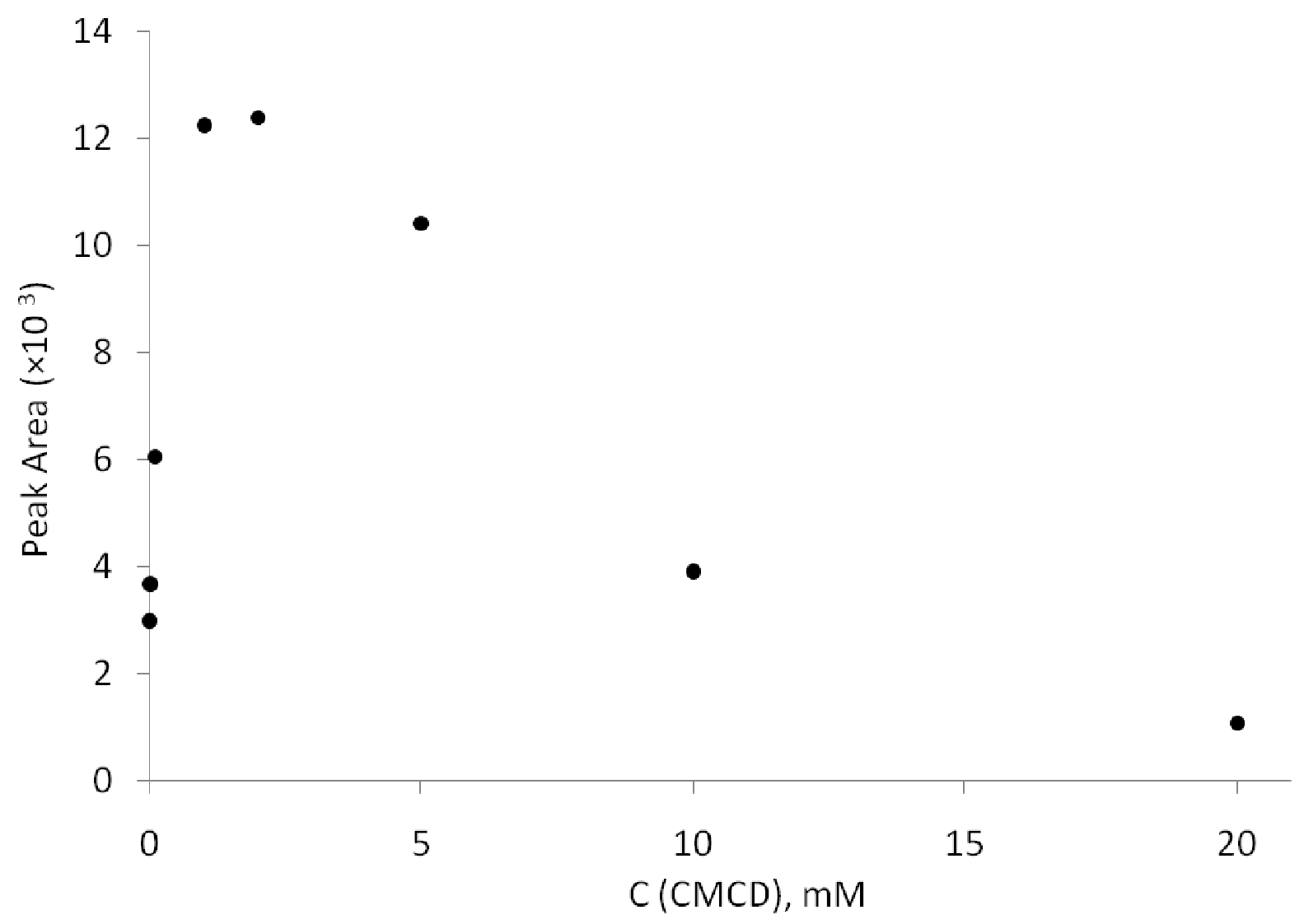

Figure 3.10. Stacking enhancement versus $\mathrm{CMCD}$ concentration in the sample buffer. Sample is $1 \mu \mathrm{M}$ estradiol in CMCD, 5\% methanol in $50 \mathrm{mM}$ CAPS, pH 10. Running buffer: $30 \mathrm{mM}$ SDS, $13 \mathrm{mM}$ HPCD in phosphate, $\mathrm{pH} 2.5$ 


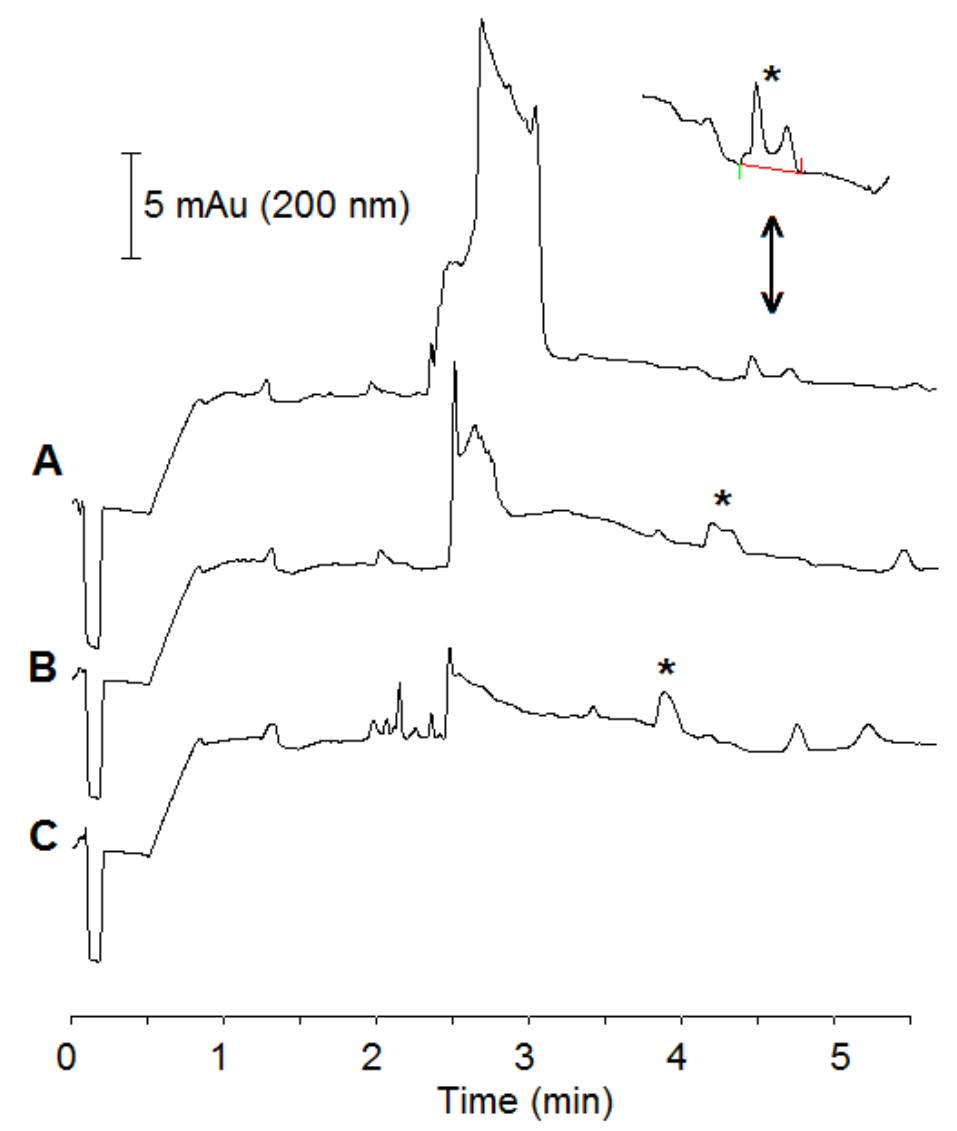

Figure 3.11. Representative electropherograms of the stacking enhancement versus CMCD concentration in the sample buffer. CMCD in the sample: A - $5 \mathrm{mM}, \mathrm{B}-2 \mathrm{mM}, \mathrm{C}-1 \mathrm{mM}$, peak labeled as * $-1 \mu \mathrm{M}$ estradiol,

\subsubsection{Stacking versus Phosphate Concentration}

Figure 3.12 shows the importance of adjusting the concentration of phosphate buffer for improving of the stacking efficiency. Since phosphate was used for the preparation of the running buffer, it was important to maintain not only a particular and constant $\mathrm{pH}$ but also a proper buffer capacity for the reproducible separation. Buffer concentration has a significant effect on the EOF because it changes the $\zeta$-potential on the capillary wall. As the concentration of the buffer increases, the ionic strength increases as well, thus lowering $\zeta$-potential and EOF. Moreover the higher the ionic strength of the 
buffer in use the more chance of getting Joule heating effect in the capillary due to high separation currents. In the present case, EOF was suppressed because the surface silanol groups were protonated at the low $\mathrm{pH}$ of the separation buffer. However, it was necessary to find out how large a phosphate concentration could be used without causing excessive Joule heating.

The separations were performed in the presence of 50,75, 100, 150, and $200 \mathrm{mM}$ phosphate buffered at pH 2.5 containing $30 \mathrm{mM}$ SDS and $13 \mathrm{mM}$ HPCD. The sample was $10 \mu \mathrm{M}$ ethynyl estradiol injected at $10 \mathrm{kV}$ for different durations of time $50,60,70,80$, and $90 \mathrm{sec}$. The use of $200 \mathrm{mM}$ phosphate produced the best stacking effect measured in the peak area as shown in the figure below. The $60 \mathrm{sec}$ sample injection was still the most advantageous since the longer sample injections produced distorted electropherograms due to peak broadening. 


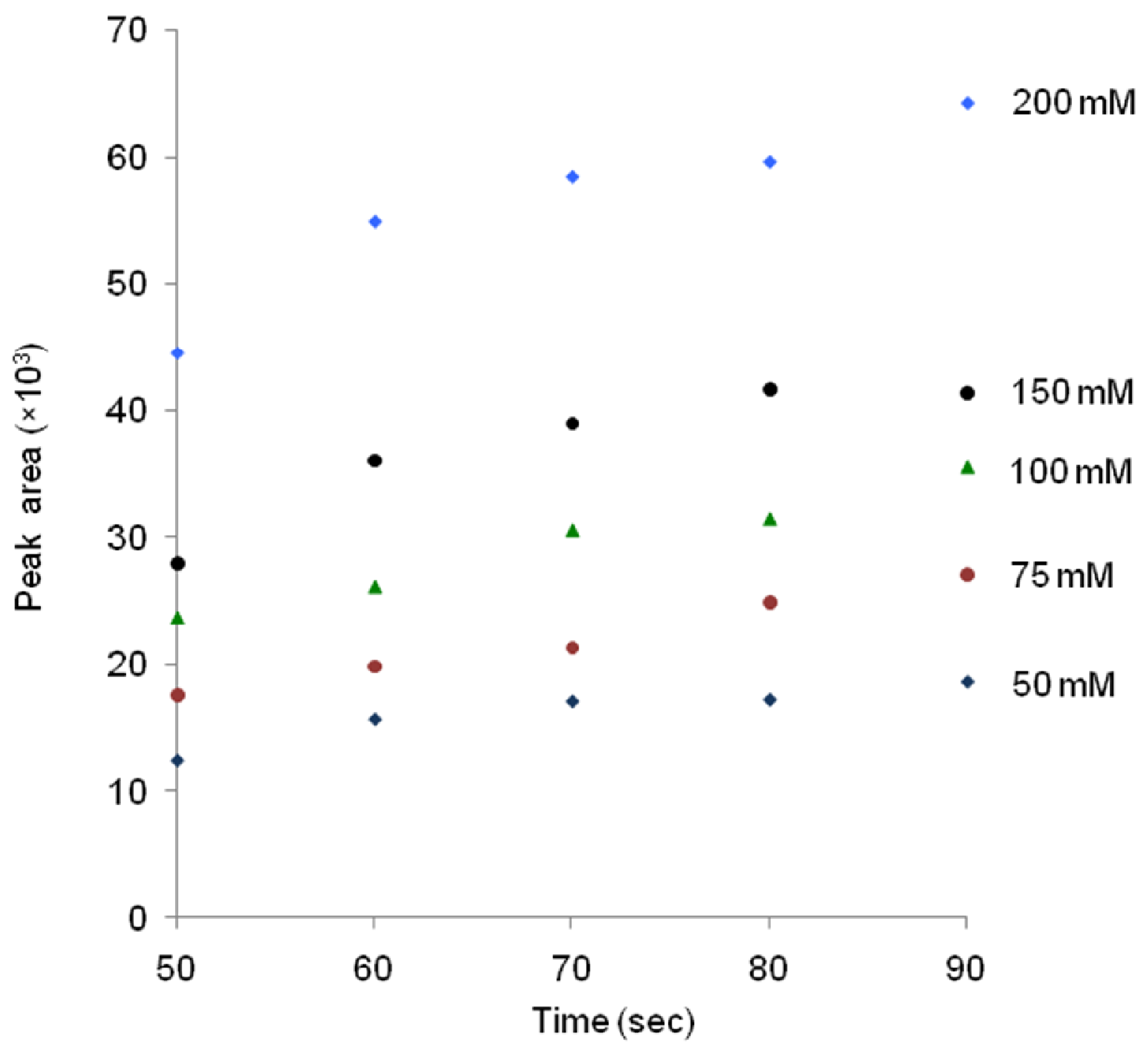

Figure 3.12. Stacking enhancement versus concentration of phosphate buffer and sample injection time. Sample injected electrokinetically at $10 \mathrm{kV}$. Sample is $10 \mu \mathrm{M}$ ethynyl estradiol in $1 \mathrm{mM} \mathrm{CMCD}$, 5\% methanol, $50 \mathrm{mM}$ CAPS buffered at $\mathrm{pH}$ 10. BGE is $30 \mathrm{mM}$ SDS, $13 \mathrm{mM}$ HPCD in phosphate buffered at $\mathrm{pH}$ 2.5. Separation: at $16 \mathrm{kV}$ and normal polarity.

\subsubsection{Stacking versus Methanol Concentration in Sample Matrix}

The effect of added methanol on stacking enhancement was investigated by increasing the volume fraction of methanol $(0.1,1,2,5,7,9,10,15,20,30,50 \%, \mathrm{v} / \mathrm{v})$ in the sample containing $1 \mu \mathrm{M}$ estradiol in $1 \mathrm{mM} \mathrm{CMCD}, 50 \mathrm{mM}$ CAPS at $\mathrm{pH} 10$. The plot of 
the peak area measured for preconcentrated estradiol versus the percentage of methanol in the sample is illustrated in Figure 3.13. It is evident that the formation of steroid-CMCD inclusion complex takes place even in the absence of methanol in the sample. The addition of $5 \%$ methanol increases the peak area by $6 \%$ versus the area for the sample without methanol. The results show that the further increase of the methanol amount in the sample shifts the equilibrium away from the formation of CMCD-steroid inclusion complex, thus, lowering the stacking efficiency.

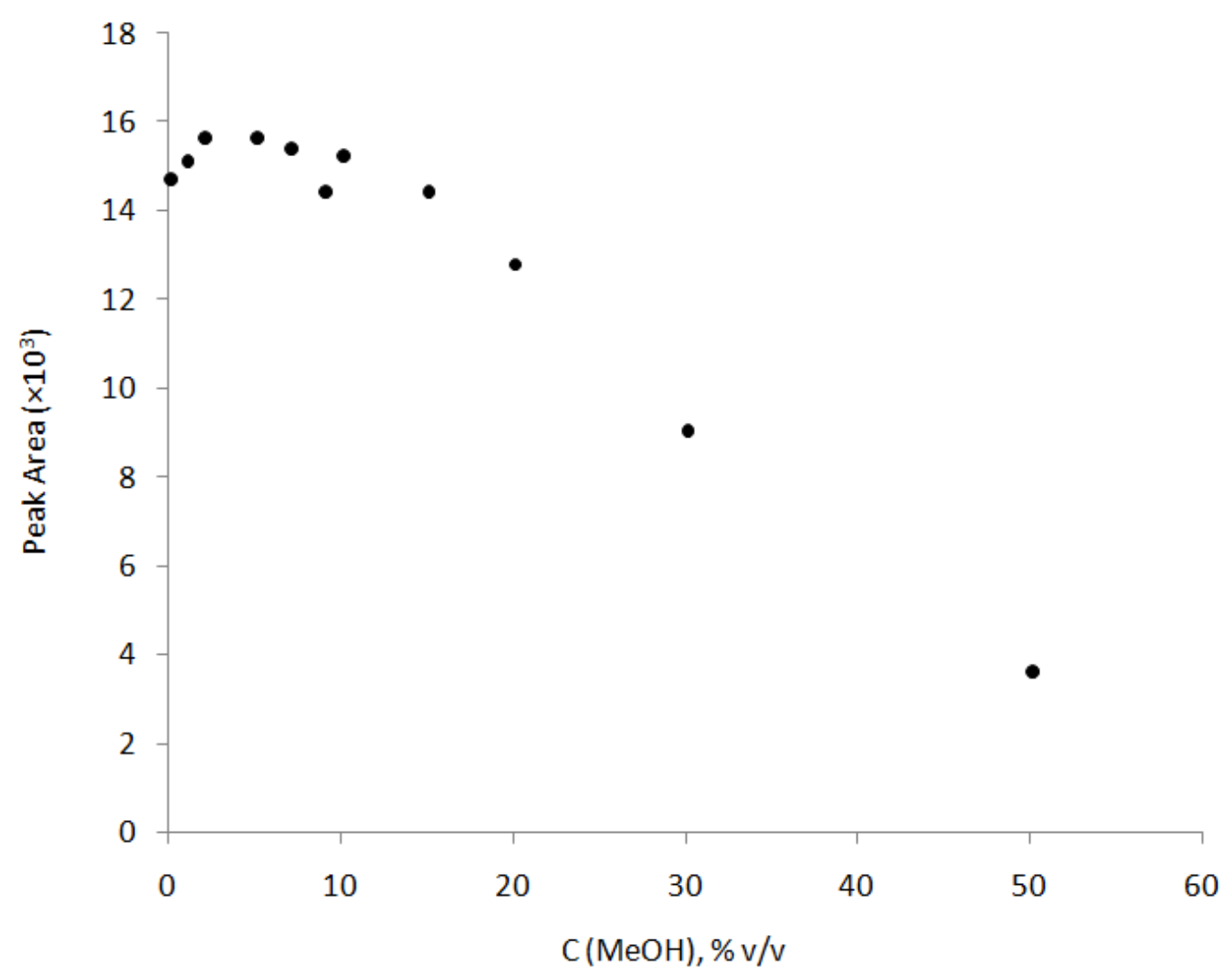

Figure 3.13. Stacking enhancement versus methanol content in the sample buffer. Sample is $1 \mu \mathrm{M}$ estradiol in $1 \mathrm{mM}$ CMCD, methanol, $50 \mathrm{mM}$ CAPS, pH 10. Running buffer: $30 \mathrm{mM}$ SDS, $13 \mathrm{mM}$ HOCD in $200 \mathrm{mM}$ phosphate, $\mathrm{pH}$ 2.5. Injection performed electrokinetically at $10 \mathrm{kV}$ for $60 \mathrm{sec}$. Separation performed at $16 \mathrm{kV}$ and normal polarity. 


\subsubsection{Stacking versus $\mathrm{pH}$ of the Sample Buffer}

An effective preconcentration by means of $\mathrm{pH}$-stacking depends on the $\mathrm{pH}$ of the buffer solutions used to create the $\mathrm{pH}$-junction and more importantly on the $\mathrm{pK}_{\mathrm{a}}$ of the analyte to be preconcentrated. As mentioned earlier, CMCD used for stacking preconcentration has $\mathrm{pK}_{\mathrm{a}} \sim 5$. From the Henderson-Hasselbalch equation:

$$
p H=p K a+\log \frac{\left[A^{-}\right]}{[H A]}
$$

CMCD is expected to be fully $(100 \%)$ deprotonated at $\mathrm{pH}=7$, and fully protonated at $\mathrm{pH}=$ 3. To completely suppress EOF, the $\mathrm{pH}$ of the running buffer must be less than 3 . Only phosphate $\left(\mathrm{pK}_{\mathrm{a}} \sim 2.1\right)$ was suitable for being used at $\mathrm{pH}<3$. The sample containing steroids was prepared in $50 \mathrm{mM}$ MOPS buffer at $\mathrm{pH} 7$ and subject to stacking procedure as described in Section 3.2.5. The results demonstrated stacking enhancement for the steroids as expected (see Fig. 3.14-A). However a 10 times better stacking enhancement was achieved using pH 10 CAPS. Figure 3.14-B, C. 


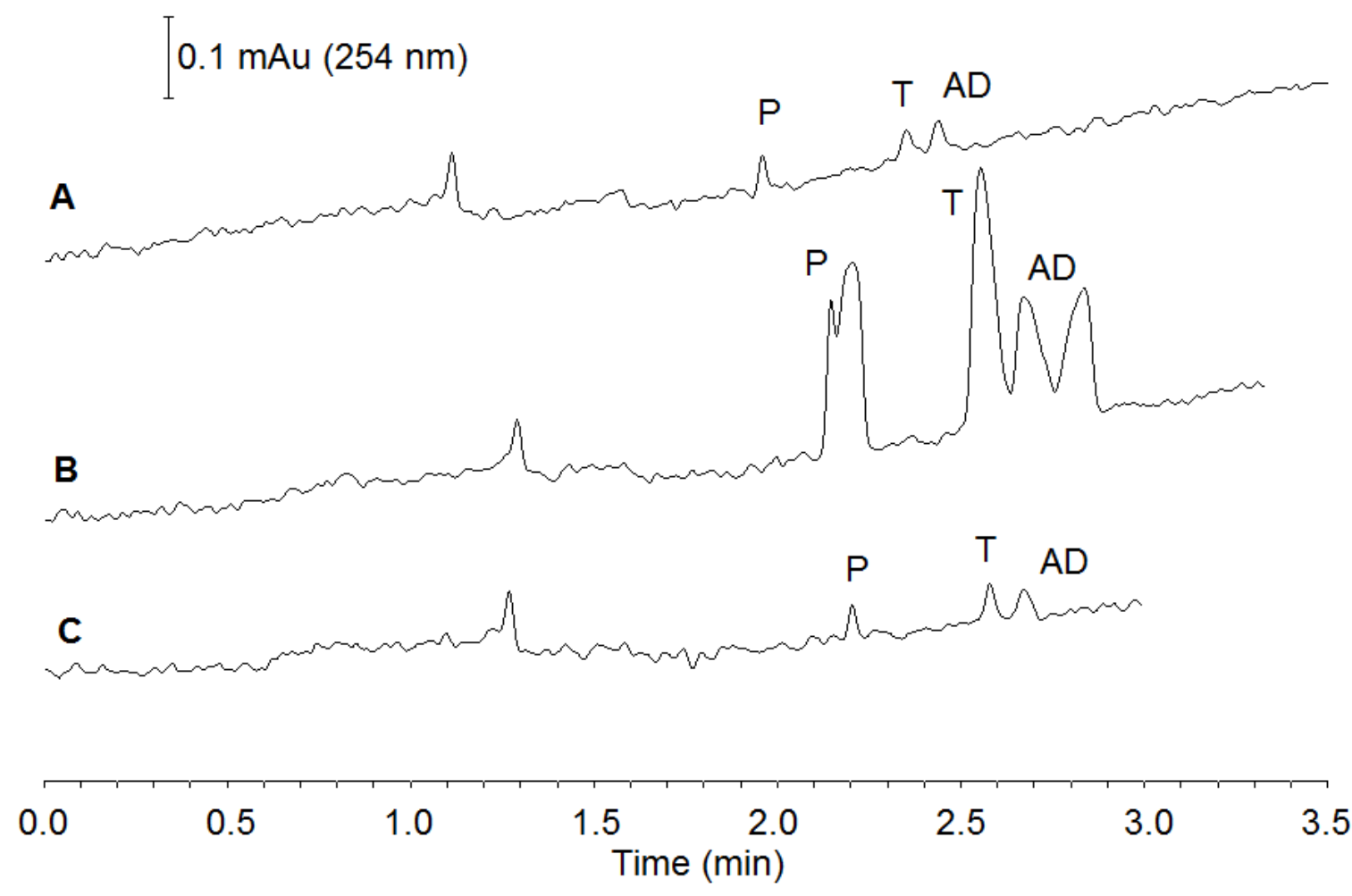

Figure 3.14. Stacking enhancement versus $\mathrm{pH}$ of the sample buffer. Sample contains $10 \mu \mathrm{M}$ progesterone, testosterone and androstenedione in $5 \%$ methanol, $1 \mathrm{mM} \mathrm{CMCD}$, and A - $50 \mathrm{mM}$ MOPS, $\mathrm{pH} 7.0$; $\mathrm{B}-50$ mM CAPS, pH 10. $\mathrm{C}$ - measured for $1 \mu \mathrm{M}$ progesterone, testosterone and androstenedione in 5\% methanol, 1 $\mathrm{mM} \mathrm{CMCD}$ in $50 \mathrm{mM}$ CAPS, pH 10. Injection performed for $60 \mathrm{sec}$ at $20 \mathrm{kV}$.

\subsubsection{Stacking Enhancement}

In capillary electrophoresis, sample injection at high injection parameters (voltage and pressure) typically leads to band broadening (2). The developed stacking method allows to use longer injection time without sacrificing separation efficiency. The advantage of the developed stacking method is demonstrated in Figure 3.15 by comparing the upper trace (stacked for 60 seconds) with the lower trace (injected electrokinetically for 2 seconds). Enhancement in limits of detection for each steroid was calculated by dividing 
the LOD obtained by means of stacking-CE by the LOD obtained with the use conventional MEKC and hydrodynamic injection.

For stacking-CE analysis the limits of detection were measured at a signal-to-noise ratio of 3. The signal and noise were determined as the peak height and the standard deviation of the baseline respectively. LODs were measured at $200 \mathrm{nM}$ progesterone $(n=9)$, $200 \mathrm{nM}$ hydroxyprogesterone ( $\mathrm{n}=6)$, and $500 \mathrm{nM}$ ketotestosterone $(\mathrm{n}=7), 50 \mathrm{nM}$ estradiol $(\mathrm{n}=9), 70 \mathrm{nM}$ estrone $(\mathrm{n}=10)$ and $70 \mathrm{nM}$ ethynyl estradiol $(\mathrm{n}=7)$. Each sample containing only one steroid was prepared in $1 \mathrm{mM} \mathrm{CMCD,} 50 \mathrm{mM}$ CAPS, $\mathrm{pH} 10$ and was analyzed by stacking-MEKC as described in Section 3.2.5. The limits of detection for conventional MEKC analysis of steroids were calculated by the same principle. A series of samples containing $50 \mu \mathrm{M}$ concentration of each steroid were prepared in the running buffer (30 $\mathrm{mM}$ SDS, $13 \mathrm{mM}$ HPCD in phosphate, $\mathrm{pH} 2.5,5 \%$ methanol) and injected at 0.5 psi for 3 sec. The peak areas were measured and used for stacking enhancement evaluation. The calculated enhancements in limits of detection are represented in Table 3.2. The stackingMEKC method demonstrated at least 350-fold up to 1100-fold improvement in LODs over the conventional hydrodynamic injection. 


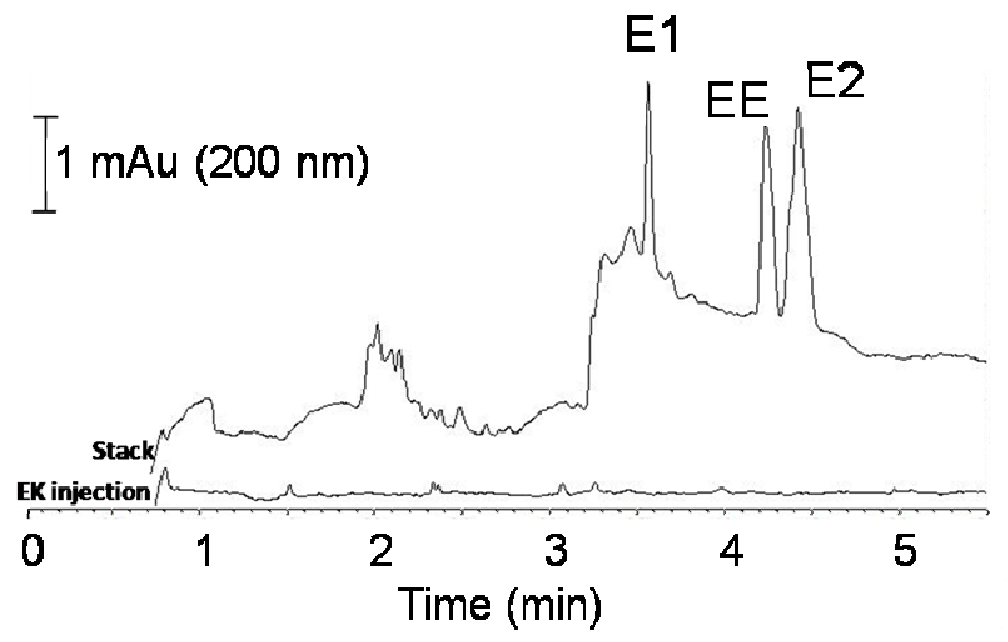

Figure 3.15. Sample containing $500 \mathrm{nM}$ estrone (E1), ethynyl estradiol (EE), and estradiol (E2) is injected at $10 \mathrm{kV}$, for $60 \mathrm{~s}$ (upper trace) or $2 \mathrm{~s}$ (lower trace) in $1 \mathrm{mM}$ carboxymethyl- $\beta$-CD diluted in $50 \mathrm{mM}$ CAPS buffered at $\mathrm{pH}$ 10. The electropherogram is obtained using $30 \mathrm{mM}$ SDS, $13 \mathrm{mM} \mathrm{HPCD}, 200 \mathrm{mM}$ phosphate buffered at $\mathrm{pH} 2.5$. Reproduced with permission from (58).

Table 3.2. Enhancement in limits of detection for steroids measured by stacking-CE injected electrokinetically versus conventional MEKC with hydrodynamic injection.

\begin{tabular}{lllll}
\hline & Steroid & $\begin{array}{l}\text { LOD }_{\text {ave }} \\
(\text { STACK })\end{array}$ & $\begin{array}{l}\text { LOD } \\
(\mathrm{MEKC})\end{array}$ & $\begin{array}{l}\text { LOD } \\
\mathrm{nM}\end{array}$ \\
& & $\mathrm{nM}$ & \\
\hline 1 & progesterone & 7.1 & 5.3 & 746 \\
2 & hydroxyprogesterone & 15 & 5.3 & 353 \\
3 & dihydroxyprogesterone & 11 & 4.7 & 427 \\
4 & testosterone & 4 & 3.5 & 875 \\
5 & estrone & 3.1 & 2.1 & 677 \\
6 & 11-ketotestosterone & 14 & 5.9 & 421 \\
7 & ethynyl estradiol & 4.7 & 2.2 & 468 \\
8 & estradiol & 2.9 & 3.2 & 1103 \\
\hline
\end{tabular}

For experimental conditions see text. 


\subsubsection{Stacking Figures of Merit}

This section outlines the figures of merit that demonstrate the effectiveness of the developed and optimized stacking approach. Figures of merit (Table 3.3) were obtained using a $10 \mathrm{kV} 60$ second stacking injection and a separation buffer containing $13 \mathrm{mM}$ HPCD, $30 \mathrm{mM}$ SDS in $200 \mathrm{mM}$ phosphate buffered at $\mathrm{pH} 2.5$. The baseline in the electropherograms that results from sample stacking had some distortion (see for example Figure 3.7). The data shown in Figure 3.7 were obtained from successive runs of a sample and blank and subsequently processed using a spreadsheet program.

For all steroids, the within-day and day-to-day reproducibility in migration time was $\leq 1 \%$ RSD and $\leq 2 \%$ RSD, respectively. The within-day and day-to-day reproducibility in peak area was $\leq 9 \%$ and $\leq 22 \% \mathrm{RSD}$, respectively. The day-to-day reproducibility was affected by the variations in room temperature from 20 to $24{ }^{\circ} \mathrm{C}$, which changes the solubility of the steroid in carboxymethyl- $\beta$-CD. Although a dedicated thermostat was not available at the time of measurements, the use of calibration curves within-day almost completely circumvents this issue due to reasonable temperature stability during the day.

Linear ranges were determined from nine calibration curves ( 3 per day for 3 days) and measured at $0.50 \mu \mathrm{M}$ hydroxyprogesterone, estrone, ethynyl estradiol and estradiol, $0.75 \mu \mathrm{M}$ progesterone, 11-ketotestosterone. The curves were measured simultaneously for 6 analytes. Detection was performed by UV-visible absorbance at detection wavelength of $254 \mathrm{~nm}$ for progesterone $\left(\mathrm{R}^{2} \geq 0.98\right)$, hydroxyprogesterone $\left(\mathrm{R}^{2} \geq 0.97\right)$, and ketotestosterone $\left(R^{2} \geq 0.99\right)$, or $200 \mathrm{~nm}$ for estradiol $\left(R^{2} \geq 0.99\right)$, estrone $\left(R^{2} \geq 0.98\right)$, and 
ethynyl estradiol $\left(\mathrm{R}^{2} \geq 0.99\right)$. The data from individual curve fitting are shown in Table 3.3. Under the experimental conditions, calibration curves for steroids with high $\beta$-CD affinity (estradiol, ethynyl estradiol, and estrone) are easily obtained in the range from 250 10,000 nM. Progesterone, 11-ketotestosterone, and hydroxyprogesterone were measured at $254 \mathrm{~nm}$ to maximize absorbance. By using a photodiode array, all steroids were detected within a single run. The different detection wavelength and lower $\beta$-CD affinity of progesterone, 11-ketotestosterone, and hydroxyprogesterone resulted in higher limits of detection and a smaller concentration range of linear response. Finally, hydroxyprogesterone formed a split peak, especially at higher concentrations. This splitting of hydroxyprogesterone may result from stereoisomers or from multiple complexation equilibria with carboxymethyl- $\beta-C D$.

Table 3.3. Stacking - MEKC Figures of Merit

\begin{tabular}{|c|c|c|c|c|c|c|}
\hline \multirow{3}{*}{ Steroid } & \multirow{3}{*}{ LOD (nM) } & \multirow{3}{*}{$\begin{array}{l}\text { Linear } \\
\text { Range }(\mu \mathbf{M})\end{array}$} & \multicolumn{4}{|c|}{ Reproducibility } \\
\hline & & & \multicolumn{2}{|c|}{ Within day $(n=10)$} & \multicolumn{2}{|c|}{ Day-to-day $(n=3)$} \\
\hline & & & Time (min) & $\operatorname{Area}(\mathbf{x 1 0})^{3}$ & Time (min) & Area $\left.(\mathbf{x 1 0})^{3}\right)$ \\
\hline progesterone & $7.1 \pm 0.7$ & $0.25-1.0$ & $2.47 \pm 0.01$ & $1.3_{8} \pm 0.0_{7}$ & $2.49 \pm 0.02$ & $1.3_{6} \pm 0.0_{5}$ \\
\hline $\begin{array}{l}\text { hydroxy- } \\
\text { progesterone }\end{array}$ & $15 \pm 1$ & $0.25-0.75$ & $2.74 \pm 0.02$ & $0.81 \pm 0.05$ & $2.77 \pm 0.04$ & $0.78 \pm 0.03$ \\
\hline estrone & $3.1 \pm 0.8$ & $0.25-5.0$ & $3.55 \pm 0.03$ & $5.2 \pm 0.5$ & $3.61 \pm 0.06$ & $5.5 \pm 0.9$ \\
\hline $\begin{array}{l}\text { 11-keto } \\
\text { testosterone }\end{array}$ & $14 \pm 3$ & $0.50-10$ & $3.68 \pm 0.03$ & $1.5 \pm 0.1$ & $3.74 \pm 0.07$ & $1.2 \pm 0.3$ \\
\hline ethynyl estradiol & $4.7 \pm 0.4$ & $0.25-10$ & $4.21 \pm 0.03$ & $7.6 \pm 0.5$ & $4.30 \pm 0.08$ & $7.9 \pm 0.4$ \\
\hline $17 \beta$-estradiol & $2.9 \pm 0.6$ & $0.25-5.0$ & $4.39 \pm 0.04$ & $8.9 \pm 0.5$ & $4.5 \pm 0.1$ & $8.8 \pm 0.2$ \\
\hline
\end{tabular}




\section{CONCLUSIONS}

A preconcentration technique using the chromatographic preconcentrator positioned in-capillary for enhancement of the detection limits for steroid analysis by $\mathrm{CE}$ has been demonstrated. The benefit of this preconcentration approach is the possibility to inject a much larger sample volume opposed to conventional $\mathrm{CE}$ or MEKC while maintaining a high efficiency separation. However, the technical limitations of this method, the resulting low reproducibility and very sophisticated packing procedure preclude its application in systematic and high throughput screening of steroid hormones required to detect endocrine disruption.

In contrast, a newly developed $\mathrm{pH}$-mediated stacking MEKC method for the preconcentration of selected sex steroid hormones demonstrated outstanding performance and stacking efficiency exceeding two orders of magnitude with targeted steroids. The analysis of parameter space revealed that the increased amount of CMCD and methanol in the sample buffer result in lower stacking efficiency. However, the high concentration of the running buffer improves the stacking. The within-day and day-to-day reproducibility of this method, and the low limits of detection justify its promise for the determination of steroids in fish plasma samples which will be presented in chapter 4.

\section{BIBLIOGRAPHY}

1. Rasmussen, H. T.; McNair, H. M. Influence of Buffer Concentration, Capillary Internal Diameter and Forced Convection on Resolution in Capillary Zone Electrophoresis. J. Chromatogr. 1990, 516 (1), 223-231. 
2. Landers, J. P., Ed., Handbook of Capillary and Microchip Electrophoresis and Associated Microtechniques, 3rd ed.; CRC Press: NW, 2007; pp 7-21.

3. Gas, B.; Stedry, M.; Kenndler, E. Peak Broadening in Capillary Zone Electrophoresis. Electrophoresis 1997, 18 (12-13), 2123-2133.

4. Cheng, Y. F.; Dovichi, N. J. Subattomole Amino Acid Analysis by Capillary Zone Electrophoresis and Laser - Induced Fluorescence. Science 1988, 242 (4878), 562-564.

5. Kuhr, W. G.; Yeung, E. S. Optimization of Sensitivity and Separation in Capillary Zone Electrophoresis with Indirect Fluorescence Detection. Anal. Chem. 1988, 60 (23), 2642-2646.

6. Wallingford, R. A.; Ewing, A. G. Capillary Zone Electrophoresis with Electrochemical Detection. Anal. Chem. 1987, 59 (14), 1762-1766.

7. Holland, L. A.; Lunte, S. M. Capillary Electrophoresis Coupled to Electrochemical Detection: a Review of Recent Advances. Anal. Commun. 1998, 35 (2), 1H-4H.

8. Wu, J. T.; Huang, P.; Li, M. X.; Qian, M. G.; Lubman, D. M. Open-Tubular Capillary Electrochromatography with an On-Line Ion Trap Storage/Reflectron Time-of-Flight Mass Detector for Ultrafast Peptide Mixture Analysis. Anal. Chem. 1997, 69 (3), 320-326.

9. Ptolemy, A. S.; Le Bihan, M.; Britz-McKibbin, P. On-Line Sample Preconcentration with Chemical Derivatization of Bacterial Biomarkers by Capillary Electrophoresis: A Dual Strategy for Integrating Sample Pretreatment with Chemical Analysis. Electrophoresis 2005, 26 (21), 4206-4214.

10. Moring, S. E.; Reel, R. T.; van Soest, R. E. J. Optical Improvements of a Z - Shaped Cell for HighSensitivity UV Absorbance Detection in Capillary Electrophoresis. Anal. Chem. 1993, 65 (23), 34543459.

11. Heiger, D. N.; Kaltenbach, P.; Sievert, H.-J. Diode Array Detection in Capillary Electrophoresis. Electrophoresis 1994, 15 (10), 1234-1247.

12. Nozal, L.; Arce, L.; Simonet, B. M.; Rios, A.; Valcarcel, M. In-Line Liquid-Phase Microextraction for Selective Enrichment and Direct Electrophoretic Analysis of Acidic Drugs. Electrophoresis 2007, 28 (18), 3284-3289. 
13. Palmarsdottir, S.; Thordarson, E.; Edholm, L.-E.; Joensson, J.; Mathiasson, L. Miniaturized Supported Liquid Membrane Device for Selective Online Enrichment of Basic Drugs in Plasma Combined with Capillary Zone Electrophoresis. Anal. Chem. 1997, 69 (9), 1732-1737.

14. Rodriguez, R.; Pico, Y.; Font, G.; Manes, J. Determination of Urea-Derived Pesticides in Fruits and Vegetables by Solid-Phase Preconcentration and Capillary electrophoresis. Electrophoresis 2001, 22 (10), 2010-2016.

15. Rundlett, K. L.; Armstrong, D. W. Mechanism of Signal Suppression by Anionic Surfactants in Capillary Electrophoresis-Electrospray Ionization Mass Spectrometry. Anal. Chem. 1996, 68 (19), 3493-3497.

16. Britz-Mckibbin, P.; Ichihashi, T.; Tsubota, K.; Chen, D. D. Y.; and Terabe, S. Complementary On-Line Preconcentration Strategies for Steroids by Capillary Electrophoresis. J. Chromatogr., A 2003, 1013, 6576.

17. Breadmore, M. C.; Thabano, J. R. E.; Dawod, M.; Kazarian, A. A.; Quirino, J. P.; Guijt, R. M. Recent Advances in Enhancing the Sensitivity of Electrophoresis and Electrochromatography in Capillaries and Microchips (2006-2008). Electrophoresis 2009, 30 (1), 230-248.

18. Zhang, C.-X.; Thormann, W. Head-Column Field - Amplified Sample Stacking in Binary System Capillary Electrophoresis: A Robust Approach Providing over 1000-Fold Sensitivity Enhancement. Anal. Chem. 1996, 68 (15), 2523-2532.

19. Chien, R. L.; Burgi, D. S. Field Amplified Sample Injection in High-Performance Capillary Electrophoresis. J. Chromatogr. 1991, 559, 141-152.

20. Stegehuis, D. S.; Irth, H.; Tjaden, U. R.; Van der Greef, J. Isotachophoresis as an On-Line Concentration Pretreatment Technique in Capillary Electrophoresis. J. Chromatogr. 1991, 538, 393-402.

21. Chien, R. L.; Burgi, D. S. Sample Stacking of an Extremely Large Injection Volume in HighPerformance Capillary Electrophoresis. Anal. Chem. 1992, 64, 1046-1050.

22. Quirino, J. P.; Kim, J.-B.; Terabe, S. Sweeping: Concentration Mechanism and Applications to High Sensitivity Analysis in Capillary Electrophoresis. J. Chromatogr., A 2002, 965 (1-2), 357-373.

23. Petersson, M.; Wahlund, K.-G.; Nilsson, S. Miniaturized On-Line Solid-Phase Extraction for Enhancement of Concentration Sensitivity in Capillary Electrophoresis. J. Chromatogr., A 1999, 841 (2), 249-261. 
24. Hoyt, A. M., Jr.; Beale, S. C.; Larmann, J. P., Jr.; Jorgenson, J. W. Preparation and Evaluation of an Online Preconcentrator for Capillary Electrophoresis. J. Microcolumn Sep. 1993, 5 (4), 325-330.

25. Claessens, H. A.; van Straten, M. A.; Kirkland, J. J. Effect of Buffers on Silica-Based Column Stability in Reversed-Phase High-Performance Liquid Chromatography. J. Chromatogr., A 1996, $728(1+2)$, $259-270$.

26. Douhal, A., Ed. Cyclodextrin Materials Photochemistry, Photophysics and Photobiology. In Chemical, Physical and Biological Aspects of Confined Systems, 1st ed.; Elsevier Science, 2006; Vol. 1.

27. Steed, J. W.; Atwood, J. L. Supramolecular Chemistry, 2nd ed.; John Wiley \& Sons, U. K., 2009; pp 327-335.

28. Wenz, G. An Overview of Host - Guest Chemistry and its Application to Nonsteroidal AntiInflammatory Drugs. Clin. Drug Investig. 2000, 19 (Suppl. 2), 21-25.

29. Saenger, W.; Steiner, T. Cyclodextrin Inclusion Complexes: Host - Guest Interactions and HydrogenBonding Networks. Acta Crystallogr., A: Found. Crystallogr. 1998, 54 (6, Pt. 1), 798-805.

30. Terekhova, I. V.; Kulikov, O. V. Cyclodextrins: Physical-Chemical Aspects of Formation of Complexes "Host - Guest" and Molecular Selectivity in Relation to Biologically Active Compounds. Chemistry of Polysaccharides 2005, 38-76.

31. Fakayode, S. O.; Lowry, M.; Fletcher, K. A.; Huang, X.; Powe, A. M.; Warner, I. M. Cyclodextrins Host - Guest Chemistry in Analytical and Environmental Chemistry. Curr. Anal. Chem. 2007, 3 (3), 171-181.

32. Khan, A. R.; Forgo, P.; Stine, K. J.; D'Souza, V. T. Methods for Selective Modifications of Cyclodextrins. Chem. Rev. 1998, 98 (5), 1977-1996.

33. Rekharsky, M. V.; Mayhew, M. P.; Goldberg, R. N.; Ross, P. D.; Yamashoji, Y.; Inoue, Y. Thermodynamic and Nuclear Magnetic Resonance Study of the Reactions of $\alpha$ - and $\beta$-Cyclodextrin with Acids, Aliphatic Amines, and Cyclic Alcohols. J. Phys. Chem. B 1997, 101 (1), 87-100.

34. Matsui, Y.; Mochida, K. Binding Forces Contributing to the Association of Cyclodextrin with Alcohol in an Aqueous Solution. Bull. Chem. Soc. Jpn. 1979, 52 (10), 2808-2814.

35. Fujiwara, H.; Arakawa, H.; Murata, S.; Sasaki, Y. Solvation Effect on Reactions in Solution. II. Entropy Changes in the Inclusion Complex Formation of $\alpha$-Cyclodextrin with Alcohols as Studied by the Titration Calorimetry. Bull. Chem. Soc. Jpn. 1987, 60 (11), 3891-3894. 
36. Sanemasa, I.; Osajima, T.; Deguchi, T. Association of C5-C9 Normal Alkanes with Cyclodextrins in Aqueous Medium. Bull. Chem. Soc. Jpn. 1990, 63 (10), 2814-2819.

37. Harrison, J. C.; Eftink, M. R. Cyclodextrin-Adamantanecarboxylate Inclusion Complexes: a Model System for the Hydrophobic Effect. Biopolymers 1982, 21 (6), 1153-1566.

38. Tabushi, I.; Kiyosuke, Y.; Sugimoto, T.; Yamamura, K. Approach to the Aspects of Driving Force of Inclusion by $\alpha$-Cyclodextrin. J. Am. Chem. Soc. 1978, 100 (3), 916-919.

39. Pitha, J.; Milecki, J.; Fales, H.; Pannell, L.; Uekama, K. Hydroxypropyl- $\beta$ - Cyclodextrin: Preparation and Characterization; Effects on Solubility of Drugs. Int. J. Pharm. 1986, 29 (1), 73-82.

40. Munro, N. J.; Palmer, J.; Stalcup, A. M.; Landers, J. P. Charged Cyclodextrin-Mediated Sample Stacking in Micellar Capillary Electrophoresis. A Simple Method for Enhancing the Detection Sensitivity of Hydrophobic Compounds. J. Chromatogr., B: Biomed. Sci. Appl. 1999, 731 (2), 369-381

41. Forgacs, E.; Cserhati, T. Study of the Interaction of Some Steroidal Drugs with Cyclodextrin Derivatives. Anal. Lett. 2004, 37 (9), 1897-1908.

42. Shakalisava, Y.; Regan, F. Determination of Association Constants of Inclusion Complexes of Steroid Hormones and Cyclodextrins From Their Electrophoretic Mobility. Electrophoresis 2006, 27 (15), 3048-3056.

43. Kano, K.; Horiki, Y.; Mabuchi, T.; Kitagishi, H. Heptakis(2,3-di-O-carboxymethyl)- $\beta$-Cyclodextrin as a pH-Sensitive Host. Chem. Lett. 2004, 33 (9), 1086-1087.

44. Osbourn, D. M.; Weiss, D. J.; Lunte, C. E. On-Line Preconcentration Methods for Capillary Electrophoresis. Electrophoresis 2000, 21 (14), 2768-2779.

45. Chien, R.-L. Sample Stacking Revisited: A Personal Perspective. Electrophoresis 2003, 24 (3), $486-$ 497.

46. Mala, Z.; Krivankova, L.; Gebauer, P.; Bocek, P. Contemporary Sample Stacking in CE: a Sophisticated Tool Based on Simple Principles. Electrophoresis 2007, 28 (1-2), 243-253.

47. Quirino, J. P.; Terabe, S.; Otsuka, K.; Vincent, J. B.; Vigh, G. Sample Concentration by Sample Stacking and Sweeping Using a Microemulsion and a Single-Isomer Sulfated $\beta$-Cyclodextrin as Pseudostationary Phases in Electrokinetic Chromatography. J. Chromatogr., A 1999, 838 (1 + 2), 3-10. 
48. Urban, P. L.; Garcia-Ruiz, C.; Garcia, M. A.; Marina, M. L. Separation and Online Preconcentration by Multistep Stacking with Large-Volume Injection of Anabolic Steroids by Capillary Electrokinetic Chromatography Using Charged Cyclodextrins and UV-Absorption Detection. J. Sep. Sci. 2005, 28 (16), 2200-2209.

49. Britz-McKibbin, P.; Ichihashi, T.; Tsubota, K.; Chen, D. D. Y.; Terabe, S. Complementary On-Line Preconcentration Strategies for Steroids by Capillary Electrophoresis. J. Chromatogr., A 2003, 1013 (1-2), 65-76.

50. Hittorf, J. W.; Wilhelm, F.; Faraday, M. Eds. The Fundamental Laws of Electrolytic Conduction, 1st ed.; BiblioBazaar: Charleston, SC, 2008; pp 84-93.

51. Quirino, J. P.; Otsuka, K.; Terabe, S. Online Concentration of Neutral Analytes for Micellar Electrokinetic Chromatography. VI. Stacking Using Reverse Migrating Micelles and a Water Plug. $J$. Chromatogr., B: Biomed. Sci. Appl. 1998, 714 (1), 29-38.

52. Huaifang, F.; Fangxing, Y.; Junling, S.; Zhaorui, Z.; Ying, X. Pressure-Assisted Field-Amplified Sample Injection with Reverse Migrating Micelles for Analyzing Trace Steroids in MEKC. Electrophoresis 2007, 28 (20), 3697-3704.

53. Rose, D. J., Jr.; Jorgenson, J. W. Characterization and Automation of Sample Introduction Methods for Capillary Zone Electrophoresis. Anal. Chem. 1988, 60 (7), 642-648.

54. Huang, X.; Gordon, M. J.; Zare, R. N. Bias in Quantitative Capillary Zone Electrophoresis Caused by Electrokinetic Sample Injection. Anal. Chem. 1988, 60 (4), 375-377.

55. Chen, X.; Xie, J.; Li, C.; Hu, Z.; Chen, X. Investigation of the Factors that Induce Analyte Peak Splitting in Capillary Electrophoresis. J. Sep. Sci. 2004, 27 (12), 1005-1010.

56. Ermakov, S. V.; Zhukov, M. Y.; Capelli, L.; Righetti, P. G. Experimental and Theoretical Study of Artifactual Peak Splitting in Capillary Electrophoresis. Anal. Chem. 1994, 66, 4034-4042.

57. Lahiani-Skiba, M.; Barbot, C.; Bounoure, F.; Joudieh, S.; Skiba, M. Solubility and Dissolution Rate of Progesterone- Cyclodextrin -Polymer Systems. Drug Dev. Ind. Pharm. 2006, 32 (9), 1043-1058.

58. Bykova, L.; Holland, L. A. Stacking Enhanced Determination of Steroids by CE. Electrophoresis 2008, 29 (18), 3794-3800. 


\section{CHAP T E R 4}

\section{MODIFICATION OF THE METHOD \\ FOR ANALYSIS OF FISH PLASMA}




\subsection{INTRODUCTION}

In the previous chapter, a newly developed $\mathrm{pH}$-mediated stacking MEKC method for analysis of sex steroid hormones was evaluated using aqueous solutions prepared from steroid standards, and demonstrated reproducible performance and low limits of detection. To fully demonstrate the applicability and efficiency of the method in endocrine disruption studies, it was required to apply the method to real-life samples such as wild fish blood or plasma. Two major challenges in this analysis are the small volume of the fish plasma and the presence of interfering compounds, which obstruct the CE separation.

The fish have long been used as biosentinel models of water quality in biological studies, mainly because of the concerns associated with the increased production, use, and disposal of chemicals in the environment (1-3). Both, the wild fish and the fish exposed to pollutants in a laboratory can provide valuable information for studying the effects of endocrine disruption. The fish acquires EDCs via the gills, skin, and the diet, including plants and smaller invertebrates, which in turn accumulate pollutants from the water or sediments during their lifecycle. The physiological system of the fish is similar to mammals, including humans, and many of the pollutant-induced disorders are likely to have similar effects. The reproductive endocrine system is particularly similar within the vertebrates (4). Furthermore, the accumulation of pollutants in the muscle of the edible fish has clear implication for the human health.

Recent effort has focused on the "environmental estrogens" - industrial chemicals that may mimic natural estrogens. EDCs affect the estrogen receptor in the fish, as well as the metabolism or catabolism of sex steroids, thus primarily disrupting the fertility of the 
fish. Suppressed reproduction and signs of feminization in the male fish, as well as sexual dimorphism (differences in the body appearance based on sex), are mainly due to estrogenic hormones such as $17 \beta$-estradiol, estrone, and ethynyl estradiol, or hormone mimics $(5,6)$. The concentration of estrogenic steroids in the aquatic environment ranges from $0.010 \mathrm{ng} / \mathrm{L}$ to $7.0 \mathrm{ng} / \mathrm{L}(7,8)$. Steroid estrogens can be harmful for the fish at a concentration as low as $2.0 \mathrm{ng} / \mathrm{L}(9)$.

Several factors must be considered when using fish to test for effects of EDCs. The temperature, photoperiod, diet, availability of spawning substrates, proximity and reproductive readiness of the potential mates, and the water quality all affect the reproductive status, ovulation, and spawning in fish (2). Seasonal and daily changes in sex hormone levels must be considered in sampling schemes because there can also be a significant contribution of extrinsic factors, such as the stress from capture, handling and confinement which have a rapid effect on the sex hormone levels in the fish blood plasma (10). The fish species desirable for EDC analysis should be easy to breed and handle in the laboratory, readily available year round, widespread, and economically feasible. Finally, it is important to choose species with the well-studied reproductive biology.

Endocrine disruption in fish can be monitored using physical and chemical biomarkers. Disrupted fertility of fish can be evaluated by the number and viability of the eggs, fertilization, the survival of the offspring, the physiological abnormalities in size and growth, and histology (the anatomical study of the microscopic structure of animal tissue). Vitellogenin has been used as a biomarker for exposure to anti-estrogenic compounds in several fish studies (11-16). Vitellogenesis is the process in which the vitellogenin, a 
female egg protein, is synthesized by the liver in response to endogenous estrogen and then absorbed by growing oocytes, where it provides nutrition for the developing embryos (17). Plasma vitellogenin concentrations increase during sexual maturation of female fish (18), and can reach tens of milligrams per milliliter in some species. In contrast, the concentration of the endogenous estrogen in male fish is too low to trigger the expression of the vitellogenin gene therefore very little vitellogenin can be detected in male fish (19). However, vitellogenesis can be induced if the male fish is exposed to various concentrations of natural and synthetic estrogens present in water (20). For example, $0.1 \mathrm{ng} / \mathrm{L}$ of $17 \alpha$-ethinylestradiol can cause a significant increase in the plasma vitellogenin concentration after a relatively brief exposure $(21,22)$. Although the high levels of vitellogenin can be related to endocrine disruption, it is essential to control the levels of sex steroid hormones in plasma. This can determine whether the high concentrations of vitellogenin in male or immature female fish were caused by exogenous EDCs and not by the endogenous secretion of $17 \beta$-estradiol, and whether the presence of estrogenic EDCs had a negative effect on endogenous steroid secretion (23).

It has been mentioned earlier that the reproduction in teleost, as in vertebrates, is controlled by the brain-pituitary-gonodal axis (Section 1.1.4.). In male teleost, 11ketotestosterone and testosterone are the most important androgens that control a variety of reproductive processes (24-27). Estradiol, in turn, is the primary female estrogen in charge of gonodal development while $\alpha, \beta$-dihydroxyprogesterone is responsible for final maturation of teleost oocytes $(28,29)$. The four steroids were therefore selected to help 
identify and study the occurrence of intersex triggered by endocrine disruption and to monitor reproduction in the fish.

In the present chapter, the complex composition of the plasma samples required the development of a sample purification procedure for steroid extraction prior to the stacking preconcentration and CE separation. Four different fish species: catfish (Ictalurus punctatus), smallmouth bass (Micropterus dolomieu), largemouth bass (Micropterus salmoides), and yellow perch (Perca flavescens) were used in order to ensure that method can handle the differences in the blood samples from different fish. An improved three-step extraction procedure, introduced here for the first time, allows for the separation of the endogenous steroids from fatty acids and highly lipophilic interferences such as cholesterol prior to CE-analysis. The method is applicable for volume-limited plasma samples.

Finally, the optimized sample preparation procedure followed by $\mathrm{pH}$-mediated stacking MEKC was applied to the analysis of endogenous steroids in plasma of the yellow perch (Perca flavescens) captured from natural aquatic environments. The results were obtained with an external standard calibration curve and compared to the results measured by means of the standard addition method. The developed method was validated by measuring the recoveries of the standard steroids added to fish plasma before extraction. The steroid levels quantified in yellow perch plasma were also measured and compared to radioimmunoassay method as a reference method. 


\subsection{EXPERIMENTAL}

\subsubsection{CHEMICALS AND MATERIALS}

CMCD, SDS, 3-[cyclohexylamino]-1-propanesulfonic acid (CAPS), 11ketotestosterone, and testosterone were purchased from Sigma-Aldrich (St. Louis, MO, USA). HPCD was purchased from VWR (West Chester, PA, USA). Steroids, $\alpha, \alpha-$ dihydroxyprogesterone, $\alpha, \beta$-dihydroxyprogesterone, 17 $\beta$-estradiol were purchased from Steraloids, Inc (Newport, RI, USA). Sodium phosphate monobasic salt was purchased from Fisher Scientific (Fair Lawn, NJ, USA). Methanol was purchased from EMD Chemicals (San Diego, CA, USA). Ethyl acetate was purchased from Mallinckrodt (ACS grade, Phillipsburg, NJ, USA). MOPS was purchased from Alfa Aesar (Ward Hill, MA, USA). Deionized water was purified using ELGA Purelab Ultra (Lowell, MA, USA). Buffered solutions were prepared as described in Section 3.2.1. Standard stock solution of each sex steroid hormone was prepared and stored as described in Section 3.2.1. Stock samples were diluted to a desired concentration each day prior to use with the proper buffer. The running electrolyte and the samples to be analyzed were prepared fresh every day prior to use. The sample buffer comprised of $1 \mathrm{mM} \mathrm{CMCD}, 5 \%$ methanol in $50 \mathrm{mM}$ CAPS, pH 10. The running buffer comprised of $30 \mathrm{mM}$ SDS, $13 \mathrm{mM}$ HPCD in $200 \mathrm{mM}$ phosphate, $\mathrm{pH} 2.5$.

\subsubsection{INSTRUMENTATION}

All CE measurements were carried out using a Beckman Coulter P/ACE MDQ capillary electrophoresis instrument (Beckman coulter, Fullerton, CA, USA) equipped with 
a photodiode array UV-visible absorbance detection system as described in Section 3.2.2. The separations were performed in a $25 \mu \mathrm{m}$ id, $360 \mu \mathrm{m}$ od, $30 \mathrm{~cm}$ long fused silica separation capillary (Polymicro Technologies, LLC, Phoenix, AZ, USA) with the detection window positioned $10.2 \mathrm{~cm}$ from the cathodic reservoir located at the sample inlet. The separations were conducted at $25 \pm 1{ }^{\circ} \mathrm{C}$. To prevent the disruption in the separation current during the electrophoresis all vials containing freshly made running buffers and samples were subject to vacuum degassing for short periods of time: 1 min for $1 \mathrm{~mL}$ vial or $15 \mathrm{sec}$ for $250 \mu \mathrm{L}$ vials. Ultrasonication was also used for this purpose when it was necessary.

\subsubsection{CE SEPARATION}

$\mathrm{CE}$ separations preceded by $\mathrm{pH}$-stacking preconcentration were performed as described in Chapter 3, Section 3.2.5. Briefly, steroid standards prepared in $1 \mathrm{mM} \mathrm{CMCD}$, $5 \%$ methanol in $50 \mathrm{mM}$ CAPS buffered at $\mathrm{pH} 10$ were injected electrokinetically at $10 \mathrm{kV}$ for $60 \mathrm{sec}$ in silica fused capillary filled with the running buffer and containing the deionized water plug injected before the sample introduction at $13.8 \mathrm{kPa}(2 \mathrm{psi})$ for $6 \mathrm{sec}$. The running buffer comprised of $30 \mathrm{mM}$ SDS, $13 \mathrm{mM}$ HPCD in $200 \mathrm{mM}$ phosphate buffered to $\mathrm{pH} 2.5$. Following the sample loading, the reverse polarity run at $16 \mathrm{kV}$ was initiated to accomplish the separation of the steroids.

\subsubsection{FISH BLOOD/PLASMA SAMPLES}

All blood and plasma samples of the fish used in this work were generously provided by our colleagues Christy Foran, and Jennifer Stueckle from WVU Department of Biology; Kristine Willett of the University of Mississippi; Luke R. Iwanowicz and 
Vicki S. Blazer from U.S. Geological Survey Leetown Science Center, Kearneysville, WV. Whole blood is a bodily fluid that flows through the heart, arteries, veins, and capillaries carrying nourishment, electrolytes, hormones, vitamins, antibodies, heat, and oxygen to the tissues of an organism. Blood contains red blood cells, white blood cells, and platelets suspended in fluid called plasma. Plasma is obtained by separating the liquid portion of blood from the cells and constitutes about $55 \%$ of blood volume. Plasma contains $90 \%$

of water, the rest $10 \%$ constitute albumin (the major protein constituent), fibrinogen (responsible for the clotting of blood), globulins, glucose, mineral ions, hormones and carbon dioxide. Frozen plasma is plasma frozen within hours after being collected in order to preserve clotting factors, stored for one to seven years, and thawed before used for research or medical purposes (30).

\subsubsection{Plasma Collection by USGS}

Plasma collection was performed by Luke R. Iwanowicz of USGS, and is described briefly here. During early March 2008 yellow perch were collected from the Choptank or Severn Rivers (U.S. state of Maryland) during their spring spawning run. Fyke nets were deployed for fish capture and checked daily. Yellow perch were removed from the nets and transported to the US Fish \& Wildlife Service, Chesapeake Bay Field Office (Annapolis, MD) for processing. Fish were maintained at the USGS laboratory in aerated water from the collection site for transport and prior to plasma sample collection. The fish were euthanized with a lethal dose of tricaine methane sulphonate (Finquel MS222) (Argent Labs, Redmond, WA). The blood was drawn from the caudal vessels from each fish with a heparinized syringe, transferred to a heparinized vacutainer, and stored 
on wet ice. The plasma was collected by centrifuging the vacutainers at $1000 \times \mathrm{g}$ for 20 min at $4{ }^{\circ} \mathrm{C}$. The plasma was removed and stored at $-80{ }^{\circ} \mathrm{C}$ in cryovials. While vitellogenin (an egg-yolk precursor protein) concentrations were not measured in 2008 female fish, the fish collected during the same time in 2007 had measurable vitellogenin concentrations ranging from $2-10 \mathrm{mg} / \mathrm{mL}$.

\subsubsection{Plasma PREtreatment Protocol \# 1}

Ethyl acetate was employed to extract free steroid hormones prior to CE separation as the first step of the plasma sample pretreatment. For this experiment the whole blood sample of the female wild catfish (Ictalurus punctatus) frozen for 6 years was used. The steroids were extracted from the blood using ethyl acetate similar to a procedure described in (22). Briefly, $250 \mu \mathrm{L}(0.28 \mathrm{~g})$ of thawed blood was extracted three times with $750 \mu \mathrm{L}$ of

ethyl acetate. This was accomplished by agitating the sample using a vortex mixer for 5 sec, then spinning it for $5 \mathrm{~min}$ at $4,000 \mathrm{rpm}$ and $4{ }^{\circ} \mathrm{C}$ followed by the removal of the top organic fraction. The three ethyl acetate fractions were pooled, evaporated to dryness under the stream of nitrogen gas, and reconstituted in the sample buffer containing $1 \mathrm{mM}$ CMCD, $5 \%$ methanol in $50 \mathrm{mM}$ CAPS buffered at $\mathrm{pH} 10$. A flow chart of the extraction protocol with ethyl acetate is illustrated in Figure 4.1. The reconstituted extract was then preconcentrated using $\mathrm{pH}$-stacking and analyzed by CE-UV-visible absorbance detection analysis as described above Section 3.2.5. 


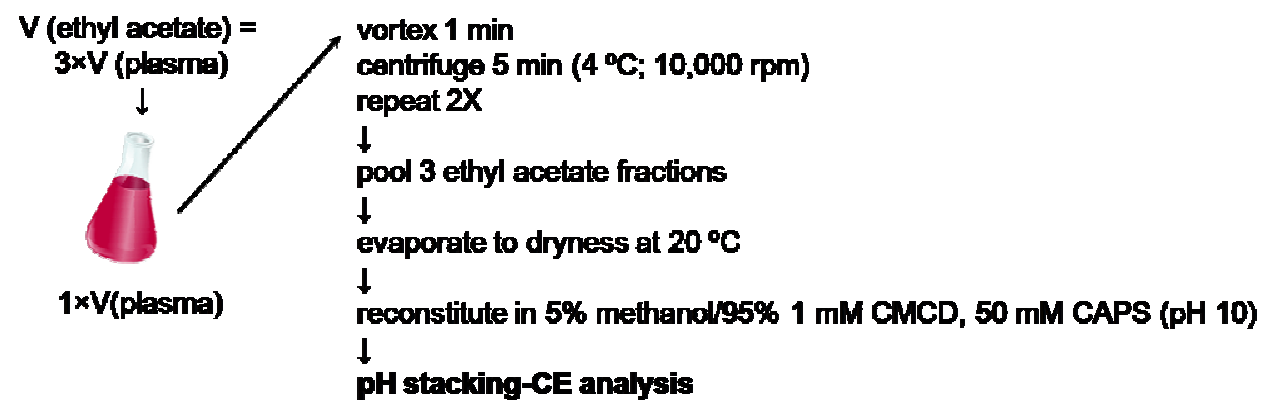

Figure 4.1. Flow chart of the plasma extraction protocol \#1.

\subsubsection{Plasma Pretreatment Protocol \#2}

The ethyl acetate extracts of fish plasma samples were further purified by strong anion exchange extraction cartridges. In the experiment, a plasma sample from a single catfish was split into two fractions each at $412 \mu \mathrm{L}$ in volume. Only one of the two fractions was spiked with 14 ng estradiol (50. pmol). Both fractions were then extracted three times with ethyl acetate (as described in Section 4.2.6). For each sample the three ethyl acetate fractions were pooled, evaporated to dryness under the stream of nitrogen gas, and reconstituted in a solution comprised of 5\% methanol, 95\% aqueous 5mM MOPS buffered at $\mathrm{pH}$ 7.0. To facilitate the removal of the fatty acids collected in the extract, the solution was then loaded on a disposable quaternary amine $\left(\mathrm{N}^{+}\right)$strong anion exchange (SAX) cartridge (BAKERBOND speTM Quaternary Amine disposable extraction columns, J.T. Baker, Phillipsburg, NJ, USA) activated twice by consecutive washes with 6 $\mathrm{mL}$ of methanol, $6 \mathrm{~mL}$ of water and $6 \mathrm{~mL}$ of $5 \mathrm{mM}$ MOPS buffered at $\mathrm{pH} 7.0$ (see Fig. 4.2). A quaternary amine is a strong base and exists as a positively-charged cation that exchanges or sequesters anionic species in the solution. It can therefore be used to isolate and discard them. The $\mathrm{pK}_{\mathrm{a}}$ of a bonded quaternary amine functional group is very high (> 
14) and leaving it charged at all pHs when in contact with an aqueous solution. For an anionic compound of interest, the $\mathrm{pH}$ of the matrix must be $2 \mathrm{pH}$ units above its $\mathrm{pK}_{\mathrm{a}}$ for it to be charged. Therefore, to extract fatty acids $\left(\mathrm{pK}_{\mathrm{a}} \sim 5\right)$ a buffer solution of $\mathrm{pH} 7$ was used. Following introduction of the sample, the column was rinsed with $1 \mathrm{~mL}$ of solution comprised of $5 \%$ methanol, $95 \%$ aqueous $5 \mathrm{mM}$ MOPS buffered at $\mathrm{pH}$ 7.0. The eluted fraction was evaporated to dryness using a rotary evaporator and reconstituted in $50 \mu \mathrm{L}$ of the solution comprised of $5 \%$ methanol, $23 \mathrm{mM} \mathrm{CMCD,} 50 \mathrm{mM}$ CAPS buffered at $\mathrm{pH}$ 10. The sample was preconcentrated and analyzed by CE as described in Section 3.2.5.

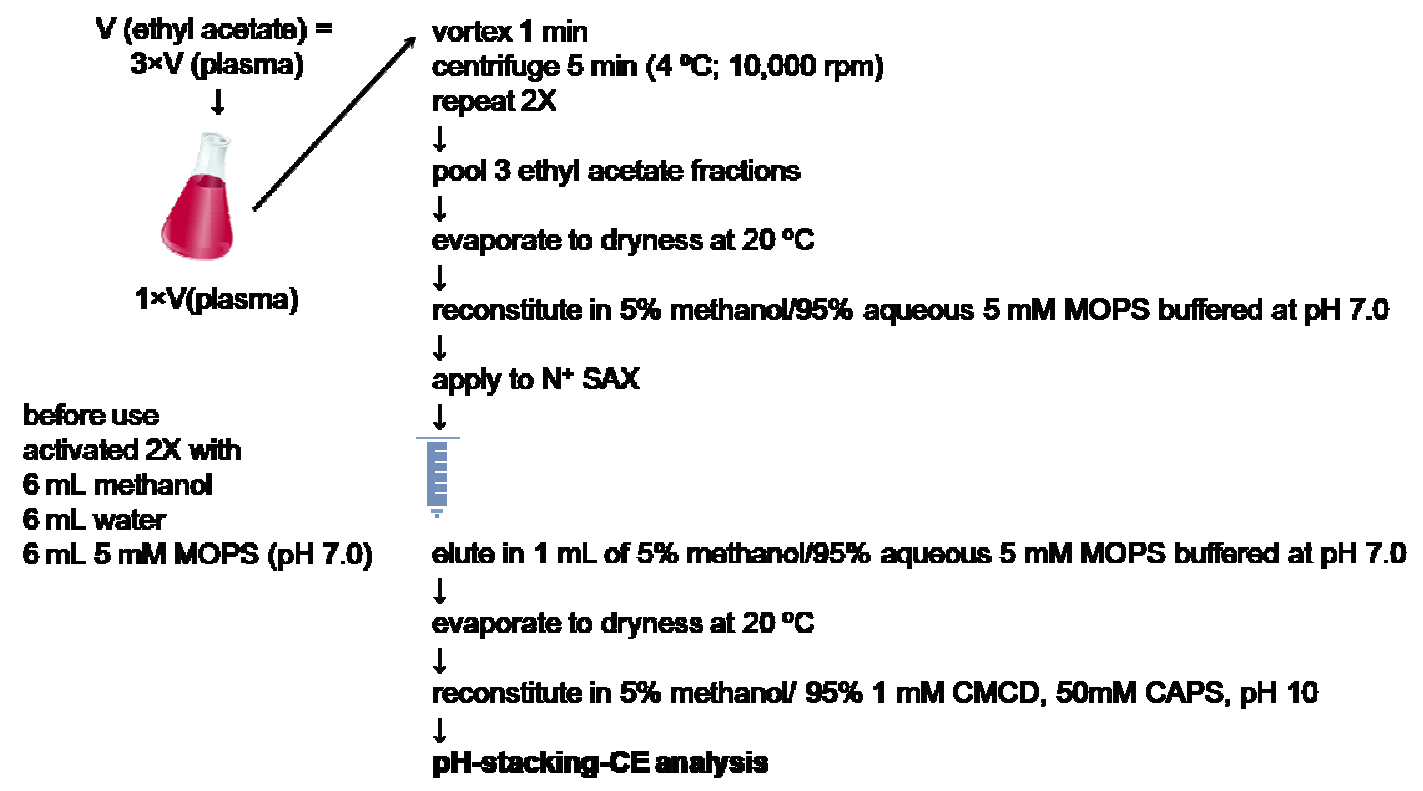

Figure 4.2. Flow chart of the plasma extraction protocol \#2.

\subsubsection{Plasma Pretreatment Protocol \#3}

For this study plasma samples from bass and yellow perch were used. An aliquot of a thawed plasma sample was split in half. Only one half was spiked with a 
gravimetrically determined amount of steroids, $2.7 \mathrm{ng}$ of estradiol and $14 \mathrm{ng}$ of testosterone. Each fraction was transferred into a separate borosilicate glass vial and extracted with the volume of ethyl acetate that is three times larger than the sample volume. After adding ethyl acetate, the solution was mixed for 1 min using a vortex mixer and then centrifuged for $5 \mathrm{~min}$ at $10,000 \mathrm{rpm}$ and $4{ }^{\circ} \mathrm{C}$. The organic fraction was then removed. Extraction was repeated two more times, and three ethyl acetate extracts were pooled together and evaporated to dryness at room temperature using a Savant SpeedVac ${ }^{\circledR}$ concentrator. Each dry extract, spiked and unspiked, was reconstituted in the solution comprised of methanol: 5mM aqueous MOPS buffered at pH 7.0 (20:80, v/v). The solution was loaded on a quaternary amine disposable extraction column (BAKERBOND spe sM $^{\mathrm{TM}}$ Quaternary Amine disposable extraction columns, J.T. Baker, Inc., Phillipsburg, NJ, USA) to remove fatty acids extracted with ethyl acetate. Before use, the ion exchange column was activated twice by consecutive washes with $6 \mathrm{~mL}$ of methanol, $6 \mathrm{~mL}$ of water and $6 \mathrm{~mL}$ of $5 \mathrm{mM}$ MOPS buffered at $\mathrm{pH}$ 7.0. The column with the loaded sample was washed with $1 \mathrm{~mL}$ of methanol: $5 \mathrm{mM}$ aqueous MOPS buffered at pH 7.0 (20:80, v/v). The eluted solution was then loaded onto a C18 extraction column (Supelco Discovery DSC-18 SPE tube bed, Sigma Aldrich, St. Louis, MO, USA), activated in advance twice with $5 \mathrm{~mL}$ of methanol and $5 \mathrm{~mL}$ of water. The column was then washed with $1 \mathrm{~mL}$ of water, and the retained steroids were eluted with $1 \mathrm{~mL}$ of methanol: water $(75: 25, \mathrm{v} / \mathrm{v})$ solution. The eluted fraction was evaporated to dryness at room temperature using the SpeedVac ${ }^{\circledR}$ concentrator. The dry sample was finally reconstituted into 30 microliters of solution comprising $5 \%$ methanol, $1 \mathrm{mM} \mathrm{CMCD}$ in 
$50 \mathrm{mM}$ CAPS buffered at pH 10, and finally analyzed by pH-stacking MEKC (see Fig.

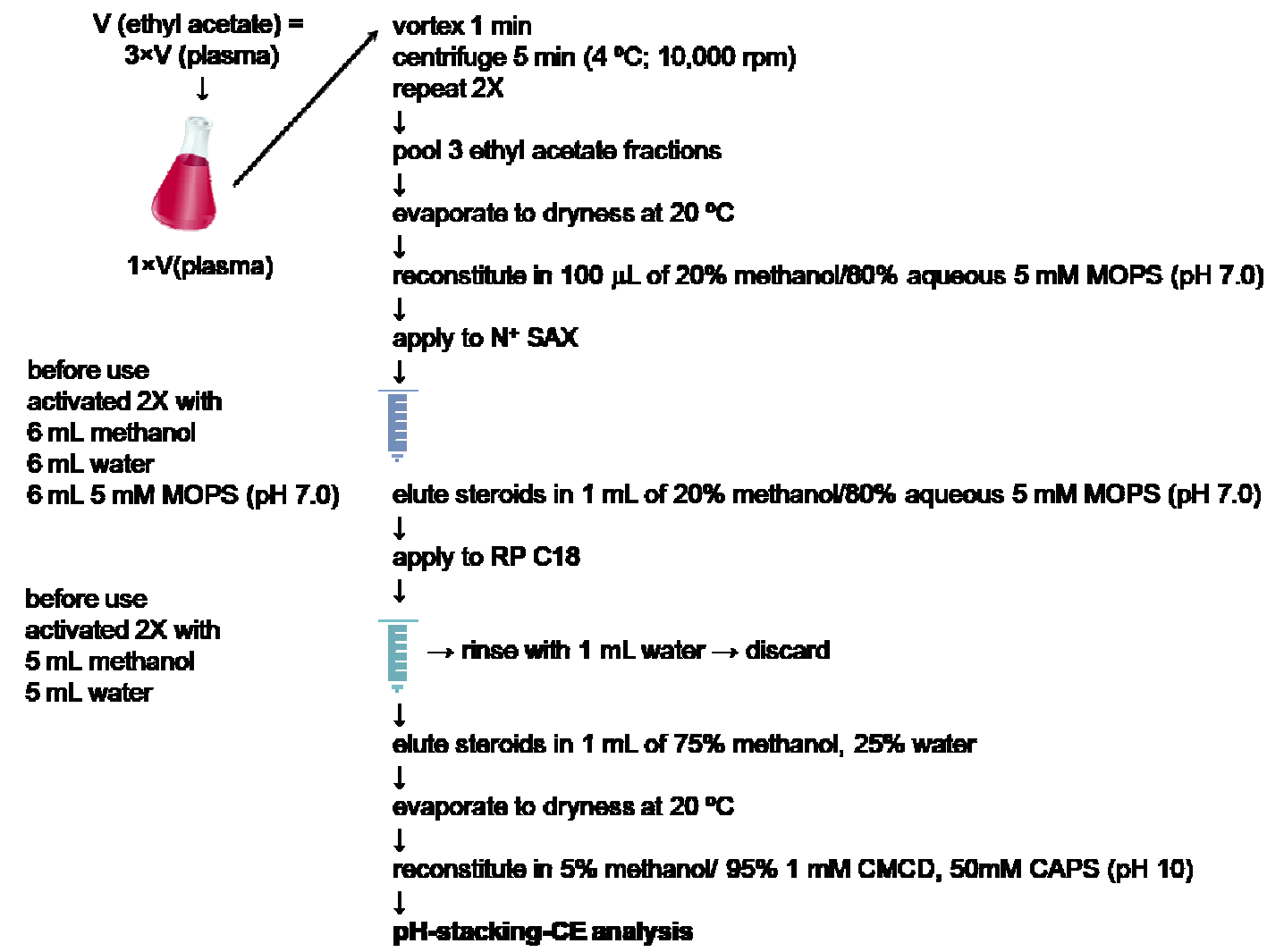

Figure 4.3. Flow chart of the plasma extraction protocol \#3

\subsubsection{RADIOIMmUNOASSAY PROCEDURE bY USGS}

Plasma samples from yellow perch were analyzed for the sex steroids $17 \beta$-estradiol (E2) and testosterone (T). All samples were quantified via radioimmunoassay (RIA) by Luke R. Iwanowicz of USGS. Estradiol antibodies (\#244 anti-estradiol-6-BSA) were purchased from Gordon Niswender (Colorado State University, Fort Collins, CO). Testosterone antibodies (polyclonal anti-testosterone R156/7) were purchased from Coralie Munroe (UC School of Veterinary Medicine, Davis, CA). Extraction efficiencies were 
determined for the sex steroids, and all assays were validated and optimized for yellow perch.

Plasma samples were extracted twice in a ten-fold excess of diethyl ether prior to RIA. Plasma estradiol concentrations were determined using the RIA method of Sower and Schreck (31) with slight modifications. The samples and estradiol standards were solubilized in $200 \mu \mathrm{L}$ of room temperature phosphate buffered saline gelatin (PG) buffer (0.1\% knox gelatin in Dulbecco's phosphate buffered saline). $100 \mu \mathrm{L}$ of anti-estradiol antiserum was added to the samples, vortexed and incubated at room temperature for 30 min. The same volume of PG buffer was added to tubes designated to determine nonspecific background and total counts per minute (CPM). Following incubation $100 \mu \mathrm{L}$ of tritiated $17 \beta$-estradiol (5000 CPM in PG buffer) was added to all tubes, vortexed and incubated at room temperature for $60 \mathrm{~min}$. Samples were immediately cooled in an ice bath for $30 \mathrm{~min}$ and $500 \mu \mathrm{L}$ of ice-cold charcoal-dextran solution $(0.63 \%$ alkaline charcoal and $0.4 \%$ dextran in PG buffer) was added. Samples were vortexed, incubated on ice for 15 min and centrifuged at $2200 \times g$ for $20 \mathrm{~min}$ at $4^{\circ} \mathrm{C}$. Supernatant was then decanted into scintillation vials containing $4 \mathrm{~mL}$ of OptiPhase HiSafe 2 scintillation fluid (Perkin Elmer, Waltham, MA, USA) and mixed well. Sample CPM were measured using a Tri Carb Liquid Scintilation Counter (Perkin Elmer, Waltham, MA, USA) and mean sample CPM was determined over an 8 minute integration time. All samples were run in duplicate and plasma estradiol values were interpolated from a standard curve. Plasma hormone concentrations were interpolated from the standard curve using curve fitting software (Prism 4.0, GraphPad Software Inc.). The same procedure was repeated on fresh plasma samples for the determination of testosterone using its specific antibody. 


\subsection{RESULTS AND DISCUSSION}

\subsubsection{FOUR STEROIDS TARGETED FOR ANALYSIS}

This study focuses on four steroids referred to as "classical reproductive steroids" considered to be important members of the endocrine system functioning in teleost fish: estradiol, $\alpha, \beta$-dihydroxyprogesterone, testosterone, and 11-ketotestosterone (Fig. 1.1). These four steroids were selected as targets for the analysis as their control can assist in the identification and study of the occurrence of intersex triggered by endocrine disruption and to monitor reproduction in fish species (32).

The endogenous levels of 11-ketotestosterone, unlike those of testosterone, in the blood plasma of teleost fish are reported to be higher in males than in females (33-37). Although sexual development and behavior of the male species is commonly due to testosterone, the dominant androgen in male teleost is 11-ketotestosterone (26). Testosterone is also secreted by both sexes; however, testosterone levels in the female fish plasma are elevated during the breading season and its concentration in most female samples is found to be comparable or higher than that in the male fish plasma $(35,38)$. The concentrations of the female hormone estradiol are higher in female fish plasma. Estradiol is produced in the follicle of the developing oocyte while $\alpha, \beta$-dihydroxyprogesterone is one of the key mediators for the final oocyte maturation (39). The molecular properties of the targeted steroids are summarized in Table 2.2. 


\subsubsection{OPTIMIZED CAPILLARY FLUSHES}

After the developed CE-method was first applied to the fish plasma extracts, the migration times of steroids became irreproducible from run to run and their detection signals decreased dramatically even in the standard samples. This stimulated a need in a new capillary flush protocol development. The poor reproducibility of the analysis of plasma samples was traced to nonspecific surface adsorption of the impurities extracted from the blood/plasma samples, and introduced into the separation capillary during the sample injection. One way to overcome this problem was to change the separation capillary daily. However, the frequent change of the capillary is not only costly and time consuming but also has a potential of introducing systematic measurement errors. Therefore the flushing protocol used to regenerate the inner surface of the separation capillary has been modified by replacing the methanol wash used in the morning described in Chapter 3 with $1 \mathrm{~N}$ sodium hydroxide. Conditioning the separation capillary with a strong base actively regenerates the inner capillary surface by dissolving the silica substrate and therefore helps remove any compounds remaining in the capillary after the blood/plasma sample analysis (40).

The recent work was conducted under the conditions of suppressed EOF when the charges of the silica surface were eliminated by the suppression of the dissociation of the surface silanol groups. The new capillary flush procedure, however, introduced a slight change in the steroid migration times. The new protocol for capillary flushes used at the beginning of each day included sequential timed flushes at $172 \mathrm{kPa}$ (25 psi) for $15 \mathrm{~min}$ with $1 \mathrm{~N}$ sodium hydroxide, $5 \mathrm{~min}$ water, $25 \min 0.1 \mathrm{~N}$ hydrochloric acid, $5 \mathrm{~min}$ water, 25 
min with running buffer. Running electrolyte was comprised of $30 \mathrm{mM}$ SDS, $13 \mathrm{mM}$ HPCD in $200 \mathrm{mM}$ phosphate buffered at pH 2.5. In between runs, the capillary was flushed at $172 \mathrm{kPa}(25 \mathrm{psi})$ for $2 \mathrm{~min}$ with the running electrolyte. Due to the change in the migration times for two of the previously analyzed steroids, estradiol and 11ketotestosterone, the linear range, the within-day and day-to-day reproducibility in peak area and migration time were determined with the new flush set. Two newly selected steroids, $\alpha, \beta$-dihydroxyprogesterone and testosterone, were included in the method evaluation studies.

\subsubsection{METHOD SELECTIVITY}

The selectivity of the method for the four targeted steroids was assessed using a set of eight steroids mixed in a single sample. These eight steroids: $\alpha, \beta-$ dihydroxyprogesterone, 17 $\beta$-estradiol, estrone, ethynyl estradiol, hydroxyprogesterone, 11-ketotestosterone, progesterone, and testosterone, were analyzed using stackingMEKC. All eight steroids were baseline separated and the resulting electropherograms are represented in Figure 4.4. The representative background subtracted electropherograms are shown in Figure 4.5. The background subtraction was not used for the peak quantitation as it does not affect the reproducibility of steroid analysis.

Interference from androstenedione was also studied. Androstenedione is a precursor of testosterone in the steroid biosynthesis pathway. A sample containing both steroids was analyzed at the stacking conditions. The resolution for both steroids was 
calculated as described in Section 2.1.3 (Equation 2.5) and was $\geq 0.91$ at the experimental conditions.

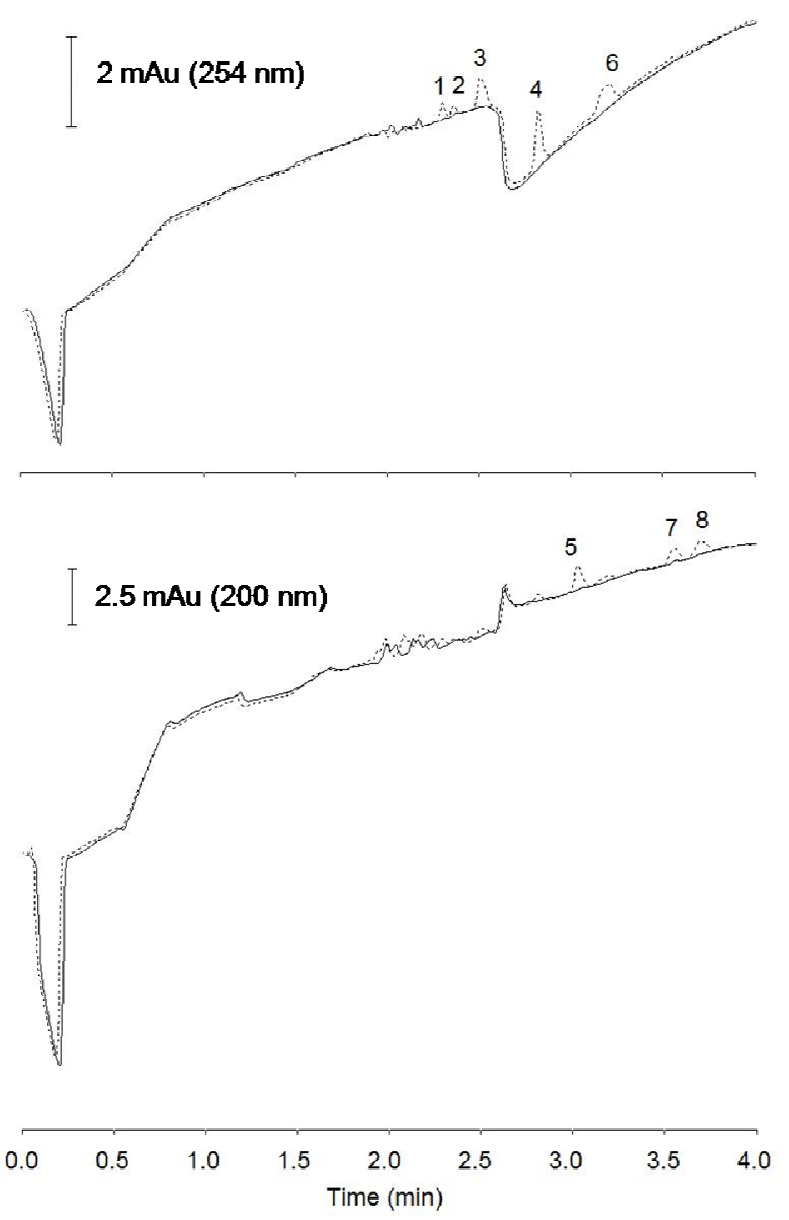

Figure 4.4 illustrates the raw electropherograms obtained for 8 steroids simultaneously present in the analyzed sample. Data collected at $254 \mathrm{~nm}$ (top): (1) progesterone (500 nM); (2) $\alpha, \beta$-dihydroxyprogesterone (500 nM); (3) hydroxyprogesterone (2 $\mu \mathrm{M})$; (4) testosterone (1 $\mu \mathrm{M})$; (6) 11-ketotestosterone (2 $\mu \mathrm{M})$.Data collected at $200 \mathrm{~nm}$ (bottom): (5) estrone (500 nM); (7) ethynyl estradiol (250 nM); and (8) 17ß-estradiol (250 $\mathrm{nM})$. 

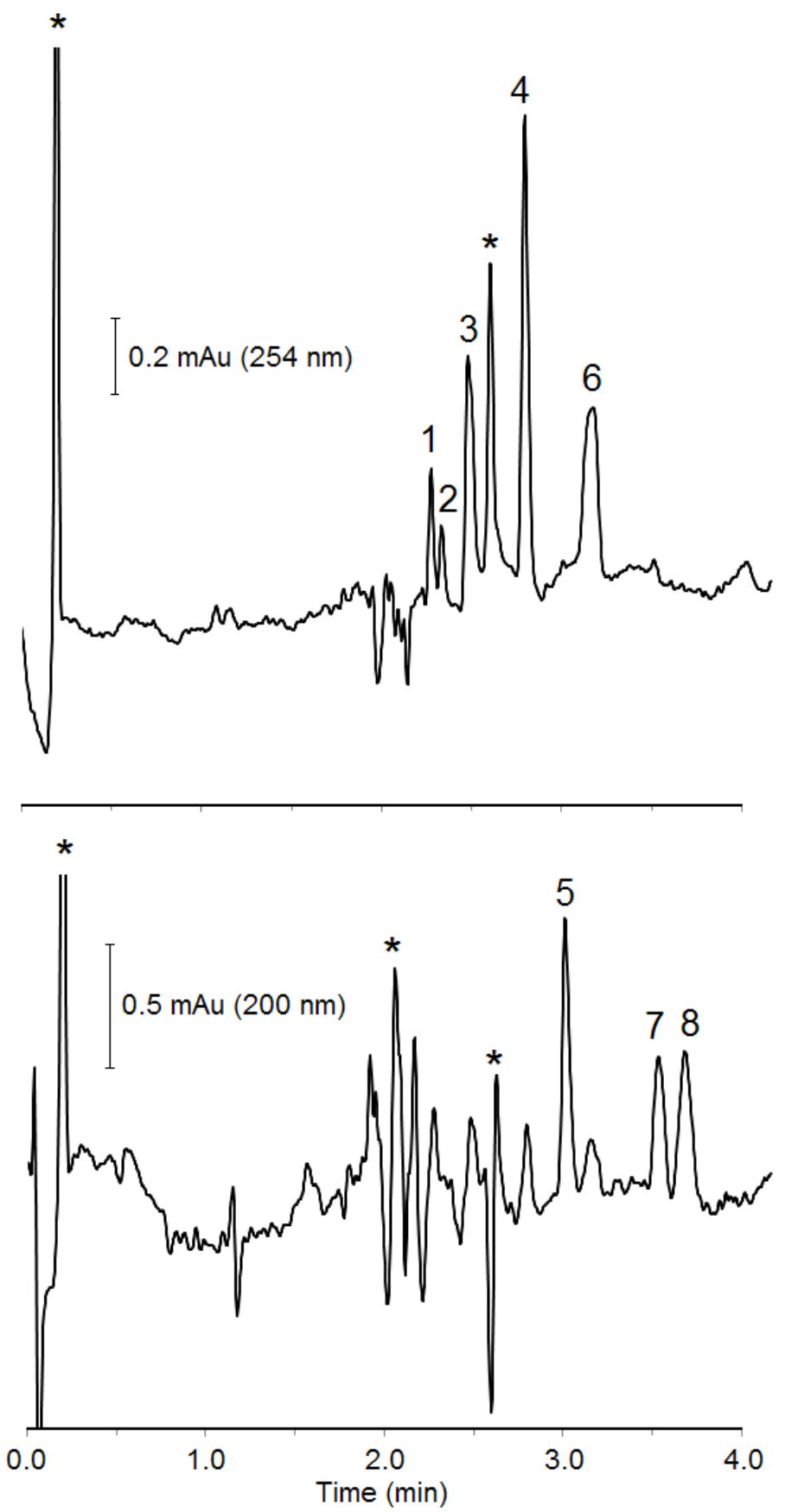

Figure 4.5. Background subtracted electropherograms obtained for 8 steroids simultaneously present in the analyzed sample. Data collected at $254 \mathrm{~nm}$ (top): (1) progesterone (500 nM); (2) $\alpha, \beta$-dihydroxyprogesterone (500 nM); (3) hydroxyprogesterone (2 $\mu \mathrm{M})$; (4) testosterone (1 $\mu \mathrm{M})$; (6) 11-ketotestosterone (2 $\mu \mathrm{M})$. (B) Data collected at $200 \mathrm{~nm}$ (bottom): (5) estrone (500 nM); (7) ethynyl estradiol (250 nM); and (8) 17ß-estradiol (250 $\mathrm{nM})$. The separation conditions are summarized in text. 
A separate study was conducted in order to determine the migration time for $\alpha, \alpha-$ dihydroxyprogesterone, an isomer of $\alpha, \beta$ - dihydroxyprogesterone that can possibly be present in plasma $(41,42)$ and interfere with the separation. The results demonstrated that $\alpha, \alpha$ - dihydroxyprogesterone co-migrated with progesterone during the analysis (Fig. 4.7). Baseline resolution of these two hormones can be achieved by adjusting the SDS/HPCD ratio in the background electrolyte. However, both of them were baseline separated from $\alpha, \beta$ - dihydroxyprogesterone, which is typically present at much higher concentration levels in the fish plasma $(41,42)$. The electropherogram in Figure 4.7 shows the separation of the three steroids. Progesterone and $\alpha, \alpha$ - dihydroxyprogesterone were not analyzed in this study because of their expected low concentrations in the fish plasma.

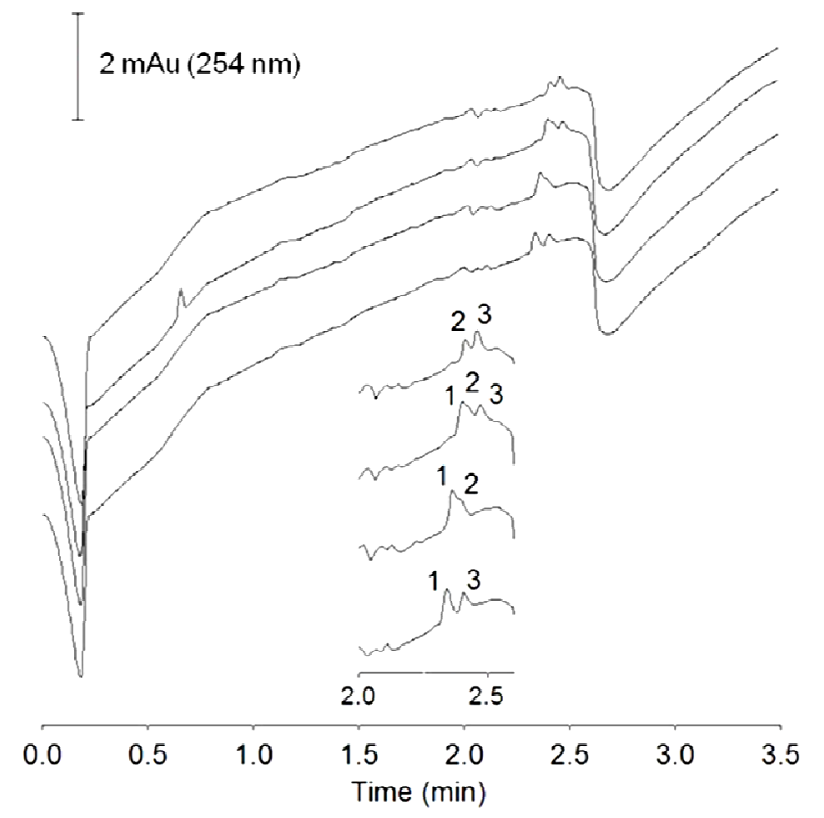

Figure 4.6. Stacking electropherograms of (1) progesterone; (2) $\alpha, \alpha$-dihydroxyprogesterone; and (3) $\alpha, \beta$ dihydroxyprogesterone. Concentration of each is $500 \mathrm{nM}$. Data collected at $254 \mathrm{~nm}$. 


\subsubsection{FIGURES OF MERIT OF MODIFIED METHOD}

The linear regression parameters for the calibration curves and all the figures of merit in this chapter were derived from the samples with four targeted steroids. The linear range for each steroid was determined from nine calibration curves ( 3 per day for 3 days). Curves were measured simultaneously for 4 analytes. The detection was performed by UVvisible absorbance at detection wavelength of $254 \mathrm{~nm}$ for dihydroxyprogesterone $\left(\mathrm{R}^{2} \geq\right.$ 0.990), testosterone $\left(\mathrm{R}^{2} \geq 0.997\right)$, and ketotestosterone $\left(\mathrm{R}^{2} \geq 0.995\right)$, or $200 \mathrm{~nm}$ for estradiol $\left(\mathrm{R}^{2} \geq 0.996\right)$. The within-day and day-to-day reproducibility were measured at $1.0 \mu \mathrm{M}$ dihydroxyprogesterone, testosterone, 11 ketotestosterone, and $0.50 \mu \mathrm{M}$ estradiol. The within-day and day-to-day reproducibility of the migration time was $\leq 1$ and $\leq 2 \%$ RSD respectively for all four steroids. The corresponding values of the peak area ranged from 1 to $6 \%$ RSD and from 1 to $20 \%$ RSD. The data are summarized in Table 4.1 .

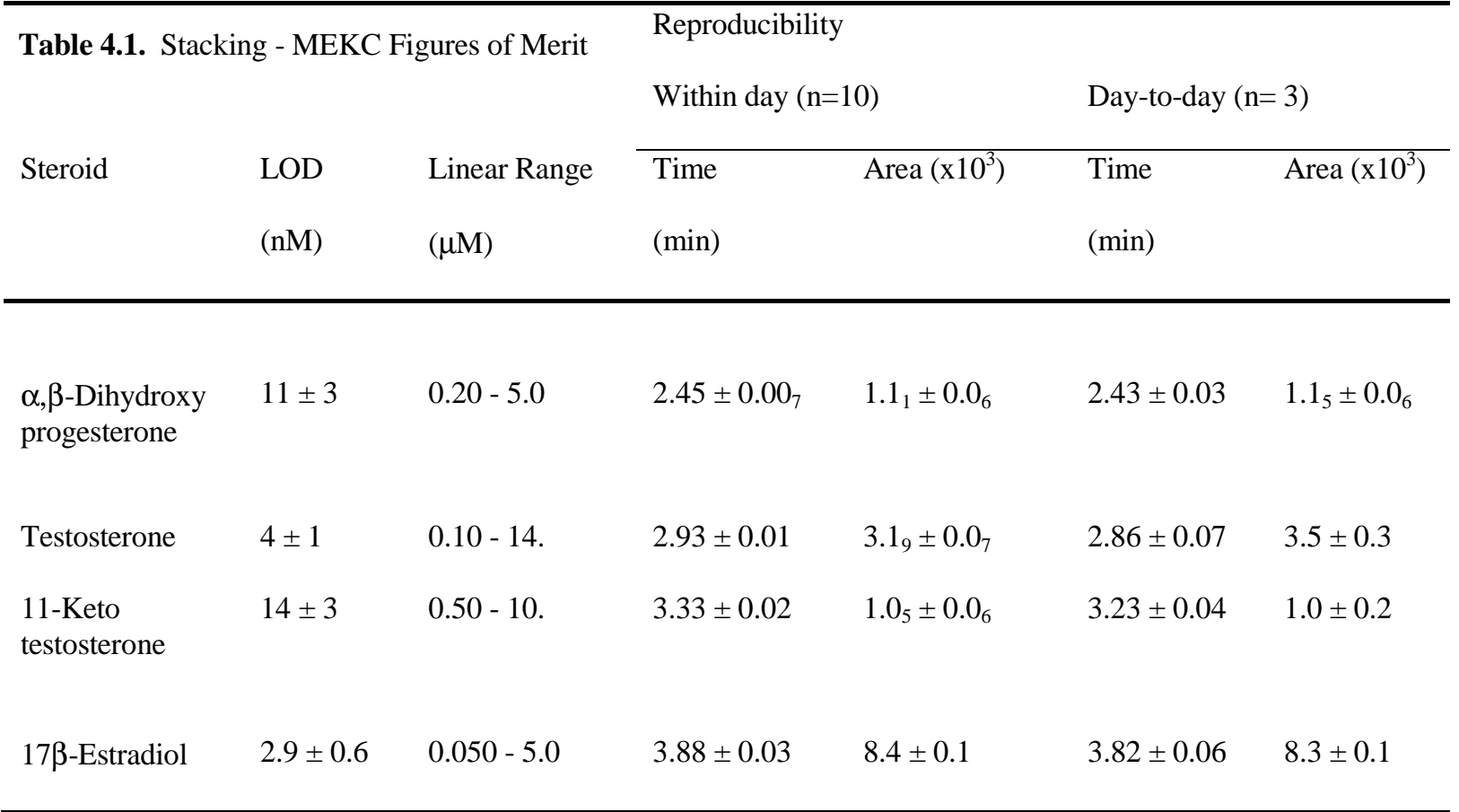




\subsubsection{Development of the Plasma Sample Purification Method}

Blood plasma is a complex mixture and contains many compounds that can interfere with the analysis of steroids by stacking preconcentration. Therefore, the analysis of plasma samples by the developed method required a development of a thorough sample purification protocol. Many methods exist for biological samples purification, including the extraction with organic solvents and different combinations of solid phase extraction (43, 44). Steroid hormones are present in plasma in the free (unconjugated) or conjugated form such as sulfated and glucuronidated conjugates. The free lipophilic steroids can be extracted from plasma using non-polar organic solvents. As mentioned earlier, immunoassay is widely used in biological laboratories to measure circulating steroid levels in fish. In immunoassay analysis the extraction of steroids from biological fluid samples is often accomplished using ethyl acetate or diethyl ether $(22,45)$. The organic solvent denatures carrier proteins releasing hormones such as estradiol and testosterone bound to SHBG with high affinity (46). Therefore the total concentration of the steroids, free and bound, can be determined while the hydrophilic sulfated and glucuronidated conjugates remain in the aqueous fraction (i.e. plasma) after ethyl acetate extraction has been performed.

One of the biggest concerns in this extraction method is the potential to concentrate trace impurities from the extraction solvent. Therefore the blank extractions of deionized water employing $4.5 \mathrm{~mL}$ of reagent grade ethyl acetate and ACS grade ethyl acetate (99.5\% purity) were first performed. The results demonstrated reagent grade ethyl 
acetate contained a large number of interfering peaks comparing to the ACS grade ethyl acetate (99.5\% purity) which was therefore used in further studies.

Additionally, the other lipid constituents of blood, i.e. cholesterol and fatty acids, are also extracted in the organic phase. Cholesterol has very high affinity to CD cavities and competes with the steroids of interest forming strong inclusion complexes with CDs (47). The fatty acids in turn are anionic at the $\mathrm{pH} 10$ owing to the presence of the carboxylic group and therefore are driven into the separation capillary along with the CMCD molecules carrying lipophilic compounds and therefore are preconcentrated at the $\mathrm{pH}$-junction. Both types of compounds will interfere with the separation of the steroids by the developed stacking-MEKC and have to be eliminated.

The limitation of the sample pretreatment using only ethyl acetate for stackingMEKC analysis is demonstrated in Figure 4.7. For this experiment the catfish fish plasma sample was pretreated with ethyl acetate as described in methods Section 4.2.6. As seen in the Figure 4.7-A the electropherogram contains several highly intensive co-migrating peaks in the migration time interval from 0 to $2 \mathrm{~min}$. The nature of these interfering peaks is caused by the compounds extracted in ethyl acetate that either have very high affinity to the SDS micelles or are anionic and therefore migrate early driven by their anodic attraction. No steroids were detected in this sample. The electropherogram in Figure 4.7B was measured for the same reconstituted plasma extract but ten times diluted with the sample buffer. The dilution decreased the concentration and as a result the signal of the interfering compounds, however, no steroids were detected in the sample as confirmed in 
the electropherogram C (Fig. 4.7) measured for the 10 times dilute extract spiked with 10 $\mu \mathrm{M}$ ethynyl estradiol and estrone.

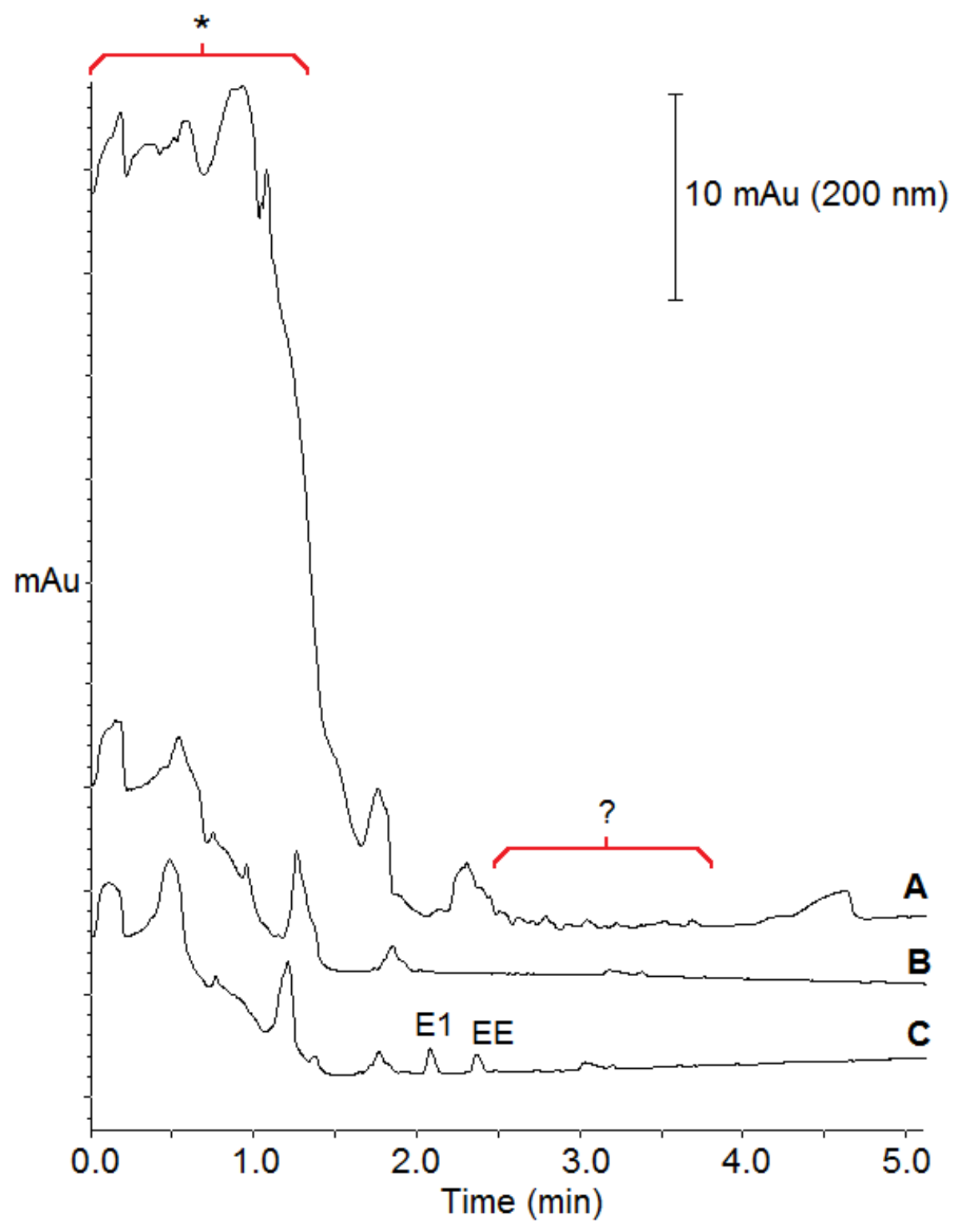

Figure 4.7. The electropherograms obtained for the catfish blood extract. A - ethyl acetate extract reonstituted in $1 \mathrm{mM} \mathrm{CMCD}, 5 \%$ methanol, $50 \mathrm{mM}$ CAPS, pH10. (* - unknown interference from blood, ? - steroid migration time window). B - extract, ten times dilute with the sample buffer; $\mathrm{C}$ - extract, ten times diluted with the sample buffer, spiked with $10 \mu \mathrm{M}$ ethynyl estradiol (EE) and estrone (E1). Stacking conditions are outlined in text. 
In order to eliminate the presence of the charged fatty acids another blood sample was subject to extraction by anion exchange using disposable cartridges. The method was applied to the blood sample from male catfish frozen for 6 years. The plasma sample was pretreated prior to analysis as described in Section 4.2.7. The spiked portion of the plasma sample reconstituted in $1 \mathrm{mM} \mathrm{CMCD} \mathrm{did} \mathrm{not} \mathrm{contain} \mathrm{an} \mathrm{analyte} \mathrm{peak} \mathrm{for} \mathrm{estradiol} \mathrm{in} \mathrm{the}$ electropherogram. This is likely due to the presence of neutral lipids, such as cholesterol, co-extracted in ethyl acetate, which solubilize the steroids so their association with CMCD is significantly reduced. This was prevented by increasing the concentration of CMCD in the sample to $23 \mathrm{mM}$, which provided more cyclodextrin available for capturing estradiol from the sample. However, standard solutions of steroid reconstituted in aqueous CMCD with the concentration greater than $1 \mathrm{mM}$ yield a lower detector response (Section 3.3.2.3). As a result, the determination of steroids in blood required the analyte quantification using a method of standard addition and increased concentration of CMCD. A three point standard addition curve was obtained for each sample $\left(R^{2} \geq 0.999\right)$ by analyzing the reconstituted sample as well as the reconstituted sample spiked successively with $6.0 \mathrm{ng}$ of estradiol. Using this method, a concentration of estradiol in the unspiked blood sample was $0.38 \pm 0.04 \mu \mathrm{M}$ that corresponds to $5.6 \pm 0.6 \mathrm{ng}$ in the sample analyzed, or in other words $14 \pm 1 \mathrm{ng} / \mathrm{mL}$ blood. The sample spiked with an additional $14 \mathrm{ng}$ estradiol prior to extraction contains a concentration of $1.4 \pm 0.1 \mu \mathrm{M}$, which corresponds to $21 \pm 2 \mathrm{ng}$ in the sample analyzed, equivalent to $110 \%$ extraction recovery. The advantage of the standard addition calibration method is a constant composition of the matrix for all the samples. However, in this study a three point external standard calibration curve would be a better 
option as it decreases the total analysis time, which is beneficial for high throughput sample screening. In addition, to properly carry out the standard addition method the sample has to be split in 4 equal volume fractions. An increasing volume of the steroid standard is added to each portion of the sample and then diluted to the same final volume with the sample buffer. In this work, the total volume of the reconstituted plasma extract was 30 microliters and further spiking and dilution of such small volume would be an error prone, therefore the standard addition was performed by repeatedly spiking the sample with the standard. In this case, the response was normalized to account for the dilution factor, which was minimized by keeping the total volume change less than $5.5 \%$. However, in this case the same sample was analyzed subsequently for at least 4 times, after which it could not be used for further analysis if necessary. Therefore the critical steps in the sample preparation protocol needed to be changed in order to: (1) enhance overall steroid recovery while eliminating the interfering compounds extracted from plasma and (2) allow for a 3-point standard calibration curve instead of the standard addition. These led to the optimization of the sample preparation protocol by including a third and final extraction step in the extraction protocol. This extraction step utilizes a reversed phase C18 extraction column used to eliminate interference from neutral highly lipophilic substances, such as cholesterol, and was measured as described in Section 4.2.8. The steroids were eluted in the solvent containing $75 \%$ methanol and therefore could easily be dried out. The complete improved extraction scheme is outlined in Figure 4.3 and includes three stages: (1) extraction with organic solvent, ethyl acetate; (2) combination of (1) and a strong anion exchange extraction cartridge; (3) combination of (2) and a reversed phase C18 extraction cartridge. 
Most aquatic exposure studies require a reasonably large population for statistical significance, therefore there was the need for automated sample preparation and fast instrumental analysis to provide high sample throughput. For faster sample preparation in this study a vacuum box with twelve cartridge holders was used. Comparing to the gravity flow methods the use of the vacuum box offers more rapid flow rates by applying increased vacuum to each extraction cartridge holding a sample, therefore, the extraction proceeds with the same rate and twelve samples can be prepared simultaneously reducing the total analysis time. In commercial laboratories sample purification protocol can be accomplished using robotic systems which increase the speed of the sample preparation and the number of the samples purified up to 96 and more.

\subsubsection{The Evaluation of the Steroid Elution from the SAX Cartridge}

Ethyl acetate extracts require reconstitution in aqueous buffer before loading them onto a SAX cartridge. Because steroids are lipophilic compounds they cannot be dissolved in aqueous solutions, therefore the addition of small amount of methanol to the dried out extract assisted steroid dissolution. Different percent concentrations of methanol in $5 \mathrm{mM}$ aqueous MOPS buffered at $\mathrm{pH} 7.0$ used for reconstitution of the dried ethyl acetate extracts before loading them onto SAX cartridge were tested. The methanol content was minimized to avoid the possible loss of steroids out of the extraction column, during sample loading. The concentrations tested were methanol: $5 \mathrm{mM}$ MOPS (15:85, 20:80, and 25:75, v/v). Aqueous samples containing $14 \mathrm{ng}$ of testosterone were prepared and extracted as described in Section 4.2.7. The evaporated extracts were reconstituted in $30 \mu \mathrm{l}$ of the sample buffer containing $1 \mathrm{mM} \mathrm{CMCD}$ and analyzed by the stacking-MEKC 
as described in Section 3.2.5. The solution comprised of methanol: $5 \mathrm{mM}$ MOPS (20:80, $\mathrm{v} / \mathrm{v})$ resulted in $64 \%$ testosterone recovery. The further increase of methanol concentration did not improve the recovery, therefore, methanol: $5 \mathrm{mM}$ MOPS (20:80, v/v) was used in the further studies.

\subsubsection{Recovery of Standard Steroids from C18 Cartridge}

The purpose of the present experiment was to determine the amount of methanol required for elution of the targeted steroids from the C18 silica while leaving the highly lipophilic compounds such as cholesterol being retained by $\mathrm{C} 18$ cartridge. The experiment was conducted using estradiol due to its high hydrophobicity $(\log P=4.1)$ comparing to the other targeted steroids (Table 2.2). The optimal amount of the methanol used to collect the most of the estradiol from the cartridge should be sufficient to elute the rest of the targeted steroids as they are less hydrophobic and require more polar solvent. Each steroid sample comprised of $2.7 \mathrm{ng}$ of estradiol prepared in $1 \mathrm{~mL}$ of methanol: 5 mM MOPS (20:80, v/v) was loaded onto a pre-activated as described in Section 4.2.8 C18 cartridge and then eluted with $1 \mathrm{~mL}$ of elution solvent comprising deionized water and different volume percent concentrations of methanol $(25,35,45,55,65,75,85,95$, 100, \%v). The Figure 4.8 demonstrates the plot of estradiol percent recovery versus the amount of methanol used to elute the steroid from the $\mathrm{C} 18$ extraction cartridge. The elution solution containing methanol: water $(75: 25, \mathrm{v} / \mathrm{v})$ was used in the further studies as it is just enough to give the highest recovery of estradiol (90\%) from the cartridge. The further increase in methanol content also resulted in a high recovery of estradiol. 
However, it can cause the elution of highly lipophilic cholesterol form the C18 cartridge and therefore was avoided.

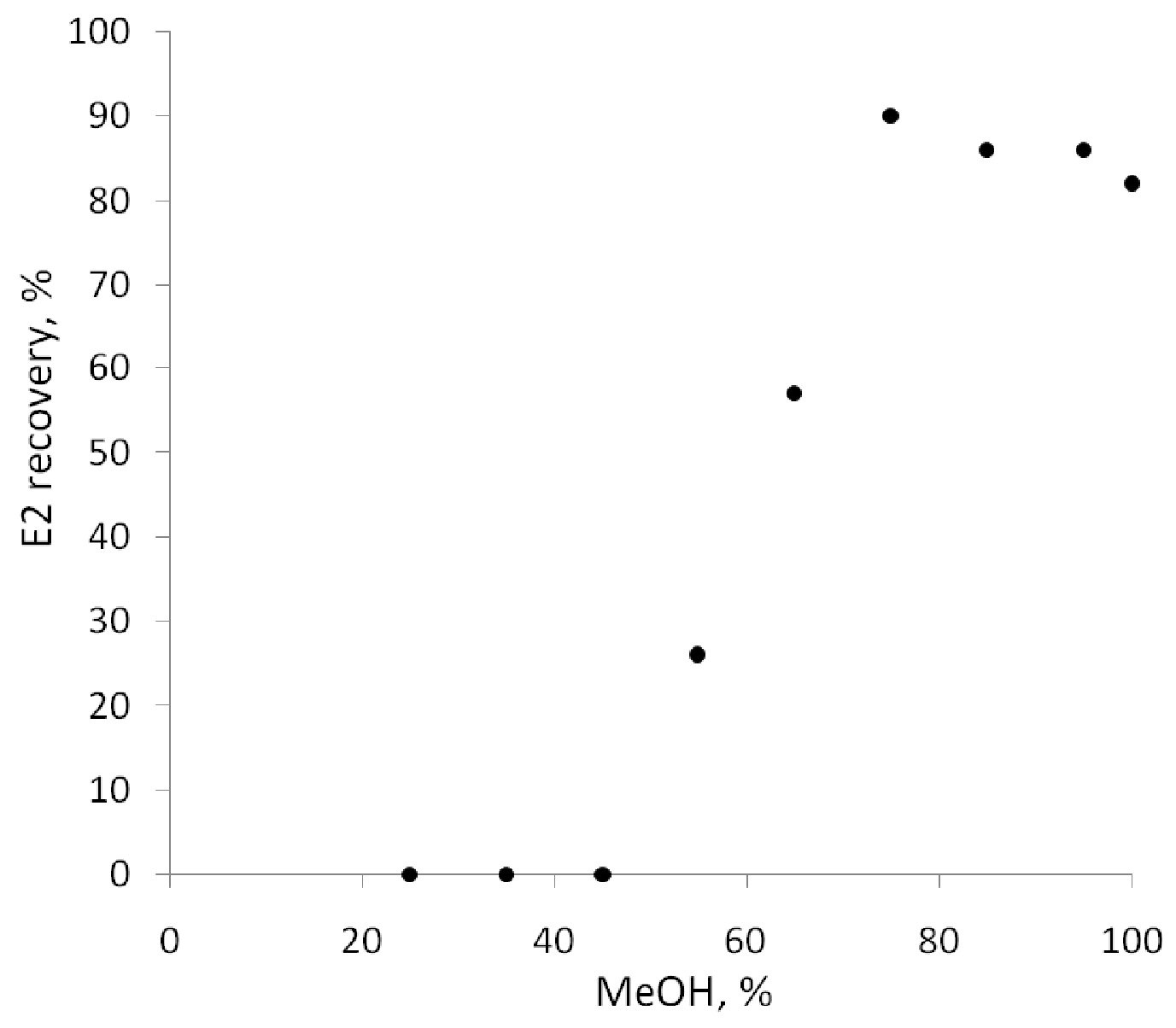

Figure 4.8. Plot of the estradiol recovery (\%) versus the percent concentration of methanol in water used to elute steroids retained by $\mathrm{C} 18$ extraction cartridge during the plasma sample pretreatment. 


\subsubsection{Stability Studies}

Two estradiol standards were compared in order to study the stability of steroids over the storage period. Two sets of four solutions of $1 \mu \mathrm{M}$ estradiol samples prepared in the sample buffer were analyzed by stacking-CE. The first set was prepared using the freshly made estradiol stock in methanol prepared from a recently purchased powdered chemical. The second set was prepared out of the 1-year old solution of estradiol in methanol made using a solid estradiol stored for 6 years in dark at room temperature. The representative electropherograms are shown in Figure 4.9. The peak areas for the fresh estradiol set were $(14.5 \pm 0.1) \times 10^{3}$ and for the old estradiol standard peak area was $(14 \pm$ $1) \times 10^{3}(n=4)$.

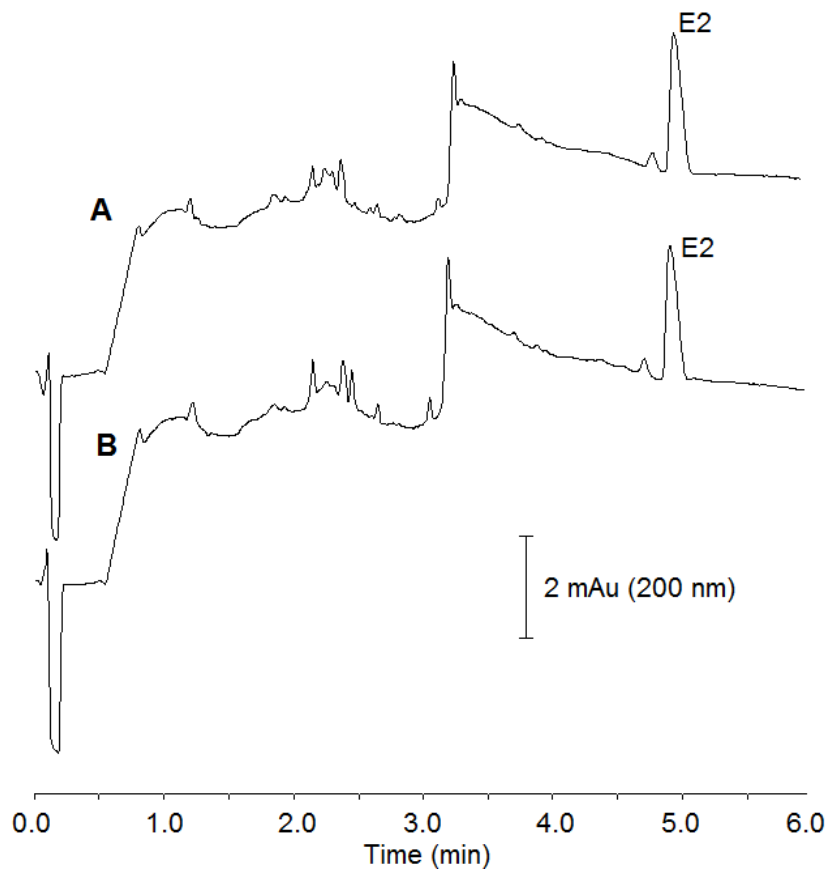

Figure 4.9. Representative electropherograms for the steroid stability study. A - $1.0 \mu \mathrm{M}$ estradiol prepared from fresh standard (peak area $=14.7 \times 10^{3}$ ), B $-1.0 \mu \mathrm{M}$ estradiol prepared from the aged standard (peak area $=15.7 \times 10^{3}$ ). Samples were prepared in the sample buffer containing CMCD and subject to stacking$\mathrm{CE}$ analysis as described in the text. 
The signals measured for both estradiol sample sets demonstrated no statistical difference which suggests that if the steroid stock is stored properly (in case of the solid reagent - in a dark dry place at room temperature, and in case of the methanol stock solution - in a dark dry place at $-20^{\circ} \mathrm{C}$ ) degradation is less than $4 \%$ during the storage period. However, it was important to eliminate the loss of the steroids due to photo- or thermal degradation during the sample preparation procedure, which consists of several steps including extraction, evaporation and sample reconstitution. The corresponding study is discusses in the following section.

\subsubsection{Effect of Temperature During Dry Down on the Recoveries}

Although the literature reports consider the photo-degradation to be the primary reason for the decomposition of testosterone (48-50) (the kinetics of the photo-degradation was not studied in this research), the experimental studies in this research demonstrated that testosterone is partially decomposed under the influence of the heat. In the early experiments for the steroid recoveries a rotary evaporator was used for the gentle removal of the solvents form the sample solutions before reconstituting them in the sample buffer containing $\mathrm{CMCD}$. The rotary evaporator device includes a condenser, a temperature controlled water bath for the sample heating, and a vacuum system for the vapor being drawn off of the sample. The samples to be evaporated where placed in clear glass vials but to prevent exposure to ambient light the rotary evaporator was covered with the layers of aluminum foil. To speed up the evaporation process of aqueous samples of $>2 \mathrm{~mL}$ the temperature of the water bath was increased to $50{ }^{\circ} \mathrm{C}$. The highest percent recovery of testosterone prepared using this evaporation system was only $64 \%$. An alternative 
experiment was conducted using a SpeedVac ${ }^{\circledR}$ concentrator device that evaporates samples containing water at room temperature. Testosterone samples covered to prevent their exposure to the ambient light were evaporated at $20^{\circ} \mathrm{C}$ and the recovery of testosterone pretreated this way was $93 \%$. Based on this the dry down of the samples extracts was further carried out at the room temperature using SpeedVac® concentrator.

\subsubsection{Recovery of Standard Steroids from Aqueous Solutions}

The sample extraction steps were studied using aqueous standards as well as fish plasma samples. Prior to estimating total recovery, the recovery of estradiol and testosterone at each step of the optimized extraction scheme (Fig. 4.3) were measured using aqueous solutions of both steroids. The recovery study was performed by taking a sample of deionized water, splitting it in half. Only one half was prepared by adding a desired amount of steroids (2.7 $\mathrm{ng}$ of estradiol and $14 \mathrm{ng}$ of testosterone) to deionized water with $5 \%$ of methanol present to avoid steroid precipitation. Each sample was extracted with ethyl acetate as described above in Section 4.2.6, evaporated to dryness, reconstituted in $\mathrm{CMCD}$ matrix and subjected to $\mathrm{CE}$ separation. The recoveries of estradiol and testosterone, extracted in ethyl acetate were $106 \%$ of each. Then the recoveries for testosterone and estradiol from extraction columns were measured. The aqueous sample of testosterone and estradiol was loaded on a quaternary amine SAX cartridge, followed by C18 cartridge application. Three elution fractions were collected, fraction 1 and 2 were $1 \mathrm{~mL}$ of methanol: water (75:25, v/v) each, and fraction 3 was 100 $\%$ methanol. The highest recovered concentration of steroids was measured only in the first fraction, $91 \%$ recovery for estradiol and $84 \%$ recovery for testosterone. No spiked 
steroids were found in fractions 2 and 3. The results are summarized in Table 4.2. The advantage of these elution techniques is a high recovery of steroids from the extraction columns in a small volume of the solvent $(1 \mathrm{~mL})$, while leaving highly lipophilic substances, which require less polar solvent for elution, strongly retained on C18 material.

Table 4.2. Recovery of standard $17 \beta$-estradiol and testosterone from aqueous solutions.

\begin{tabular}{llll}
\hline Steroid & Spiked & \multicolumn{2}{c}{ Recovered } \\
& $\mathrm{ng}$ & $\mathrm{ng}$ & $\%$ \\
& & & \\
\hline
\end{tabular}

\section{г $17 \beta$-estradiol}

$\begin{array}{llcc}\text { EA extraction } & 2.7 & 2.9 \pm 0.6 & 106 \\ \left(\mathrm{~N}^{+}\right) \text {SAX + RP C18 fraction 1 } & 2.7 & 2.5 \pm 0.2 & 91\end{array}$

\section{Testosterone}

\begin{tabular}{llcc} 
EA extraction & 14 & $15 \pm 3$ & 106 \\
$\left(\mathrm{~N}^{+}\right)$SAX + RP C18 fraction 1 & 14 & $12 \pm 2$ & 84 \\
\hline
\end{tabular}

$\mathrm{EA}=$ ethyl acetate

$\mathrm{SAX}=$ strong anion exchange cartridge

RP C $18=$ reversed phase $\mathrm{C} 18$ cartridge 


\subsubsection{Steroid Recovery from Fish Plasma}

To determine whether the biological origin of the fish species can affect the steroid analysis using the optimized procedure, four different fish species: catfish (Ictalurus punctatus), smallmouth bass (Micropterus dolomieu), largemouth bass (Micropterus salmoides), and yellow perch (Perca flavescens) were used for investigation. Each blood or blood plasma sample was split in half. One half was unspiked and analyzed to measure the endogenous steroids. The other half of the plasma sample was spiked with $2.7 \mathrm{ng}$ of estradiol and $14 \mathrm{ng}$ of testosterone and was used to measure the recovery of steroids comparing to the unspiked sample. The sample pretreatment and sample analysis were performed similar to the method described in Section 4.2.8. Briefly, each sample was extracted with ethyl acetate, evaporated to dryness, reconstituted in MOPS, loaded on a quaternary amine SAX cartridge, followed by $\mathrm{C} 18$ cartridge purification. The first $1 \mathrm{~mL}$ of methanol: water $(75: 25, \mathrm{v} / \mathrm{v})$ was collected, evaporated to dryness, reconstituted in CMCD buffer and analyzed by $\mathrm{CE}$ as described in 3.2.5. A schematic flow-chart for sample pretreatment is illustrated in Figure 4.10.

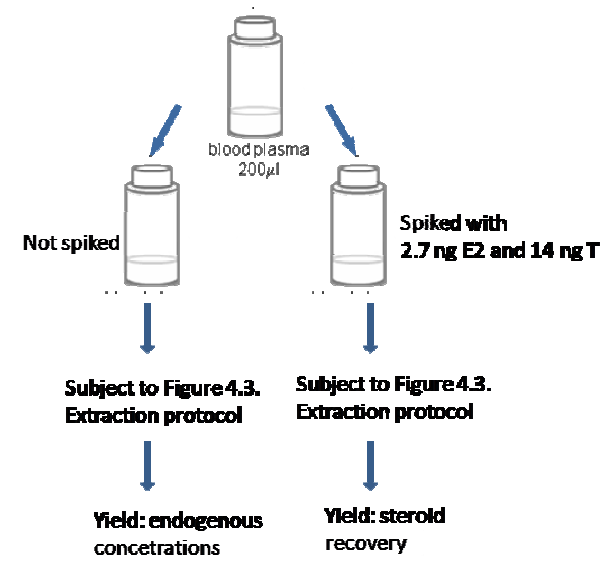

Figure 4.10. Steroid recovery from fish plasma. Flow chart of the plasma sample preparation. 
The results are summarized in Table 4.3. All the concentrations were measured using a three-point external standard calibration curve. The estradiol recovery ranged from $74 \%$ in catfish blood to $85 \%$ in yellow perch plasma, and testosterone recovery ranged from $77 \%$ in catfish blood to $102 \%$ in largemouth bass $\left(\mathrm{R}^{2} \geq 0.98\right)$. Figure 4.11 illustrates representative electropherograms of estradiol and testosterone recovery from a catfish blood sample. After running the sample by CE, it was spiked with additional amounts of targeted steroid and reanalyzed. The increase of the peak at a specific migration time for each added steroid confirmed the presence of the steroid in the sample.

Table 4.3. Recovery of standard steroids from fish plasma.

\begin{tabular}{|c|c|c|c|c|c|c|c|}
\hline \multirow[t]{2}{*}{ Steroid } & \multirow{2}{*}{$\begin{array}{l}\text { Sample } \\
\text { volume }\end{array}$} & \multirow{2}{*}{$\begin{array}{l}\text { Spiked } \\
\text { ng }\end{array}$} & \multicolumn{2}{|l|}{ Recovered } & \multicolumn{3}{|c|}{ Linear regression data parameters } \\
\hline & & & ng & $\%$ & Slope & $\begin{array}{l}\text { Intercept } \\
\left(\times 10^{3}\right)\end{array}$ & $\mathrm{R}^{2}$ \\
\hline \multicolumn{8}{|l|}{$17 \beta$-estradiol } \\
\hline Catfish* & 120 & 2.7 & $2.0 \pm 0.2$ & 74 & $19 \pm 1$ & $-0.1 \pm 0.1$ & 0.998 \\
\hline Smallmouth bass & 100 & 2.7 & $2.1 \pm 0.0_{5}$ & 78 & $14 \pm 0.3$ & $0.1 \pm 0.0_{5}$ & 1.000 \\
\hline Yellow perch & 100 & 2.7 & $2.3 \pm 0.6$ & 85 & $17 \pm 1$ & $-0.2 \pm 0.3$ & 0.997 \\
\hline \multicolumn{8}{|l|}{ Testosterone } \\
\hline Catfish* & 120 & 14 & $11 \pm 1$ & 77 & $3.4 \pm 0.2$ & $0.0_{2} \pm 0.1$ & 0.997 \\
\hline Smallmouth bass & 100 & 14 & $13.3 \pm 0.2$ & 94 & $3.1 \pm 0.0_{2}$ & $0.1 \pm 0.0_{1}$ & 1.000 \\
\hline Largemouth bass & 100 & 14 & $14.5 \pm 0.2$ & 102 & $3.1 \pm 0.0_{2}$ & $0.1 \pm 0.0_{1}$ & 1.000 \\
\hline Yellow perch & 100 & 14 & $12 \pm 3$ & 84 & $2.6 \pm 0.4$ & $0.0_{8} \pm 0.2$ & 0.982 \\
\hline
\end{tabular}

* - catfish blood stored at $-80^{\circ} \mathrm{C}$ for 7 years. 


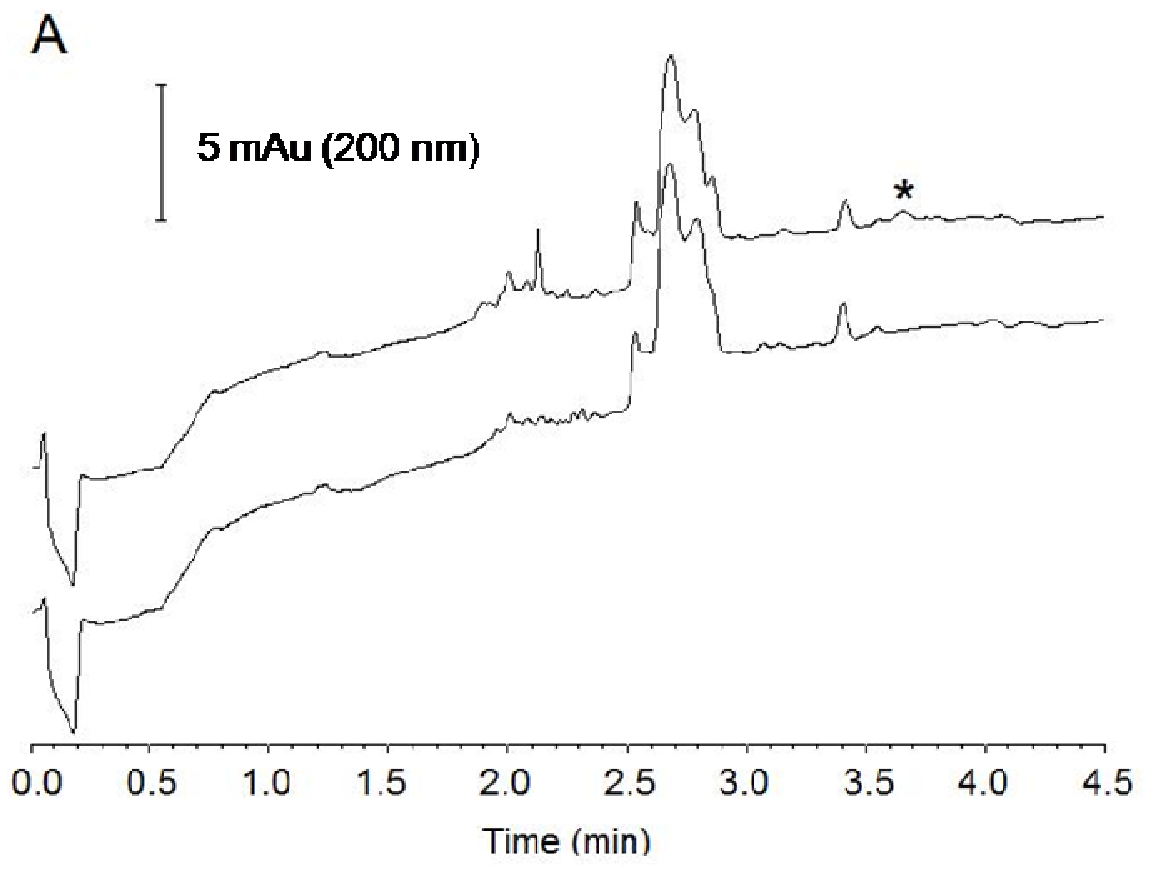

B

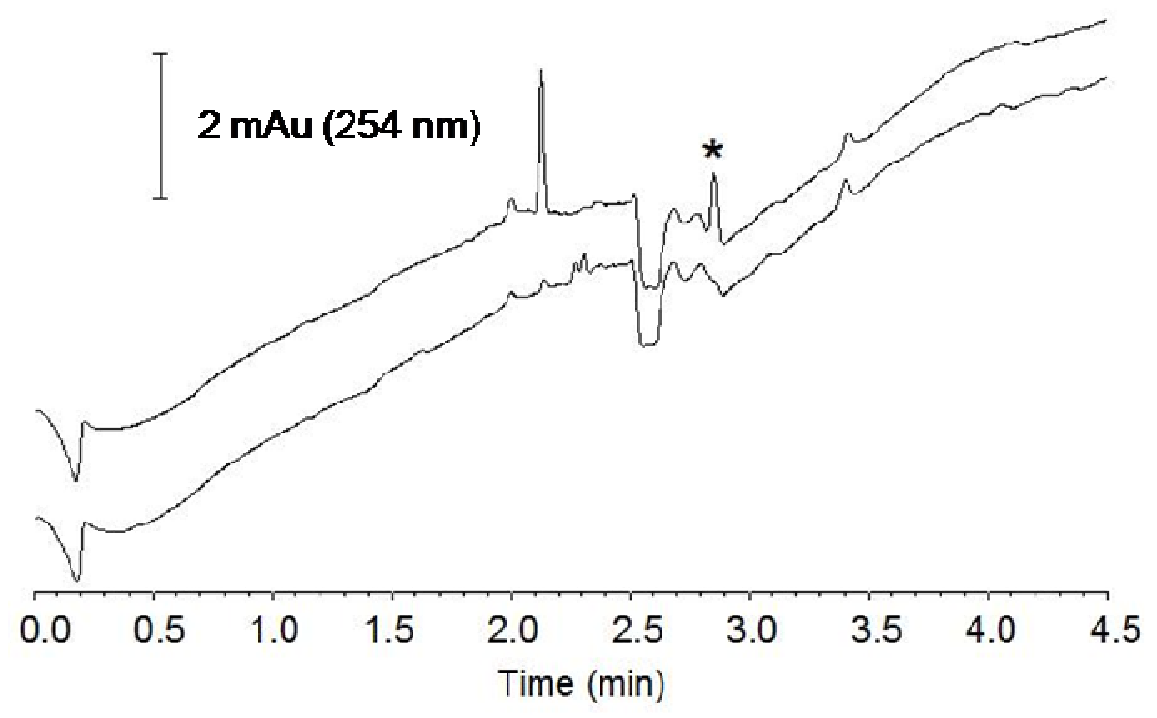

Figure 4.11. Steroid recovery data from a single catfish blood sample. Lower trace in A and B is the electropherogram obtained for the unspiked catfish blood extract. Top trace in A and B is catfish blood spiked with $14 \mathrm{ng}$ of testosterone and $2.7 \mathrm{ng}$ of $17 \beta$-estradiol prior to extraction. In A, * is recovered estradiol; in $\mathrm{B}$, * is recovered testosterone. 
In teleost fish 11-ketotestosterone is important for sexual differentiation and male sexual development $(51,52)$ and is a mediator of altered cellular function and differentiation, which makes steroid availability susceptible to environmental signals. While performing the measurement of the steroids in the fish plasma it was noticed that the levels of 11-ketotestosterone were much higher comparing to the results reported in the literature. Although both testosterone and 11-ketotestosterone strongly absorb light at the $254 \mathrm{~nm}$ wavelength they also produce low detection response at $200 \mathrm{~nm}$ as demonstrated in Figure 4.12-A. The intensity of the peak corresponding to the migration time of testosterone in the reconstituted fish plasma did not deviate from the effect observed for a standard steroid mixture, however, the opposite was observed for the peak corresponding to the migration time of ketotestosterone (Fig. 4.12-B). The intensity of this peak was much higher at $200 \mathrm{~nm}$ than at $254 \mathrm{~nm}$ thus suggesting the presence of an interfering compound which migrates at the same time as 11-ketotetsosterone. 11ketotestosterone was not quantified in the following fish studies as it requires massspectrometry detection in order to evaluate the nature of the interference and eliminate its presence from the sample for the accurate 11ketotestosterone detection. 


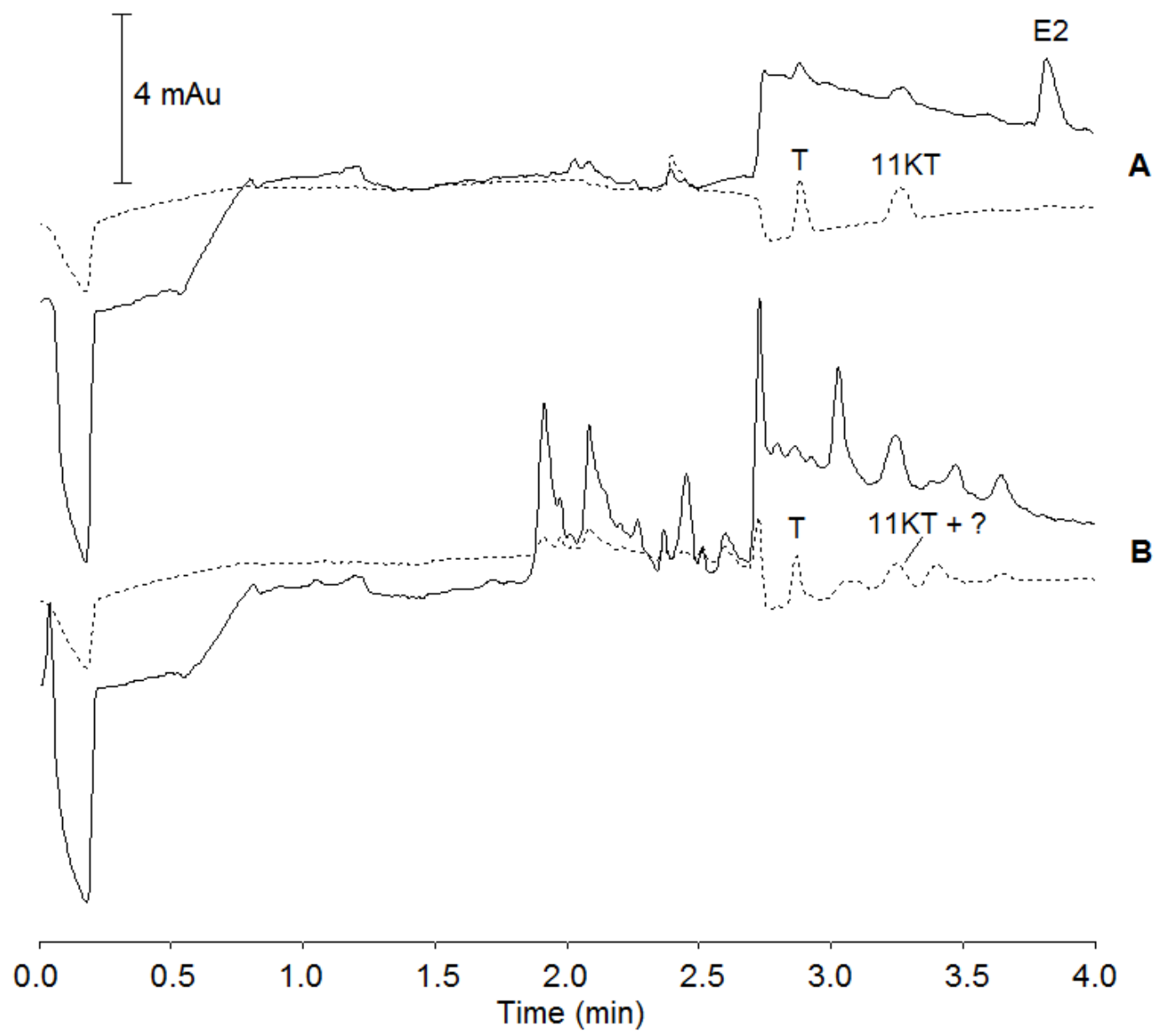

Figure 4.12. The electropherograms representing the analysis of a sample containing standard $\mathrm{T}, 11 \mathrm{KT}$, and E2 (A), and yellow perch plasma extract (B). Electropherograms shown in solid are measured at 200 $\mathrm{nm}$, electropherograms represented in dotted lines are measured at $254 \mathrm{~nm}$. Standard sample contained 250 $\mathrm{nM}$ of estradiol, $550 \mathrm{nM}$ testosterone and $2 \mu \mathrm{M} 11$ ketotestosterone. Standard samples were prepared in 1 $\mathrm{mM}$ CMCD, $5 \%$ methanol in $50 \mathrm{mM}$ CAPS buffered at $\mathrm{pH} 10$. The blood extract was reconstituted in the same sample buffer. The separation conditions are outlined in the text. 


\subsubsection{Calibration Method and Effect of Plasma Volume on Stacking}

The results obtained with the use of a three point external standard calibration curve were compared to the results measured with a three point standard addition method. The effect of the plasma sample volume on the analysis of steroids by the stackingmethod was studied as plasma volume can cause the variance in steroid recovery because the amount of extracted steroids as well as the interfering compounds increases with the increased plasma volume. A plasma sample from a single yellow perch fish was used for this experiment. A $100 \mu \mathrm{L}$ plasma volume was subjected to extraction with ethyl acetate and two solid-phase extraction columns as described in Section 4.2.8. An endogenous concentration of testosterone measured using a three point standard calibration curve was equal to $12 .{ }_{6} \pm 0 .{ }_{1} \mathrm{ng} / \mathrm{mL}$ plasma $\left(\mathrm{R}^{2}=1.000\right)$. By means of a standard addition method $11 \pm 1 \mathrm{ng}$ of testosterone was measured per $1 \mathrm{~mL}$ of plasma $\left(\mathrm{R}^{2}=0.990\right)$. As a standard addition curve the sample was sequentially spiked with $0.85 \mathrm{ng}$ of testosterone. Figure 4.13 is a representative example of a three point standard addition method used for analysis a yellow perch blood plasma sample. The results obtained by both calibration methods demonstrated close values, based on what, a 3-point standard calibration curve was further used for all the measurements.

In order to investigate how the volume of plasma taken for analysis affects the recovery of steroids the higher amount of the same plasma sample was extracted. The endogenous concentration of testosterone analyzed in $200 \mu \mathrm{L}$ of the same yellow perch plasma sample was found to be $13.5 \pm 0.3 \mathrm{ng} / \mathrm{mL}$ of plasma $\left(\mathrm{R}^{2}=1.000\right)$. Thus, the 
extraction procedure combined with stacking-CE analysis was not limited by a plasma sample volume.

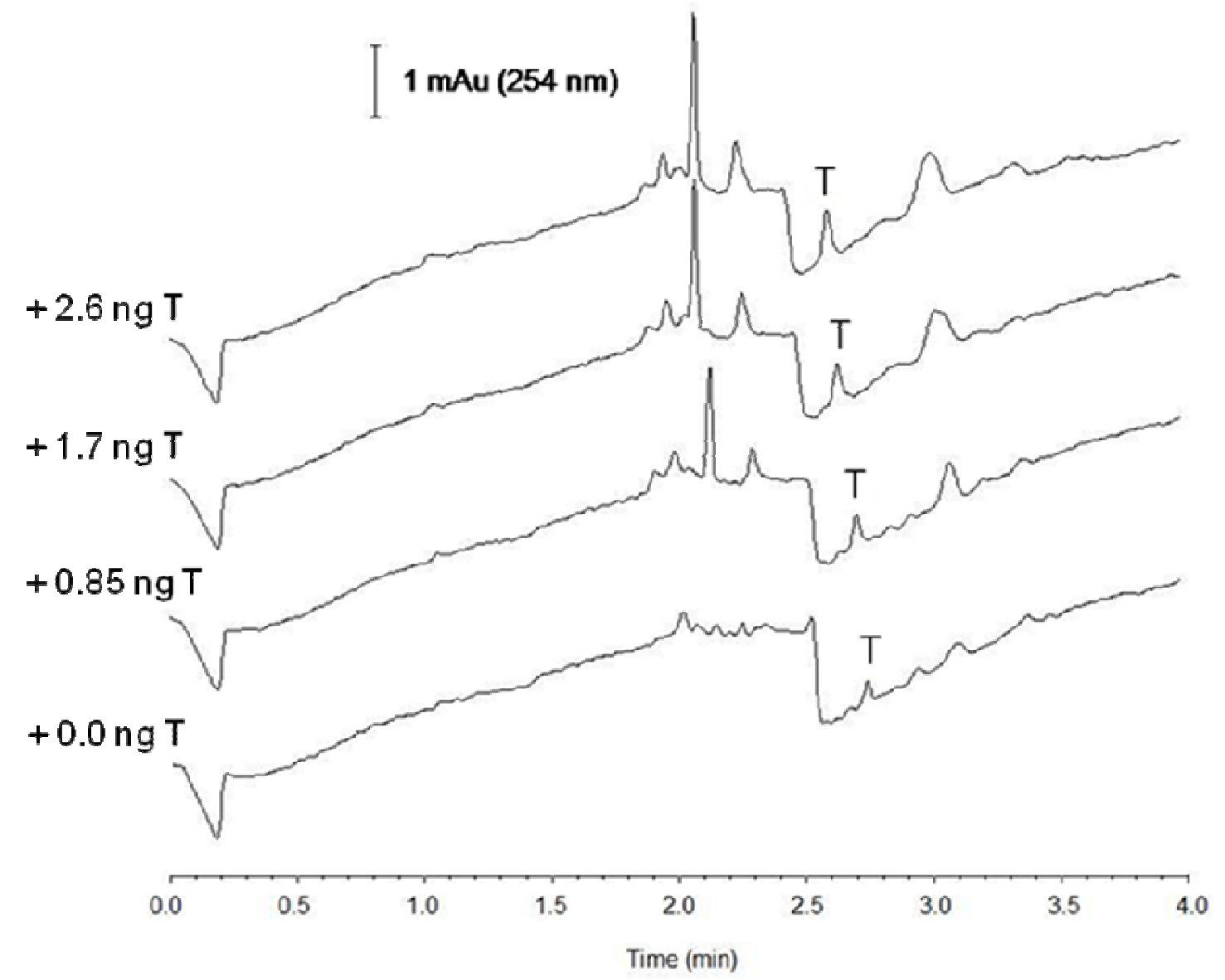

Figure 4.13. Illustrative stacking electropherograms obtained by the method of standard addition for a blood plasma sample from a single yellow perch fish. The lower trace is unspiked plasma sample. A three point standard addition curve $\left(\mathrm{R}^{2}=0.990\right)$ was obtained by repeatedly spiking the plasma extract with $0.85 \mathrm{ng}$ of testosterone. Peak labeled T is testosterone. 


\subsubsection{METHOD APPLICATION TO THE STEROID ANALYSIS IN YELLOW PERCH}

The stacking-MEKC method was applied to the analysis of a larger set of yellow perch fish provided by the researchers from USGS who were interested in studying the possibility of endocrine disruption in yellow perch. Yellow perch (Perca flavescens) are a valued resource in the Chesapeake Bay watershed and the Great Lakes as they are exploited commercially and recreationally. Historically, yellow perch in the Chesapeake Bay have supported a major commercial fishery, as well. However, the harvest declined from over one million pounds per year around 1900 to 66,000 pounds in 1990 (53). Landings rebounded to nearly 300,000 pounds by 2002 , driven primarily by catches in the Head-of-Bay region (54). In 1989, these population declines led to commercial and recreational closures (54). While some rivers have reopened their recreational fishery, several suburbanized tributaries (Severn, Magothy, South, and West Rivers) have not. One operational hypothesis for the decline of yellow perch in these rivers was that urban growth and development near the watersheds reduced the water quality, thereby decreasing recruitment success (55). Poor yellow recruitment has been observed in the Severn River, while stocks remain rather health in the Choptank River.

In the method application study eleven fish plasma samples were analyzed by $\mathrm{pH}-$ stacking MEKC. The fish samples were collected by the USGS researchers from two different sites: Severn River and Choptank River, sacrificed and processed for plasma samples as described in Section 4.2.5. The reproductive characteristics of the yellow perch fish used in this research have been studied by different fish biologists for several years (56-61). The plasma levels of estradiol, testosterone, 11-ketotestosterone and 
dihydroxyprogesterone in male and female yellow perch are summarized in Table 4.4. For female fish the concentration range for steroids in plasma are: $0.1-5 \mathrm{ng} / \mathrm{mL}$ estradiol; 0.1 $30 \mathrm{ng} / \mathrm{mL}$ testosterone; $0.1-2 \mathrm{ng} / \mathrm{mL}$ dihydroxyprogesterone. In the male fish the reported levels of the steroids in plasma are: $0.2-8 \mathrm{ng} / \mathrm{mL}$ 11-ketotestosterone range; $0.1-8$ $\mathrm{ng} / \mathrm{mL}$ testosterone; $0.01-0.02 \mathrm{ng} / \mathrm{mL}$ estradiol. All the values reported in the literature were determined by radioimmunoassay.

Table 4.4. Levels of plasma steroids in yellow perch fish measured by RIA reported in the literature.

\begin{tabular}{|c|c|c|c|c|c|c|}
\hline \multicolumn{3}{|c|}{ Female yellow perch } & \multicolumn{3}{|c|}{ Male yellow perch } & \multirow[t]{2}{*}{ Ref. } \\
\hline $\mathrm{E} 2, \mathrm{ng} / \mathrm{mL}$ & $\mathrm{T}, \mathrm{ng} / \mathrm{mL}$ & DHP, ng/mL & $11 \mathrm{KT}, \mathrm{ng} / \mathrm{mL}$ & $\mathrm{T}, \mathrm{ng} / \mathrm{mL}$ & $\mathrm{E} 2, \mathrm{ng} / \mathrm{mL}$ & \\
\hline $\begin{array}{l}0.4 \pm 0.1 \text { to } \\
3.0 \pm 0.3 \text { (fall) } \\
0.2 \pm 0.1 \text { to } \\
2.5 \pm 0.5 \\
\text { (winter) }\end{array}$ & $\begin{array}{l}2.0 \pm 0.5 \text { to } \\
3.0 \pm 0.5 \text { (fall) } \\
2.0 \pm 0.5 \text { to } \\
8 \pm 3 \text { (winter) }\end{array}$ & Not reported & $\begin{array}{l}2.0 \pm 0.5 \text { to } \\
4.0 \pm 0.5 \text { (fall) } \\
2.0 \pm 0.5 \text { to } \\
7 \pm 2 \text { (winter) }\end{array}$ & $\begin{array}{l}2.5 \pm 0.5 \text { to } \\
6.0 \pm 0.5 \text { (fall) } \\
2.0 \pm 0.2 \text { to } \\
8 \pm 4 \text { (winter) }\end{array}$ & Not reported & 56 \\
\hline Not reported & Not reported & Not reported & $\begin{array}{l}0.20 \pm 0.05 \\
\text { to } 0.6 \pm 0.3\end{array}$ & 0.1 to 4.3 & 0.01 to 0.02 & 57 \\
\hline 0.087 to 0.155 & 0.469 to 0.793 & Not reported & 0.523 to 0.881 & 0.856 to 1.035 & Not reported & 58 \\
\hline $\begin{array}{l}0.08 \pm 0.05 \text { to } \\
5.13 \pm 1.42\end{array}$ & 0.1 to 30 & Not reported & Not reported & Not reported & Not reported & 59 \\
\hline 0.1 to $3 \pm 1$ & 0.1 to $7 \pm 1$ & 0.1 to $2.0 \pm 0.5$ & $8.0 \pm 1.2$ & $2.8 \pm 0.8$ & Not reported & 60 \\
\hline
\end{tabular}

If $200 \mu \mathrm{L}$ of blood is collected from each fish, extracted and reconstituted in a sample volume suitable for automated CE measurements $(30 \mu \mathrm{L})$ the endogenous concentrations of steroids in this sample are expected to be for the female fish: $2.5-120$ 
nM estradiol; 2.3 - $690 \mathrm{nM}$ testosterone; 2.0 - $40 \mathrm{nM}$ dihydroxyprogesterone. In male fish samples these concentrations will be: $4.4-180 \mathrm{nM}$ 11-ketotestosterone; $2.3-190 \mathrm{nM}$ testosterone; $0.25-0.50 \mathrm{nM}$ estradiol. The limits of detection of the developed method are reported in Table 4.1 and are $2.9 \pm 0.6 \mathrm{nM}$ estradiol, $4 \pm 1 \mathrm{nM}$ testosterone, $11 \pm 3 \mathrm{nM}$ dihydroxyprogesterone and $14 \pm 3 \mathrm{nM}$ 11-ketotestosterone. The linear range of the method is $0.050-5.0 \mu \mathrm{L}$ estradiol, $0.10-14 \mu \mathrm{L}$ testosterone, $0.20-5.0 \mu \mathrm{L}$ dihydroxyprogesterone, and $0.50-10 . \mu \mathrm{L} 11$-ketotestosterone. Due to the low concentrations of the endogenous steroids in fish only major steroids were quantified in this work. The results for steroids measured in yellow perch by stacking-CE are summarized in Table 4.5. The results are obtained from a three point external calibration curve. Because of the limited plasma volumes available for this study, the obtained values were based on a single analysis for each yellow perch sample. Each analyzed plasma volume was $200 \mu$ l except for SE 21, which was $250 \mu \mathrm{l}$. As seen from the data the concentrations of steroids measured by the developed method were at the higher range of the expected levels reported in the literature. 
Table 4.5. Analysis of endogenous steroids in blood plasma of yellow perch ${ }^{\mathrm{a}}$

\begin{tabular}{|c|c|c|c|c|c|c|c|c|}
\hline & & Testosterone & Testos & & Estradiol & $\overline{\text { Estrad }}$ & & Dihydroxy- \\
\hline Plasma & Fish & Stacking-CE & RIA & & Stacking-CE & RIA & & Stacking-CE \\
\hline sample & sex & (ng/mL & $(\mathrm{ng} / \mathrm{ml}$ & lasma) & (ng/mL & (ng/mI & lasma) & (ng/mL \\
\hline & & & 1 & 2 & & 1 & 2 & \\
\hline$\overline{S E} 21$ & $\bar{F}$ & $28.28 \pm 0.04$ & 25.16 & 26.67 & $1.5 \pm 0.4$ & 1.35 & 1.21 & - \\
\hline SE 24 & $\mathrm{~F}$ & $13.5 \pm 0.3$ & 10.91 & 11.73 & - & 0.97 & 0.93 & $16 \pm 7$ \\
\hline SE 25 & M & $30.5 \pm 0.7$ & 29.28 & 26.64 & - & 0.264 & 0.203 & $16 \pm 6$ \\
\hline SE 26 & $\mathrm{~F}$ & $43.9 \pm 0.9$ & 41.59 & 39.6 & - & 0.997 & 0.924 & $5 \pm 7$ \\
\hline SE 28 & $\mathrm{~F}$ & $1.3 \pm 0.9$ & 2.68 & 1.91 & - & 0.688 & 0.725 & $34 \pm 6$ \\
\hline SE 29 & M & $9.3 \pm 0.8$ & 7.34 & 7.82 & - & 0.277 & 0.31 & $11 \pm 7$ \\
\hline SE 32 & M & $15.5 \pm 0.5$ & 13.55 & 12.94 & $1.3 \pm 0.3$ & 0.248 & 0.281 & - \\
\hline $\mathrm{CH} 23$ & $\mathrm{~F}$ & $0.9 \pm 0.6$ & 0.986 & 1.0 & $1.7 \pm 0.8$ & 1.44 & 1.62 & - \\
\hline $\mathrm{CH} 24$ & M & $4.8 \pm 0.6$ & 4.69 & 4.74 & - & 0.294 & 0.221 & - \\
\hline CH 27 & $\mathrm{~F}$ & $20 \pm 2$ & 27.22 & 28.38 & - & 0.993 & 1.07 & $19 \pm 8$ \\
\hline CH 36 & M & ND & 30.52 & 27.8 & $1.2_{8} \pm 0.0_{5}$ & 0.281 & 0.392 & - \\
\hline
\end{tabular}

${ }^{a}$ Results are obtained using a 3 point external calibration curve $(n=1)$. Each analyzed plasma volume was $200 \mu \mathrm{l}$ except for SE 21 which was $250 \mu \mathrm{l} .{ }^{\mathrm{b}}$ SE - Severn River; CH - Choptank River; ND - not determined; and $(-)$ - below lowest standard, not quantified. 


\subsubsection{MEthod Comparison to Commercially AVAILABLE TECHNIQUES}

There are two ways to evaluate the accuracy of the developed method: (1) by performing the recovery studies of the steroid-free plasma that is spiked with gravimetrically determined amounts of a steroid and (2) by comparison to the measurements obtained by an independent method. In biomedical laboratories steroid hormones are frequently quantified by immunoassay technique (Section 1.2.3). Most of the immunoassays used are commercially available kits, which contain all the reagents required to perform an instrumental measurement of steroids in biological samples. However, a few publications reported a need for more thorough validation of the commercial immunoassay kits prior to use (62-65). The lack of specificity and the need of a different assay for each steroid are the major problems associated with immunoassays for the steroids. Taieb and co-workers (66) conducted a study in which they compared ten different commercially available immunoassay kits with isotope-dilution GC-MS for analysis of testosterone in sera of 116 men, women and children. They concluded that none of the immunoassays tested were fully reliable for analysis of testosterone. Seven immunoassays demonstrated systematic $46 \%$ overestimation and the other three showed systematic $12 \%$ underestimation of the testosterone levels compared to the results obtained by the isotope dilution GC-MS. The possible reasons for the poor agreement between the results obtained by the two methods were: (1) matrix effect; (2) crossreactivity of the antibody with structurally similar steroids and metabolites; (3) the limit of detection and sensitivity of the immunoassay. Other reports suggested the measurement of 
plasma testosterone by current commercially available immunoassay is also a matter of concern for similar reasons $(67,68)$.

Isotope-dilution GC-MS, another reference method (Section 1.2.2) requires expensive isotope standards and in order to be applied for method comparison in our lab, the method had to be developed and optimized with respect to the fish plasma sample matrix. In order to save time an attempt to find contract laboratory groups who had validated the isotope-dilution GC-MS method in-house and would be interested to analyze a few fish plasma samples prepared by our method for the presence of targeted steroids and method comparison. Due to difficulty locating any commercial laboratories capable of isotope-dilution GC-MS analyses of steroids a few laboratories which analyzed steroids by isotope-dilution LC-MS/MS were contacted. It was shown previously that isotope-dilution LC-MS/MS demonstrates the same accuracy for steroid analysis as isotope dilution GCMS (69-71) and is more popular in the clinical laboratories. Several contract laboratories have been contacted (72, personal communication by L. Bykova); however, most indicated concern that their methods have not been validated for the fish plasma matrices. Therefore, the developed method was evaluated by performing the recovery studies and by comparison to immunoassay which was available from the USGS collaboration group.

As expected some steroids were below the limit of detection, some fell into the expected concentration range, while some steroids were detected at higher concentrations than expected. The results were compared to radioimmunoassay as described in Section 4.2.9. The $80 \%$ of the results measured by stacking-CE were close to and deviated by no more than $20 \%$ from the results measured by radioimmunoassay. Testosterone was not detected by the stacking method in the sample $\mathrm{CH} 36$ due to a shift in the baseline of the 
electropherogram caused by unknown reasons that interfered with the detection of the testosterone peak. The levels of estradiol in SE 32 and $\mathrm{CH} 36$ exceeded the results reported by radioimmunoassay by $>74 \%$ and could be due to the fact that the peak areas for estradiol measured by stacking-CE corresponded to the concentrations at the very low region of the calibration curve where larger standard deviations were observed. The concentration of estradiol in samples SE 24-26, 28, 29 and CH 24, 27 was not quantified because the peak areas for estradiol corresponded to the concentrations below the lowest steroid standard in the calibration curve. Dihydroxyprogesterone, in turn, was not measured by radioimmunoassay and, therefore, could not be compared to stacking-CE. However, the presence of dihydroxyprogesterone was determined in the female plasma samples SE 24, 26, 28, and CH 27 as well as in two male plasma samples SE 25 , and 29 by stacking-CE.

\subsubsection{FISH INSIGHT}

While in males the levels of 11-ketotestosterone and testosterone remain constant throughout the year, the high levels of testosterone in female fish are due to the fact that no estradiol needs to be produced after the vitellogenesis (formation of the yolk of an egg) in the females (17). Because the yellow perch in this study were captured during their spawning which occurs after the vitellogenesis the high levels of testosterone in the female fish (see Table 4.5) are not surprising. The presence of dihydroxyprogesterone in female samples SE 24, 26, 28, and CH 27 suggests the presence of the developing oocytes in these fish species, while the presence of dihydroxyprogesterone in two male plasma samples, SE 25 and 29 , is alarming because it can be associated with the presence of the developing eggs in the males. Both, SE 25 and 29, samples were collected from the Severn River 
where the recruitment of the yellow perch population has been decreasing over the past few years due to the water pollution caused by the rapid urbanization of the surrounding areas (55). Ethynyl estradiol, a component of the birth control pills and a potential EDC, was not found in the fish plasma samples. The data for 11-ketotestosterone is not included (Table 4.5) as it co-migrates with an unknown interference and thus requires a mass-spectrometry analysis in order to determine it.

\section{CONCLUSIONS AND FUTURE DIRECTIONS}

Chapter 4 demonstrated the development of a three step extraction protocol for the plasma pretreatment prior to the stacking-MEKC analysis which was validated using the aqueous steroid samples and the extracts of the plasma from four different fish species. The optimized extraction protocol followed by $\mathrm{pH}$-stacking-MEKC method was applied to the analysis of steroids in the plasma of yellow perch and the obtained results were validated by immunoassay. The method showed good promise for the analysis of steroids in plasma samples.

In future studies, the method can be applied to other fish species, wild or lab maintained. The lab maintained fish, for example Japanese medaka, is widely used in biological studies due to their ability to reproduce in the lab and the short period of the development of sexual differentiation, which is extremely important for monitoring endocrine disruption. The small size of the fish allows for the statistical description of a large fish population. Using robotic systems available in many pharmaceutical laboratories, it is possible to multiplex the set of the samples prepared for analysis simultaneously to a 
minimum of 96 samples. Therefore the total sample preparation time will be considerably decreased.

Additional studies may include the analysis of the steroid conjugates circulating in the plasma, glucuronides and sulfates. Plasma samples can be treated by enzymes for hydrolysis of the steroid conjugates. Simultaneous analysis of all the sample constituents is important because it is desirable to determine not only the targeted steroids but also any interfering compounds or unexpected steroid metabolites which may appear as a result of the fish exposure to the EDCs. CE-MS can be used for structural elucidation of those steroids and conjugated steroids for which no standards are available.

The method can be incorporated on a microchip to create a portable device that can be used for the field studies. This device will eliminate the need of collecting fish plasma samples and sending them over to chemistry laboratories for profiling steroids in fish samples.

Finally the method can be applied for analysis of steroids in human plasma. In this dissertation research the developed method was applied to the analysis of a human serum certified reference material with a known content of estradiol. Human serum (17ßestradiol, high level) certified reference material was purchased from RT-Corp (Laramie, WY). The sample was certified by BCR (Community Bureau of Reference, the former reference materials program of the European Commission). A certified concentration of $17 \beta$-estradiol present in human serum standard was $1.34 \pm 0.07 \mathrm{nmol} / \mathrm{L}$ measured by isotope dilution GC-MS. The method used different isotopic labeled internal standards and chromatographic columns, following extraction with $\mathrm{CH}_{2} \mathrm{Cl}_{2}$ and clean-up by solid-phase 
extraction. The standard was reconstituted following instructions in the certificate of analysis. However, the obtained results for the estradiol concentration measured in human serum standard were inconclusive because of the sample matrix effect. This was expected to occur as the composition of human serum differs from the composition of fish plasma and the levels of endogenous steroids in fish are higher than those in humans. Therefore the analysis of human biological fluids requires a reconsideration of the plasma/serum pretreatment scheme prior to the use of the stacking-CE analysis.

\section{BIBLIOGRAPHY}

1. Keith, L. H.; Jones-Lepp, T. L.; Needham, L. L., Eds. Analysis of Environmental Endocrine Disruptors, ACS Symposium Series 747; American Chemical Society: Washington, DC, 2000; pp 80-82.

2. Kime, D.E. Endocrine disruption in fish, 1st ed.; Springer Kluwer: Boston, MA, 1998; pp 1-14.

3. Metzler, M., Ed. Endocrine disruptors, Part I, 1st ed.; Springer, NY, 2001; Chapters 7-9.

4. Sherwood, N. M.; Hew, C. L. Molecular endocrinology of fish. In: Fish physiology, Academic Press: San Diego, CA, 1994; Vol. XIII.

5. Jobling, S.; Tyler, C. R. Endocrine Disruption in Wild Freshwater Fish. Pure Appl. Chem. 2003, 75 (11-12), 2219-2234.

6. Lathers, C. M. Endocrine Disruptors: A New Scientific Role for Clinical Pharmacologists? Impact on Human Health, Wildlife, and the Environment. J. Clin. Pharmacol. 2002, 42 (1), 7-23.

7. Desbrow, C.; Routledge, E. J.; Brighty, G. C.; Sumpter, J. P.; Waldock, M. Identification of Estrogenic Chemicals in STW Effluent. 1. Chemical Fractionation and in Vitro Biological Screening. Environ. Sci. Technol. 1998, 32 (11), 1549-1558.

8. Ternes, T. A.; Stumpf, M.; Mueller, .J.; Haberer, K.; Wilken, R. D.; Servos, M. Behavior and Occurrence of Estrogens in Municipal Sewage Treatment Plants I. Investigations in Germany, Canada and Brazil. Sci. Total Environ. 1999, 225 (1-2), 81-90. 
9. Jobling, S.; Sheahan, D.; Osborne, J. A.; Matthiessen, P.; Sumpter, J. P. Inhibition of Testicular Growth in Rainbow Trout (Oncorhynchus Mykiss) Exposed to Estrogenic Alkylphenolic Chemicals. Environ. Toxicol. Chem. 1996, 15 (2), 194-202.

10. Iwama, G. K.; Pickering, A. D.; Sumpter, J. P.; Schreck, C. B. Eds. Fish stress and health in aquaculture. Cambridge University Press, U.K., 1997; pp 73-94.

11. Vethaak, A. D.; Lahr, J.; Kuiper, R. V.; Grinwis, G. C. M.; Rankouhi, T. R.; Giesy, J. P; Gerritsen, A. Estrogenic Effects in Fish in The Netherlands: Some Preliminary Results. Toxicology 2002, 181-182, $147-150$.

12. Shilling, A. D.; Williams, D. E. Determining Relative Estrogenicity by Quantifying Vitellogenin Induction in Rainbow Trout Liver Slices. Toxicol. Appl. Pharmacol. 2000, 164 (3), 330-335.

13. Rodgers-Gray, T. P.; Jobling, S.; Morris, S.; Kelly, C.; Kirby, S.; Janbakhsh, A.; Harries, J. E.; Waldock, M. J.; Sumpter, J. P.; Tyler, C. R. Long-Term Temporal Changes in the Estrogenic Composition of Treated Sewage Effluent and Its Biological Effects on Fish. Environ. Sci. Technol. 2000, 34 (8), 1521-1528.

14. Smeets, J. M. W.; Van Holsteijn, I.; Giesy, J. P.; Seinen, W.; Van den Berg, M. Estrogenic Potencies of Several Environmental Pollutants, as Determined by Vitellogenin Induction in a Carp Hepatocyte Assay. Toxicol. Sci. 1999, 50 (2), 206-213.

15. Tolar, J. F.; Mehollin, A. R.; Watson, R. D.; Angus, R. A. Mosquitofish (Gambusia Affinis) Vitellogenin: Identification, Purification, and Immunoassay. Comp. Biochem. Physiol., C: Toxicol. Pharmacol. 2001, 128 (2), 237-245.

16. Scott, A. P.; Sumpter, J. P. A Comparison of the Female Reproductive Cycles of Autumn-Spawning and Winter-Spawning Strains of Rainbow Trout (Salmo Gairdneri Richardson). Gen. Comp. Endocrinol. 1983, 52 (1), 79-85.

17. Sumpter, J. P.; Jobling, S. Vitellogenesis as a Biomarker for Estrogenic Contamination of the Aquatic Environment. Environ. Health Perspect. 1995, 103 (Suppl. 7), 173-178.

18. Copeland, P. A.; Sumpter, J. P.; Walker, T. K.; Croft, M. Vitellogenin Levels in Male and Female Rainbow Trout (Salmo Gairdneri Richardson) at Various Stages of the Reproductive Cycle. Comp. Biochem. Physiol., B: Biochem. Mol. Biol. 1986, 83 (2), 487-493. 
19. Tyler, C. R.; Sumpter, J. P.; Bromage, N. R. In vivo Ovarian Uptake and Processing of Vitellogenin in the Rainbow Trout, Salmo Gairdneri. J. Exp. Zool. 1988, 246 (2), 171-179.

20. Purdom, C. E.; Hardiman, P. A.; Bye, V. J.; Eno, N. C.; Tyler, C. R.; Sumpter, J. P. Estrogenic Effects of Effluents From Sewage Treatment Works. Chem. Ecol. 1994, 8 (4), 275-285.

21. Scott, A. P; Katsiadaki, I.; Kirby, M. F; Thain, J. Relationship between Sex Steroid and Vitellogenin Concentrations in Flounder (Platichthys Flesus) Sampled from an Estuary Contaminated with Estrogenic Endocrine-Disrupting Compounds. Environ. Health Perspect. 2006, 114 (Suppl. 1), 27-31.

22. Foran, C. M.; Peterson, B. N.; Benson, W. H. Transgenerational and Developmental Exposure of Japanese Medaka (Oryzias Latipes) to Ethinylestradiol Results in Endocrine and Reproductive Differences in the Response to Ethinylestradiol as Adults. Toxicol. Sci. 2002, 68 (2), 389-402.

23. Fostier, A.; Jalabert, B.; Billard, R.; Breton, B.; Zohar, Y. The Gonadal Steroids. Fish. Physiol. 1983, 9 (A), 277-372.

24. Lofts, B. Testicular Function. In Hormones and Reproduction in Fishes, Amphibians, and Reptiles; Norris, D. O., Jones, R. E., Eds.; Plenum Press: New York, 1987.

25. Miura, T.; Yamauchi, K.; Takahashi, H.; Nagahama, Y. Hormonal Induction of All Stages of Spermatogenesis in vitro in the Male Japanese Eel (Anguilla Japonica). Proc. Natl. Acad. Sci. U.S.A. 1991, 88 (13), 5774-5778.

26. Redding, M.; Patino, R. Reproductive physiology. In Physiology of Fishes; Evans, D. H. Ed.; CRC Press: Boca Raton, 1993.

27. Borg, B. Androgens in Teleost Fishes. Comp. Biochem. Physiol., C: Pharmacol. Toxicol. Endocrinol. 1994, 109 (3), 219-245.

28. Goetz, F. W.; Theofan, G. In vitro Stimulation of Germinal Vesicle Breakdown and Ovulation of Yellow Perch (Perca Flavescens) Oocytes. Effects of 17 $\alpha$-hydroxy-20 $\beta$-dihydroprogesterone and Prostaglandins. Gen. Comp. Endocrinol. 1979, 37 (3), 273-285.

29. Duffey, R. J.; Goetz, F. W. The in vitro Effects of $17 \alpha$-hydroxy-20 $\beta$-dihydroprogesterone on Germinal Vesicle Breakdown in Brook Trout (Salvelinus Fontinalis) Oocytes. Gen. Comp. Endocrinol. 1980, 41 (4), 563-565. 
30. Devlin, T. M. Textbook of Biochemistry with Clinical Correlations, 5th ed., John Wiley \& Sons Ltd., U.K., 2001.

31. Sower, S. A.; Schreck, C. B. Steroid and Thyroid Hormones During Sexual Maturation of Coho Salmon (Oncorhynchus Kisutch) in Seawater or Fresh Water. Gen. Comp. Endocrinol. 1982, 47 (1), $42-53$.

32. Kime, D. 'Classical' and 'Non-classical' Reproductive Steroids in Fish. Rev. Fish Biol. Fish. 1993, 3 (2), 160-180.

33. Hunt, S. M. V.; Simpson, T. H.; Wright, R. S. Seasonal Changes in the Levels of 11-Oxotestosterone and Testosterone in the Serum of Male Salmon, Salmo Salar L., and Their Relationship to Growth and Maturation Cycle. J. Fish Biol. 1982, 20 (1), 105-119.

34. Truscott, B.; Idler, D. R.; So, Y. P.; Walsh, J. M. Maturational Steroids and Gonadotropin in Upstream Migratory Sockeye Salmon. Gen. Comp. Endocrinol. 1986, 62 (1), 99-110.

35. Rosenblum, P. M.; Yamada, L.; Callard, I. P.; Callard, G.V. Validation of Radioimmunoassay Systems for the Measurement of 11-keto- and 11ß-hydroxytestosterone in Teleost Blood. Comp. Biochem. Physiol., B: Biochem. Mol. Biol. 1985, 82 (4), 659-665.

36. Leatherland, J. F.; Copeland, P.; Sumpter, J. P.; Sonstegard, R. A. Hormonal Control of Gonadal Maturation and Development of Secondary Sexual Characteristics in Coho Salmon, Oncorhynchus Kisutch, from Lakes Ontario, Erie, and Michigan. Gen. Comp. Endocrinol. 1982, 48 (2), 196-204.

37. Stuart-Kregor, P. A. C.; Sumpter, J. P.; Dodd, J. M. The Involvement of Gonadotrophin and Sex Steroids in the Control of Reproduction in the Parr and Adults of Atlantic Salmon, Salmo Salar L. $J$. Fish Biol. 1981, 18 (1), 59-72.

38. Mayer, I.; Schmitz, M.; Borg, B.; Schulz, R. Seasonal Endocrine Changes in Male and Female Arctic Charr (Salvelinus Alpinus). I. Plasma Levels of Three Androgens, 17 $\alpha$-hydroxy-20 $\beta$ dihydroprogesterone, and $17 \beta$-estradiol. Can. J. Zool. 1992, 70 (1), 37-42.

39. Goetz, F. W.; Bergman, H. L. The Effects of Steroids on Final Maturation and Ovulation of Oocytes from Brook Trout (Salvelinus Fontinalis) and Yellow Perch (Perca Flavescens). Biol. Reprod. 1978, 18 (2), 293-298.

40. Kaupp, S.; Bubert, H.; Baur, L.; Nelson, G.; Watzig, H. Unexpected Surface Chemistry in Capillaries for Electrophoresis. J. Chromatogr., A 2000, 894 (1+2), 73-77. 
41. Pinillos, M. L.; Delgado, M. J.; Scott, A. P. Seasonal Changes in Plasma Gonadal Steroid Concentrations and Gonadal Morphology of Male and Female Tench (Tinca Tinca, L.). Aquac. Res. 2003, 34 (13), 1181-1189.

42. Kime, D. E.; Ebrahimi, M. Synthesis of 17,20 $\alpha$ - and 17,20 $\beta$-dihydroxy-4-pregnen-3-ones, 11ketotestosterone and Their Conjugates by Gills of Teleost Fish. Fish Physiol. Biochem. 1997, 17 (1-6), 117-121.

43. Zief, M.; Crane, L. J.; Horvath, J. Preparation of Steroid Samples by Solid-Phase Extraction. Am. Lab. (Shelton, CT, United States) 1982, 14 (5), 120 - 130.

44. Al-Alousi, L. M.; Anderson, R. A. A Relatively Simple and Rapid Multi-Component Method for Analysis of Steroid Profiles in Blood, Fecal and Liver Samples. Steroids 2002, 67 (3, 4), 269-275.

45. Heinz, B. Methods of Hormone Analysis. Wiley, John \& Sons, Inc.: New York, 1976; pp 520.

46. Nelson, D. L.; Cox, M. M., Eds.; Lehninger Principles of Biochemistry, $4^{\text {th }}$ ed.; W. H. Freeman: New York, NY, 2004; Chapter 12, pp 412-479.

47. Williams, R. O., III; Mahaguna, V.; Sriwongjanya, M. Characterization of an Inclusion Complex of

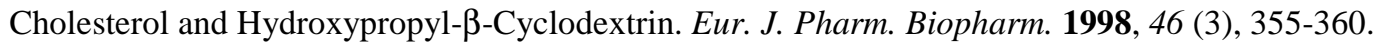

48. Mazellier, P.; Meite, L.; De Laat, J. Photodegradation of the Steroid Hormones 17ß-estradiol (E2) and 17 $\alpha$-ethinylestradiol (EE2) in Dilute Aqueous Solution. Chemosphere 2008, 73 (8), 1216-1223.

49. Rosenfeldt, E. J.; Linden, K.G. Degradation of Endocrine Disrupting Chemicals Bisphenol A, Ethinyl Estradiol, and Estradiol during UV Photolysis and Advanced Oxidation Processes. Environ. Sci. Technol. 2004, 38 (20), 5476-5483.

50. Tonnesen, H. H. Photostability of Drugs and Drug Formulations, 2nd ed., CRC, 2004; pp 9-40.

51. Brantley, R. K.; Wingfield, J. C.; Bass, A. H. Sex Steroid Levels in Porichthys Notatus, a Fish with Alternative Reproductive Tactics, and a Review of the Hormonal Bases for Male Dimorphism among Teleost Fishes. Horm. Behav. 1993, 27 (3), 332-347.

52. Baroiller, J.-F.; Guiguen, Y.; Fostier, A. Endocrine and Environmental Aspects of Sex Differentiation in Fish. Cell. Mol. Life Sci. 1999, 55 (6/7), 910-931. 
53. Piavis, P. Yellow Perch Perca Flavescens. In Habitat Requirements for Chesapeake Bay Living Resources; Funderburk, S. L., Jordan, S. J., Mihursky, J. A., Riley, D., Eds., 2nd ed.; Chesapeake Bay Program, Living Resources Subcommittee, Annapolis, MD, 1991; 14.1-14.15.

54. Maryland Department of Natural Resources Home page. http://www.dnr.state.md.us/ (accessed April 10, 2009)

55. Iwanowicz, L. R. U.S. Geological Survey Leetown Science Center, Kearneysville, WV. Personal Communication, 2009.

56. Van den Heuvel, M. R.; Power, M.; MacKinnon, M. D.; Dixon, D. G. Effects of Oil Sands Related Aquatic Reclamation on Yellow Perch (Perca Flavescens). II. Chemical and Biochemical Indicators of Exposure to Oil Sands Related Waters. Can. J. Fish. Aquat. Sci. 1999, 56 (7), 1226-1233.

57. Ciereszko, R. E.; Dabrowski, K.; Ciereszko, A.; Ottobre, J. S. Plasma Concentrations of Steroid Hormones in Male Yellow Perch, Perca flavescens: the Effect of Age and Photothermal Manipulation. Environ. Biol. Fishes 1998, 51, 97-105.

58. Dabrowska, H.; Fisher, S.W.; Ciereszko, R.; Dabrowski, K.; Woodin, B.R.; Stegeman, J.J. Hepatic P4501A Activity, Plasma Sex Steroids, and Gonadal Steroidogenesis in vitro in Yellow Perch Exposed to 3,3',4,4',5-pentachlorobiphenyl. Environ. Toxicol. Chem. 2000, 19 (12), 3052-3060.

59. Ciereszko, R. E.; Dabrowski, K.; Ciereszko, A.; Ebeling, J.; Ottobre, J. S. Effects of Temperature and Photoperiod on Reproduction of Female Yellow Perch Perca Flavescens: Plasma Concentrations of Steroid Hormones, Spontaneous and Induced Ovulation, and Quality of Eggs. J. World Aquac. Soc. 1997, 28, 344-356.

60. Rinchard, J.; Dabrowski, K.; Ottobre, J. Changes of Plasma Steroid Concentrations Associated with Spontaneous or Induced Ovulation in Yellow Perch Perca Flavescens. Fish Physiol. Biochem. 2003, 26 (3), 239-248.

61. Dabrowski, K.; Ciereszko, R. E; Ciereszko, A.; Ottobre, J. S. In vitro Production of Ovarian Steroids in Yellow Perch (Perca Flavescens): Effects of Photothermal Manipulation, Gonadotropin and Phorbol Ester. Reprod. Biol. 2002, 2 (2), 163-186.

62. Findlay, J. W.; Smith, W. C.; Lee, J. W.; Nordblom, G. D.; Das, I.; DeSilva, B. S.; Khan, M. N.; Bowsher, R. R. Validation of Immunoassays for Bioanalysis: a Pharmaceutical Industry Perspective. J. Pharm. Biomed. Anal. 2000, 21 (6), 1249-1273. 
63. Rosner, W.; Auchus, R. J.; Azziz, R.; Sluss, P. M.; Raff, H. Utility, Limitations, and Pitfalls in Measuring Testosterone: an Endocrine Society Position Statement. J. Clin. Endocrinol. Metab. 2007, $92(2), 405-413$.

64. Matsumoto, A. M; Bremner, W. J. Serum Testosterone Assays - Accuracy Matters. J. Clin. Endocrinol. Metab. 2004, 89 (2), 520-524.

65. Herold, D. A; Fitzgerald, R. L. Immunoassays for Testosterone in Women: Better than a Guess? Clin. Chem. 2003, 49 (8), 1250-1251.

66. Taieb, J.; Mathian, B.; Millot, F.; Patricot, M.-C.; Mathieu, E.; Queyrel, N.; Lacroix, I.; SommaDelpero, C.; Boudou, P. Testosterone Measured by 10 Immunoassays and by Isotope-Dilution Gas Chromatography-Mass Spectrometry in Sera from 116 Men, Women, and Children. Clin. Chem. 2003, 49 (8), 1381-1395.

67. Fitzgerald, R. L.; Herold, D. A. Serum Total Testosterone: Immunoassay Compared with Negative Chemical Ionization Gas Chromatography-Mass Spectrometry. Clin. Chem. 1996, 42 (5), 749-755.

68. Wang, C.; Catlin, D. H.; Demers, L.M.; Starcevic, B.; Swerdloff, R. S. Measurement of Total Serum Testosterone in Adult Men: Comparison of Current Laboratory Methods Versus Liquid Chromatography-Tandem Mass Spectrometry. J. Clin. Endocrinol. Metab. 2004, 89 (2), 534-543.

69. Tai, S. S.-C.; Welch, M. J. Development and Evaluation of a Reference Measurement Procedure for the Determination of Estradiol-17 $\beta$ in Human Serum Using Isotope-Dilution Liquid ChromatographyTandem Mass Spectrometry. Anal. Chem. 2005, 77 (19), 6359-6363.

70. Kozak, M.; Torchilin, K. Quantitative Analysis of Testosterone in Plasma by LC-MS. LC-GC Europe 2008, 8 .

71. Guo, T.; Taylor, R. L.; Singh, R. J.; Soldin, S.J. Simultaneous Determination of 12 Steroids by Isotope Dilution Liquid Chromatography-Photospray Ionization Tandem Mass Spectrometry. Clin. Chim. Acta 2006, 372 (1-2), 76-82. 
72. BioScreen Testing Services, Torrance, CA; Olympic Analytical Laboratory, Los Angeles, CA; Analytical Chemistry Division, Chemical Science and Technology Laboratory, NIST, Gaithersburg, MD; Thermo Electron Corporation (Thermo Finnigan), San Jose, CA; Department of Obstetrics and Gynecology - WVU Center for Reproductive Medicine, Morgantown, WV; Bioanalytical Core Laboratory, General Clinical Research Center, Georgetown University, Washington, DC, USA; Redwood toxicology lab, Santa Rosa, CA; Drug test systems, Dover, NH. Personal Communication, 2009. 


\section{APPENDIX}

Table A.1. Chemical structures of sex steroid hormones employed in research.

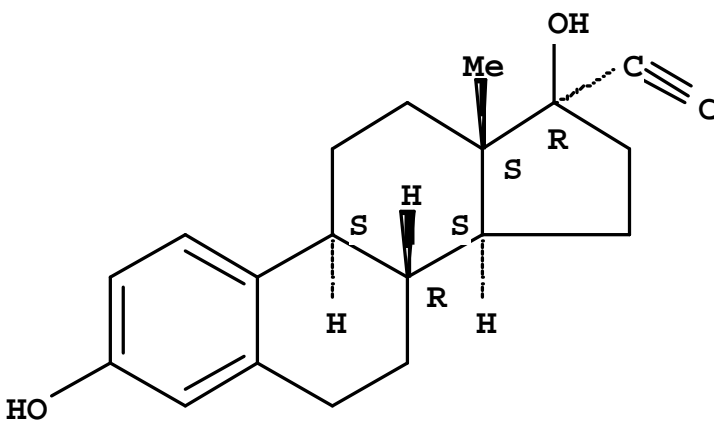

17- $\alpha$-ethynyl estradiol

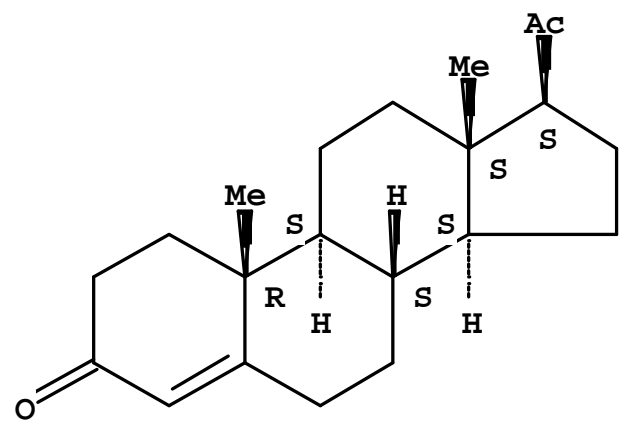

Progesterone

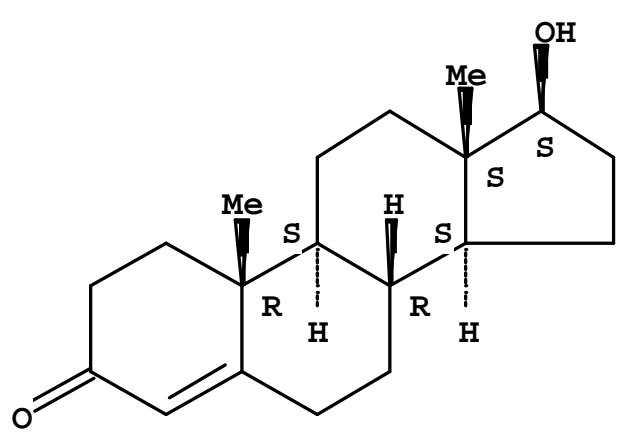

Testosterone

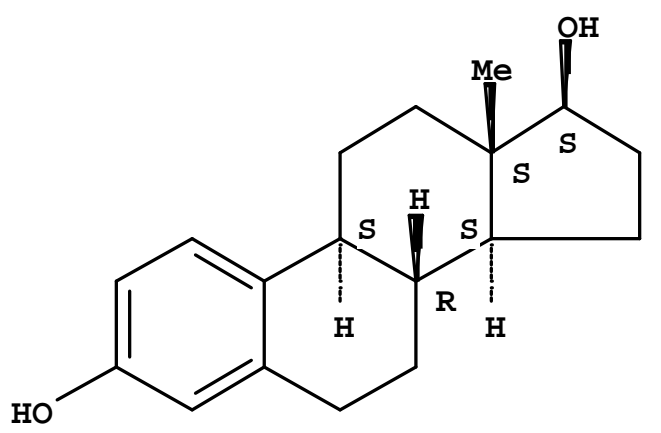

$17 \beta$-Estradiol

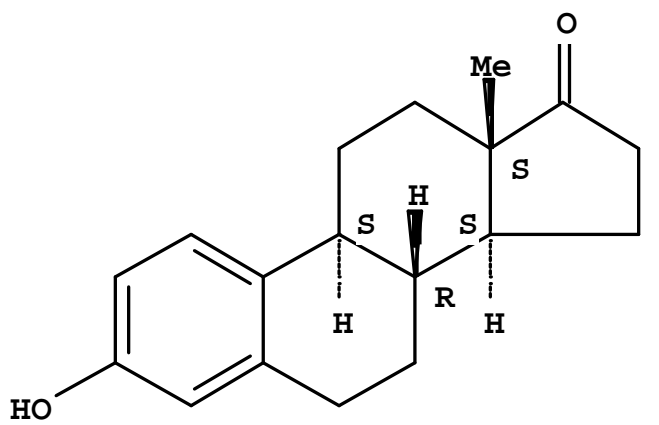

Estrone

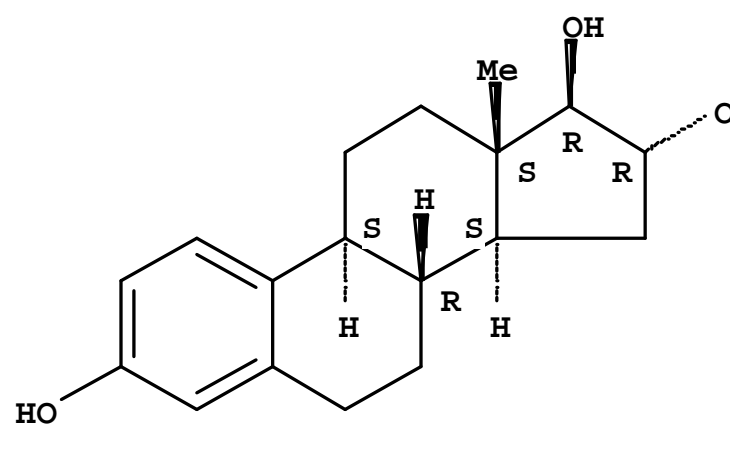

Estriol 


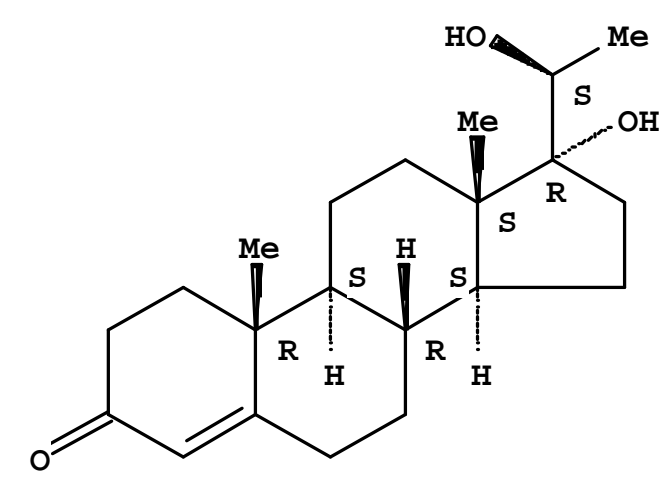

$\alpha \alpha$-Dihydroxyprogesterone

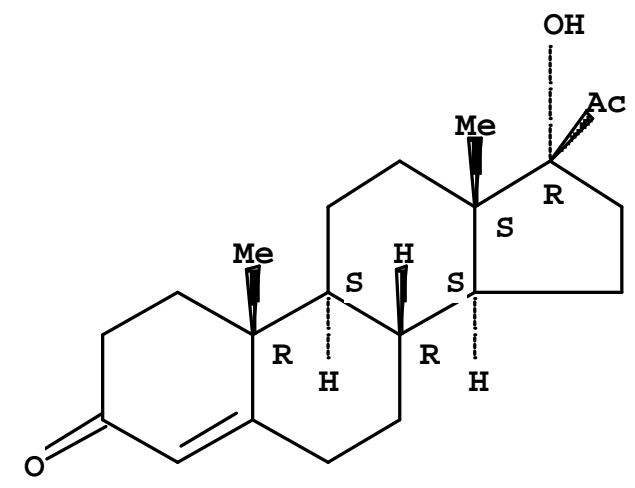

17-hydroxy-progesterone

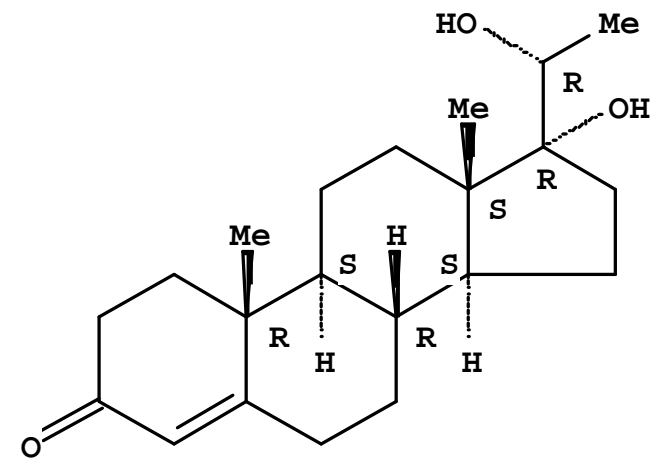

$\alpha \beta$-Dihydroxyprogesterone

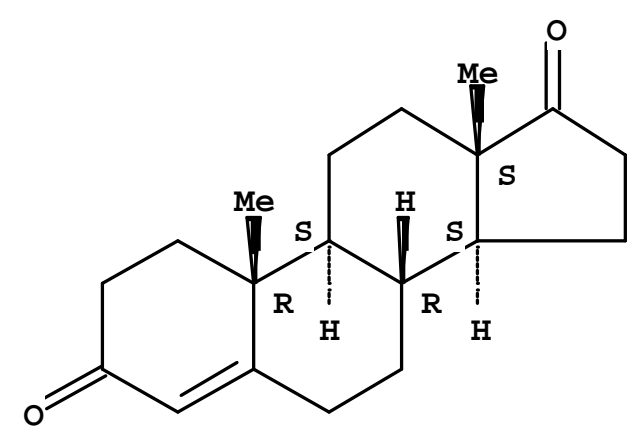

Andorstenedione

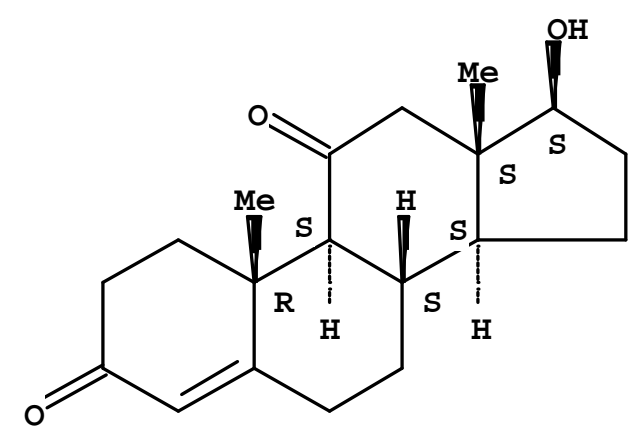

11-Ketotestosterone 
CURRICULUM VITAE

\section{EDUCATION}

2004 - 2009: Ph.D. Student - Analytical Chemistry, Chemistry Department, West

Virginia University, Morgantown, WV, USA

Graduation: May 2009

Advisor: Dr. Lisa A. Holland

2001 - 2002: Specialist of Science - Environmental Chemistry, Department of

Chemistry, National Taras Shevchenko University of Kyiv, Kyiv, UKRAINE

Advisor: Prof. Olga A. Zaporozhets

1997 - 2001: Bachelor of Science - Environmental Chemistry, Department of Chemistry, National Taras Shevchenko University of Kyiv, Kyiv, UKRAINE

Advisor: Prof. Olga A. Zaporozhets

RESEARCH EXPERIENCE

Separation chemistry (capillary electrophoresis, micellar electrokinetic chromatography, high performance liquid chromatography, gas chromatography); development of preconcentration techniques for sensitivity enhancement in separation methods; analysis of endocrine disruption compounds.

\section{TEACHING EXPERIENCE}

2004 - 2008: Teaching assistant for general chemistry laboratory sessions (CHEM $110,112,115,116)$.

2008 (spring): Developed and introduced into practice a new laboratory procedure for CHEM 112 under the supervision of Dr. Betsy Ratcliff.

\section{AWARDS}

WVU Dissertation Fellowship 2008-2009

Forrest Ferrell Award 2008 (outstanding teaching assistant award)

\section{Conference Presentations}

1. pH-Stacking CE Analysis of Steroids in Fish. Liliya Bykova; Bollinger, C. ; White, C.; Holland, L. A. 60th Pittsburgh Conference on Analytical Chemistry and Applied Spectroscopy, McCormick Place, Chicago, IL, USA, March 2009 
2. Analysis of Sex Steroid Hormones by Sample Stacking CE. Liliya Bykova and Lisa A. Holland Eberly College of Arts \& Sciences' Research Horizons Poster Day, Morgantown, WV, USA, March 2008

3. Sample Stacking MEKC Approach for Profiling Endogenous Sex Steroid Hormones for Monitoring Environmental Contamination. Liliya Bykova and Lisa A. Holland 59th Pittsburgh Conference on Analytical Chemistry and Applied Spectroscopy, Morial Convention Center, New Orleans, LA, USA, March 2008

4. MEKC Approach for Analysis of Sex Steroid Hormones. Liliya Bykova and Lisa A. Holland Eberly College of Arts \& Sciences' Research Horizons Poster Day, Morgantown, WV, USA, April 2007

5. Capillary Electrophoresis Approach for Sex Steroid Hormones. Liliya Bykova and Lisa A. Holland 58th Pittsburgh Conference on Analytical Chemistry and Applied Spectroscopy, McCormick Place, Chicago, IL, USA, March 2007

6. Rapid Separation-Based Analysis of Sex Steroid Hormones. Liliya Bykova; C. White, L. A. Holland 57th Pittsburgh Conference on Analytical Chemistry and Applied Spectroscopy, Orange County Convention Center, Orlando, FL, USA, March 2006

7. Microanalytical Approaches for Concentration and Separation of Sex Steroid Hormones. Liliya Bykova; C. White; L. A. Holland ECAS Research Poster Session, Morgantown, WV, USA, October 2005

8. Micellar Electrokinetic Capillary Chromatography Approach of Sex Steroid Hormones. Liliya Bykova; C. White; L. A. Holland 2005 Conference on the Application of Systems Biology Methodologies to Environmental Research, Morgantown, WV, USA, August 2005

\section{Peer Review Journal Publications}

1. L. Bykova, L. R. Iwanowicz, V. Blazer, L. A. Holland, "Steroid analysis in fish plasma by pH-mediated Stacking MEKC", to be submitted in Environmental Toxicology and Chemistry.

2. L. Bykova, L. A. Holland, "Stacking enhanced determination of steroids by CE", Electrophoresis 2008, 29, 3794-3800. 